Removing Contaminants from non-ideal Hydrometallurgical Solutions Assessment of Cd(II) Liquid-liquid Extraction with Aliquat 336 in Toluene

Hans Vigeland Lerum 
(C) Hans Vigeland Lerum, 2020

Series of dissertations submitted to the

Faculty of Mathematics and Natural Sciences, University of Oslo

No. 2261

ISSN $1501-7710$

All rights reserved. No part of this publication may be reproduced or transmitted, in any form or by any means, without permission.

Cover: Hanne Baadsgaard Utigard.

Print production: Reprosentralen, University of Oslo. 


\section{PRefaCe}

This thesis is presented to fulfil the requirement for the Doctor of Philosophy degree at University of Oslo. The work has been carried out under the nuclear chemistry group under the Environmental science section. The main supervisor for the work was Jon Petter Omtvedt, with co-supervisors Dag Øistein Eriksen, Eddy Walter Hansen and Grethe Wibetoe.

This thesis work is part of a larger project - Hydromet - funded by the Research Council of Norway and three industry partners: Boliden Odda, Glencore Nikkelverk, and Yara International. The full title of the Hydromet project is 'Energy and environmentally friendly hydrometallurgical technology for exploitation and refining of complex and poor mineral resources', with Research Council project number 236674. 



\section{ACKNOWLEDGEMENTS}

This thesis is submitted in partial fulfillment of the requirements of the degree of Philosophiae Doctor at the Department of Chemistry, Faculty of Mathematics and Natural Sciences, University of Oslo. First, I would like to thank my supervisor, Professor Jon Petter Omtvedt, for his support and guidance throughout this work. I would especially thank him for his great patience during our many discussions. I would also like to take this opportunity to thank my co-supervisors. Senior advisor, Dag Øistein Eriksen, for always helping with the initial work of the manuscripts and always suggesting new possible techniques or instruments for further investigations. Professor Eddy Walter Hansen, for his enthusiasm and help with our experimental results. Professor Grethe Wibetoe, for great discussions and an unparalleled eye for detail.

This project would not have existed without our industrial partners: Boliden Odda, Glencore Nikkelverk, and Yara Internationals contributions, sharing literally hundreds of years of practical experience.

I would like to thank Niels Højmark Andersen for providing Raman spectroscopy measurements and analysis as well as sharing his general expertise of metal speciation.

A special thanks to the UiO NMR center which let us run NMR on weird nuclei. Thanks to Dirk Petersen, who readied the instruments expertly for any nuclei needed. I would like to thank my co-author, Svetlana. You were very patient with the ICP-MS samples. Thanks to Ina my long distance coworker.

I have been a part of the Nuclear chemistry group for many years. A great thanks to all the colleges and students there are to many to mention.

Thanks to my great flatmates, Gunnhild, Svanhild. Finally, I would like to thank my parents for their support during these years, including their suggestion of me taking some well-needed breaks, as well as the rest of my family and friends. 



\section{SUMMARY}

This thesis started as part of a project for building competence within the field of hydrometallurgy.

In article I, we studied how the ionic strength and matrix composition affected extraction. We discovered considerable shifts in the equilibrium of high salinity solutions caused by minor changes in the concentration. Also, the benefit of multiple experimental techniques for studying liquid-liquid extraction were discussed. For instance, Raman spectroscopy showed why the matrix ions hindered extraction, and NMR spectroscopy enabled us to quantify the amount of extracted nitrate into the organic phase.

In article II, we took advantage of our findings in the Article I. In multi-element solutions, sulfate could be used for back-extraction from the organic phase. In addition, the difference in extraction properties between a single and a two-phase system was investigated. The results showed clearly that the distribution ratio was higher in a single-phase measurement. Furthermore, the distribution ratio was found to be much more uncertain in the single-phase measurement.

In Article III, we consider the change in the organic phase when it is subjected to various aqueous phases. The amount of water extracted with $\mathrm{LiCl}$ and the lack of molecular water in the organic phase as the acid is extracted significantly affect the speciation in the organic phase. This observation cast doubt on the assumptions made regarding the bulk liquid behavior.

In summary, this thesis concerns contaminants and undesirable metal ions present in hydrometallurgical solutions. We discuss the different techniques which can be used to characterize these species. Also, the weakness of using only one method to assess the extraction of these complicated solutions is discussed. During the work, it became evident that there is a need for speciation diagrams, also at high ionic strengths. It also became apparent that the available data on stability constants was at much lower ionic strength compared to the solutions used in the industry. 



\section{DEFINITIONS AND ABBREVIATIONS}

\begin{tabular}{|c|c|c|}
\hline Name/ symbol & Definition or usage & Abbreviation \\
\hline Adduct & $\begin{array}{l}\text { A chemical species } \mathrm{AB} \text {, } \\
\text { formed by two separate } \\
\text { molecular entities. }\end{array}$ & \\
\hline Aliquat 336 & Quaternary amine extractant & A336 \\
\hline Carrier & $\begin{array}{l}\text { A compound that exists in } \\
\text { macroscopic concentrations, } \\
\text { is chemically similar to the } \\
\text { tracer in the solution. }\end{array}$ & \\
\hline Chemical activity coefficient & $\begin{array}{l}\text { Chemical activity }= \\
\text { concentration multiplied by } \\
\text { activity coefficient. }\end{array}$ & \\
\hline Contaminant & $\begin{array}{l}\text { In this work contaminant is } \\
\text { used to mean an unwanted } \\
\text { metal species present in the } \\
\text { feed solution. It can be } \\
\text { unwanted due to its toxicity } \\
\text { or that it hinders the } \\
\text { production. }\end{array}$ & \\
\hline Distribution ratio & $\begin{array}{l}\text { The concentration of analyte } \\
\text { in the organic phase over the } \\
\text { concentration in the aqueous } \\
\text { phase } \\
\qquad D=\frac{[A]_{\text {org }}}{[A]_{A q}}\end{array}$ & D-ratio \\
\hline Extractable global resource & & EGR \\
\hline Entrainment & $\begin{array}{l}\text { Entrapment of an unwanted } \\
\text { phase in the other phase. }\end{array}$ & \\
\hline Feed & $\begin{array}{l}\text { Aqueous solution before } \\
\text { extraction. }\end{array}$ & \\
\hline Flashpoint & $\begin{array}{l}\text { At this temperature, there } \\
\text { are enough molecules of the } \\
\text { compound in a gaseous state } \\
\text { for it to start burning. }\end{array}$ & \\
\hline Gross national product & $\begin{array}{l}\text { Total value of goods and } \\
\text { services produced by a } \\
\text { country during one year, } \\
\text { equal to the gross domestic } \\
\text { product plus the net income } \\
\text { from foreign investments. }\end{array}$ & \\
\hline $\begin{array}{l}\text { High purity germanium } \\
\text { detector }\end{array}$ & $\begin{array}{l}\text { An instrument for High } \\
\text { resolution } \gamma \text { spectroscopy }\end{array}$ & HPGe \\
\hline
\end{tabular}




\begin{tabular}{|c|c|c|}
\hline $\begin{array}{l}\text { High resolution } \gamma \\
\text { spectroscopy }\end{array}$ & $\begin{array}{l}\text { A technique to identify } \\
\text { different radiotracers by } \\
\text { their unique } \gamma \text {-rays. }\end{array}$ & HRGS \\
\hline Hydrophilic & $\begin{array}{l}\text { The capacity of a } \\
\text { molecular entity } \\
\text { or of a } \\
\text { substituent } \\
\text { to interact with polar } \\
\text { solvents, in particular with } \\
\text { water, or with other polar } \\
\text { groups[1]. }\end{array}$ & \\
\hline Ideal Dilute Solution & $\begin{array}{l}\text { The solute is obeying } \\
\text { Henry's law, all the solute } \\
\text { activity coefficients } \\
\text { approximate to } 1 \text {. }\end{array}$ & \\
\hline Immiscibility & $\begin{array}{l}\text { Inability of a mixture to } \\
\text { form a single phase [1]. }\end{array}$ & \\
\hline Ionic strength & $\begin{array}{l}\text { The number of ions in the } \\
\text { solution } \\
\qquad I=0.5 \sum\left[C_{i}\right] z^{2} \\
C_{i} \text { is the concentration of } \\
\text { species } i \text {, and } z \text { is the charge } \\
\text { of species } i \text {. }\end{array}$ & \\
\hline $\begin{array}{l}\text { Inductive coupled plasma } \\
\text { mass spectroscopy }\end{array}$ & $\begin{array}{l}\text { An analytical instrument to } \\
\text { determine the concentration } \\
\text { of multiple elements, by } \\
\text { measuring the mass of the } \\
\text { elements. }\end{array}$ & ICP-MS \\
\hline $\begin{array}{l}\text { Inductive coupled plasma } \\
\text { optical emission } \\
\text { spectroscopy }\end{array}$ & $\begin{array}{l}\text { An analytical instrument to } \\
\text { determine the concentration } \\
\text { of multiple elements by } \\
\text { measuring the emissions } \\
\text { from various exited states of } \\
\text { the ions. }\end{array}$ & ICP-OES \\
\hline Leaching & $\begin{array}{l}\text { The process of transferring } \\
\text { metal from raw material into } \\
\text { a liquid phase. }\end{array}$ & \\
\hline Ligand & $\begin{array}{l}\text { In an inorganic coordination } \\
\text { entity, the atoms or } \\
\text { molecular group joined to a } \\
\text { central cation. }\end{array}$ & \\
\hline Liquid ion exchanger & $\begin{array}{l}\text { An extractant that can be } \\
\text { dissolved in a solvent, and } \\
\text { that works by exchanging } \\
\text { ions. }\end{array}$ & \\
\hline Liquid-liquid extraction & $\begin{array}{l}\text { The process of mixing two } \\
\text { immiscible phases to } \\
\text { transfer entities from one } \\
\text { phase to the other. }\end{array}$ & LLX \\
\hline
\end{tabular}


Liquid scintillation

spectroscopy

Nuclear magnetic resonance

Organic solution

Radiotracer

Raman spectroscopy

Raffinate

Regenerated organic solution

Species

Stripped aqueous

Solution

Solvent

Solute

Standard temperature and pressure

Trioctylphosphine oxide Tracer

Virgin organic

Virgin stripping solution

$\alpha$-particle
A technique to detect

LSS

radioactivity, primarily used

for charged particles.

An instrument to determine

the various species in a

solution by measuring the

interactions the nuclear spin

is experiencing.

Organic solution after

extraction.

Like a tracer but radioactive.

A technique to determine the various species in a solution or solid by measuring the scattering of light the sample is exposed to.

Aqueous solution after $\quad\left[\mathrm{A}_{\text {raf }}\right]$ extraction.

Organic solution after $\quad\left[\mathrm{A}_{\text {regorg }}\right]$

stripping.

An ensemble of chemically identical molecular entities.

Aqueous solution after stripping.

$\left[\mathrm{A}_{\text {org }}\right]$

NMR

Usually an aqueous phase

containing various ions

and/or ligands.

The chemical that the solute is dissolved in.

A component in the solution, an ion, or an extractant molecule.

$1 \mathrm{~mol} / \mathrm{L} 1$ atmosphere

STP pressure, and 25 degrees centigrade.

A liquid-liquid extractant

TOPO A compound added to the solution behaving in a similar way to the compound studied. The tracer should be easy to detect.

Organic solution before [A extraction.

Aqueous stripping solution [Avstrip] before stripping.

$\mathrm{A} \mathrm{He}^{2+}$ nucleus emitted from another bigger nuclei. 
$\alpha$-position

$\beta$-particle

$\beta$-position

$\delta(\mathrm{X})$

$\gamma_{\mathrm{x}}$

$\gamma$-ray
The carbon atom closest to the nitrate in an amine.

An electron emitted from a nucleus.

The carbon atom secondclosest to the nitrate in an amine.

The chemical shift of nuclei $\mathrm{X}$.

Activity coefficient for species $\mathrm{X}$.

Photons emitted from a radioactive nucleus. 


\section{List of Manuscripts}

\section{Article I:}

Methodology for Studying Cadmium Extraction from Highly Saline Solutions

Hans Vigeland Lerum, Niels Højmark Andersen, Dag Øistein Eriksen, Eddy Walther Hansen, Dirk Pettersen, Grethe Wibetoe, Jon Petter Omtvedt.

Published: Journal of Solution Chemistry 47, 1395-1417 (2018)

\section{Article II:}

Comparison of distribution ratios using single-phase and two-phase measurements. Extraction of $\mathrm{Cd}, \mathrm{Zn}$ and $\mathrm{Co}$ with Aliquat 336 from a multi-element chloride matrix

Hans Vigeland Lerum, Svetlana Sand, Dag Øistein Eriksen, Grethe Wibetoe, Jon Petter Omtvedt.

Accepted: Journal of Radioanlytical and Nuclear Chemistry

\section{Article III:}

NMR study of influence and interplay of water, $\mathrm{HCl}$ and $\mathrm{LiCl}$ with the extraction agent Aliquat 336 dissolved in toluene

Hans Vigeland Lerum, Niels Højmark Andersen, Dag Øistein Eriksen, Eddy Walther Hansen, Jon Petter Omtvedt.

Under revision: Journal of Molecular Liquids 



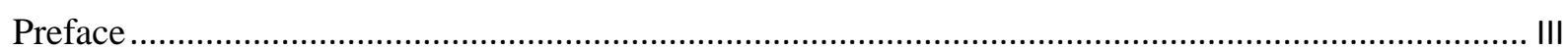

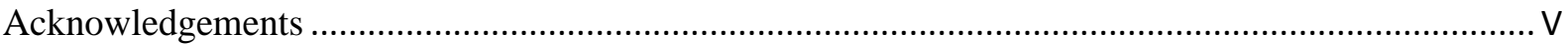

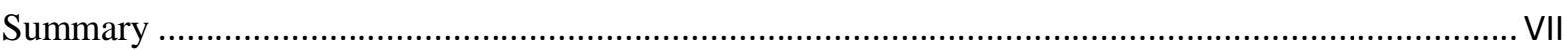

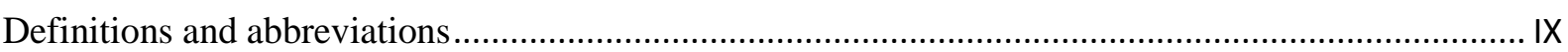

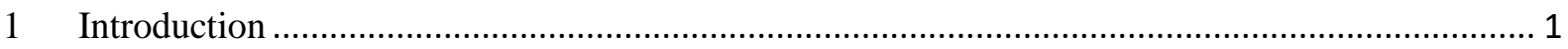

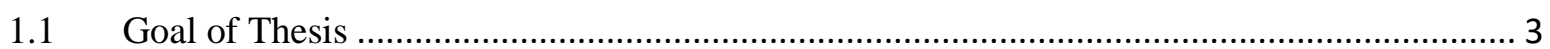

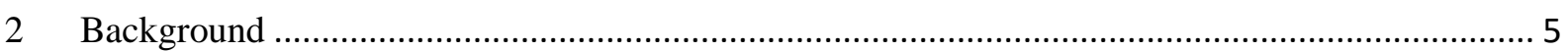

2.1 Liquid-liquid Extraction in Industrial Hydrometallurgy …................................................ 5

2.2 Brief History of our Understanding of how Solvated Ions Interact....................................... 6

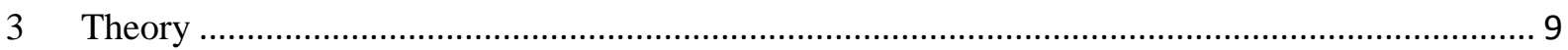

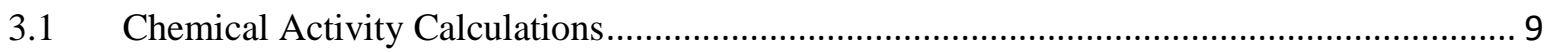

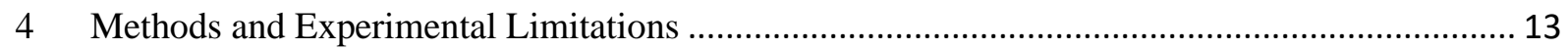

$4.1 \quad$ Liquid-liquid Extraction a Separation Method ............................................................... 13

4.2 Potential Problems when Performing Liquid-liquid Extraction ............................................ 14

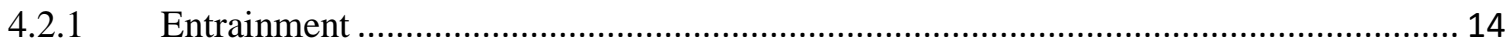

4.2.2 Determination of D-ratios by Single-phase Measurement ......................................... 15

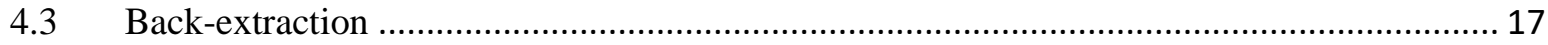

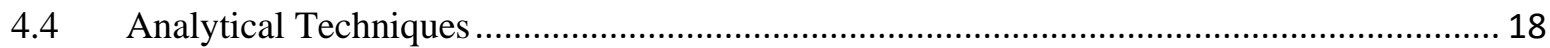

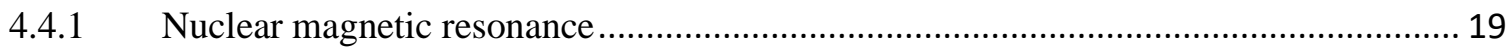

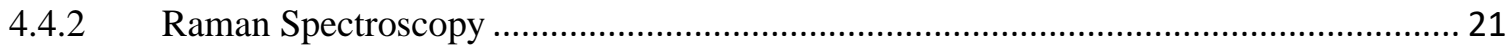

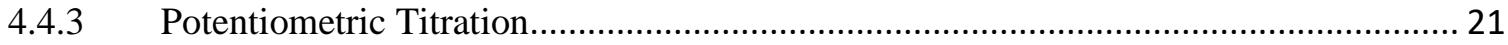

4.4.4 Measurement of Radioactivity …………….......................................................... 21

4.4.5 Inductively Coupled Plasma Mass Spectrometry and Optical Emission Spectrometry 22

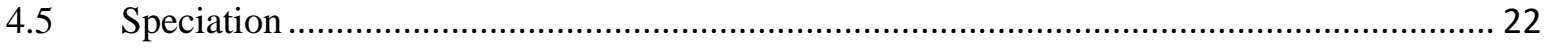

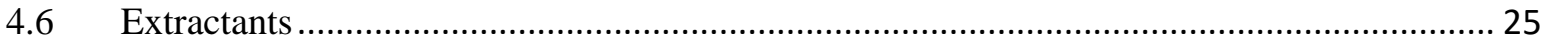

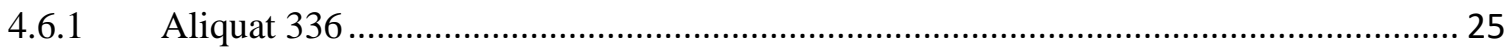

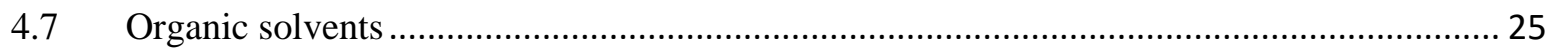

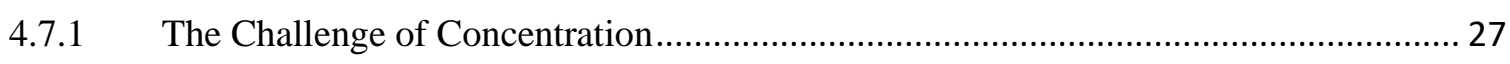

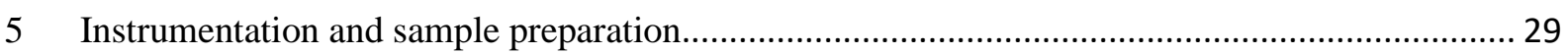

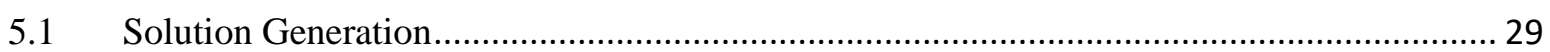

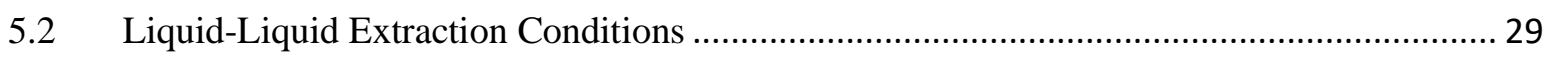

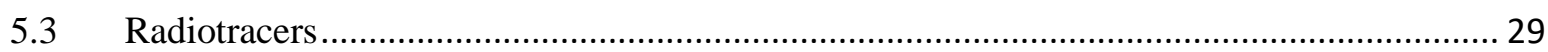




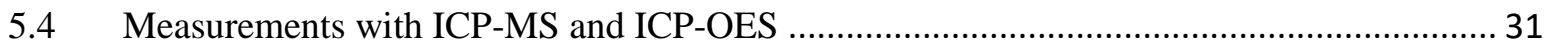

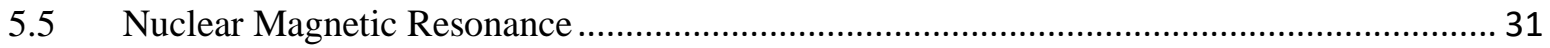

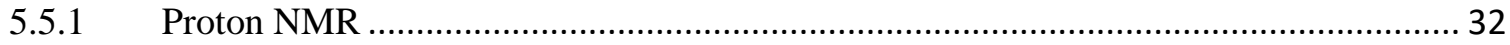

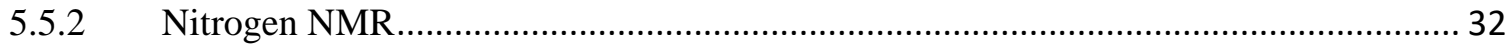

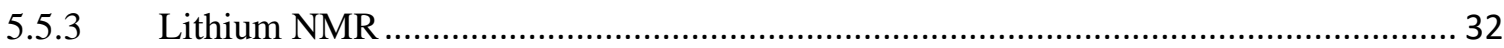

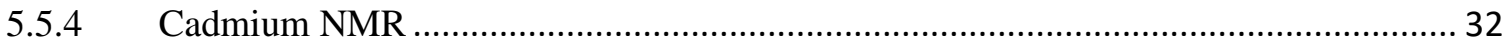

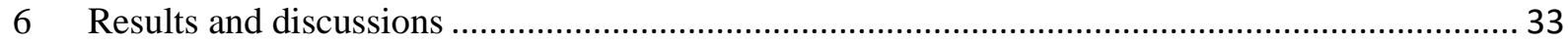

6.1 Metal Extraction from Solutions Containing Several Metals............................................... 33

6.2 Metal Extraction from Simplified Synthetic Solutions ..................................................... 35

6.3 Co-extraction of Molecular Anions and Acids..................................................................... 36

6.4 The Organic Phase after Extraction Studied using NMR .................................................... 44

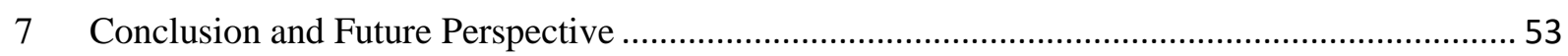

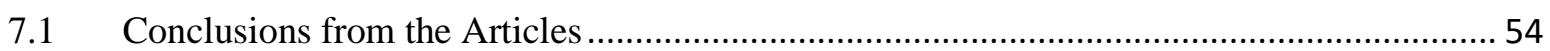

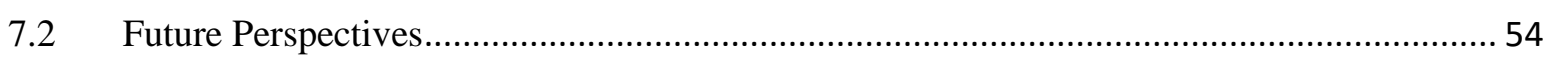

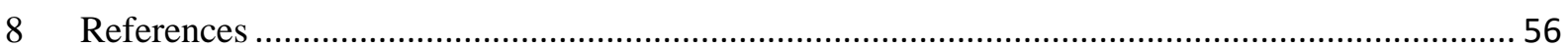

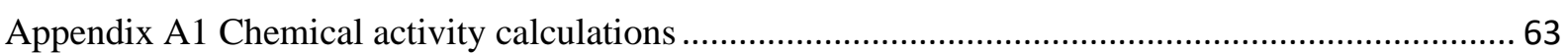

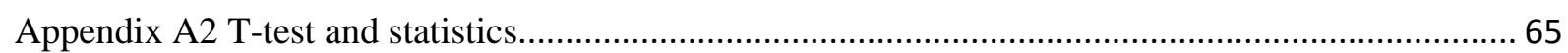

Appendix A3 fraction of molecular acid and disassociated acid....................................................... 67

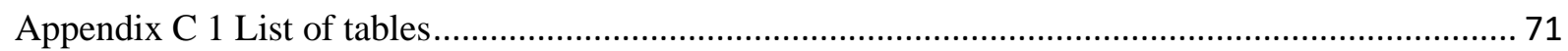

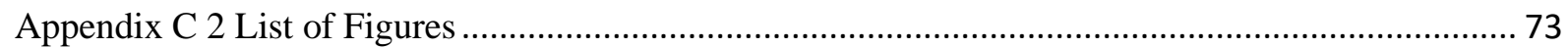




\section{INTRODUCTION}

Our current standard of living depends on access to a range of different metals. The usage of metals stretches from large scale infrastructure to small microchips and highly specialised materials. Thus, demands for the metal used are equally diverse. In general, there has been an increase in metal consumption by $3 \%$ annually since 1970 . In addition to this increase, the concentration of products wanted in the source materials has decreased [2-4]. Poorer ore quality and an increase of trace pollutants can result in the need for the development of new or revised industrial processes.

The United Nations Sustainable Development Goals is a plan to build a better world for the people and the planet by 2030. There are 17 different goals in this plan and 6 of them are either directly related to metal production or have a need metals. Therefore, the sustainable development goals will result in more metal consumption [5] . The important question then becomes whether there are enough metals to go around. Table 1.1 shows the United Nation's list of 60 elements of high concern. These estimations are made under the assumption of a continued 3\% annual increase in metal consumption until 2040.

There are several methods of metal production; however, only hydrometallurgy will be discussed for this work. Hydrometallurgy is a means to extract the metal of interest from the source material into an aqueous phase, including separation from other metals and elements. This thesis focuses on the liquid-liquid extraction part of the hydrometallurgy process and will not discuss other parts.

Source material for metal ranges from rock ores to waste material. Waste material can range from municipal waste, industrial waste or special waste where certain products have been presorted from general waste or specifically collected. A typical and important example is electronic waste.

The chemical conditions found in the hydrometallurgical industry are usually far removed from typical conditions preferred in academia, when performing chemical research. It is common in industry solutions that the mass of dissolved matter to the amount of the solvent matrix may be a 50/50 ratio. These solutions then exhibit properties chemically and physically far removed from more dilute and 'ideal solutions' used in chemical research. The reason for the deviation is discussed in greater detail in chapters 2 and 3. 
Table 1.1 Exhaustion periods of 60 elements in years after 2050. It is assumed that the extraction of all elements mentioned increases annually by 3\% until 2050 and then levels off. EGR means extractable global resource as defined by Henckens et al. [6], table taken from [7]. EGR depletion time given in brackets.

\begin{tabular}{|c|c|c|c|c|c|c|}
\hline $\begin{array}{l}\text { Very scarce } \\
\text { (within 2050) }\end{array}$ & \multicolumn{2}{|c|}{$\begin{array}{l}\text { Scarce } \\
(100 \text { years after } \\
2050) \\
\end{array}$} & \multicolumn{2}{|c|}{$\begin{array}{l}\text { Moderately scarce } \\
\text { (100 to } 1000 \text { years } \\
\text { after } 2050)\end{array}$} & \multicolumn{2}{|c|}{$\begin{array}{l}\text { Not scarce } \\
\text { (1000 years after 2050) }\end{array}$} \\
\hline-10 & $\mathrm{Au}$ & 10 & $\mathrm{Ag}$ & 200 & $\mathrm{Al}$ & 20000 \\
\hline & Mo & 50 & As & 400 & $\mathrm{Ba}$ & 1000 \\
\hline & $\mathrm{Rh}$ & 80 & $\mathrm{~B}$ & 200 & $\mathrm{Be}$ & 200000 \\
\hline & $\mathrm{Zn}$ & 50 & $\mathrm{Cd}$ & 500 & $\mathrm{Co}$ & 2000 \\
\hline & & & $\mathrm{Cr}$ & 200 & $\mathrm{Ga}$ & 1000000 \\
\hline & & & $\mathrm{Cu}$ & 100 & $\mathrm{Ge}$ & 200000 \\
\hline & & & $\mathrm{Fe}$ & 300 & In & 10000 \\
\hline & & & $\mathrm{Pb}$ & 300 & $\mathrm{Li}$ & 9000 \\
\hline & & & $\mathrm{Ni}$ & 300 & $\mathrm{Mg}$ & 30000 \\
\hline & & & $\mathrm{Sn}$ & 200 & $\mathrm{Mn}$ & 2000 \\
\hline & & & $\mathrm{W}$ & 300 & $\mathrm{Hg}$ & 400000 \\
\hline & & & & & $\mathrm{Nb}$ & 2000 \\
\hline & & & & & $\begin{array}{l}\text { Pt group } \\
\text { metals }\end{array}$ & 1000 \\
\hline & & & & & Lanthanides & 20000 \\
\hline & & & & & $\mathrm{Se}$ & 300000 \\
\hline & & & & & $\mathrm{Sr}$ & 10000 \\
\hline & & & & & $\mathrm{Tl}$ & 1000000 \\
\hline & & & & & $\mathrm{Ti}$ & 10000 \\
\hline & & & & & $\mathrm{U}$ & 2000 \\
\hline & & & & & $\mathrm{V}$ & 20000 \\
\hline & & & & & $\mathrm{Zr}$ & 2000 \\
\hline
\end{tabular}




\subsection{GOAL OF THESIS}

Future decrease in the availability of raw materials and the decline in ore quality introduce important challenges. As the most attractive raw materials have mostly been consumed, one is forced to work with 'poorer' material of more diverse composition.

The above trends will affect the industrial feed solutions which will be less pure and non-ideal. Also, the solutions will contain substantial amounts of metals. Hence, removing contaminants that affect or pollute the industrial processes will become more critical, and more demanding due to the increased complexity of the feed. One of the most essential parts to control are the metals present in the feed. If interfering contaminants can be selectively removed, this may ease the process operation and reduce the waste production.

Thesis' goal:

Removal of contaminants from industrial hydrometallurgical processes.

Contaminants are here defined as species of relatively low concentration, as compared to the products in the process.

A secondary goal of the thesis is to assess techniques for speciation of metals at ionic strengths higher than $1 \mathrm{~mol} / \mathrm{kg}$.

The chemical systems used in this thesis are rather varied. The thesis has studied the extraction of cadmium and this has been done in a chloride rich environment. To have the largest solubility range $\mathrm{HCl}$ and $\mathrm{LiCl}$ were used as the chloride sources. For the highest solubility lithium salts were used to explore the effect of additional matrix ions. Some systems, especially the mixed salt system were limited by precipitation at higher concentrations.

Chapter 6 discusses the main results and places them either within the industrial context or within the academic context. A sub-objective has been to examine the potential for removal of contaminants (e.g., cadmium) from industrial feed solution. This is critical because the raw material is likely to be obtainable in the future, in this case nickel matte, is from poorer ores having more pollutants. 



\section{BACKGROUND}

As mentioned in Chapter 1, this thesis focuses on the liquid-liquid extraction part of hydrometallurgy. For a general introduction to hydrometallurgy and its importance for many industrial applications, the reader will find many excellent textbooks available (e.g., Introduction to Hydrometallurgy by Michael L. Free [8]). Below is some relevant background on aqueous solutions and how the ionic content of hydrometallurgical process feeds can result in additional challenges for speciation.

\subsection{LIQUID-LIQUID EXTRACTION IN INDUSTRIAL HYDROMETALLURGY}

Liquid-liquid extraction (LLX) is a process used to transfer species, often metal ions or some other solvated species, from one liquid phase to another. A solvated species will, when presented with an interphase, distribute between the two phases. The solvated species can prefer one phase over the other and this can be controlled by an extractant. These extractants are sometimes called a phase-transfer catalyst [9]. Properties of extractants will be discussed in more detail in the following theory chapter.

In broad terms, the species' varying affinity for different extractants can be used to separate them. As an example, if the metal ions have very different properties, they are easy to separate, for example, alkaline metals from most transition metals. For metals with very different properties one single extraction can be enough to separate it sufficiently from others, while for the lanthanides, for instance, several extraction steps have to be used. For the most efficient utilization of the extractant 'counter-current mode' contacts the organic phase with the lowest concentration of product with the aqueous phase that also have the lowest concentration. This enables a maximum loading of the metals of interest. Depending on the maximum load this can change both the physical and chemical properties of the organic phase drastically. An example is that the specific gravity of the organic phase can become higher than the raffinate (the aqueous phase), resulting in phase inversion [10].

To properly explain the process occurring during the extraction, the properties of the aqueous phase must be described. The aqueous phases employed in the industry tend to have high ionic concentrations [11]. There are several reasons for the high concentrations, in general smaller volumes and higher densities gives lower operating costs, and with higher concentration there is less water. Lower amounts of water keeps energy costs lower and it results in less wastewater to handle.

The hydrometallurgical process starts with the leaching process, where usually a concentrated strong acid is used to dissolve the raw material. In this dissolution process the corresponding base of the acid usually is the dominating anion. If this anion has the ability to form ligands of the metallic species, we then have adducts.

Industrial hydrometallurgical processes are often operated at higher temperatures than standard temperature and pressure (STP). In addition, the concentrations are far removed from ideal aqueous solutions. The result is that the thermodynamic properties of these solutions differ from what is expected. In practise, both the speciation, and kinetics of reactions can change from standard conditions. Detecting and determining species of low concentration in these solutions 
is therefore challenging. Most contaminants will be in low concentration in these solutions with a probability for up-concentration in different parts of the industrial process or entering the product itself. The need for removal of contaminants from process solutions have already emerged and is believed to increase in the future. Therefore, the challenge is to separate metal impurities at low concentrations from metals present at high concentrations.

\subsection{BRIEF HISTORY OF OUR UNDERSTANDING OF HOW SOLVATED IONS INTERACT}

Water is one of the most-used solvents. Water can solvate metal ions, acids, and several organic compounds. While water has several uses, its chemical and thermodynamic properties are hard to describe. There are several reasons for this. Water is amphoteric, and its tendency to form hydrogen bonds results in several additional interactions with the solute compared to, for example, carbontetrachloride. Since water is so often used, there has been much work done to describe how it is affected by various solutes. A rough outline of this follows.

It was observed that adding salt to the aqueous phase changed the properties of the water as a solvent. The earliest attempts to explore and explain these properties focused on the physical properties of water. Properties such as vapour pressure and freezing point depression were observable and controllable. From such observations, Debye and Hückel developed their famous equation and limiting law [12]. When salts were added to solutions, it was observed that the $\mathrm{pK}_{\mathrm{a}}$ of weak acids would change and that the change would depend not only on the concentration of the salt added but also on the salts used [13]. In addition, it became evident that the higher the concentration, the more the result deviated from the mass action law and the limiting law. The law of mass action could not predict the outcome without substituting activity for the concentrations.

Ionic strength higher than $1 \mathrm{~mol} / \mathrm{kg}$ makes a solution difficult to properly describe thermodynamically. Multivalent species and multiple different ions make it even harder. This is reflected in the literature where it can be seen that most chemical potential calculations are challenged by high ionic strengths [11,14-16].

The International Union of Pure and Applied Chemistry (IUPAC) has defined activity as $a=$ $e^{\frac{\mu-\mu^{\circ}}{R T}}$ where $\mu$ is the chemical potential and $\mu^{\circ}$ the standard chemical potential. $\mathrm{R}$ is the gas constant, and $\mathrm{T}$ is absolute temperature [1]. However, in aqueous solutions using activity coefficients, it is more common to define $a=[C] \cdot \gamma_{ \pm}$, (here $[\mathrm{C}]$ is the concentration of an ion and $\gamma_{ \pm}$is the average activity coefficient of the ions in the solution). It became evident that activity calculations needed experimental data to work, that is, they were based on empirical data. However, the formulas used for calculating activity incorporate many parameters related to physical interactions and restrictions:

- The Debye-Hückel term $A\left|z_{1} Z_{2}\right| \sqrt{ } I$

- A way to account for short-range interactions between ions

- Interaction between equally charged ions

- Interaction between oppositely charged ions

- Interaction between solvent and solutes

- Non-electrostatic interactions 
The predictive powers of the equations are quite small, and they quickly fall apart if more than one salt is used, or the concentrations exceed $2 \mathrm{~mol} / \mathrm{kg}$. Kusik and Meissner [17] attempted to make a complete empirical model for highly concentrated hydrometallurgical solutions. They accepted an uncertainty of $20 \%$ and developed an equation for solutions exceeding $10 \mathrm{~mol} / \mathrm{L}$.

As mentioned, the measured $\mathrm{pK}_{\mathrm{a}}$ of weak acids was affected by changes in the ion concentration [13]. Of course, the measurable changes in chemical constants are not limited to acids. The equilibrium constants for adduct formation of various metals will also be affected by the ion concentration. For metals that can form different adducts with differing numbers of ligands, there will be an equilibrium equation for each species. To form some of these species, concentrations in the required solution can be very high. Concentrations can be so high that not only is it difficult to compare the solutions to the more dilute versions, but the high concentrations can also hinder measurements. Thus, experimental determination of a species' thermodynamic properties can be challenging. This is exemplified in the IUPAC series of environmentally significant metals. IUPAC argue that for $\mathrm{Cu}(\mathrm{II}), \mathrm{Zn}(\mathrm{II}), \mathrm{Cd}(\mathrm{II})$ and $\mathrm{Pb}$ (II) that the $\mathrm{MCl}_{4}{ }^{2-}$ should exist; however, the only stability constant they trust is for $\mathrm{Hg}$, which is 10 times higher than the second-highest element Cd [18-22]. 



\section{THEORY}

Industrial solutions usually have high ionic strength due to the high concentration of the products. High ionic strength affect the activity coefficients, which are no longer unity (see figure 3.1 for which concentrations of the activity coefficients deviate from unity). Thus, the concept of concentration, as used in the thermodynamic equations, is insufficient. If any chemical relation is to be described, then a chemical activity must be used. In practice, activity coefficients considering non-ideal behaviour are introduced, that is, $a=\gamma c$, where $a$ is chemical activity, $\gamma$ the activity coefficient and $c$ the concentration.

\subsection{Chemical Activity Calculations}

Chemical activity accounts for non-ideality. For a chemical equilibrium reaction:

$$
\mathrm{nA}+\mathrm{mB} \leftrightharpoons \mathrm{lC}+\mathrm{kD}
$$

were $n, m, l$ and $k$ express the moiety of the individual molecules or ions the equilibrium constant $\mathrm{K}_{\mathrm{c}}$ of Eq. 3.1 can be expressed as:

$$
\mathrm{K}_{c}=\frac{[C]^{l}[D]^{k}}{[A]^{n}[B]^{m}}
$$

With activity coefficients it is expressed as:

$$
\mathrm{K}_{\mathrm{a}}=\frac{\left([C] \gamma_{C}\right)^{l}\left([D] \gamma_{D}\right)^{k}}{\left([A] \gamma_{A}\right)^{n}\left([B] \gamma_{B}\right)^{m}}
$$

where $\gamma_{X}$ represents the activity coefficient of species $X$.

Several approximate equations exist for the chemical activity coefficient, and most of them include the term [11] [23-26,17]:

$$
\ln \left(\gamma_{ \pm}\right)=-A \frac{\left|z_{1} z_{2}\right| \sqrt{I}}{1+b \sqrt{I}}
$$

Where $I$ is the ionic strength, as defined by:

$$
\mathrm{I}=\frac{1}{2} \sum m_{i} \cdot z_{i}^{2}
$$

Here the $m_{i}$ is the molality of species $I$ and $z_{i}$ is the charge of species $i$. Therefore, ionic strength has a concentration unit. One of the main problems with ionic strength is that it assumes that the aqueous phase is a perfect solvent and the salt added is a strong electrolyte. This means that the salt is perfectly disassociated and that all ions present in the solution only interact with the solute. The $A$ term used is often referred to as the Debye-Hückel coefficient [27], which is dependent on temperature and the relative permittivity of the solvent. For water at standard conditions, $A$ is assumed to be 0.51 [27,28]. Consideration of the validity of assuming that $A$ is valid at high saline concentrations was deemed outside the scope of this work. However, discussion of the change in the dielectric constant can be found, for example, in [29-31] or more recently [15].

In this work, the equations developed by Pitzer et al. were used [23,24]. The Pitzer equations are empirical equations enabling the calculation of activity factors up to a nominal 
concentration of $5 \mathrm{~mol} / \mathrm{kg}$. Since most of the data presented in this thesis were obtained on solutions with an ionic strength higher than $5 \mathrm{~mol} / \mathrm{kg}$, it follows - inevitably - that the derived parameters become more uncertain.

The Pitzer equations are based on empirical constants [23-25, 32], as discussed in Appendix A1. We will omit any detailed derivation of these equations and only present a final simplified expression (Eq. 3.6). The first term gives a reasonable approximation of the ionic strength when lower than 0.1 . It is when the ionic strength increases past 0.1 that the short-range electrostatic interactions become important. $E$ is supposed to account for these. When there are three or more types of ions in the aqueous solution, there is an increase in possible interactions. $F$ uses empirically derived constants to account for these.

$$
\ln \left(\gamma_{M X}\right)=\left|z_{1} z_{2}\right| f^{\gamma}+m\left(E+m^{2} \mathrm{~F}\right)
$$

Here $z_{1} z_{2}$ are the charges of the ions in the solution, and the number will have to be extended if more ions are added, $m$ represents the total molality of the solution.

Equation 3.6 for two $\mathrm{LiCl}$ solutions are used and calculated in Figure 3.1. Here $\mathrm{LiCl}$ is used as an example of activity coefficients from low ionic concentrations to high ionic concentrations. It is also showing the effect on the activity coefficients of when two salts are sharing a common ion.

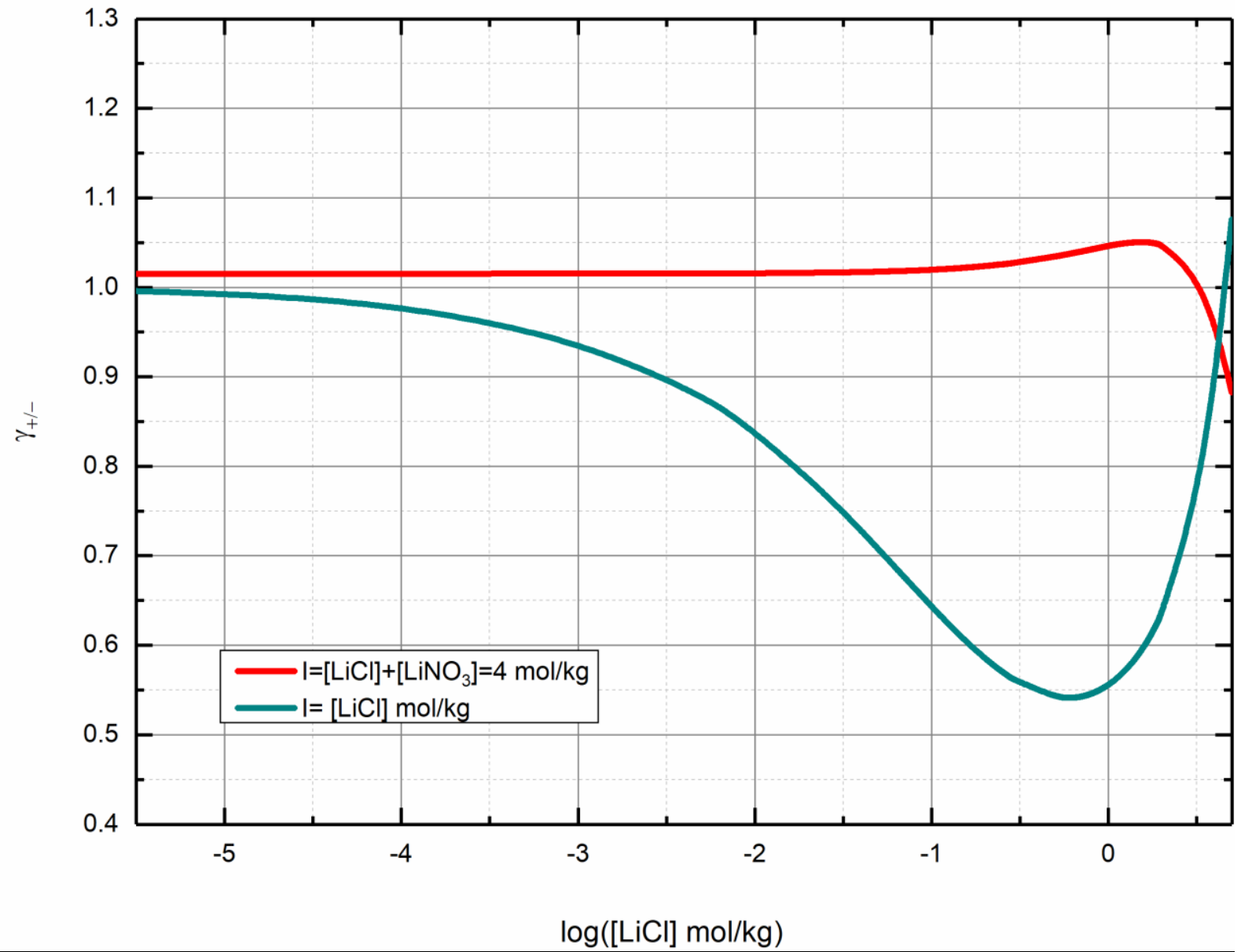

Figure 3.1 Calculated activity coefficients of LiCl where the green line has activity coefficients calculated when the ionic strength is the same as the concentration. The red line calculates the activity coefficients as the ionic strength is kept constant at 4 with $\mathrm{LiNO}_{3}$. 
Figure 3.1 shows that $\mathrm{LiCl}$ deviates from unity as the concentration increases. An activity coefficient of one would make the concentration additive. It can be seen that there is a quick drop of the activity coefficient until roughly a concentration of $1 \mathrm{~mol} / \mathrm{kg}$ is reached, then there is a sharp increase. The model cannot account for precipitation of $\mathrm{LiCl}$, which occurs around 5-7 mol/ $\mathrm{kg}$ (depending on the purity of the water and the temperature). In addition to failing to predict precipitation, the model loses accuracy at such high concentrations. The red line shows the effect of keeping a constant ionic strength. The main contributors to the activity coefficients is the concentration of ions. By choosing salts that share an ion (in this case, the salt $\mathrm{LiNO}_{3}$ was chosen), it is possible to keep the activity coefficient stable as the concentration changes. However, when the two salts start to have equal concentration, the activity coefficients change.

The activity effect of very high concentrations in liquid-liquid extraction is exemplified by the LiCl example above: The difficulties of choosing so-called inert salts are clear and are discussed below. As can be seen from Figure 3.1, increasing the concentration does not provoke a linear response in activity. The result is that it is challenging to be precise when it comes to the speciation of highly complex aqueous solutions. Some of this stems from how chemical potential advances as the concentration increases. The fact that the slope of the activity constant is accelerating means that there can be massive changes over small concentration ranges. 



\section{METHODS AND EXPERIMENTAL LIMITATIONS}

\subsection{LiQUid-LIQUid EXTRACTION A SEPARATION METHOD}

Liquid-liquid extraction is a suitable technique to measure both speciation, and, to a certain extent, the chemical potential of the species studied.

Liquid-liquid extraction transfers masses between two phases. Distribution ratios are well suited to explain chemical processes, and the reason will be discussed here. The distribution ratio is defined as the concentration of the analyte in the organic phase divided by the concentration of the analyte in the aqueous phase:

$$
D=\frac{\left[\sum A_{I}\right]_{\text {org }}}{\left[\sum A_{i}\right]_{a q}}
$$

Here, the values in the organic and the aqueous phases are the summation of all the species present in each phase.

To further explain why the D-ratio is such a useful term, note this simple extraction equilibrium:

$$
n L B_{\text {org }}+A_{a q}+m C_{a q} \rightleftharpoons L_{n}\left(A C_{m}\right)_{\text {org }}+n B_{a q}
$$

where the suffix org and $a q$ represent the organic or the aqueous phase and $n$ and $m$ represent the stoichiometric amount of the components. $\mathrm{L}$ is the extractant forming the adduct with the analyte A. B represents a compound depending on the system: If the extractant is an ionexchanger, it is an ion, if the system is solvating, $\mathrm{B}$ is not needed. $\mathrm{C}$ is a ligand which could be anything from a halogen to compounds such as ethylenediaminetetraacetic acid. For ease of writing, the activity coefficients are ignored. Setting up the equilibrium:

$$
K=\frac{\left[L_{n} A C_{m}\right]_{\text {org }}[B]_{a q}^{n}}{[L B]^{n}{ }_{\text {org }}[A]_{a q}[C]^{m}{ }_{a q}}
$$

So, if we can hold valid that:

$$
D=\frac{\left[\sum A_{i}\right]_{\text {org }}}{\left[\sum A_{i}\right]_{a q}} \approx \frac{\left[L_{n} A C_{m}\right]_{\text {org }}}{[A]_{a q}}
$$

We can write:

$$
K=D \frac{[B]_{a q}^{n}}{[L B]^{n}{ }_{\text {org }}[C]^{m}{ }_{a q}}
$$

validation can be done by plotting the distribution ratio vs extractant concentration, or ligand concentration.

$$
\log (D)=\log (K)+n \log ([L B])-n \log ([B])+m \log ([C])
$$

Plotting the $D$ ratio vs either [LB], [B] or [C] should then give a straight line with the slope decided by $n$ or $m$. Slope analysis can then confirm which species is extracted. Deviations can be explained by competition between several species extracted. However, the most likely source of deviation from a straight line is unforeseen reactions occurring in solutions. Unexpected 
reactions will be discussed below. A more comprehensive explanation of slope analysis and liquid extraction can be found in, for example, [33].

\subsection{Potential Problems when Performing LiQuid-LiQuid Extraction}

Liquid-liquid extraction (LLX) entails using two immiscible phases. However, even if the phases are immiscible, a small amount of each phase can be found in the other phase. If this occurs, it is called entrainment. It is important that the experiment is conducted in such a manner that entrainment is minimised. High stir rates are needed to properly mix the two solvents. For an expedient transfer of mass, the surface area between the two phases must be as high as possible [33].

\subsubsection{Entrainment}

Figure 4.1 shows how entrainment becomes more important for D-ratios far away from unity. In the figure, only the entrainment of organic into the aqueous phase is considered; however, the divergence is equal but opposite. Here, the effects of entrainment have been simulated by using the 'real' D-ratio to estimate the amount of analyte in each phase. Then, entrainment will reduce the concentration in the organic phase and add it to the aqueous phase. The effect is a drop in D-ratios. The higher the D-ratio, the more severe the drop. Of course, entrainment of the aqueous phase into the organic has a similar negative effect on precision when low D-ratios are measured. Underestimation of the D-ratios can result in extraction schemes where backextraction is close to impossible. It is also vital for experiment design that the higher the expected D-ratios the more care has to be taken for the experiment to be performed. It also suggests that great care should be taken when a D-ratios of much higher than 100 (or lower than $0.01)$ is reported. 


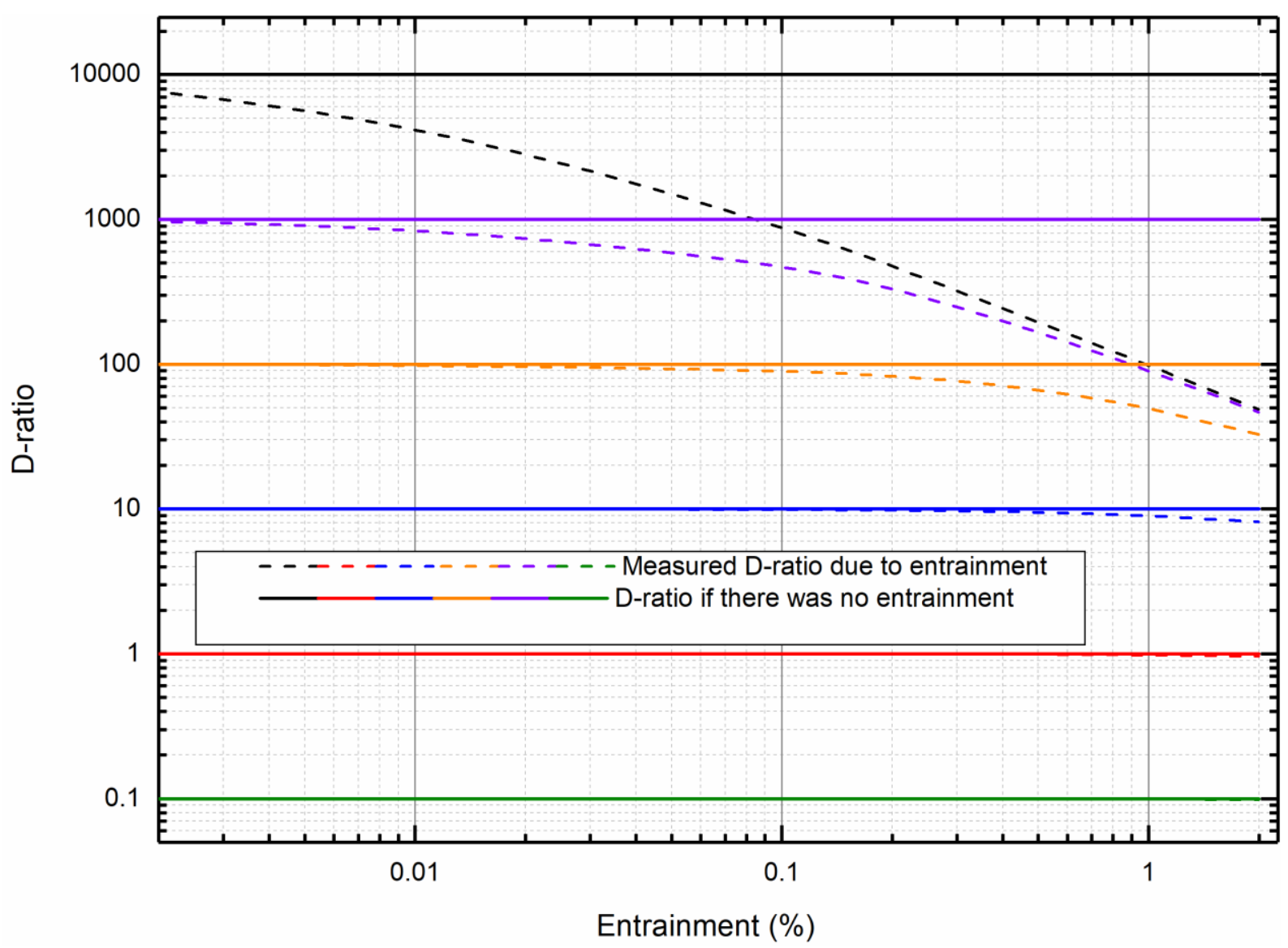

Figure 4.1 The unbroken coloured lines represent the true D-ratio, the stapled coloured lines represent the D-ratios for the same coloured whole line but with increasing entrainment.

\subsubsection{Determination of D-ratios by Single-phase Measurement}

Single-phase measurement is used when only one of the phases in a liquid-liquid extraction experiment can be measured. The advantages of single-phase measurement are that it is faster and cheaper, multi-element analysis is possible and there are more methods for single-phase measurements.

Single-phase measurements should, in principle, give the same values as two-phase measurements; however, there are some practical consequences and inherent statistical limitations, as discussed below.

Several measurement techniques can determine concentration in the aqueous phase. However, organic phases are often much more varied, and not all solvents fit all measurement techniques. Therefore, when no volume change is observed, only the aqueous phase is measured [34] (a thorough discussion of the math can be found in appendix II and paper II). The result is that the distribution ratio equation is changed by using:

$$
[A]_{\text {feed }}=[A]_{\text {org }}+[A]_{\text {raf }}
$$

Where $[\mathrm{A}]_{\text {feed }}$ is the aqueous solution prior to extraction. $[\mathrm{A}]_{\mathrm{rat}}$ is the aqueous phase after extraction and $[\mathrm{A}]_{\text {org }}$ is the organic phase after extraction. With the demand for equal volume still in place. 
Inserting this into the distribution ratio equation, we obtain:

$$
D=\frac{[A]_{\text {feed }}-[A]_{\text {raf }}}{[A]_{\text {raf }}}
$$

The uncertainty is then given by the following equation (as mentioned above, details are explained in Paper II):

$$
S_{D}=(D+1)\left(\left(\frac{\sigma_{\text {feed }}}{[A]_{\text {feed }}}\right)^{2}+\left(\frac{\sigma_{\text {raf }}}{[A]_{\text {raf }}}\right)^{2}\right)^{0.5}
$$

In general, using Eq. 4.9, we can state that uncertainty of single-phase measurement will increase faster than for two-phase measurements at low D-ratios. For two-phase ratio exchange the $(\mathrm{D}+1)$ with $\mathrm{D}$. The uncertainty of single-phase measurements will have steeper incline than for two-phase measurements. Figure 4.2 assumes equal uncertainty in the measurements and shows how, for single-phase measurements, the uncertainty is higher for D-ratios lower than 10. Figure 4.2 further shows that the uncertainty minima has changed from a D-ratio of 1 in two-phase measurements to roughly 3 in single-phase measurements. This indicates that for the most accurate and precise D-ratios determined by single-phase measurements, the extraction should be performed when the D-ratios range from 1 to 10 .

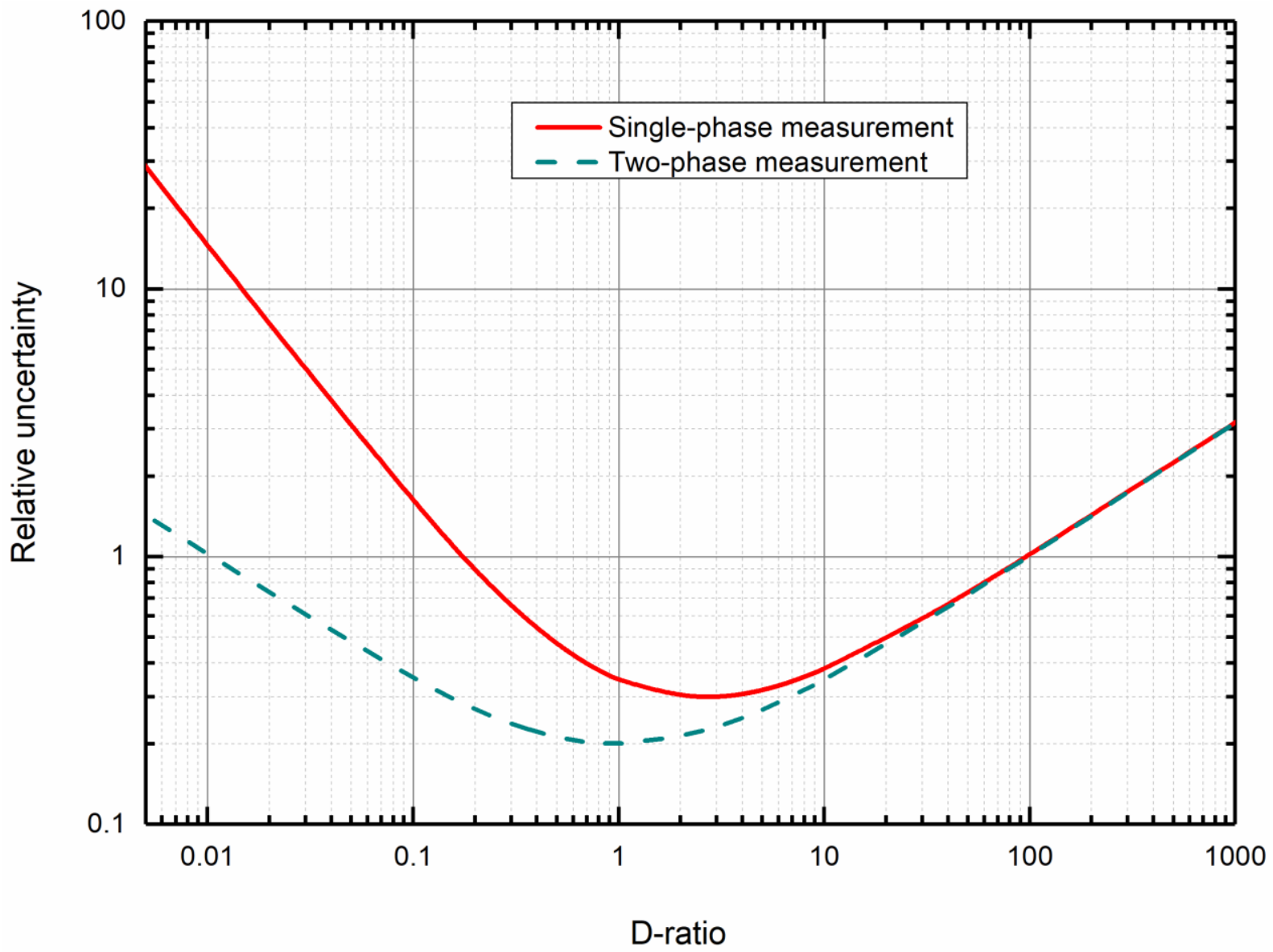

Figure 4.2 The red line shows the relative uncertainty D-ratios of single-phase measurements, while the stapled line shows relative uncertainty for two-phase measurements. 
Figure 4.2 shows that the lower the D-ratio is, the more uncertain it becomes. To determine a D-ratio, the feed and raffinate must be significantly different. Because $[A]_{\text {feed }}>[A]_{\text {raf }}$ for there to be a determinable D-ratio in Eq. 4.8. A one-tailed t-test can, be used to ensure that the difference between feed and raffinate is higher than random error [35,36]. The t-test is a standard statistical tool to determine whether two measured values are significantly different. The t-test can also be used to estimate the minimum difference between feed and raffinate necessary to be certain of the D-ratio. Figure 4.3 shows that more replicas will enable lower D-ratios to be determined.

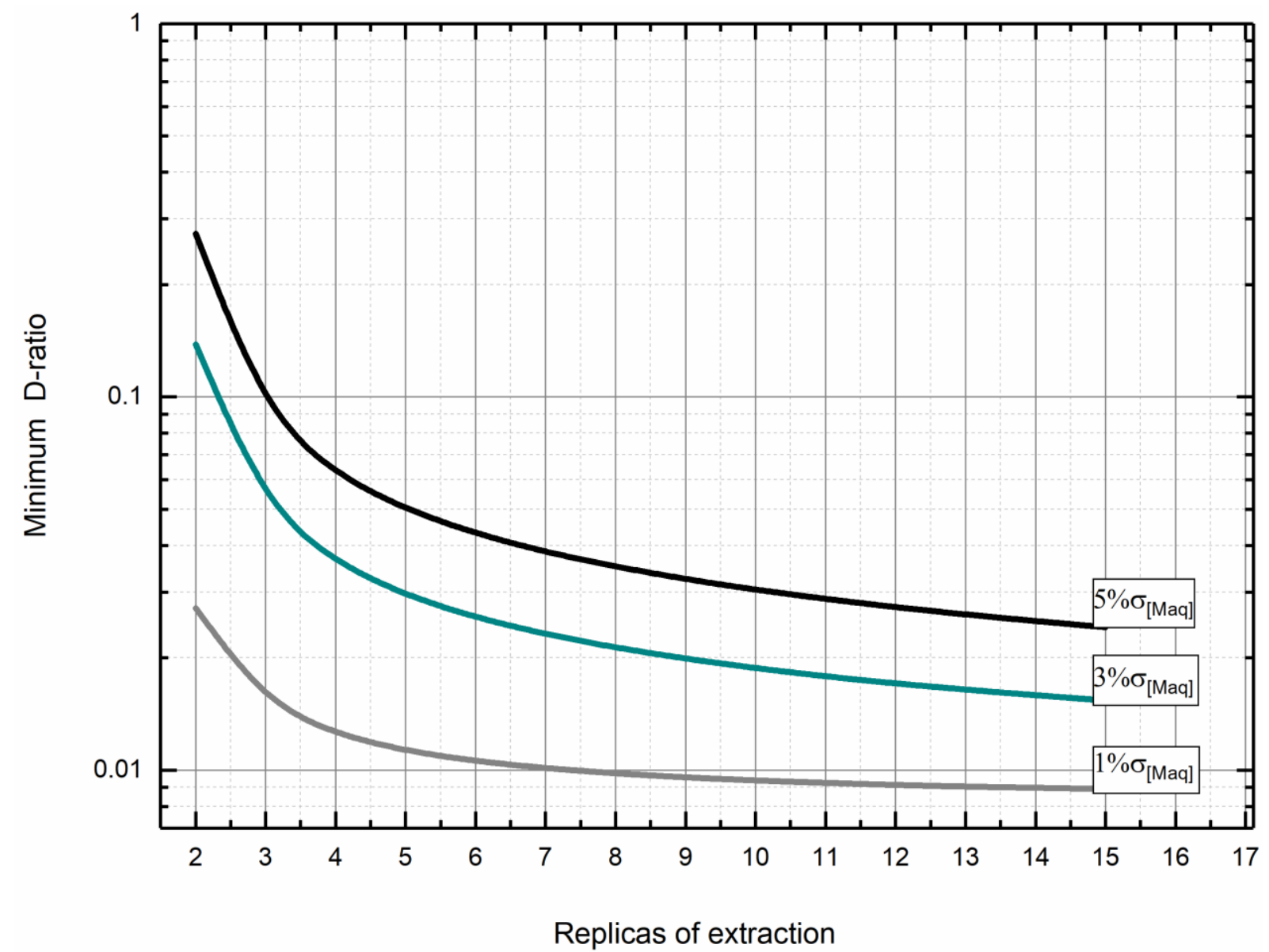

Figure 4.3 Minimum D-ratio in single-phase measurement as a function of replicates. The lines show the number of replicas needed to determine a minimum D-ratio at different relative uncertainties, for a one-tailed t-test where the feed relative uncertainty is set to $1 \%$.

\subsection{BACK-EXTRACTION}

Back-extraction, or stripping, is the process of removing metal from an organic phase and back into a new aqueous phase. In industrial processes, stripping is also necessary to regenerate the organic phase. This is normally an economic requirement, which also ensures that harmful waste is reduced to a minimum. Frequently, a 'scrubbing' step is included to ensure the organic phase can be reused without being affected by its previous use. Stripping should ideally remove all the metals from the organic phase. This can be verified by measuring the concentration of analyte in the stripped aqueous phase, $[A]_{\text {stripaq }}$. The following equation will then apply assuming equal volumes throughout:

$$
[A]_{\text {feed }}=[A]_{\text {raf }}+[A]_{\text {stripaq }}
$$


The random error and inherent uncertainty in the measurement implies that $[A]_{\text {feed }}$ will not be exactly equal to the sum of concentrations of the raffinate and the stripped aqueous phase. In addition, some of the metal may be retained in the organic phase; therefore, the sum will always be a bit lower than the feed. However, as only the aqueous phase is measured, it is impossible to determine with $100 \%$ certainty whether the loss is due to metal being retained in the organic phase, a statistical uncertainty in the measurements, or a true loss. Again, it is possible to determine if the loss is not due to statistical uncertainty by performing a t-test to check if Eq. 4.10 holds true. Furthermore, it is possible to estimate the magnitude of the random loss for different obtained uncertainties. Figure 4.4 shows the minimum amount of loss necessary to determine whether the difference is more than statistical uncertainty. In addition, Fig. 4.4 shows that D-ratios determined from raffinate and stripped aqueous solutions should not be trusted.

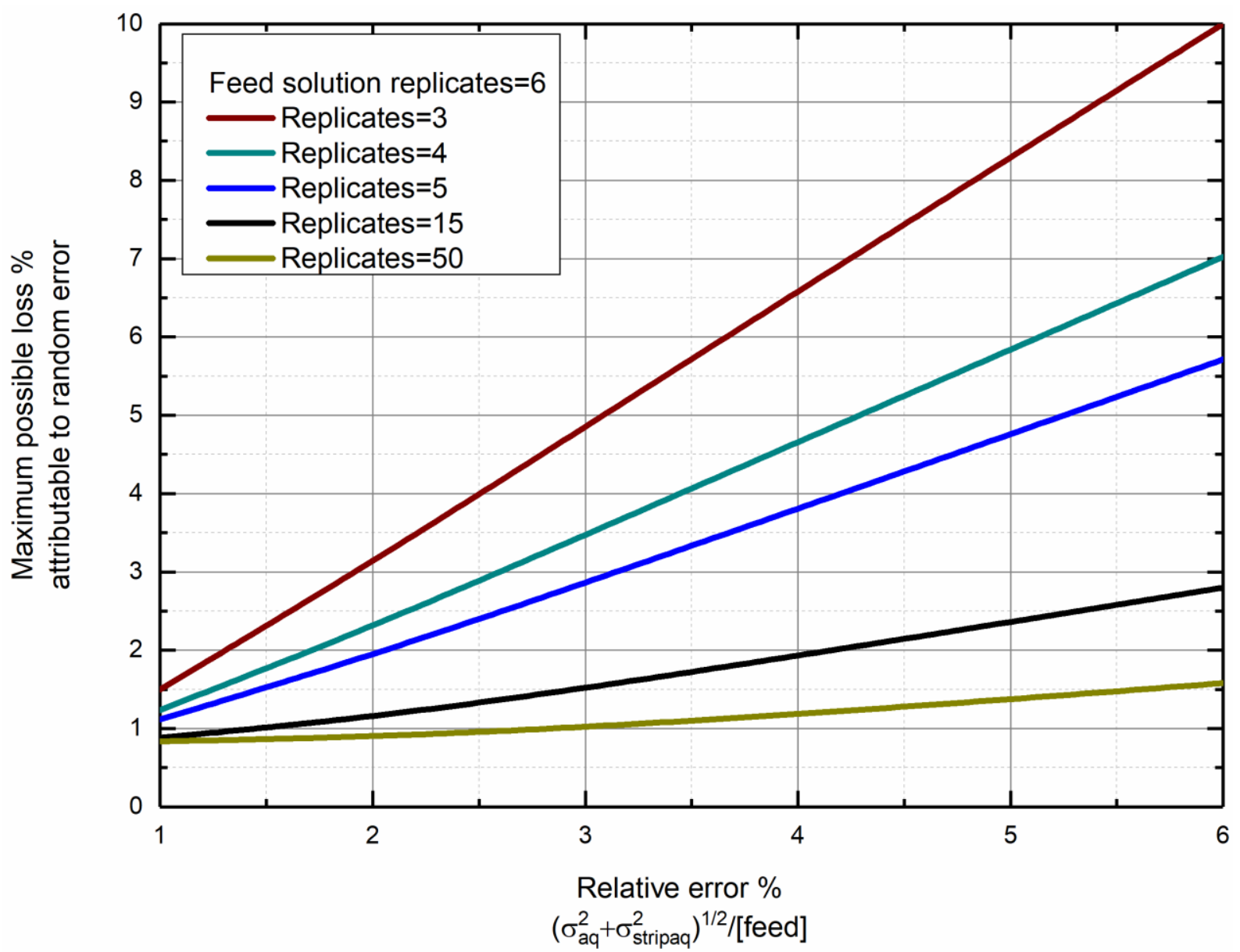

Figure 4.4 The coloured lines show the relative deviation possible for Eq. 4.10 estimated with different amount of replicates, for a one-tailed t-test where the feed relative uncertainty is set to $1 \%$.

\subsection{Analytical TeChNiQues}

In this work several analytical instruments have been used. With the concentrations and extractants used classical techniques such as radiotracers gave to little information. None of the instruments individually gave enough information about the chemical systems. Further 
development of these instruments would need dedication that was outside of the scope of this thesis. Therefore, instrumentation have been used in a basic manner.

\subsubsection{Nuclear magnetic resonance}

Elements in the periodic system which have a stable isotope with nuclear spin $\underline{I}$ different from zero will possess a magnetic moment $\mu$ whose magnitude depends on the nuclear spin $(\mu=\gamma h I$; where $\mathrm{h}$ is Planck's constant and $\gamma$ is the magnetogyric ratio of the nucleus). Hence, when confined in a magnetic field, these magnetic moments will precess with a characteristic (circular) frequency $\omega=\gamma \mathrm{B}$, where $\mathrm{B}$ represents the magnetic field sensed by the nuclear spin. In general, $\mathrm{B}$ is described by the strength of the external magnetic field $B_{0}$ (instrument characteristics) plus the smaller magnetic field $\triangle B$ created by the electrons and the neighbouring nuclei in the molecule, that is: $B=B_{0}+\Delta B$. Depending on the location of a nucleus within a molecule, the magnetic field $\Delta B$ may thus differ between different nuclei and will give rise to distinct processionals frequencies $\left(\omega_{i}\right)$. It is these various chemical shifts which form the NMR 'fingerprint' of the molecule and are visible in measured NMR spectra. (In this subchapter, $I$ refers to nuclear spin, and $\gamma$ will refer to the magnetogyric ratio.)

The sensitivity of NMR is mainly determined by the magnitude of $\gamma$, which is largest for the proton $\left({ }^{1} \mathrm{H}\right)$. Nuclei with higher spin $(I>1 / 2)$ will, in addition, possess quadrupole moments and this may result in more complex spectra that have broader lines and contain less fine structure [37].

Another aspect that can be highlighted with NMR measurements relates to the formation of metal complexes in a solvent, in which different numbers and types of ligands may exist. Depending on the exchange rate (relative to the NMR time scale), the NMR spectrum may be rather simple (fast exchange) or more complex (intermediate or slow exchange rate), depending on temperature and solvent.

An important concern relating to the quantitative sampling using NMR depends on the spinlattice relaxation time $T 1$ of the nucleus under study. Due to the inherent lack of sensitivity of some nuclei, the overall NMR signal intensity is obtained by repeating the experiment many times $(n)$ and adding them successively together. If a quantitative sampling is required, the time $t_{R}$ between successive experiments (transients) must be larger than 5 times $T 1$, implying that the overall experimental time will be of the order of $5 \cdot t_{R} \cdot N$ [38]. From sampling theory, it is important to keep in mind that the signal-to-noise $(N / S)$ ratio only increases as $\sqrt{N}$ [37].

NMR has been used in this thesis mainly to study how the extractant and metals are affected by different chemical conditions. Therefore, only terms used will be explained. In-depth explanation of spectrum analysis and constraints for NMR and its uses can be found in texts such as Introduction to Spectroscopy [39], and Multinuclear NMR [37].

According to classical electromagnetic theory [40], the application of a radiofrequency (RF)pulse of amplitude $B_{1}$ for a time $t_{p}$ along the Y-axis in a Cartesian axis system (Figure [Switch to 4.5]) causes the macroscopic magnetization $\overrightarrow{M_{0}}$ of the sample to rotate at an angle $\theta=\tau$. $B_{1} \cdot t_{p}$ around the Y-axis. Here $\tau$ is the magnetogyric ratio, which is the nuclear magnetic moment over the nuclear spin angular momentum [37]. Hence, for a tip-angle $a=\frac{\pi}{2}$ radians, the duration of the RF-pulse equals $t_{p}=t_{\pi / 2}=\frac{\pi / 2}{\tau \cdot B_{1}}$ which defines a $90^{\circ-R F-p u l s e . ~ A f t e r ~}$ 
application of the RF-pulse, the macroscopic magnetization $\vec{M}$ as a function of time can be described by the Bloch equation(s):

$$
\begin{gathered}
\frac{d M_{x y}}{d t}=-\frac{M_{x y}}{T_{2}} \\
\frac{d M_{z}}{d t}=-\frac{M_{z}-M_{0}}{T_{1}}
\end{gathered}
$$

where $M_{\mathrm{xy}}$ and $M_{\mathrm{z}}$ represent the magnetization components of $\vec{M}$ in the xy-plane and along the z-axis and T1 and T2 define the corresponding spin-lattice (longitudinal) and the spin-spin (transversal) relaxation times, respectively.

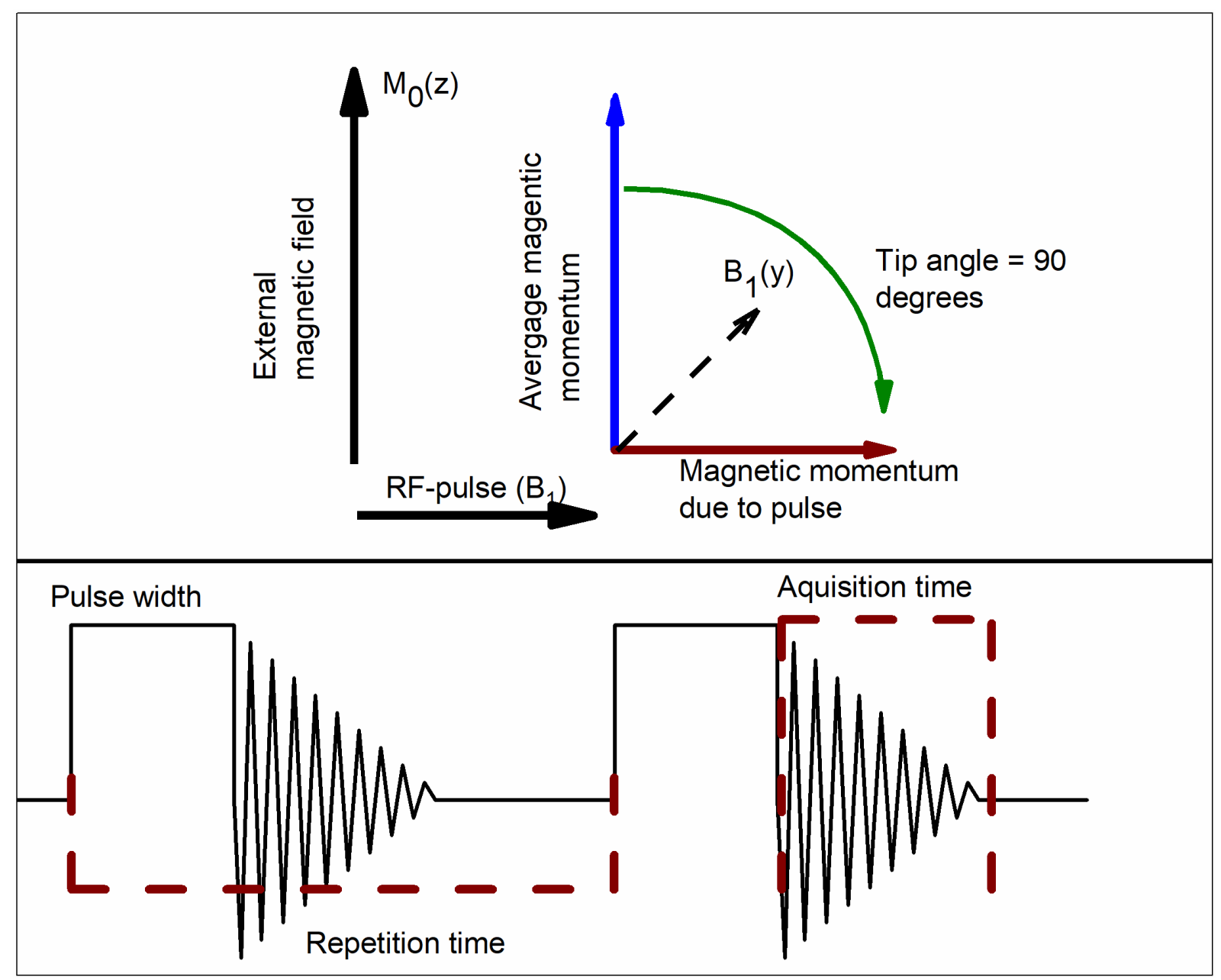

Figure 4.5the uppermost panel shows how the external magnetic field forces the average magnetic momentum of the nuclei to align with it. The 90-degree pulse forces some of the nuclei to change their magnetic moment perpendicular to the external magnetic field. The bottom half shows the pulse width, the acquisition time and the repetition time.

Figure 4.5 shows a simplification of NMR theory. The external magnetic field forces the average magnetic momentum of the nuclei in the sample to align with the external magnetic field. The pulse forces some of the nuclei to have a magnetic momentum pointing perpendicular to the external magnetic field. The relaxation that appears when the nuclear magnetic moment recovers along the external field (after a pulse) defines the spin-lattice relaxation time or longitudinal relaxation time T1. The time taken for the magnetization component in the xyplane to disappear defines the spin-spin relaxation time or the transversal relaxation time $\mathrm{T} 2$. 
Chemical shift is the common term used to describe the position of the resonance band in the NMR spectrum. The chemical shift arises from changes in the magnetic field surrounding the nuclei. The chemical shift is defined relative to a resonance band of a common reference. For proton and carbon NMR, this reference is often tetramethyl silane. The chemical shift is then defined by IUPAC as [41]:

$$
\frac{\delta_{s}}{p p m}=\frac{\left(\vartheta_{S}-\vartheta_{r e f}\right) / H z}{\vartheta_{\text {ref }} / M H z}
$$

Here $\delta_{s}$ represents the chemical shift of a given nuclei as referenced to $\vartheta_{\text {ref }}$. Up to 1972 both chemical shift and chemical shielding was used, these terms had equal but opposing sign [41]. After 1972 chemical shift was set as the standard, but for some years after 1972 chemical shifts were reported as chemical shielding, positive values then became negative.

\subsubsection{Raman Spectroscopy}

The technique is based on inelastic scattering of photons. Raman utilises the change in polarizability of the molecule as it vibrates. Raman active vibrations give rise to emissions of a distinct wavelength that are referred to as bands. It is possible to mathematically explain how these bands are formed, but such theory is beyond the scope of this work (more can be read in [42]). In this work, Raman has been used to identify and detect well known molecular ions with well defined bands.

\subsubsection{Potentiometric Titration}

Potentiometric titration measures the activity of the hydronium ion. The activity of the hydronium ion has a drastic change when the source of hydronium ions or when the source of hydroxide is depleted. The drastic change in activity is easily detectable by a $\mathrm{pH}$ electrode. The source of hydroxide or hydronium can be depleted by adding an opposing acid or base.

Two-phase titration can be used to determine the amount of extractant in the organic phase, if the extractant is an acid or a base. It can also be used to determine if any acid from the aqueous phase is extracted to the organic phase. For these titrations it is assumed that the phase boundary does not hinder the reaction between the titrant and the acid/base. In addition it has to be checked if the extractant can be measured by titration and this has to be accounted for. Also if the organic phase extracts the titrant this has to be accounted for in the measurement.

\subsubsection{Measurement of Radioactivity}

In large or complex system, it is important to decide what is to be studied. To have control over different parts of these systems, easily traceable components can be added. It is important that these components are easy to detect, and that their behaviour does not differ markedly from the parts of the system that are studied. Radionuclei are easily detectable and, since the only difference between a radio nucleus and a stable nucleus is mass, they are chemically identical. In sum, a tracer must be easily detected and exhibit the same properties and behaviour as the component traced.

\subsubsection{High-resolution $\gamma$-Spectroscopy}

$\gamma$-spectroscopy is a quantitative measurement technique that can be used to identify specific radioactive nuclei. It detects $\gamma$-rays emitted from the nuclei, that is, radiotracers. $\gamma$-rays probability to interact with matter decreases inversely with their energy. Normally, $\gamma$ - 
spectroscopy is used by comparing relative amounts of activity. The count rate can then be employed to calculate the concentration of the carrier in the solution. If two different samples are to be compared, it is important that the two samples have the same geometry.

\subsubsection{Liquid Scintillation Spectroscopy}

Liquid-scintillation spectroscopy is a common method for detecting $\alpha$ and $\beta$ radiation from radioactive nuclei. It is based on the detection of light emitted from special compounds when excited by ionizing radiation. Challenges related to liquid-scintillation spectroscopy stem from the fact that the sample is dissolved in the detector. Frequently, the constituents of the samples interfere with the light-producing process and this affects the detection efficiency. The effect on the detection efficiency is monitored by a so called 'quench correction' process that will not be explained here. The reader is kindly referred to standard textbooks on radiochemistry [43].

\subsubsection{Sodium-iodide Well Detector}

Crystals of sodium iodide doped with thallium (abbreviated as $\mathrm{NaI}(\mathrm{Tl})$ or simply $\mathrm{NaI}$ ) will emit light when exited by ionizing radiation. Coupled with a suitable photo-multiplier tube, NaI density, $\mathrm{NaI}$ is suitable for detecting electromagnetic radiation ( $\gamma$-rays and $\mathrm{X}$-rays), which is its main attraction despite rather poor energy resolution. This deficiency is countered by its high detection efficiency and relatively low price (compared to the much more expensive semiconductor Ge-detectors). For applications where only one radionuclide that emits electromagnetic radiation above $20-30 \mathrm{keV}$ is present, it is a good detector choice.

\subsubsection{Inductively Coupled Plasma Mass Spectrometry and Optical Emission Spectrometry}

To quantitatively determine several elements in a single sample, Inductively Coupled Plasma Mass-Spectroscopy (ICP-MS) and Inductively Coupled Plasma Optical-Emission Spectroscopy (ICP-OES) were used. A thorough discussion and explanation of ICP-MS can be found in Handbook of Inductively Coupled Plasma Mass Spectrometry [44]. ICP-MS can quantify metals present in the solution over 8 orders of magnitude [45].

ICP-MS sensitivity is heavily dependent on the matrix, and it is suggested to keep the total dissolved matter below $0.2 \%$ [46]. It is possible to have higher amounts of total dissolved matter using advanced injection techniques[45].

ICP-OES can handle higher concentration of dissolved matter than ICP-MS, the injection system in ICP-OES is more varied than ICP-MS and common setups can handle up to 1-2\% total dissolved matter [47]. Specialized injection systems exist that can handle up to 20\% [47]. ICP-OES have a smaller quantification range but it is more robust, and was used to handle less diluted solutions than the ICP-MS. ICP-OES can quantify concentrations over 6 orders of magnitude [47].

ICP-OES utilizes the emission of the exited atoms and ions in the plasma. The results is several spectral lines that are specific to the elements.

\subsection{SPECIATION}

The extraction process in liquid-liquid extraction (as explained in Chap. 4.1) is, among other things, dependent upon the aqueous species. When there is only a single adduct-forming metal present in the solution, it is straightforward to predict the speciation if the stability constants are known. For a single metallic element with one type of ligand and a given number of adducts, we have: 


$$
[M]_{t o t}=\sum\left[M L_{n}\right]
$$

Where $[M]_{\text {tot }}$ is the total concentration of the metal and $\left[\mathrm{ML}_{\mathrm{n}}\right]$ the concentration of individual species. If the stability constant of the individual species is known, the concentration of each species can be calculated as:

$$
\frac{\left[M_{t o t}\right]}{\left(1+\sum\left[M L_{n}\right]\right)} \beta_{i}[L]^{i}=\left[M L_{i}\right]
$$

Here $n$ and $i$ are integers representing the number of ligands on the central atom, and $\beta$ represents the stability constant for species $i$.

In this section, the speciation of $\mathrm{Cd}(\mathrm{II})$ is discussed from a theoretical viewpoint and will support the discussion of the experimental results presented later.

$\mathrm{Cd}(\mathrm{II})$ has four chloride species, with the highest chloride species only viable in high-chloride concentration. In Figure 4.6, Eq.4.15 was used to calculate the concentration of the different cadmium species at different chloride concentrations.
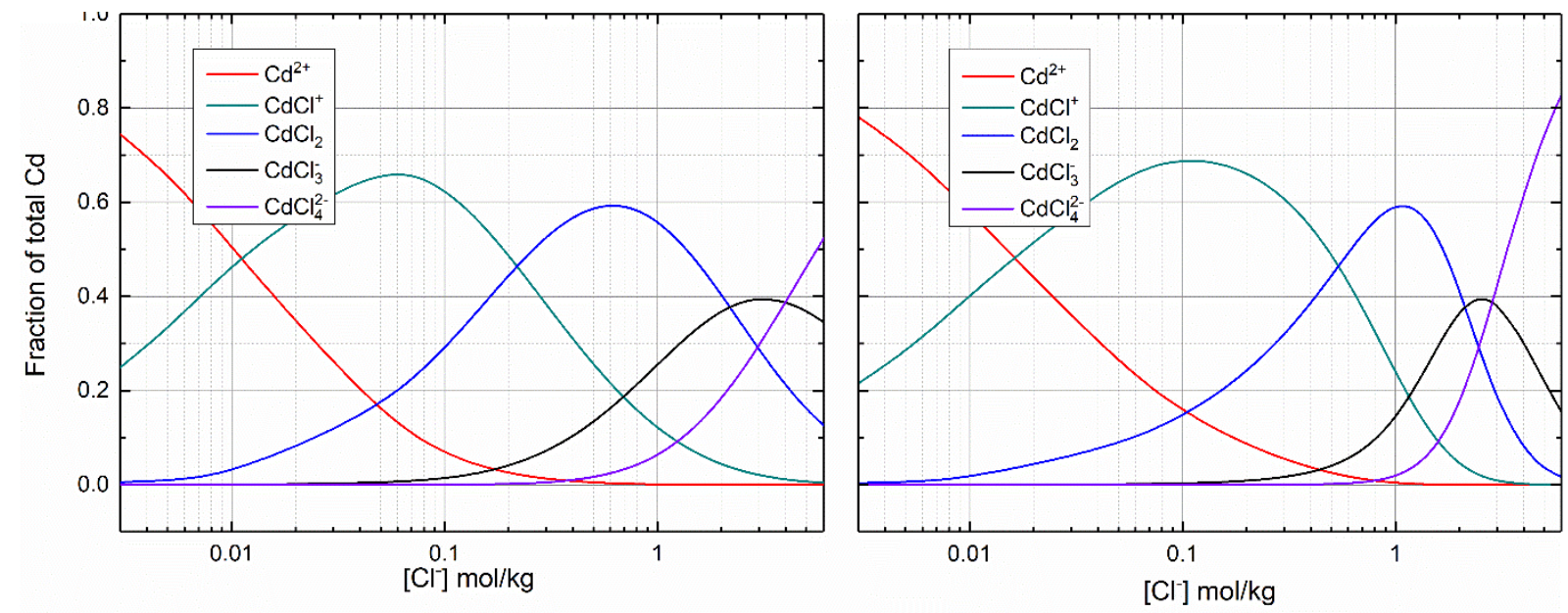

Figure 4.6 Left side of the figure shows the speciation of Cd(II) in chloride solutions as a function of the nominal concentration (disregarding the chemical activity). The right side shows the speciation when the activity is considered.

Figure 4.6 shows two estimations for the various chloride species of $\mathrm{Cd}(\mathrm{II})$. The left panel shows speciation where the activity coefficients are shown as unity, and the right side shows the speciation where the activity coefficients are calculated using Pitzer equations (see appendix A1 for an explanation of the Pitzer equations). The activity coefficients start to differ significantly from unity around $0.1 \mathrm{~mol} / \mathrm{kg}$ chloride in the solution. The activity coefficients decrease until a concentration of roughly $0.5 \mathrm{~mol} / \mathrm{kg}$ is reached. Therefore, the $\mathrm{CdCl}^{+}$species dominates for a more significant concentration range when chemical activity is taken into account (as can be seen in the right panel). At higher molality, the activity coefficients increase rapidly, resulting in the marked increase in the $\mathrm{CdCl}_{4}{ }^{2-}$ species in the right panel compared to the left panel.

Table 4.1 lists the equations used to calculate the nominal concentration different species shown in Figure 4.7. The stability constants shown in the table are for standard conditions, expect they are calculated to infinite dilution. The stability constants were the most valid found. 
Table 4.1 The chloride species and the equilibrium equation for Cd. Stability constants from Powell et al.'s technical IUPAC report [18].

\begin{tabular}{cccc}
\hline$C d^{2+}+C l^{-} \rightleftharpoons C d C l$ & $k_{1}=\frac{\left[C d C l^{+}\right]}{\left[C d^{2+}\right]\left[C l^{-}\right]}$ & & $\mathrm{K}_{1}=95 \pm 1$ \\
$C d C l_{1}+C l^{-} \rightleftharpoons C d C l_{2}$ & $k_{2}=\frac{\left[C d C l_{2}\right]}{\left[C d C l^{+}\right]\left[C l^{-}\right]}$ & $\beta_{2}=\frac{\left[C d C l_{2}\right]}{\left[C d^{2+}\right]\left[C l^{-}\right]^{2}}$ & $\beta_{2}=436 \pm 1$ \\
$C d C l_{2}+C l^{-} \rightleftharpoons C d C l_{3}^{-}$ & $k_{3}=\frac{\left[C d C l_{3}^{-}\right]}{\left[C d C l_{2}\right]\left[C l^{-}\right]}$ & $\beta_{3}=\frac{\left[C d C l_{3}^{-}\right]}{\left[C d^{2+}\right]\left[C l^{-}\right]^{3}}$ & $\beta_{3}=200 \pm 1$ \\
$C d C l_{3}^{-}+C l^{-} \rightleftharpoons C d C l_{4}^{2-}$ & $k_{4}=\frac{\left[C d C l_{4}^{2-}\right]}{\left[C d C l_{3}^{-}\right]\left[C l^{-}\right]}$ & $\beta_{4}=\frac{\left[C d C l_{4}^{2-}\right]}{\left[C d^{2+}\right]\left[C l^{-}\right]^{4}}$ & $\beta_{4}=160 \pm 2$ \\
\hline
\end{tabular}

If there is more than one ligand in the aqueous solution, the metal species formed depends on the concentration and stability constant for the individual species. As an example of such effects, Figure 4.7 shows sulfate and chloride present in the solution simultaneously.
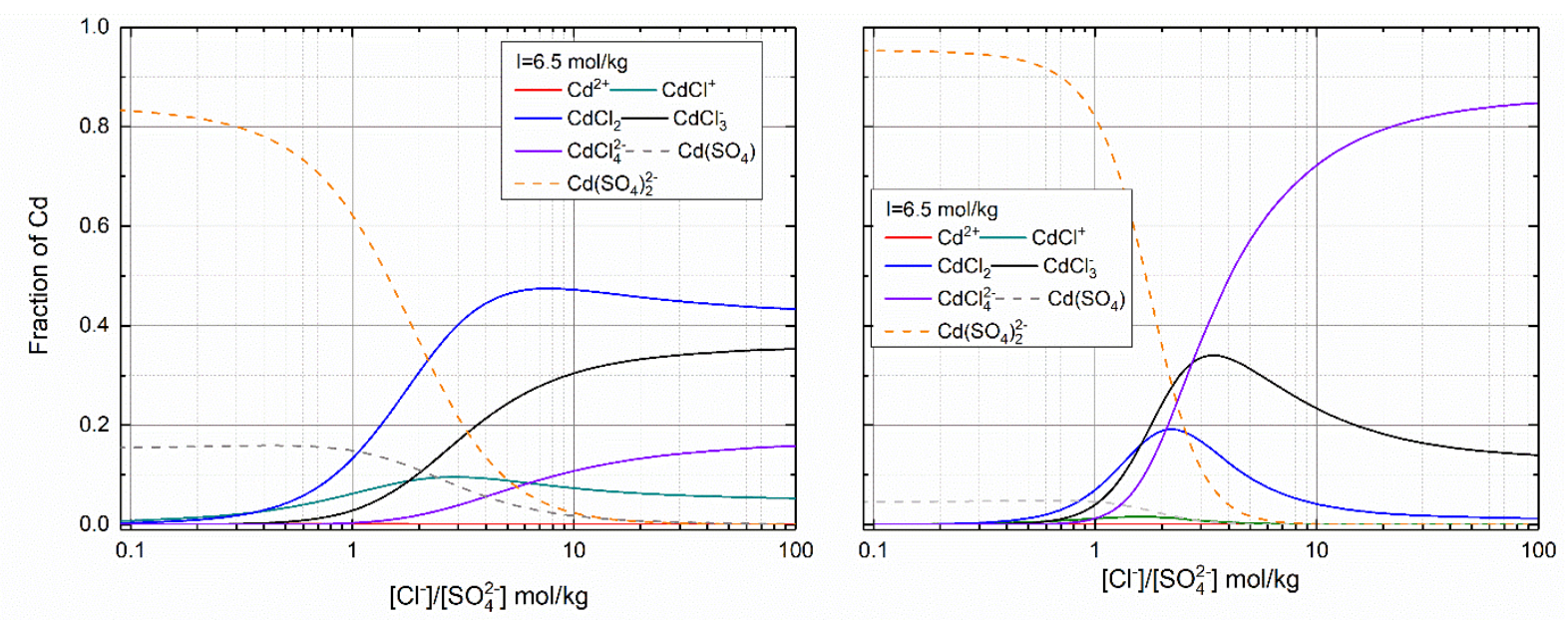

Figure 4.7 Left side of the figure shows the speciation of Cd(II) in chloride solutions as a function of the nominal concentration (disregarding the chemical activity). The right side shows the speciation when the activity is considered. Total ionic strength kept at $6.5 \mathrm{~mol} / \mathrm{kg}$.

Figure 4.7 shows estimations of the speciation of $\mathrm{Cd}(\mathrm{II})$ in a mixed solution of $\mathrm{Li}_{2} \mathrm{SO}_{4}$ and $\mathrm{LiCl}$. The estimations assume that there are no mixed ligand species (e.g., $\left.\mathrm{CdCl}\left(\mathrm{SO}_{4}\right)^{-}\right)$. It is also assumed that the stability constants measured in solutions with only one ligand present are valid for solutions with two ligands. The left panel shows the speciation with the activity coefficients set to unity, the right panel shows the speciation with the activity coefficients calculated using Pitzer equations, the ionic strength was kept constant at 6.5. The left panel shows how the species will change in the aqueous phase in an ideal solution (i.e., $\gamma_{ \pm}=1$ ). Increasing the concentration of chloride will lower the relative concentration of $\mathrm{Cd}\left(\mathrm{SO}_{4}\right)_{2}{ }^{2-}$. With increasing chloride concentration, $\mathrm{CdCl}_{2}$ will start to dominate. However, several other $\mathrm{Cd}(\mathrm{II})$ chloride species will be present in the aqueous solution. When activity is accounted for as it is in the right panel, the $\mathrm{CdCl}_{4}{ }^{2-}$ species dominates. More than $80 \%$ of the $\mathrm{Cd}(\mathrm{II})$ will be in $\mathrm{CdCl}_{4}{ }^{2-}$ form when activity is taken into account.

For Figure 4.7, Eq. 4.15 was used to calculate the amount of each species according to the following equation: 


$$
\frac{\left[M_{\text {tot }}\right]}{\left(1+\sum\left[M L_{n}\right]+\sum\left[M R_{n}\right]\right)} \beta_{n}[\text { or } R]^{n}=\left[M L_{n} \text { or } R_{n}\right]
$$

\subsection{EXtractants}

Liquid-liquid extraction uses extractants to selectively bind and transport the analyte across the phase boundary, between the immiscible liquids. Here, immiscible liquids are defined as two liquids that have a visible interphase.

\subsubsection{Aliquat 336}

In this work, the main focus has been on using the extractant Aliquat 336 (A336). It is usually described as a liquid ion exchanger. A336 is a quaternary amine with a chloride as a counter ion. It has 3 carbon chains with 8 to 10 carbons, and a methyl group coupled to the nitrogen (see Figure 4.8).

A336 is also known as Starks catalyst since Charles M. Starks used A336 as a catalytic reagent to transport halides and cyanide from the aqueous phase into the organic phase $[9,48]$. A336 extracts anions, and can therefore extract several metallic elements from different aqueous solutions [49-69]. However, it does not work well in solutions containing nitrate or perchlorate as these bind strongly to A336 [51,70]. A336

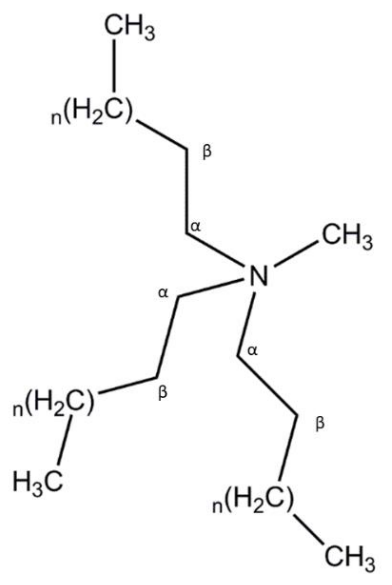

Figure 4.8 Aliquat 336 with $\alpha$-carbon and $\beta$-carbon marked, as well as the end point for the chain. The n can vary from 6-9 as drawn here. No charge or counter ion added to the molecule for simplicity. does not enter the aqueous phase and there are two general equilibrium equations that apply [71,72]. The first is:

$$
\left(M C l_{n}\right)_{\text {org }}+A 336 \cdot C l_{\text {org }} \rightleftharpoons A 336 \cdot\left(M C l_{n+1}\right)_{\text {org }}
$$

Here $n$ is the charge of the metal. Eq. 4.17 applies when a neutral metal species, enters the organic phase and is then bound to A336 by association. This reaction can happen both at the phase boundary and within the organic phase, assuming the neutral metal-chloride species is at least slightly soluble in the organic phase. The second reaction is when a negatively charged metal-chloride ion displaces the chloride ion associated to A336:

$$
\begin{aligned}
\left(M C l_{n+1}^{-}\right)_{a q}+ & A 336 \cdot C l_{\text {org }} \\
& \rightleftharpoons A 336 \cdot\left(M C l_{n+1}\right)_{\text {org }}+C l_{a q}^{-}
\end{aligned}
$$

However, assuming anion exchange is the only way that the extraction can occur, the bond between A336 and the metal could then only happen at the interphase since anions are not solvable in the organic phase.

There are, of course, more extractions occurring with A336 than just extraction of the wanted metal ion. For example, there will also be some water extracted. Starks postulates that the amount of water in the organic phase is chiefly dependent on the hydration of the anion [9].

\subsection{ORgANIC SOLVENTS}

Organic solvents are needed to dissolve the extractant and form the organic phase. The solvents should not be too viscous and have a reasonably low vapour pressure. The first requirement is to ensure good flow when pumping and separating the organic liquid. The second is to reduce 
the fire hazard normally associated with high vapour pressures. In addition, low toxicity of both solvent and extractant, in their various forms, is important. The most common organic solvents are either aliphatic or aromatic. Halogenated solvents were frequently used in the past, for example, [73], but they are less common today due to their health issues and environmental impact. The most common commercial solvents are made from technical grade petroleum distillates, and therefore consist of a mixture of several different aliphatic hydrocarbons and aromatic compounds. The mixtures are prepared for optimal dissolution of typical extractants. Furthermore, their composition should be such that third phase formation (e.g., foam or aqueous-organic mixtures) is hindered.

Using distillates in the study of speciation of solutes leads to difficulty explaining the observations. The unknown factors and the probability of different molecules interacting makes any estimation of the dominating extraction mechanism guesswork. Therefore, since our goal has been to study speciation of solutes present in minute amounts in highly saline solutions, we used pure toluene as solvent. There are some practical experimental problems with toluene, which will be presented in the discussion (Chap. 6) and conclusion (Chap. 7).

Aromatic solvents are dominated by an aromatic group. The $\pi$-electrons disperse their charge making it possible to induce a charge distribution. The main drawback for aromatic compounds is that they are toxic and carcinogenic [74,75]. Since the aromatic solvents are lipophilic and have low vapour pressure, they can be absorbed through contact and are easy to inhale and also represent a fire hazard, as can be seen in Table 4.2. Vapour pressure can be decreased by increasing the molecular mass, but this normally comes at the cost of either increased viscosity or a higher melting point. Table 4.2 displays some examples of aromatic compounds. Note that their flashpoints are low.

Table 4.2 Liquid range and flashpoint of some aromatic compounds.

\begin{tabular}{lll}
\hline Compound & Flashpoint $^{\circ} \mathrm{C}$ & $\begin{array}{l}\text { Melting point/boiling } \\
\text { point }{ }^{\circ} \mathrm{C}\end{array}$ \\
\hline Benzene & -11 & $5.5 / 80[76]$ \\
Toluene & 4.4 & $-95 / 110.6[77]$ \\
Naphthalene & 78 & $80.26 / 218[78]$ \\
\hline
\end{tabular}

Aliphatic solvents consist of hydrocarbon chains or carbon rings. Aliphatic components only interact by Van der Waals forces. Due to chain lengths and chain branching, they can be liquid and more fluid at a higher mass than aromatic components.

Table 4.3 Examples of aliphatic solvents with their liquid range and flashpoint.

\begin{tabular}{lll}
\hline Compound & Flashpoint ${ }^{\circ} \mathrm{C}$ & $\begin{array}{l}\text { Melting point/boiling } \\
\text { point }{ }^{\circ} \mathrm{C}\end{array}$ \\
\hline Cyclohexane & -20 & $6.47 / 81[79]$ \\
Decane & 46 & $-30 / 174[80]$ \\
\hline
\end{tabular}

In the hydrometallurgical industry, it is seldom that pure aliphatic or pure aromatic components are used because pure compounds are often too toxic or do not dissolve enough extractant. In addition, third-phase formation is more likely to occur and is hard to control. Third phase can severely disrupt a process plant. Therefore, several commercial solvents have been developed, which are usually mixtures of aromatic and aliphatic hydrocarbons. There may also be some 
surfactants or long-chained alcohols added. The aromatic parts enable the extractant to dissolve, the aliphatic part lowers toxicity and lowers the vapour pressure while the long-chained alcohol increase the amount of water accepted in the organic phase and thereby lowers the probability for forming third phase. As already mentioned, commercial solvents are suited to perform work at actual hydrometallurgical plants but are less suitable for detailed studies of the extraction process. An added complication for the commercial solvent mixtures is their hidden content and mixing ratios, which makes precise description of the relevant chemical interactions and reactions difficult or impossible.

Table 4.4 liquid range and flashpoint of some commercial solvents

\begin{tabular}{llll}
\hline Product name & Flashpoint ${ }^{\circ} \mathrm{C}$ & $\begin{array}{l}\text { Melting point/boiling } \\
\text { point }{ }^{\circ} \mathrm{C}\end{array}$ & Percentage aromatic \\
\hline Solvesso 200Nd & 107 & $-13 / 248-295$ & $99 \%[81]$ \\
ShellSol T & 56 & $-20 / 178-191$ & Less than 2\% [82] \\
Exxsol D60 & 61.5 & Not defined/180-217 & Less than 1\% [83] \\
\hline
\end{tabular}

Furthermore, the complex mixture of commercial solvents makes spectroscopic techniques such as infrared, Raman and NMR more complicated or even impossible. The reason for this is the signal complexity emitted from all the different molecules.

\subsubsection{The Challenge of Concentration}

In dilute solutions (e.g., aqueous solutions with concentrations lower than $0.5 \mathrm{~mol} / \mathrm{kg}$ ) the concentration of the solvent is often ignored. Usually this is valid because there is no significant change in the solvent concentration during the extraction. However, as can be seen from table 4.5 , the numerical concentrations of the solvents are not the same. When the metal ions are present at high concentrations, as is typical for processes at industrial scales, interaction with the solvent molecules can become dependent on availability, for example, the solvent concentration. In typical cases, the solvent concentration is lower for organic solvents than for water.

Table 4.5 Density, molarity and molality of various solvents [1] at standard condition.

\begin{tabular}{llll}
\hline Molecule & Density $\mathrm{kg} / \mathrm{L}[84]$ & $\mathrm{mol} / \mathrm{L}$ & $\mathrm{mol} / \mathrm{kg}$ \\
\hline Water & 1.00 & 55.6 & 55.6 \\
Benzene & 0.876 & 11.2 & 14.6 \\
Toluene & 0.867 & 9.40 & 12.5 \\
Naphthalene & 1.14 & 8.89 & 6.84 \\
Cyclohexane & 0.779 & 9.25 & 15.3 \\
Decane & 0.730 & 5.13 & 9.63 \\
Carbon tetrachloride & 1.59 & 10.3 & 4.09 \\
\hline
\end{tabular}

There are several common concentration units in use. Molarity, molality and mole fraction. Molarity is useful if the concentrations are low enough to not change the density of the solution significantly. However, with rising concentrations, there is an increasing divergence between molarity and molality. Molality can be used for all concentrations, and there will be an equal amount of solvent at all concentrations. Mole fraction is the most descriptive but can only be used if all species and solutes are known for the sample. 
Molality was used for this thesis as it is the most practical unit for highly concentrated solutions. Using molarity gives unknown quantities of solvent resulting in imprecise data. It was deemed too complicated to determine all species post-extraction to use mole fraction. 


\section{INSTRUMENTATION AND SAMPLE PREPARATION}

\subsection{SOLUTION GENERATION}

As this project was closely linked to industrial hydrometallurgy and its concerns, a valid question to ask is why the solutions generated were not from an industrial plant. There are three reasons for this: First of all, the Cd(II) contamination studied in the present work is not currently present in the industrial solutions, at least not at such high concentrations. Secondly, the industrial solutions need to be 'fresh', as they are close to saturation and precipitate, changing the composition of the solution. Lastly, industrial solutions depend on the raw material input, which constantly changes. Therefore, a well-defined industrial solution is non-existent - it changes over time and is unsuitable as a reference solution. Based on this, all solutions were 'synthetic', that is, they were made in the lab to exact specifications.

\subsection{LIQUID-LIQUID EXTRACTION CONDITIONS}

Extractions were performed at ambient temperature $\left(21 \pm 2{ }^{\circ} \mathrm{C}\right)$ using equal volumes of the organic and aqueous phase. The needed shaking time was determined by measuring the D-ratios at various shaking times until the D-ratios stabilised. It was assumed that the lowest concentration of extractant needed the longest shaking time to reach equilibrium, thus the time of extraction was only tested at these low concentrations. After mixing, separation was done with a centrifuge at a minimum 3000 RPM for at least 5 minutes. However, the solutions with the lowest ionic strength and the highest A336 concentration needed up to 20 hours. The organic phase was separated from the aqueous phase using an automatic pipette. The top layer of the organic phase was siphoned from the aqueous, leaving a thin layer on top of the aqueous solution. The pipette tip was changed, and the remaining organic and some aqueous solution was removed. Then the top layer of the aqueous solution was removed. There was again a pipette tip change, and the remaining aqueous solution was then sampled.

To ascertain that the organic and the aqueous phases had not changed, a specific volume was extracted, and its mass measured before and after extraction to determine if there had been a change in density.

\subsection{RADIOTRACERS}

A coaxial $80 \%$ High Purity Germanium detector (HPGe) supplied from Canberra was used for high-resolution $\gamma$ spectroscopy. For ${ }^{65} \mathrm{Zn}$ the area under the $1115-\mathrm{keV}$ peak (see Figure [Switch to 4.11]) was used, and for ${ }^{60} \mathrm{Co}$, the sum of the areas under the peaks at $1173-\mathrm{keV}$ and $1332-$ $\mathrm{keV}$ (see figure 4.11) was used. The spectra were recorded and analysed using the Maestro software suite (version 6.08) developed and supplied by Ortec.

The phases were prepared by adding the radioactive tracer to the aqueous solution of the selected composition. ${ }^{60} \mathrm{Co}$ and ${ }^{65} \mathrm{Zn}$ were carefully measured to ensure that the measurement geometry was equal for both phases. Here the geometry means that both the distance and the shape of the samples are as similar as possible. 
The amount of ${ }^{109} \mathrm{Cd}$-tracer in the solutions was determined by measurement of the conversionelectron spectrum from the disintegration of ${ }^{109} \mathrm{Cd}$ (see Figure 5.1 where the $88 \mathrm{keV}$ Conversion electron peak is labelled).
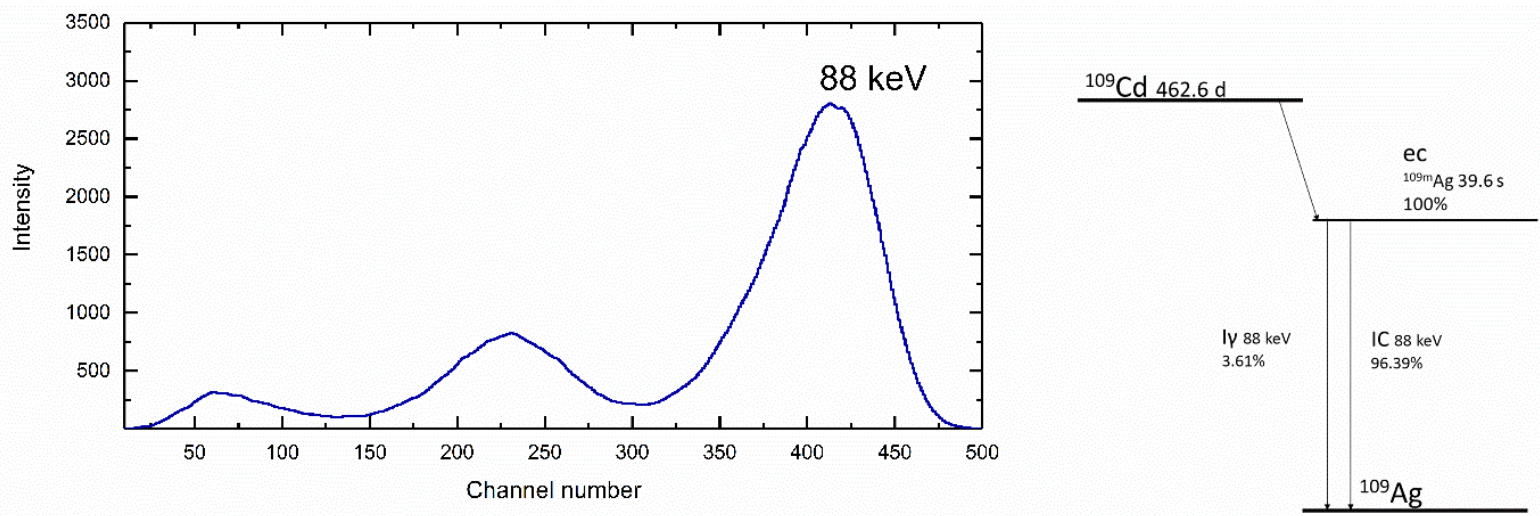

Figure 5.1 Spectrum of ${ }^{109} \mathrm{Cd}$ from Liquid-scintillation counting. The spectra are not energy calibrated. Decay scheme redrawn from [85].
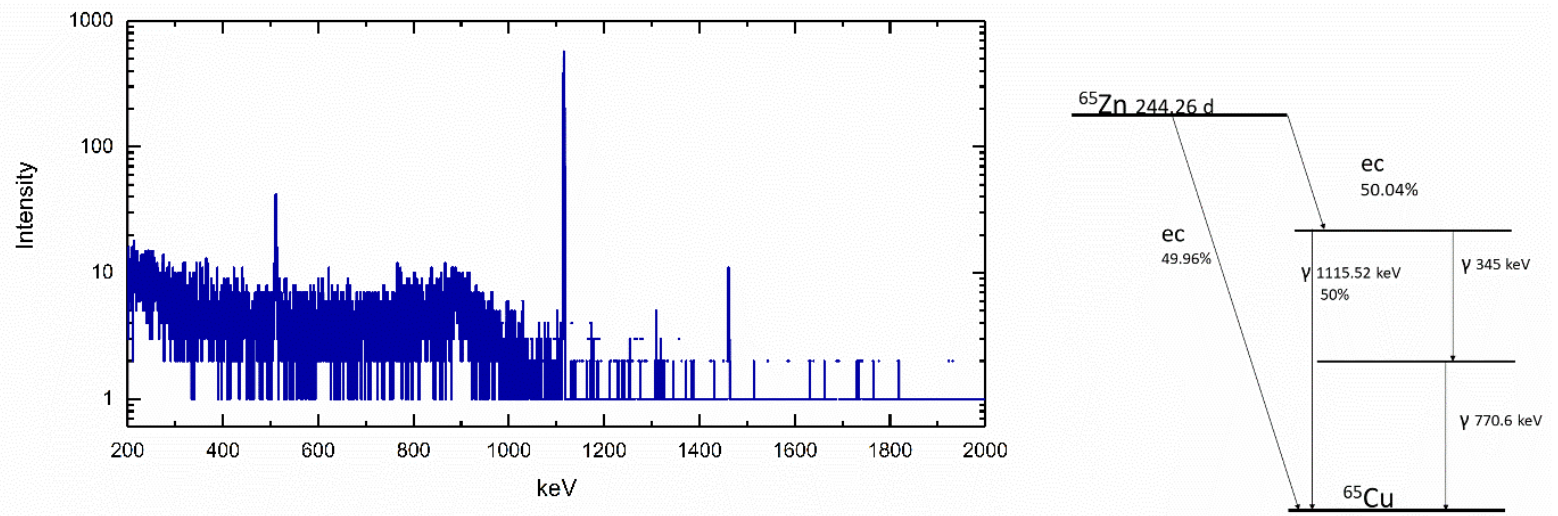

Figure 5.2 Spectrum of ${ }^{65} \mathrm{Zn}$ resolved with a high purity germanium detector [86].
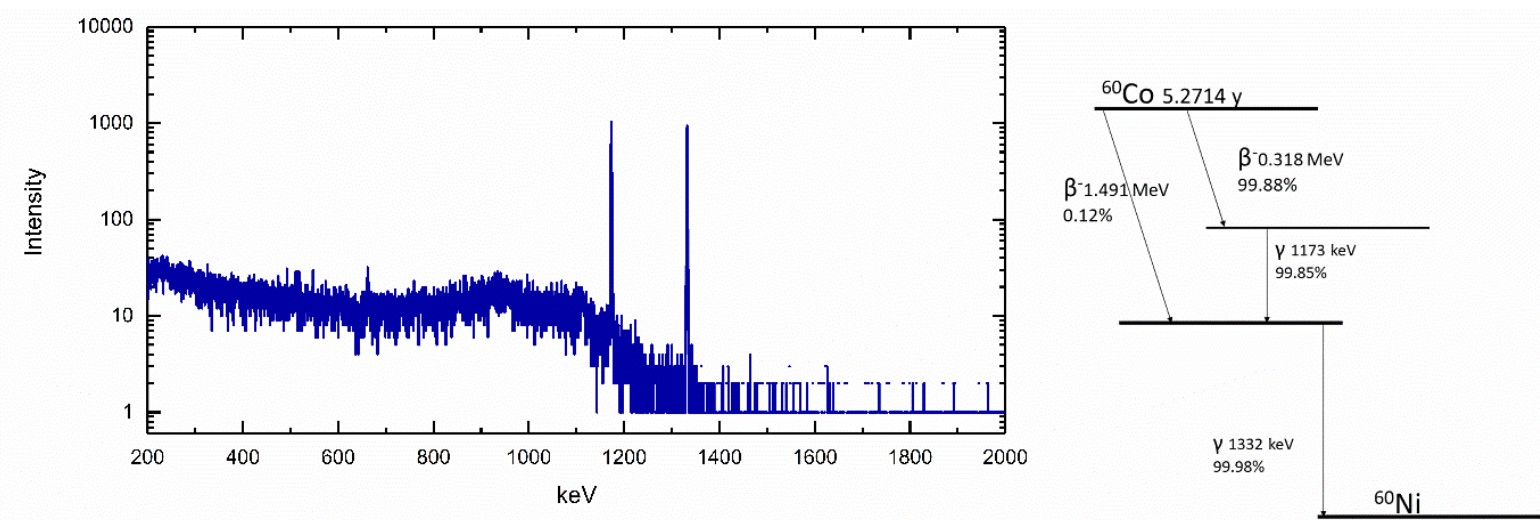

Figure 5.3 Spectrum of ${ }^{60}$ Co resolved with a high-purity germanium detector [87].

Liquid-scintillation spectroscopy using a Hidex 300 liquid-scintillation spectrometer was used to measure the conversion-electron spectrum. The liquid-scintillator cocktail used was Ultima Gold XR produced by Packard and used as supplied. Varying degrees of quenching of the lighttransfer process by the constituents of the different solutions were compensated (efficiency calibration) by measuring the shift in the peak position of electrons from the $88-\mathrm{keV}$ transition 
in ${ }^{109 m} \mathrm{Ag}$ [88]. The quench correction curve was determined by adding $\mathrm{CCl}_{4}$, as a deliberate quencher, to known amounts of ${ }^{109} \mathrm{Cd}$ solutions [89].

The spectra were analysed using the peak-fit function in the Origin software package version 9.1 from OriginLab Corporation. All radiotracer experiments were performed at a minimum of three replicates.

\subsection{MEASUREMENTS WITH ICP-MS AND ICP-OES}

Concentrations of the target elements were determined using ICP-MS; model NexION 300D, manufactured by PerkinElmer Inc. (Waltham, MA, USA). The instrument's software was NexION ICP-MS Software (version 1.2), from the same manufacturer. The concentration of the pertinent elements was determined from the following isotopes: ${ }^{27} \mathrm{Al},{ }^{114} \mathrm{Cd},{ }^{63} \mathrm{Cu},{ }^{59} \mathrm{Co}$, ${ }^{52} \mathrm{Cr},{ }^{55} \mathrm{Mn},{ }^{60} \mathrm{Ni},{ }^{207} \mathrm{~Pb},{ }^{66} \mathrm{Zn}$. Indium was used as an internal standard from Teknolab As. Additional isotopes were used for control when available.

The following elements were determined with a ICP-OES (Vista AX CCD simultaneous ICPAES) using the following spectral lines: $\mathrm{Al}(226.483 \mathrm{~nm}), \mathrm{Ba}(389 \mathrm{~nm}), \mathrm{Bi}(298 \mathrm{~nm}), \mathrm{Cd}(214.439$ $\mathrm{nm}), \mathrm{Cu}(324.754 \mathrm{~nm}), \mathrm{Co}(236.379 \mathrm{~nm}), \operatorname{Sr}(407.771 \mathrm{~nm}), \mathrm{Te}(238.579 \mathrm{~nm}), \mathrm{Sb}(206.834 \mathrm{~nm})$, $\mathrm{W}(220.449 \mathrm{~nm})$, and $\mathrm{Mo}(379 \mathrm{~nm})$. Additional spectral were used for control when available. For consistency between ICP-MS and ICP-OES it was checked that both instruments gave the same concentration.

Sterile polypropylene tubes of $15 \mathrm{~mL}(120 \times 17 \mathrm{~mm})$ and $50 \mathrm{~mL}(115 \times 28 \mathrm{~mm})$, purchased from Sarstedt AG \& Co (Nümbrecht, Germany), were used as solution vessels during extraction, back-extraction and ICP-MS procedures. Calibration standards for were prepared from Multielement standard solution IV for ICP, TraceCERT®, in 10\% nitric acid, purchased from Sigma-Aldrich Co. LLC (St. Louis, MO, USA). For the additional elements single element standards were used $(1000 \mu \mathrm{g} / \mathrm{mL})$.

Preparation of samples for were done by taking $0.5 \mathrm{~g}$ of the aqueous solution and adding it to $10 \mathrm{~g}$ of $2 \%(\mathrm{~m} / \mathrm{v})$ nitric acid $\left(\mathrm{HNO}_{3}\right)$.

The limits of determination (LOD) were based on measurements of two blank solutions: a 5 $\mathrm{mol} / \mathrm{kg} \mathrm{HCl}$ solution and a $1 \mathrm{~mol} / \mathrm{kg} \mathrm{Li}_{2} \mathrm{SO}_{4}$ solution. The LOD was defined as 10 times the standard deviation of the background signal from 10 repeated measurements.

All IPC experiments were performed with a minimum of three replicates.

\subsection{NuClear Magnetic ResonanCe}

In this work, NMR has been used as a technique to both quantify and determine species. To determine the amount, the individual resonance bands were integrated and referenced to a resonance bond with a known amount.

NMR spectra were acquired using a Bruker DRX 500 spectrometer operating at a magnetic field strength of $11.74 \mathrm{~T}$. The instrument was equipped with a $5 \mathrm{~mm} \mathrm{BBO}\left(\mathrm{BB} /{ }^{1} \mathrm{H} /{ }^{2} \mathrm{H}\right)$ probe with Z-gradient. All spectra were acquired at $25^{\circ} \mathrm{C}$. The intensity (integrated area) of an NMR peak was determined by fitting certain spectral functions (a linear combination of a Gaussian and a Lorentzian peak function) to the observed NMR spectra by a non-linear least squares technique.

For speciation and measurement with NMR, it is common to add a molecule containing deuterium. The NMR-instrument locks onto the signal of the deuterium and is used to control 
the stability of the magnetic field [37]. Normally, when performing liquid-liquid extraction, there is no problem adding deuterated molecules as there is either water present or there is an abundance of an organic solvent. Hence, small additions of deuterated solvent will not change the properties of the solution. However, some experiments were performed using the Aliquat 336 extraction agent without any solvent present. It was assumed here that adding a small amount of deuterated solvent would not change the species. In some of the experiments, a thin glass tube was inserted into the NMR sample tube containing a deuterated solvent. The added inhomogeneity, coupled with the high ionic content of the organic solution, increased the time needed to obtain a reasonable magnetic field homogeneity. The high viscosity of the A336 solution was decreased by heating A336 to roughly $40^{\circ} \mathrm{C}$ before inserting it into the $5 \mathrm{~mm}$ NMR tube. NMR experiments of qualitative nature were only repeated when errors were suspected.

\subsubsection{Proton NMR}

Proton NMR spectra were acquired for both the aqueous phase and the organic phase. Spectra were recorded using a single-pulse program with an RF-pulse (Radio-Frequency pulse) duration of $12.9 \mu \mathrm{s}$ (90-degree pulse), a repetition time of $10.0 \mathrm{~s}$ between pulses and an acquisition time of $3.17 \mathrm{~s}$.

\subsubsection{Nitrogen NMR}

${ }^{14} \mathrm{~N}$ was chosen as it is the most abundant isotope [90]. Due to its quadrupolar property, its signal (frequency domain) may broaden to such an extent that it becomes unobservable, in particular if it is located in an unsymmetrical position in the molecule. Ethylene amine was tested as a reference sample. However, due to the unsymmetrical position of nitrogen, it was not easily detected in either the organic phase or the aqueous phase. Nitrate in a separate tube was used as a relative reference. Spectra were recorded using a single-pulse program with a RFpulse duration of $13.25 \mu \mathrm{s}$ (90-degree pulse), a repetition time of $5.0 \mathrm{~s}$ between pulses and an acquisition time of $1.5 \mathrm{~s}$.

\subsubsection{Lithium NMR}

${ }^{7} \mathrm{Li}$ was used chosen as it is the most abundant of the isotopes [90]. This has larger quadrupole momentum than ${ }^{6} \mathrm{Li}$ but it was easily detected in both phases. Lithium nitrate was used as an external reference. Due to the water content extracted with lithium present in the solution, NMR samples were run with and without the external reference. Spectra were recorded using a singlepulse program with an RF-pulse duration of $8.5 \mu \mathrm{s}$ (90-degree pulse), a repetition time of $20.0 \mathrm{~s}$ between pulses and an acquisition time of $5.6 \mathrm{~s}$.

\subsubsection{Cadmium NMR}

${ }^{113} \mathrm{Cd}$ was chosen as it is slightly more NMR sensitive than ${ }^{111} \mathrm{Cd} .{ }^{113} \mathrm{Cd}$ abundance is only $12.22 \%$, but is relatively easy to detect at concentrations higher than $0.1 \mathrm{~mol} / \mathrm{kg}$ [91-93]. To shorten the acquisition time, there then needs to be a high concentration of cadmium [90]. Millimolar concentrations of cadmium have been determined by measurement times longer than 4 hours[94]. Spectra were recorded using a single-pulse program with an RF-pulse duration of $10 \mu \mathrm{s}$ (90-degree pulse), a repetition time of $15.0 \mathrm{~s}$ between pulses and an acquisition time of $0.16 \mathrm{~s}$. 


\section{RESULTS AND DISCUSSIONS}

\subsection{Metal Extraction from Solutions Containing Several Metals}

In aqueous solutions containing different metal ions and different anions, it is essential to determine their interactions. A metal ion can interact with another metal ion forming a new species. It is, therefore, crucial to determine if the constituents will interact with the organic phase and be extracted or if they somehow change the species of the extracted species. An important step is to determine what metals are present and if they interact with each other or the extractant.

The first step in making a feed solution for this study was then to estimate what representative samples from industrial processing plants contain and their respective concentrations. The information obtained from such screening tests was then used to determine the composition of the synthetic solutions used for detailed extraction and speciation experiments. Hence some screening experiments were performed with a high concentration $(0.2 \mathrm{~mol} / \mathrm{kg})$ of extractant Aliquat 336 to determine which have a measurable extraction.

Table 6.1 List of elements and their extraction properties with A336 from a chloride matrix

\begin{tabular}{ll}
\hline Element & \\
\hline $\mathrm{Al}(\mathrm{III})$ & D-ratio under determination limit \\
$\mathrm{Ba}(\mathrm{II})$ & D-ratio under determination limit \\
$\mathrm{Bi}(\mathrm{III})$ & D-ratio under determination limit \\
$\mathrm{Co}(\mathrm{II})$ & D-ratio determinable at $5 \mathrm{~mol} / \mathrm{kg} \mathrm{HCl}$ \\
$\mathrm{Cd}(\mathrm{II})$ & D-ratio determinable at 0.5 and $5 \mathrm{~mol} / \mathrm{kg} \mathrm{HCl}$ \\
$\mathrm{Cr}(\mathrm{IV})$ & D-ratio under determination limit \\
$\mathrm{Cu}(\mathrm{II})$ & D-ratio determinable at $5 \mathrm{~mol} / \mathrm{kg} \mathrm{HCl}$ \\
$\mathrm{Ni}(\mathrm{II})$ & D-ratio under determination limit \\
$\mathrm{Mn}(\mathrm{IV})$ & D-ratio under determination limit \\
$\mathrm{Mo}(\mathrm{VI})$ & D-ratio under determination limit \\
$\mathrm{Pb}(\mathrm{II})$ & D-ratio under determination limit \\
$\mathrm{W}(\mathrm{VI})$ & D-ratio under determination limit \\
$\mathrm{Zn}(\mathrm{II})$ & D-ratio determinable at 0.5 and $5 \mathrm{~mol} / \mathrm{kg} \mathrm{HCl}$ \\
\hline
\end{tabular}

Table 6.1 shows that $\mathrm{Co}(\mathrm{II}), \mathrm{Zn}(\mathrm{II}), \mathrm{Cu}(\mathrm{II})$ and $\mathrm{Cd}(\mathrm{II})$ have a measurable extraction with $\mathrm{A} 336$, with an aqueous phase of $5 \mathrm{~mol} / \mathrm{kg} \mathrm{HCl}$ and $0.5 \mathrm{~mol} / \mathrm{kg} \mathrm{HCl}$. The metal ions present in the sample had some small difference in the concentration (detailed information in article II or appendix BI). Here, too-low extraction is defined to mean that the feed and raffinate are statistically the same (see chapter 4.1.2, appendix A.II or Article II). The limitations of singlephase measurement can be exemplified using $\mathrm{Cd}(\mathrm{II}), \mathrm{Zn}$ (II) and $\mathrm{Co}(\mathrm{II})$. Figure 6.1 shows the extraction measured in a single phase. The difference between the raffinate and the feed is insufficient to investigate the extraction in detail. Furthermore, determining the amount of $\mathrm{Cd}(\mathrm{II})$ and $\mathrm{Zn}$ (II) extracted is not possible, since the amount in the aqueous phase after extraction is below the detection limits. The ICP-MS measurements indicate that at low $\mathrm{HCl}$ 
concentrations, $\mathrm{Cd}(\mathrm{II})$ will have a higher D-ratio than at high $\mathrm{HCl}$ concentrations, while the opposite is true for $\mathrm{Co}(\mathrm{II})$ and $\mathrm{Zn}(\mathrm{II})$. The presence of organic or carbon in the samples can increase the sensitivity of the ICP-MS [95]. However, the dilution of the samples hindered the effect. It would also have been controlled by the internal standard used.

Single-phase measurements can then be used to determine the most significant extractions occurring in a system. While extraction could not be determined for most of the elements it is still possible that they are extracted and that with a continuous feed there could be a build up at an industrial extraction step.

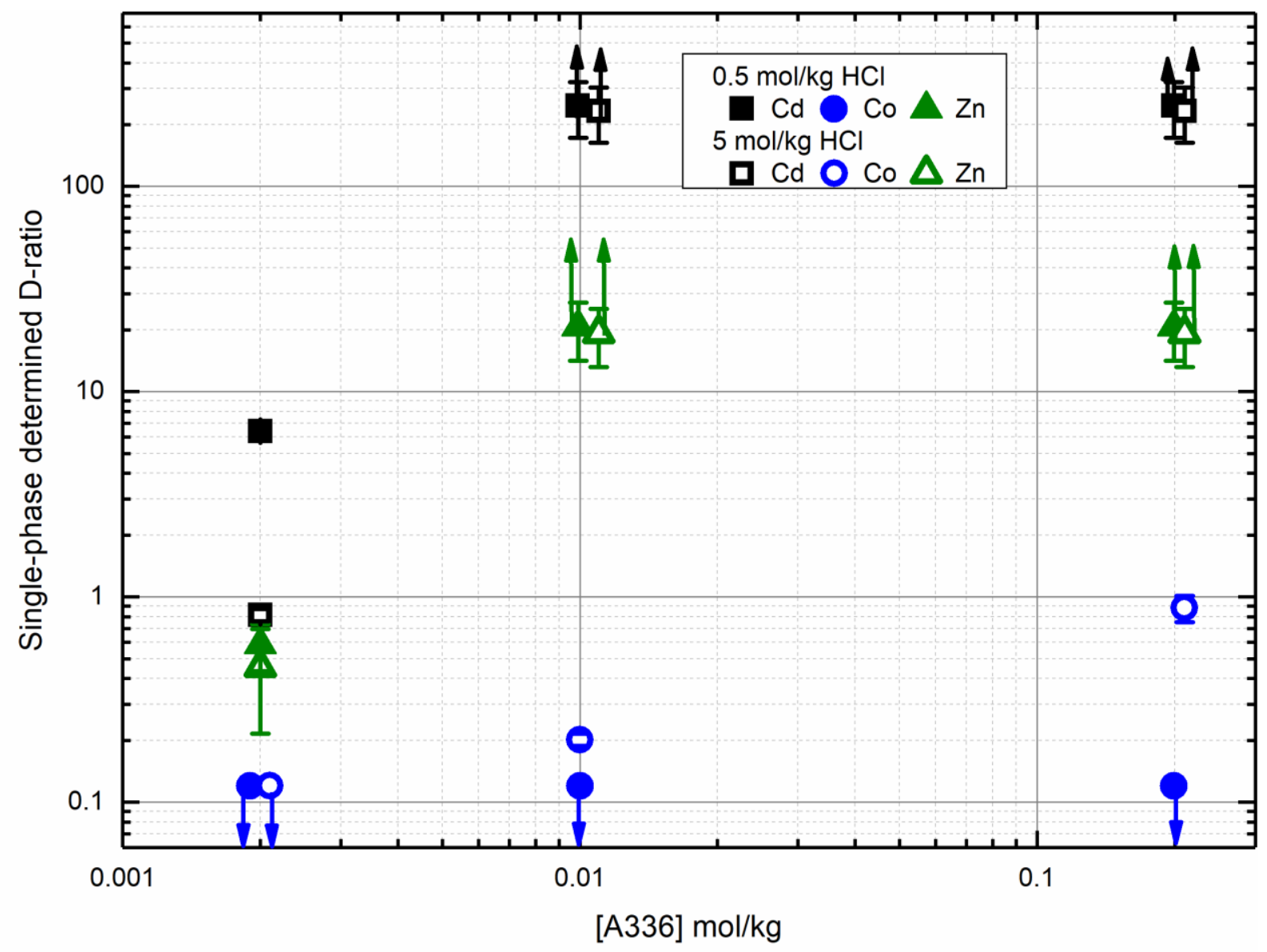

Figure 6.1 Extraction data of Cd(II), Zn(II), Co(II) and Cu(II) using ICP-MS as a function of A336 concentration and two different $\mathrm{HCl}$ concentrations. Error bars represent one standard deviation. In some cases, the error is so small that the error bars are masked by the symbol showing the measurement point. Arrows represent values exceeding the measurable D-ratio.

$\mathrm{Co}(\mathrm{II}), \mathrm{Zn}$ (II) and $\mathrm{Cd}(\mathrm{II})$ all have readily available radiotracers, which enables measurement of both phases, as shown in Figure 6.2. The two-phase measurement expands the range of measurable D-ratios and results in a lower relative uncertainty. 


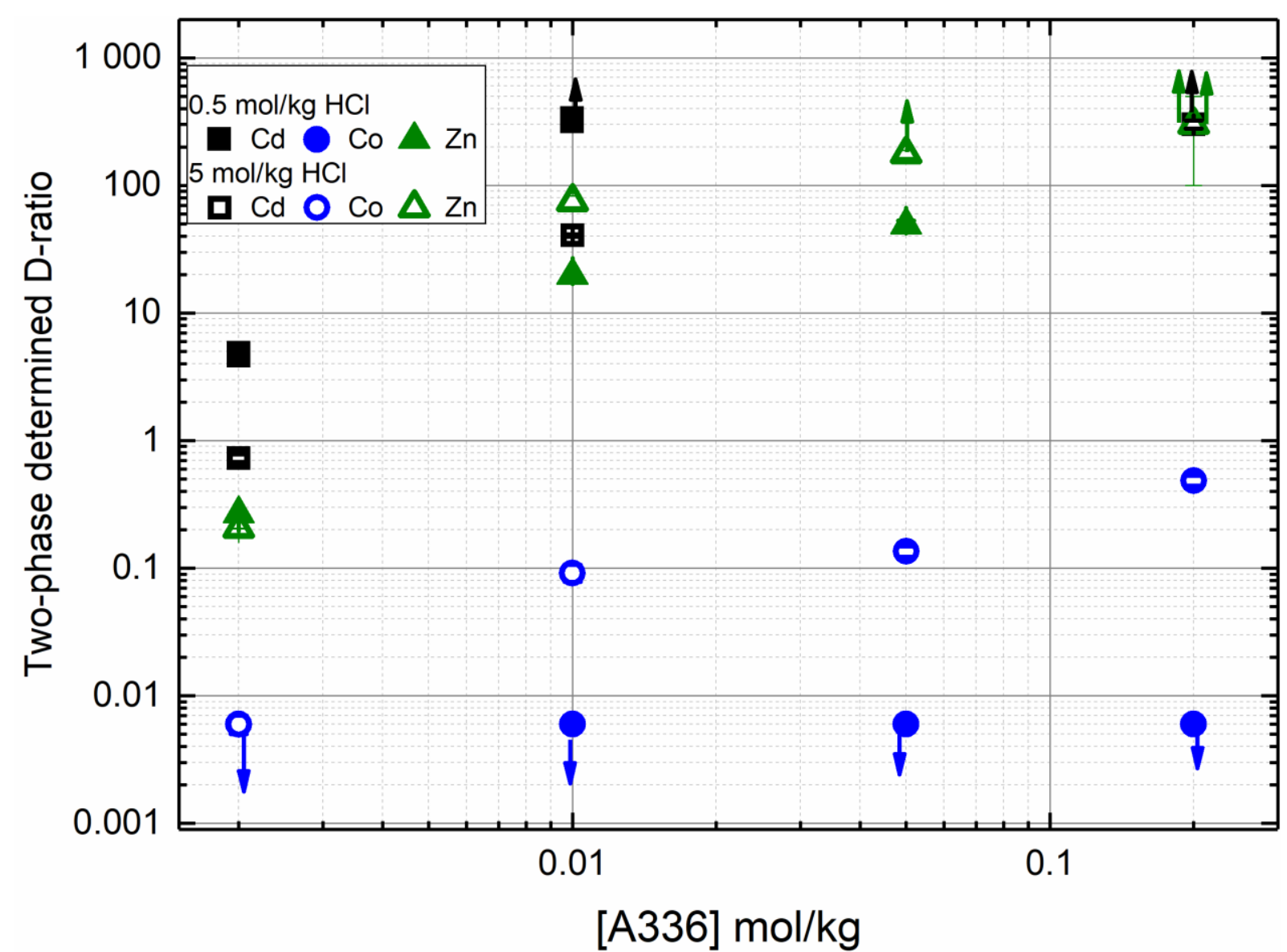

Figure 6.2 D-ratios for $\mathrm{Cd}(\mathrm{II}), \mathrm{Zn}(\mathrm{II})$ and $\mathrm{Co}(\mathrm{II})$ as a function of A336 concentration and two different $\mathrm{HCl}$ concentrations using radiotracers. The error bars represent one standard deviation. Arrows represent values exceeding the measurable D-ratio.

The increased D-ratio range is needed to determine any of the properties of the various elements in the chemical system. However, determination of specific properties of the element is difficult due to the multiple elements in the solution. A simpler chemical system is needed to determine the chemical properties of the individual elements.

For correct determination of separation factors they should be determined with both elements present in the aqueous solution. The interaction between the metals is important for an accurate determination.

\subsection{Metal EXTRACTION FROM SimPlifiEd SynTHETIC SOLUTIONS}

Based on the discussion in chapter 6.1, it was decided to perform experiments with only $\mathrm{Cd}(\mathrm{II})$ present in the solution to better understand the extraction mechanisms for $\mathrm{Cd}(\mathrm{II})$. In addition, $\mathrm{LiCl}$ was used instead of $\mathrm{HCl}$ to reduce the complexity added by variation in the acidity. 


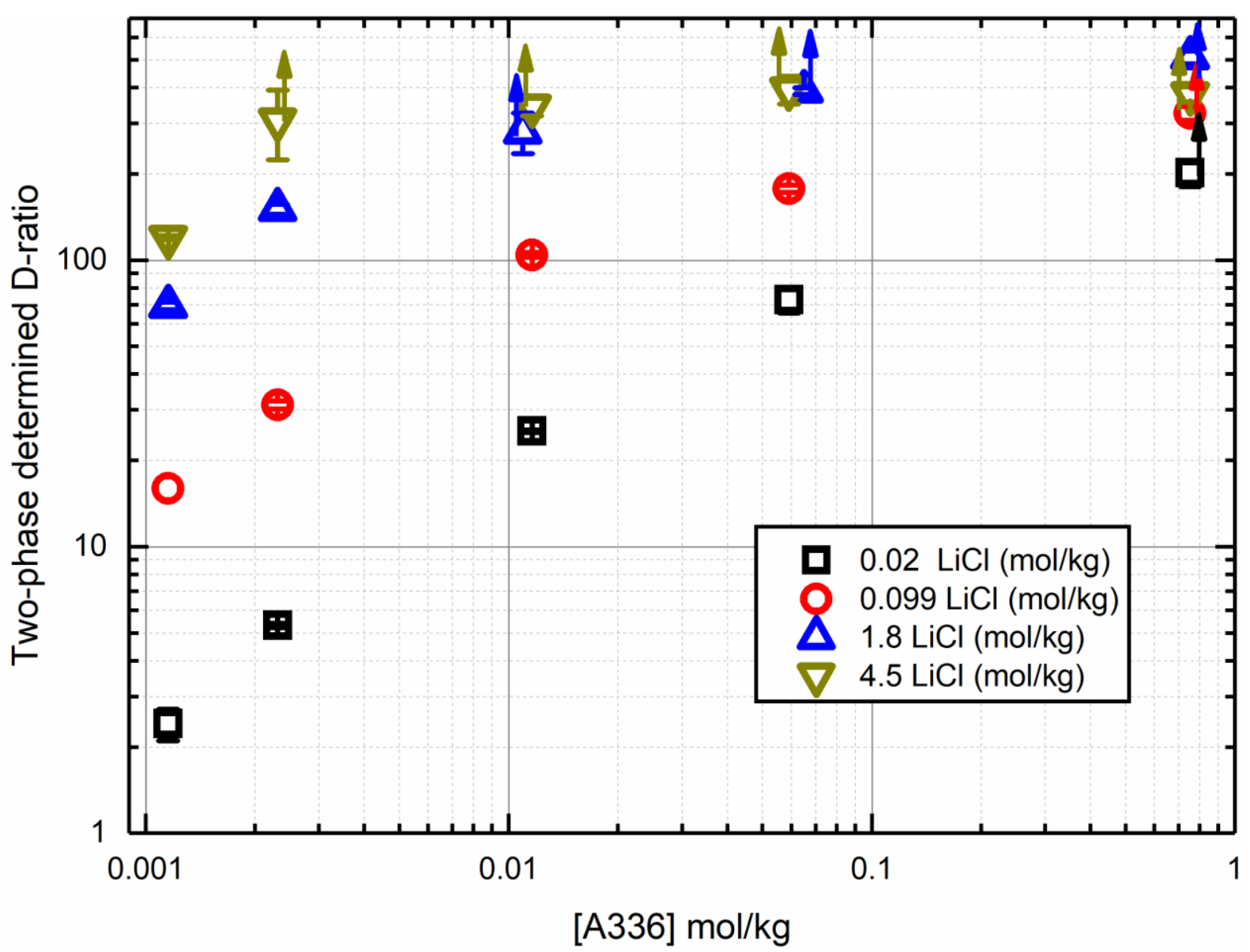

Figure 6.3 D-ratios of cadmium from various LiCl solutions as a function of A336 concentration. Error bars represent one standard deviation. Arrows represent values exceeding the measurable D-ratio.

Figure 6.3 shows that A336 is an efficient extractant for $\mathrm{Cd}(\mathrm{II})$. Even at low chloride concentrations (as low as $0.02 \mathrm{~mol} / \mathrm{kg} \mathrm{LiCl}$ ), A336 is extracting more than $60 \%$ of the $\mathrm{Cd}(\mathrm{II})$. The extraction increases as the $\mathrm{LiCl}$ concentration increases. The disadvantage is that with such high D-ratios, back-extraction of $\mathrm{Cd}(\mathrm{II})$ becomes impossible. Back-extraction has been demonstrated using perchlorate and nitrate [70]; however, both of those anions reduced the efficiency of A336 as an extractant. Closer inspection of the extraction trends (in log-log scale) reveals that the $\mathrm{Cd}(\mathrm{II}) \mathrm{D}$-ratios neither increase linearly versus A336 concentration (Figure 6.3) nor versus the chloride concentration (Figure 6.4). The lack of linearity suggests that there are several different equilibria in play. Therefore, any proposed reaction will only apply for part of the concentration range. In particular, it is the higher concentrations range which deviates from the main trend [51]. The extraction is affected by the concentration in the aqueous phase and the concentration in the organic phase.

\subsection{Co-eXtraction Of Molecular ANions AND ACIDS}

Extractions performed on aqueous solutions containing several species may lead to coextraction. The following discusses co-extraction and the effect additional ions (matrix ions) have on the solution. In addition, how different ions interact with anion exchanger Aliquat 336 and a solvating extractant trioctyl phospine oxide (TOPO) is examined. 
Table 6.2 List of aqueous solutions used for extraction with A336 and TOPO

\begin{tabular}{lll}
\hline Primary salt & Secondary salt & Ionic strength $\mathrm{mol} / \mathrm{kg}$ \\
\hline $\mathrm{LiCl}$ & Not applicable & Varying \\
$\mathrm{LiCl}$ & $\mathrm{LiNO}_{3}$ & $6.6 \pm 0.1$ \\
$\mathrm{LiCl}$ & $\mathrm{NaClO}_{4}$ & $6.6 \pm 0.8$ \\
\hline
\end{tabular}

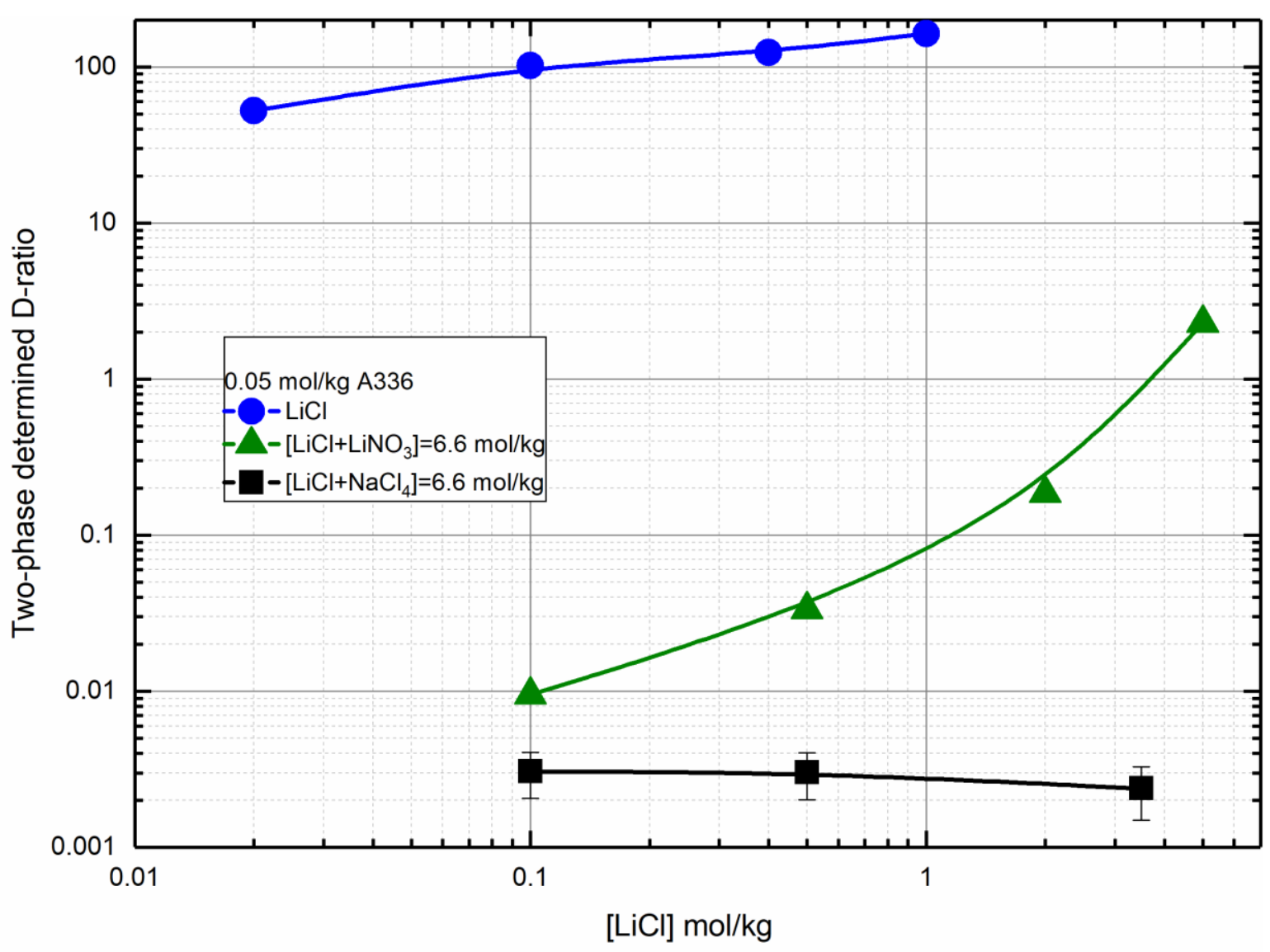

Figure 6.4 D-ratios of Cd(II) as a function of chloride concentration, A336 in toluene as extractant. Three different aqueous solutions with constant ionic strength were used: $\mathrm{LiCl}$ blue dots, $\mathrm{LiCl}$ and $\mathrm{LiNO}_{3}$ green triangles with ionic strength $6.6 \mathrm{~mol} / \mathrm{kg}, \mathrm{LiCl}$ and $\mathrm{NaClO}_{4}$ black squares with an ionic strength of $6.6 \mathrm{~mol} / \mathrm{kg}$. Lines to guide the eye, error bars are one standard deviation.

Figure 6.4 shows the extraction of $\mathrm{Cd}(\mathrm{II})$ with $\mathrm{A} 336$. The blue dots and line show that in a system where only $\mathrm{LiCl}$ is used, nearly all the $\mathrm{Cd}(\mathrm{II})$ is extracted. The green triangles show that the presence of nitrate reduces the extraction severely but as $\mathrm{LiCl}$ concentration is increased it is possible to extract $\mathrm{Cd}(\mathrm{II})$. When perchlorate and A336 are in the same system, the extraction of $\mathrm{Cd}(\mathrm{II})$ is minute, and extraction does not seem to change as chloride is added. Constant ionic strength should only be trusted to keep the chemical activity coefficient constant when the matrix ion is dominant. Figure 6.4 shows that co-extraction is important for the mechanism. As described in article I, both nitrate and perchlorate are extracted with A336. Perchlorate is more strongly extracted, and $\mathrm{Cd}(\mathrm{II})$ cannot bind to the extractant. 
It is possible to explore co-extraction further, which can lead to suggestions of different extraction mechanisms. Exploring the extraction of $\mathrm{Cd}(\mathrm{II})$ with $\mathrm{A} 336$ in the presence of $\mathrm{LiCl}$ and $\mathrm{LiNO}_{3}$, it is possible to hypothesise the extraction mechanism:

$$
A 336 \cdot \mathrm{Cl}_{\text {org }}+\mathrm{Cd}\left(\mathrm{NO}_{3}\right)_{2 a q}+\mathrm{Cl}_{a q}^{-} \rightleftharpoons A 336 \cdot\left(\mathrm{Cd}\left(\mathrm{NO}_{3}\right) \mathrm{Cl}_{2}\right)_{\text {org }}+\mathrm{NO}_{3}^{-}{ }_{a q} \quad \text { Eq. } 6.1
$$

Which results in an equilibrium constant:

$$
K_{1 e x}=\frac{\left.\left[\mathrm{A336} \cdot \mathrm{Cd}\left(\mathrm{NO}_{3}\right) \mathrm{Cl}_{2}\right)\right]_{\text {org }}\left[\mathrm{NO}_{3}^{-}\right]_{a q}}{[\mathrm{A336} \cdot \mathrm{Cl}]_{\text {org }}\left[\mathrm{Cd}\left(\mathrm{NO}_{3}\right)_{2}\right]_{a q}\left[\mathrm{Cl}^{-}\right]_{a q}}
$$

Which then can be related to the logarithm of the D-ratio as:

$$
\log D=\log K_{1 e x}+\log [A 336 \cdot C l]_{o r g}+\log \left(\frac{\left[\mathrm{Cl}^{-}\right]_{a q}}{\left[\mathrm{NO}_{3}^{-}\right]_{a q}}\right)
$$

If Eq. 6.3 can be used, then plotting the log of the D-ratio versus the log of the chloride nitrate ratio should result in a slope of 1 .

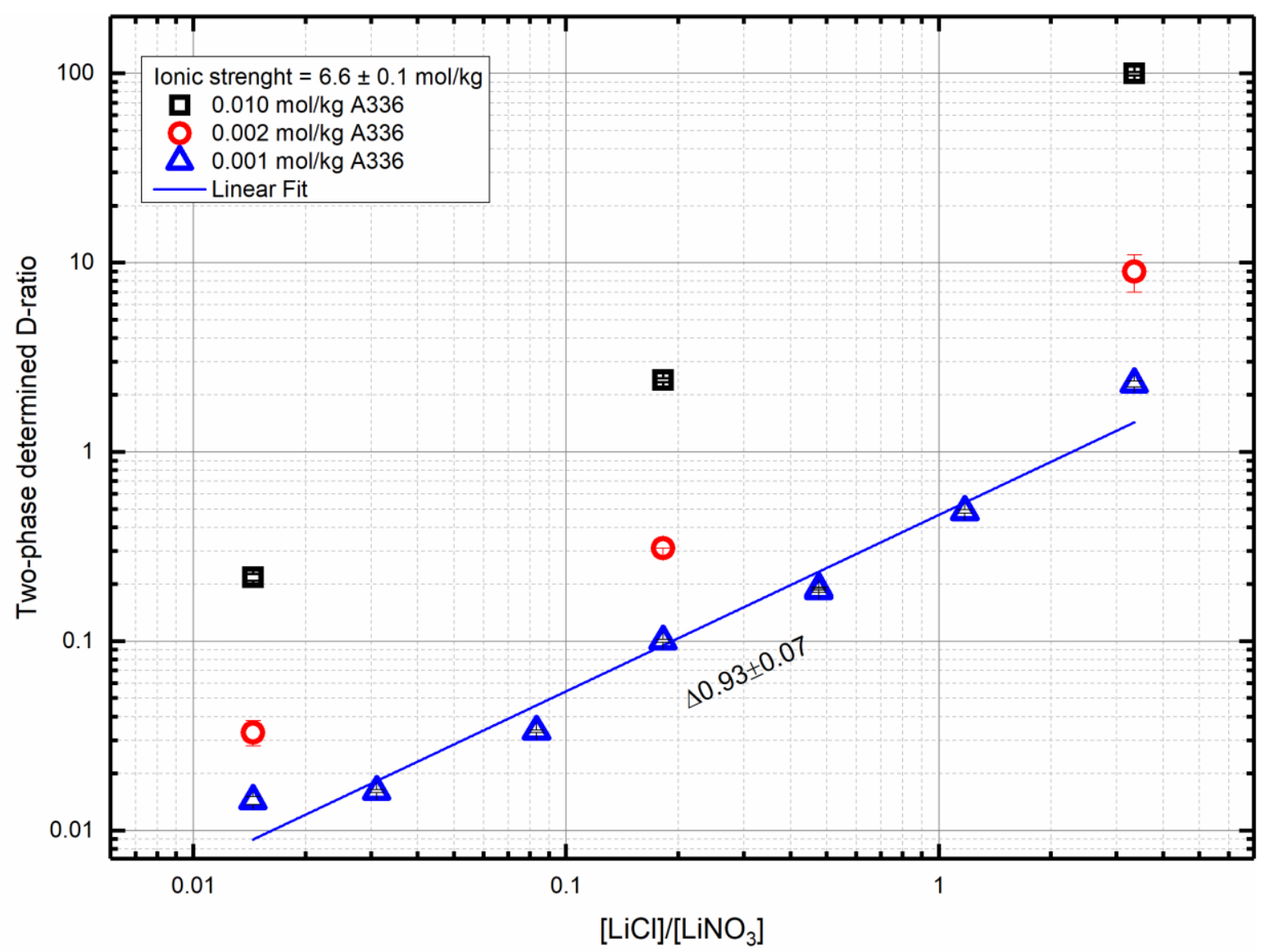

Figure 6.5 D-ratios of $\mathrm{Cd}(\mathrm{II})$ with increasing $\mathrm{LiCl}_{\mathrm{LiNO}}$ ratio. The blue line represents a linear regression for the blue triangles. The blue triangles represent $0.001 \mathrm{~mol} / \mathrm{kg}$ A336, red rings represent $0.002 \mathrm{~mol} / \mathrm{kg}$ A336 and black squares represent $0.01 \mathrm{~mol} / \mathrm{kg}$ A336. A constant ionic strength of $6.6 \pm 0.1 \mathrm{~mol} / \mathrm{kg}$ was held by controlling the ratio of $\mathrm{LiCl}$ and $\mathrm{LiNO}_{3}$. Error bars represent one standard deviation. Linear fit $y=a+b x, a=0.29 \pm 0.06$ and $b=0.93 \pm 0, r^{2}=98$. 
The extraction slope in Figure 6.5 suggests that Eq. 6.3 works. Eq. 6.3 is suggested as an alternative to the equation

$$
\begin{aligned}
A 336 \cdot \mathrm{NO}_{3} \cdot \mathrm{LiNO}_{3_{\mathrm{org}}}+\mathrm{CdCl}_{2} \mathrm{aq} & +\mathrm{Cl}_{\mathrm{aq}}^{-} \\
& \rightleftharpoons \mathrm{A336} \cdot\left(\mathrm{CdCl}_{3}\right)_{\mathrm{org}}+2 \mathrm{NO}_{3}^{-}{ }_{a q}+\mathrm{Li}^{+}{ }_{\mathrm{Aq}}
\end{aligned}
$$

which is presented in article I [51] to show that there are several possible extraction schemes. With NMR, we measured and suggested a binding constant for nitrate to A336 and, therefore, it also possible to suggest the reaction at equilibrium:

$$
A 336 \cdot\left(\mathrm{NO}_{3}\right)_{\text {org }}+\mathrm{CdCl}_{2 a q}+\mathrm{Cl}_{a q}^{-} \rightleftharpoons A 336 \cdot\left(\mathrm{CdCl}_{3}\right)_{\mathrm{org}}+\mathrm{NO}_{3_{a q}}
$$

The observed slope in Figure 6.5 could also be explained by Eq. 6.5. Therefore, to determine if nitrate can make a neutral species with $\mathrm{Cd}(\mathrm{II})$, the solution was also tested together with the solvating extractant TOPO. Here extraction with perchlorate is shown to represent a nonsolvating anion present.

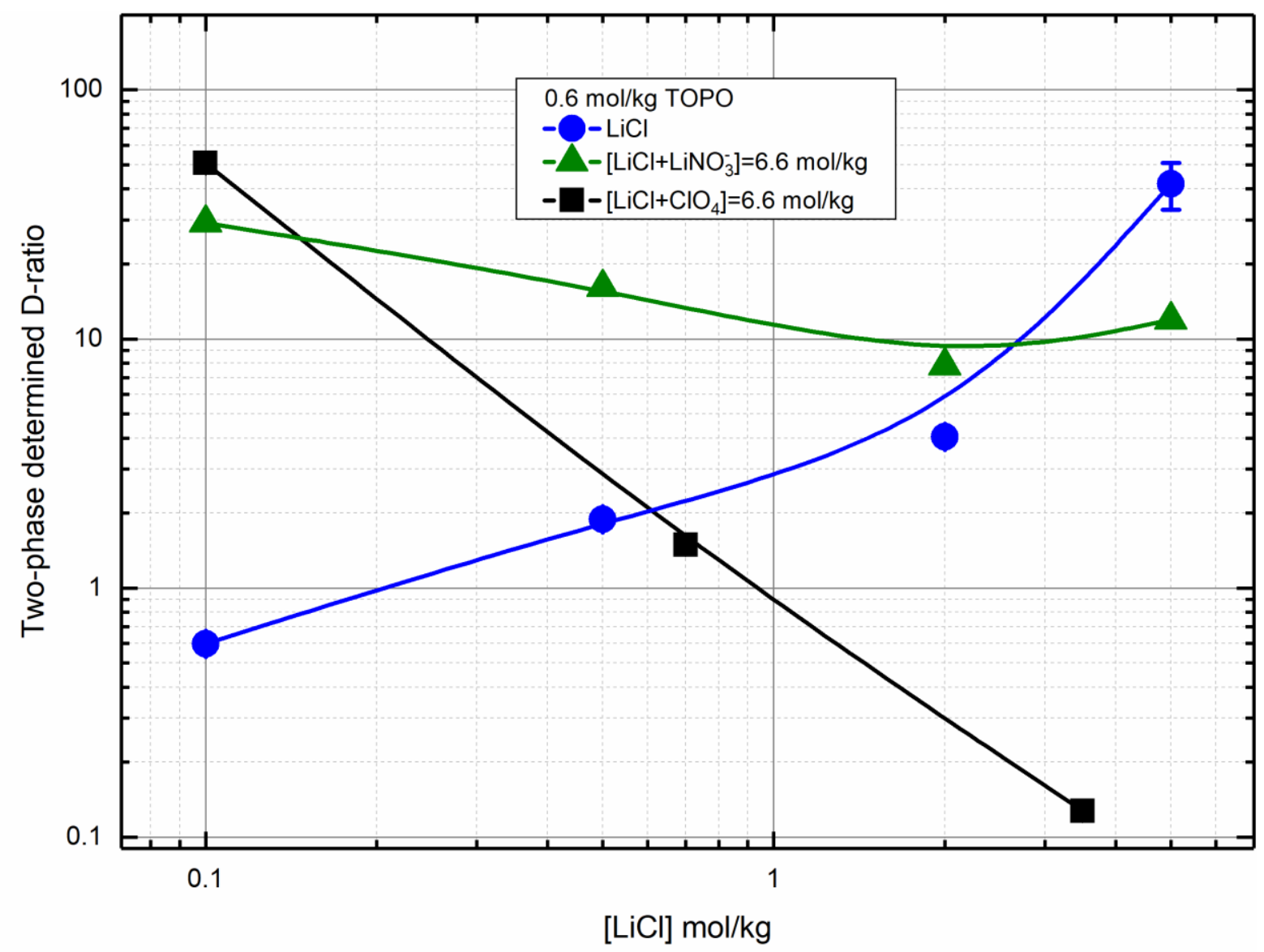

Figure 6.6 D-ratios of $C d(I I)$ as a function of chloride concentration, TOPO in toluene as extractant. Three different aqueous solutions with constant ionic strength were used: LiCl blue dots, LiCl and $\mathrm{LiNO}_{3}$ green triangles with ionic strength $6.6 \mathrm{~mol} / \mathrm{kg}, \mathrm{LiCl}$ and $\mathrm{NaClO}_{4}$ black squares with an ionic strength of $6.6 \mathrm{~mol} / \mathrm{kg}$. Lines to guide the eye, error bars are one standard deviation.

Blue dots show the extraction of Cd(II) with TOPO in toluene, the D-ratio increases as the chloride concentration increases. More negative species of Cd(II) should be forming when the chloride concentration increases. The increasing D-ratio can tentatively be attributed to the lack 
of control over the chemical activity of chloride and $\mathrm{Cd}(\mathrm{II})$. An extraction equilibrium which could explain the increasing D-ratio as a function of chloride would be:

$$
\mathrm{TOPO}_{\text {org }}+\mathrm{Cd}_{a q}^{2+}+2 \mathrm{Cl}^{-} \rightleftharpoons \mathrm{TOPO} \cdot\left(\mathrm{CdCl}_{2}\right)_{\text {org }}
$$

However, the slope is not steep enough nor straight, suggesting a more complicated extraction scheme. Explanation models that could give a more detailed answer would need to use the stability constants of all the species in the solution, or a polynomial expression [33]. However, previously determined stability constants did not give a better fit, and there was not enough data for a polynomial expression.

The green triangles show the extraction of $\mathrm{Cd}(\mathrm{II})$ when the ionic strength is kept at $6.6 \pm 0.1 \mathrm{~mol} / \mathrm{kg}$, with $\mathrm{LiCl}$ and $\mathrm{LiNO}_{3}$. Nitrate is an anion that coordinates to a lesser extent than chloride. However, nitrate seems to interact with either cadmium or with the extractant, since the D-ratio is rather flat. From this, it was inconclusive whether nitrate can form neutral species with Cd(II).

The black squares represent the extraction of $\mathrm{Cd}(\mathrm{II})$ in the perchlorate chloride solution. This system seems to be the only system that follows what would be the expected in a classical progression. The slope of the D-ratio for this system is $-1.66 \pm 0.09$. To explain the slope, the following reaction is suggested:

$$
\mathrm{TOPO}_{\text {org }}+\mathrm{CdCl}_{4}^{2-}{ }_{\mathrm{aq}} \rightleftharpoons \mathrm{TOPO} \cdot\left(\mathrm{CdCl}_{2}\right)+2 \mathrm{Cl}^{-}
$$

The equilibrium constant is then:

$$
K_{1 e x}=\frac{\left[T O P O \cdot\left(\mathrm{CdCl}_{2}\right)\right]_{o r g}\left[\mathrm{Cl}^{-}\right]_{a q}^{2}}{[\mathrm{TOPO}]_{\text {org }}\left[\mathrm{CdCl}_{4}^{2-}\right]_{a q}}
$$

and then to relate the chloride concentration to the D-ratio as:

$$
\log D=\log K_{1 e x}+\log [T O P O]_{\text {org }}-2 \log \left[\mathrm{Cl}^{-}\right]_{a q}
$$

Here a negative slope $-1.66 \pm .09$ is not too far from -2 when there are only three points. Note that even though there is no perchlorate in Eq. 6.1, it seems to be the most correct interpretation.

A mixture of $\mathrm{LiCl} / \mathrm{Li}_{2} \mathrm{SO}_{4}$ with an ionic strength of 6.5 was also tested with $\mathrm{A} 336$ in toluene. Here the expected extraction reaction was:

$$
A 336 \cdot \mathrm{Cl}_{\text {org }}+\mathrm{Cd}\left(\mathrm{SO}_{4}\right)_{2}^{2-}{ }_{a q}+2 C l^{-} \rightleftharpoons A 336 \cdot\left(\mathrm{CdCl}_{3}\right)+2\left(\mathrm{SO}_{4}^{2-}\right)_{a q} \quad \text { Eq. } 6.10
$$

The equilibrium constant is then:

$$
K_{2 e x}=\frac{\left[\mathrm{A336} \cdot\left(\mathrm{CdCl}_{3}\right)\right]_{\mathrm{org}}\left[\mathrm{SO}_{4}^{2-}\right]_{a q}^{2}}{[\mathrm{A336} \cdot \mathrm{Cl}]_{\mathrm{org}}\left[\mathrm{Cd}\left(\mathrm{SO}_{4}\right)_{2}^{2-}\right]_{a q}\left[\mathrm{Cl}^{-}\right]_{a q}^{2}}
$$

Eq. 6.5 can then be related to the D-ratio as:

$$
\log D=\log K+\log [A 336]+2 \log \left(\frac{\left[\mathrm{Cl}^{-}\right]}{\left[\mathrm{SO}_{4}^{2-}\right]}\right)
$$




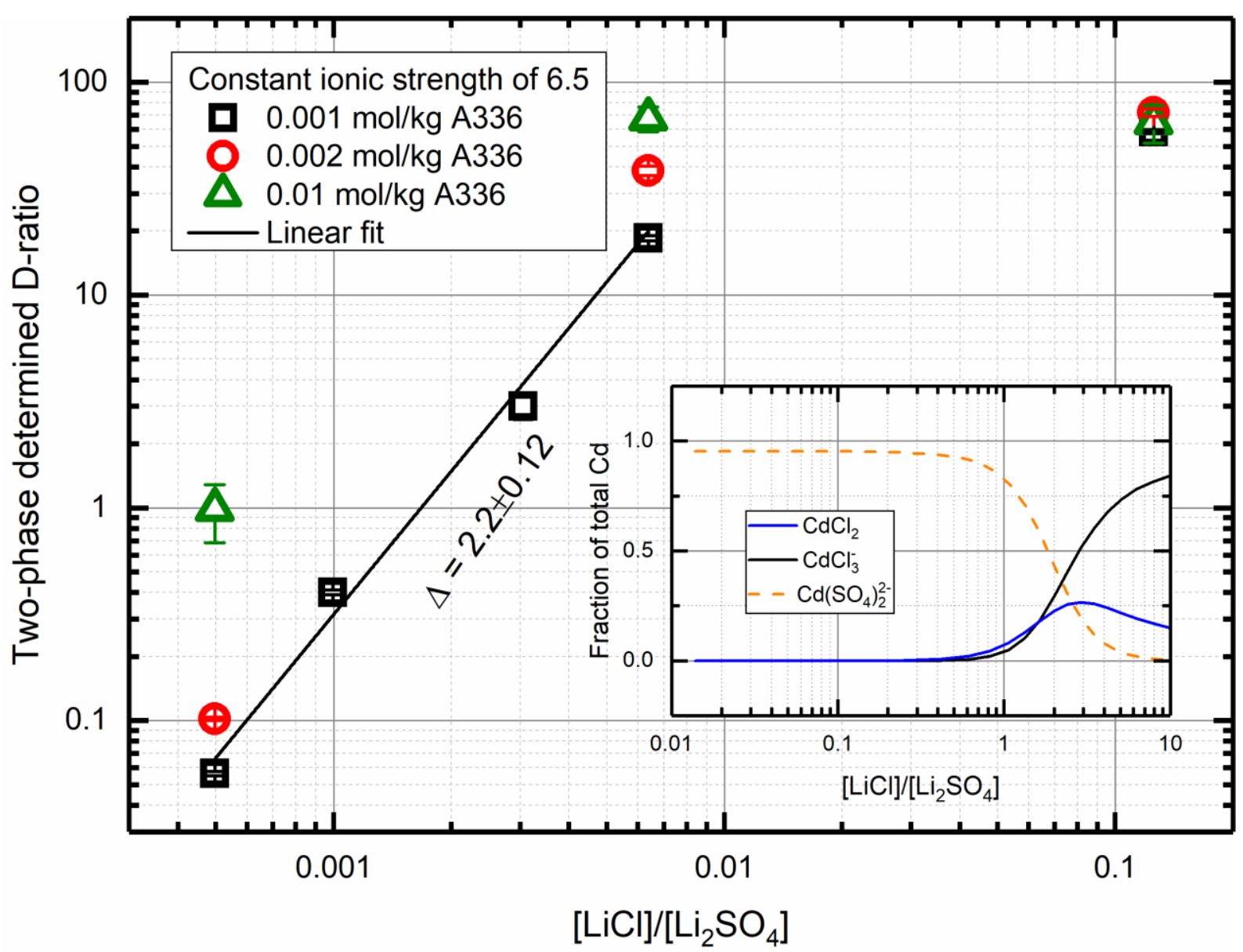

Figure 6.7 The D-ratio of $\mathrm{Cd}(\mathrm{II})$ in a mixed solution of $\mathrm{LiCl}$ and $\mathrm{Li}_{2} \mathrm{SO}_{4}$ as a function of the concentration ratio of $\mathrm{LiCl} / \mathrm{Li}_{2} \mathrm{SO}_{4}$ with varying $\mathrm{A} 336$ concentrations used. The small panel shows the speciation diagram for Cd(II) with an increasing $\mathrm{LiCl}_{\mathrm{Li}} \mathrm{SO}_{4}$ ratio. In the small panel $\mathrm{CdCl}$ is assumed to not form, activity coefficients are calculated using Pitzer equations [32,23,25,24] and the ionic strength is kept at 6.5. Linear fit $y=a+b x, a=6.2 \pm 0.4$ $b=2.2 \pm 0.12, r^{2}=99$.

Eq. 6.12 shows that the slope of extraction should be 2 in a log-log plot as the ratio $\mathrm{Cl}^{-} / \mathrm{SO}_{4}{ }^{2-}$ increases. Figure 6.6 shows that for low ratios, the slope is slightly more than 2 . When the ratio increases the assumption does not hold anymore. The small panel in Figure 6.7 suggests an explanation for this. The small panel is a modification of the right panel in Figure 4.3, where the species $\mathrm{CdCl}_{4}{ }^{2-}$ is removed from the calculation. At a low $\mathrm{Cl}^{-} / \mathrm{SO}_{4}{ }^{2-}$ ratio, the sulfate species dominates, but when the ration increases, there is a sudden shift to the chloride dominating species. When chloride species dominates in the aqueous phase, there will be little change in the speciation by adding more chloride.

The speciation diagram has the shift occurring at a much higher ratio than the extraction measures it. A suggested explanation for why this occurs is that the stability constant used to calculate the speciation diagram was not collected at such a high ionic strength [18]. Also, the equations developed by Pitzer were not accurate as to the ionic strength of the solution past $5 \mathrm{~mol} / \mathrm{kg}$ [23-25]. All in all, Eq. 6.12 seems to function well for up to a ratio of 0.01 .

Showing the change of D-ratio as a function of a ratio of the salts used in the matrix turned out to be a powerful technique. It enabled the connection between the experimental result and more equilibrium reactions, resulting in easier definable reactions. 
Eq. 6.7 indicates that high concentrations of sulfate should lower the amount of $\mathrm{Cd}(\mathrm{II})$ extracted. Tests of the performance of sulfate as a back-extractant were performed, and the results are presented in Figure 6.6. Note that the back-extraction is more efficient with lower amounts of $\mathrm{HCl}$ in the first extraction step. This indicates that more chloride is extracted for high $\mathrm{HCl}$ concentrations in the first step. The effect of $\mathrm{HCl}$ in the feed and the effect that it has on the organic phase are discussed to a greater extent below.

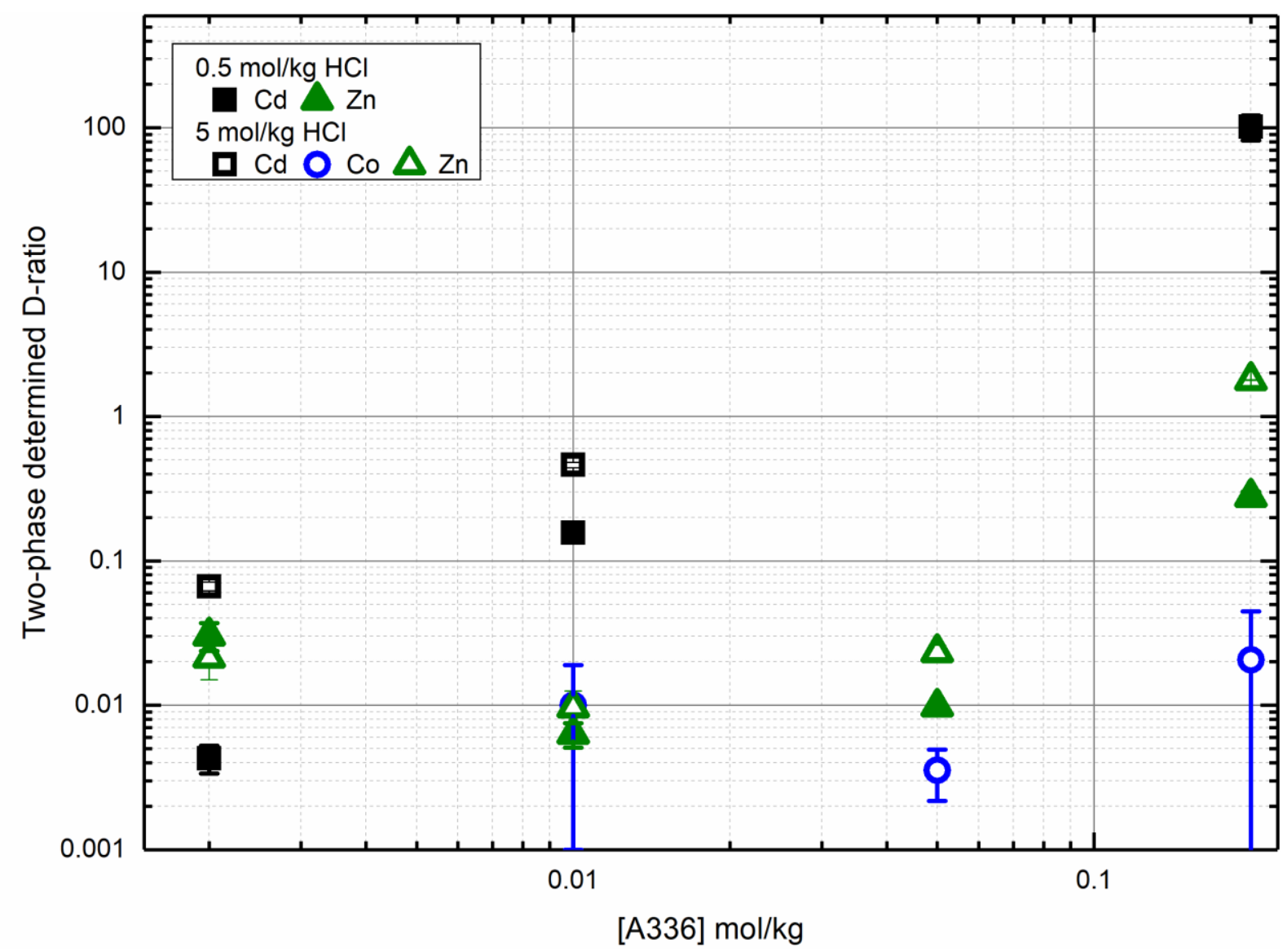

Figure 6.8 Example of back-extraction of $C d(I I), Z n(I I)$ and Co(II) using lithium sulfate, from organic phases with A336 as extractant.

The extraction strongly suggests that the additional ions are extracted. Raman was well suited to detect molecular ions in both the organic and the aqueous solutions. Figure 6.9 A and B display the Raman spectra of the nitrate solutions and the perchlorate solutions, respectively. It was clear from both the extraction experiments and from the Raman spectra that the reason nitrate and perchlorate hindered the extraction was due to extraction of these ions. 

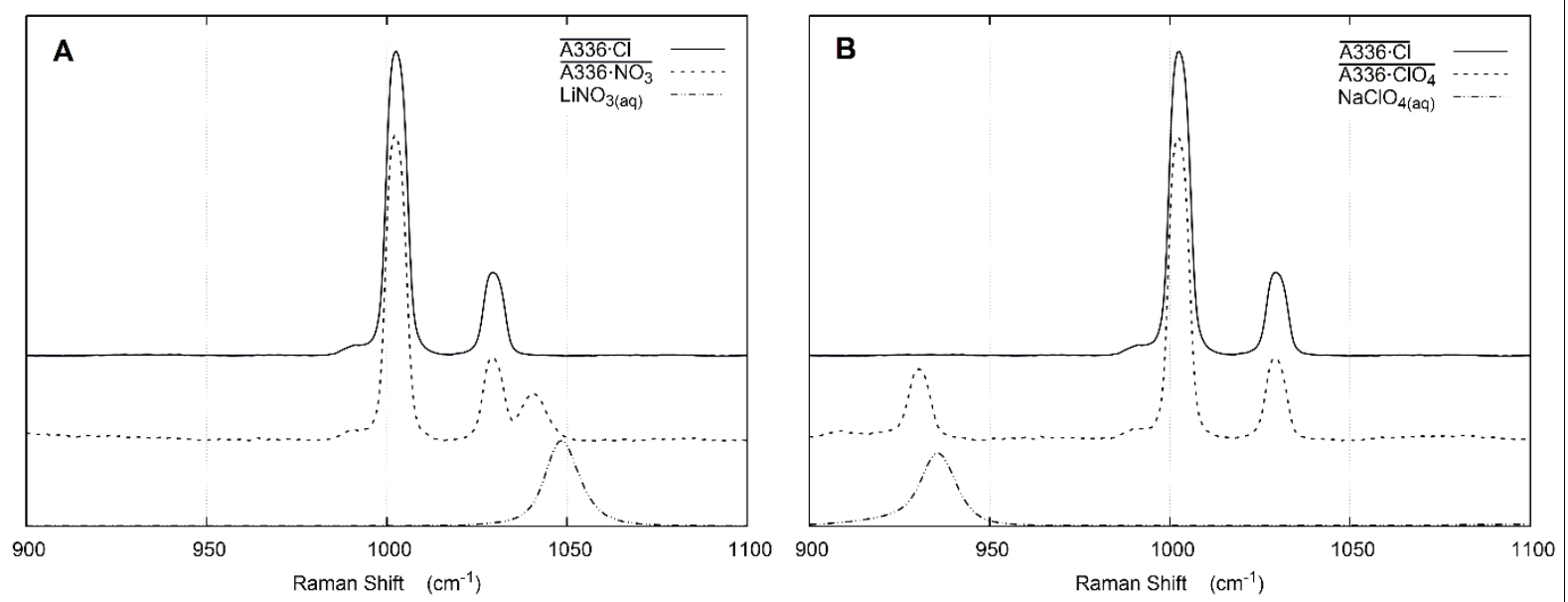

Fig 6.9 Raman spectra of A336 in toluene after contact with nitrate-and perchlorate-containing solution. In the left panel, the top line shows A336 prior to contact with nitrate solution, the dotted line shows A336 after contact with a nitrate solution and the bottom line shows a nitrate solution before contact with A336. The right panel the top line shows A336 before contact with a perchlorate solution, the dotted line shows A336 after contact with a perchlorate solution and the bottom line shows a perchlorate solution before contact with A336. Reproduced from article $I$.

Sulfate was not detected in the organic phase despite having an intense Raman active resonance [96]. However, it was detected by increasing the acid concentration and forming more bisulfate, which binds stronger to A336. Hence, the more acid present in the organic solution or the stripping solution, the more bisulfate will be extracted.
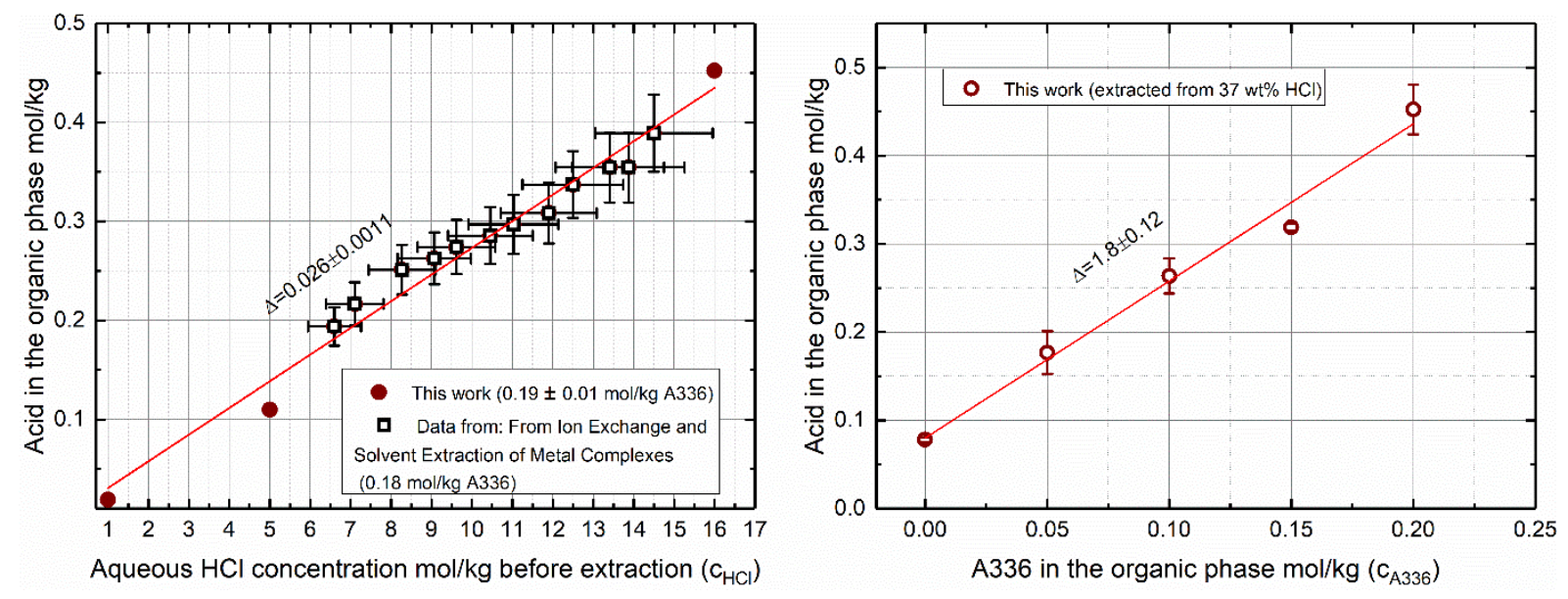

Figure 6.10 HCl extraction with A336. The left panel shows extraction as a function of HCl concentration. The black open squares are from Marcus and Kertes book[97]. The right side shows the extraction as a function of increasing A336 concentration. Red error bars represent one standard deviation, black error bars are $10 \%$ of the value. Linear fit left graph $y=a+b x$ a $0.004 \pm 0.012 b=0.026 \pm 0.0011 r^{2}=98$ right graph $y=a+b x a=0.09 \pm 0.02 b$ $1.8 \pm 0.12, r^{2}=98$.

Figure 6.10 shows the titration of A336 in toluene after contact with different concentrations of acid, left panel, and versus different concentrations of A336, right panel. A linear relationship is seen for the amount of acid extracted both as a function of acid concentration and as a function of A336 concentration. The left panel shows acid extraction where the red dots are extraction performed by this work and the black squares are derived from Marcus and Kertes [97]. While the amount of extracted acid progresses linearly, it is interesting to note that when the aqueous concentration of acid is more than $7 \mathrm{~mol} / \mathrm{kg}$, the concentration of acid in the organic phase is 
higher than the concentration of A336. The panel on the right shows that when toluene without A336 is used, roughly $0.08 \mathrm{~mol} / \mathrm{kg}$ acid will be extracted from concentrated hydrochloric acid. The mechanism for the high acid extraction is further discussed in the NMR studies. Determination of chloride in the organic phase is simple when $\mathrm{HCl}$ is used in the aqueous matrix. However, when additional metals are extracted the determination becomes more challenging, as the moiety can differ to a greater extent.

\subsection{The Organic Phase after Extraction Studied using NMR}

A system containing only one source of ions is simpler than one with several sources. However, as has been discussed in chapter 4, the single-ion source systems will have several possible interactions as the concentration increases. In this chapter, the effects that various concentrations have on the organic phase are discussed.

Cd is NMR sensitive, that is, it has magnetic spin and was used to study the change in species composition. In theory, nuclei that have a half-integer spin are NMR active. However, few of them are NMR sensitive enough for practical purposes. Cadmium has a few NMR-sensitive isotopes, and some work has been published on aqueous cadmium-chloride species. The chemical shift of individual species has been estimated and is summarised in table 6.3. The reference used for Cd-NMR is $0.1 \mathrm{~mol} / \mathrm{L} \mathrm{Cd}\left(\mathrm{ClO}_{4}\right)_{2}$ [98].

Table 6.3 Chemical shift of cadmium chloride species. The chemical shift reference peak is $\mathrm{Cd}\left(\mathrm{ClO}_{4}\right)_{2}$ at $0.1 \mathrm{~mol} / \mathrm{kg}[98]$.

\begin{tabular}{ll}
\hline Species & Chemical shift \\
\hline${ }^{113} \mathrm{Cd}^{2+}$ & 0 \\
${ }^{113} \mathrm{CdCl}^{+}$ & 89 \\
${ }^{113} \mathrm{CdCl}_{2}$ & 114 \\
${ }^{113} \mathrm{CdCl}_{3}^{-}$ & 292 \\
${ }^{113} \mathrm{CdCl}_{4}^{2-}$ & 495 \\
\hline
\end{tabular}

$\mathrm{Cd}$ (II) halide species are in fast exchange in the aqueous phase (with reference to the NMR sampling time). Therefore, there will be only one peak where the position is a weighted average of the chemical shift of the individual species:

$$
\delta_{C d_{t o t}}=\sum\left[C d C l_{i}\right] \cdot \delta_{C d C l_{i}}
$$

Here $\delta_{C d_{t o t}}$ is the chemical shift of the resonance band, $\left[\mathrm{CdCl}_{i}{ }^{2+-i}\right]$ is the concentration of a cadmium species, and $\delta_{C d C l_{i}}$ is the chemical shift of that species. 


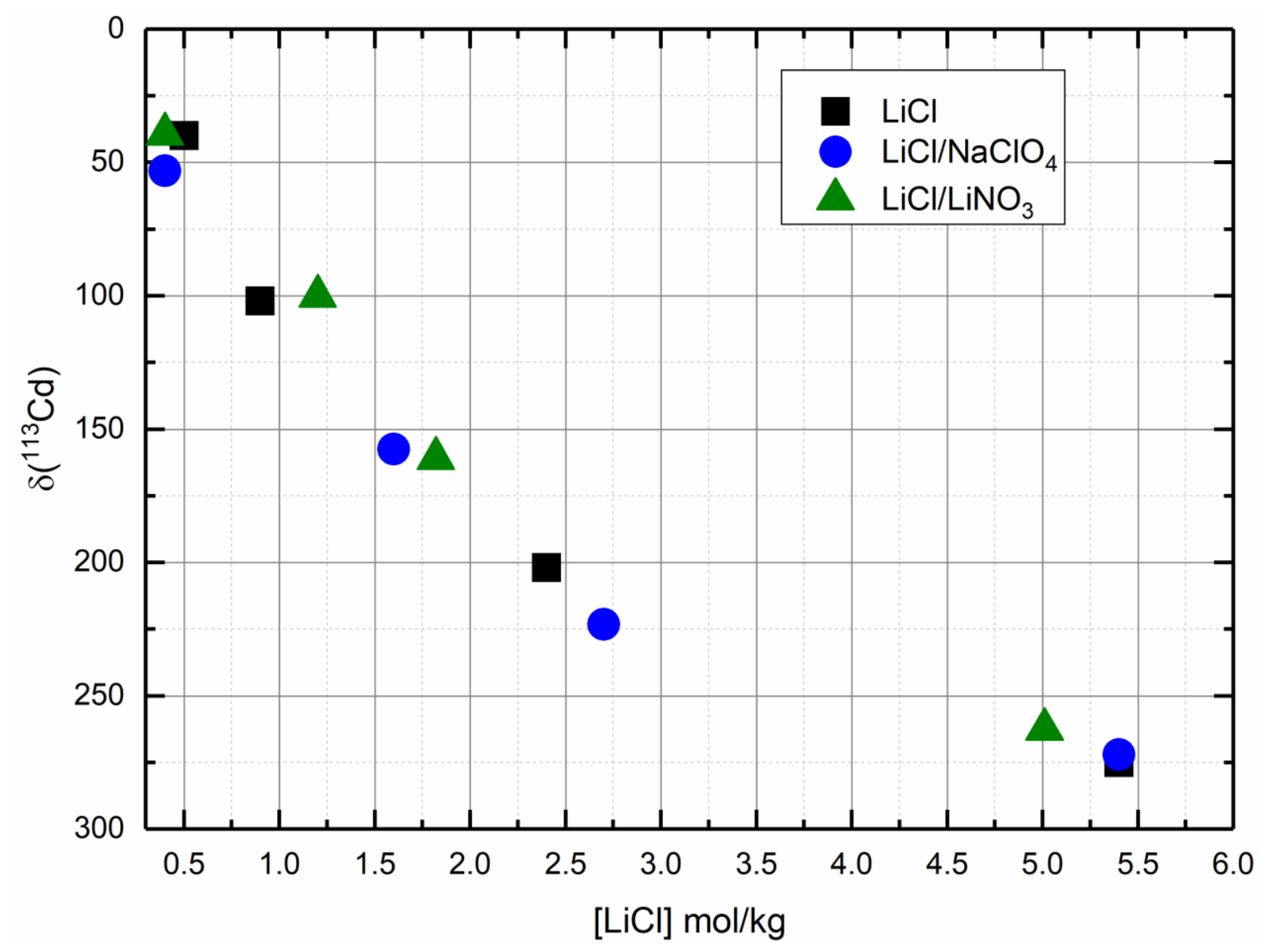

Figure 6.11 The chemical shift of $C d(I I)$ as a function of the chloride. The chemical shift reference peak is $\mathrm{Cd}\left(\mathrm{ClO}_{4}\right)_{2}$ at $0.1 \mathrm{~mol} / \mathrm{kg}$.

Figure 6.11 shows the chemical shift of ${ }^{113} \mathrm{Cd}$ in three different aqueous solutions. The chemical shift range goes from roughly $50 \mathrm{ppm}$ to $275 \mathrm{ppm}$. Figure 6.11 shows the change in chemical shift for three different solutions. These were designed to check how the chemical shift of Cd(II) is changed by both various ionic strengths and by different salts used to keep the ionic strength constant. It is evident that the chloride concentration enforces the change in the chemical shift of Cd(II). For all three solutions, increasing the chloride concentration increases the chemical shift. The main reason for the chemical shift of $\mathrm{Cd}(\mathrm{II})$ in the aqueous phase is the change of the species and not the change of the aqueous solution.

While the trends and changes of the chemical shift in the aqueous phase are large and easily detectable, the organic phase chemical shift for $\mathrm{Cd}(\mathrm{II})$ is much smaller. Extraction of $\mathrm{Cd}(\mathrm{II})$ was performed with variation of aqueous phase chloride concentration as well as organic phase A336 concentration. The chemical shift after extraction was 421-428 with no trends. From table 6.3, it could then be assumed that the dominant species in the organic phase is $\mathrm{CdCl}_{4}{ }^{2-}$, while in the aqueous phase it is $\mathrm{CdCl}_{3}{ }^{-}$and lower. However, the chemical shift of $\mathrm{Cd}$ (II) has been reported to be generally higher in solutions with a lower dielectric constant $[99,94]$.

As it was not possible to determine which species of $\mathrm{Cd}(\mathrm{II})$ which was present, a cooling experiment was attempted to determine if there were two species present. As was mentioned, the exchange between the $\mathrm{Cd}(\mathrm{II})$ species is faster than the NMR sampling time. The exchange can be slowed down by cooling the solution. If it is slowed down below the NMR sampling time, then the exchange should be resolved into several peaks [100] representing the different 
species. A mixture of ethanol and saline water was used to cool the aqueous phase to $-50^{\circ} \mathrm{C}$. Some broadening was observed of the Cd(II) signal as the solution was cooled, but the signalto-noise ratio became too high and no splitting was observed. No splitting was observed in the organic phase at $-50^{\circ} \mathrm{C}$.

However, splitting of the Cd(II) peak was observed when A336 saturated with 37 wt $\% \mathrm{HCl}$ was contacted with solid $\mathrm{CdCl}_{2}$.

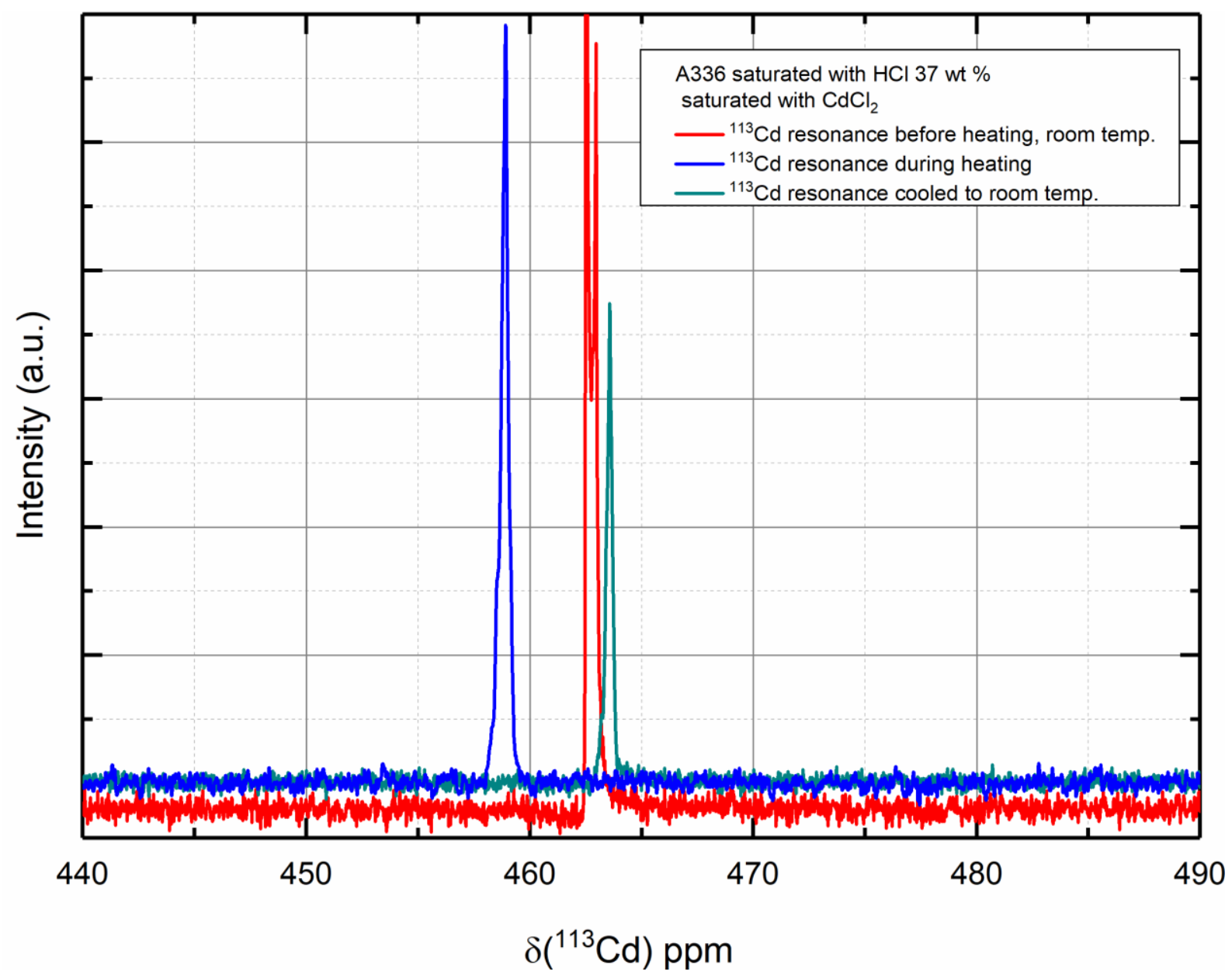

Figure 6.12 The resonance bands of Cd(II) in A336 saturated with $37 \mathrm{wt} \% \mathrm{HCl}$. The red signal shows the sample before heating, the blue line shows the signal during heating and the green line shows the signal after cooling down to room temperature.

The initial ${ }^{113} \mathrm{Cd}$ spectrum indicates that there are two different $\mathrm{Cd}(\mathrm{II})$-species or conformations at room temperature, both having a high chemical shift corresponding to $\mathrm{CdCl}_{3}{ }^{-}$and/or $\mathrm{CdCl}_{4}{ }^{2-}$ species. After heating to $50^{\circ} \mathrm{C}$, a single peak appears. After subsequent cooling to room temperature, this peak is no longer split into two peaks but remains a single peak. A suggested explanation is that on a microscale, the solution is heterogeneous but becomes more homogenous after heat treatment.

Determination of $\mathrm{Cd}(\mathrm{II})$ species in the organic phase using NMR need more background information. It would also need an extractant with a more defined extraction mechanism than what has been determined using A336 previously. With the data collected it was tentatively assumed that 1 species was extracted, but it was not possible to determine if this was $\mathrm{CdCl}_{4}{ }^{2-}$ or $\mathrm{CdCl}_{3}{ }^{-}$. 


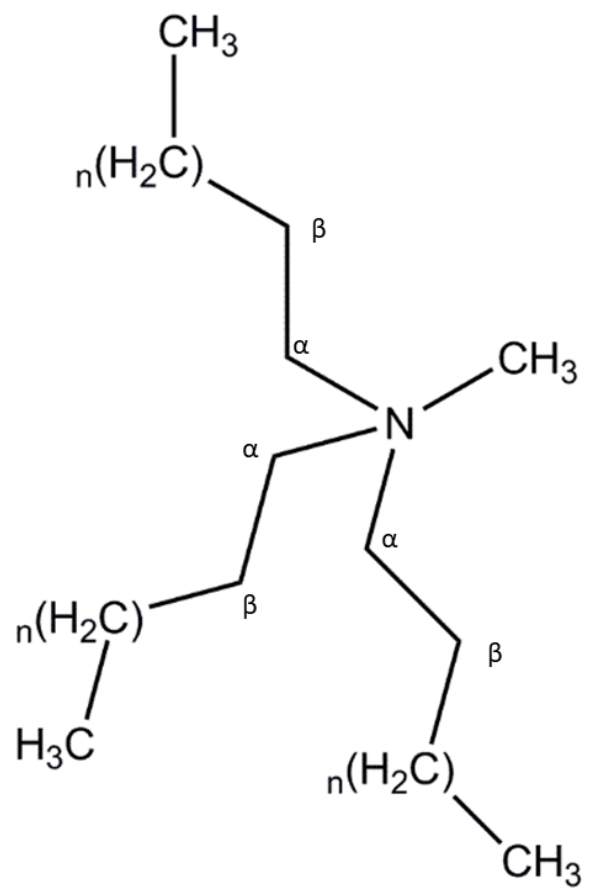

Figure 6.13 Drawing of A336 with terms on the different carbon atoms to help identify their positions in the spectrum. Shown without counter ion for simplicity.

The different peaks are assigned the spectrum shown in Figures 6.14-6.17.

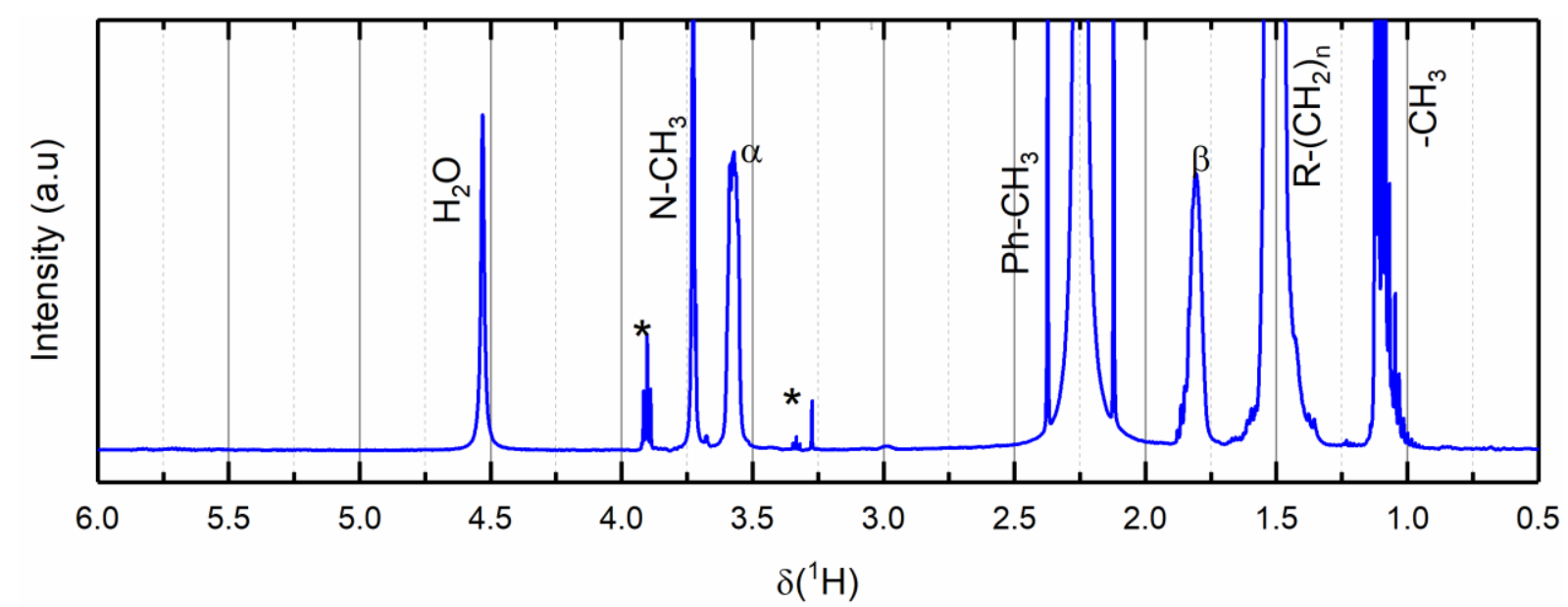

Figure $6.14{ }^{l} H-N M R$ spectrum of A336 in toluene, bands marked with * were not assigned.

Figure 6.15 shows the spectrum of A336 without any solvent. The high viscosity and ionic strength of A336 results in broad peaks. In addition, the $\alpha$-peak and the $\mathrm{N}-\mathrm{CH}_{3}$ peak have changed positions. 


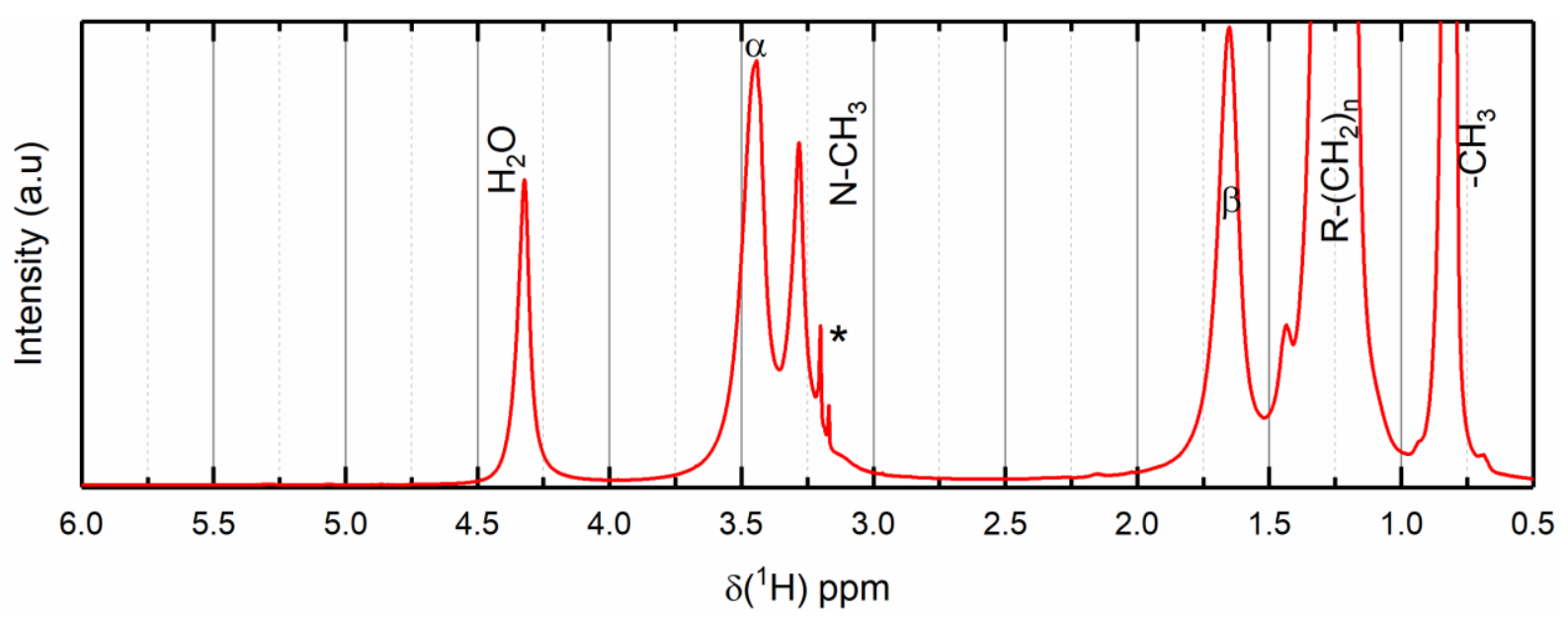

Figure $6.15^{1} \mathrm{H}$-NMR spectrum of A336 NMR without any solvent present.

Figure 6.16 shows the ${ }^{1} \mathrm{H}$-spectrum of $\mathrm{A} 336$ saturated with $37 \mathrm{wt} \% \mathrm{HCl}$ contacted with $\mathrm{CdCl}_{2}$. The proton peaks above $8 \mathrm{ppm}$ are water peaks in close proximity to $\mathrm{HCl}$. As can be seen in Figure 6.16, one acid peak is split into several. Figure 6.17 is the same sample as in 6.16 , but here it is heated to $50^{\circ} \mathrm{C}$. Increasing the temperature made the signal-to-noise ratio more advantageous and shimming of the samples faster. Further NMR experiments performed on A336 should be performed at an elevated temperature.

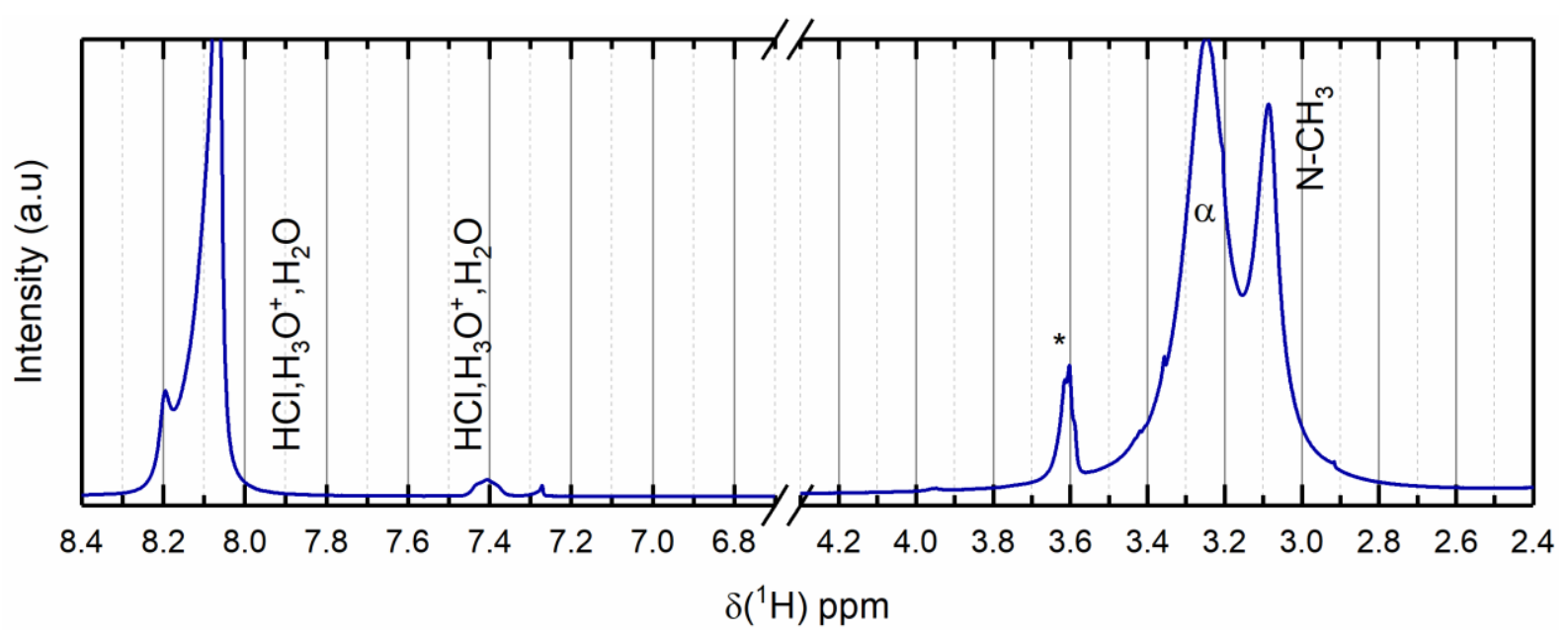

Figure $6.16^{1} \mathrm{H}$-NMR spectrum of the organic phase A336 without any solvent after extraction from a liquid phase containing $\mathrm{CdCl}_{2}$ and a concentrated $\mathrm{HCl}$ solution, measured at room temperature. 


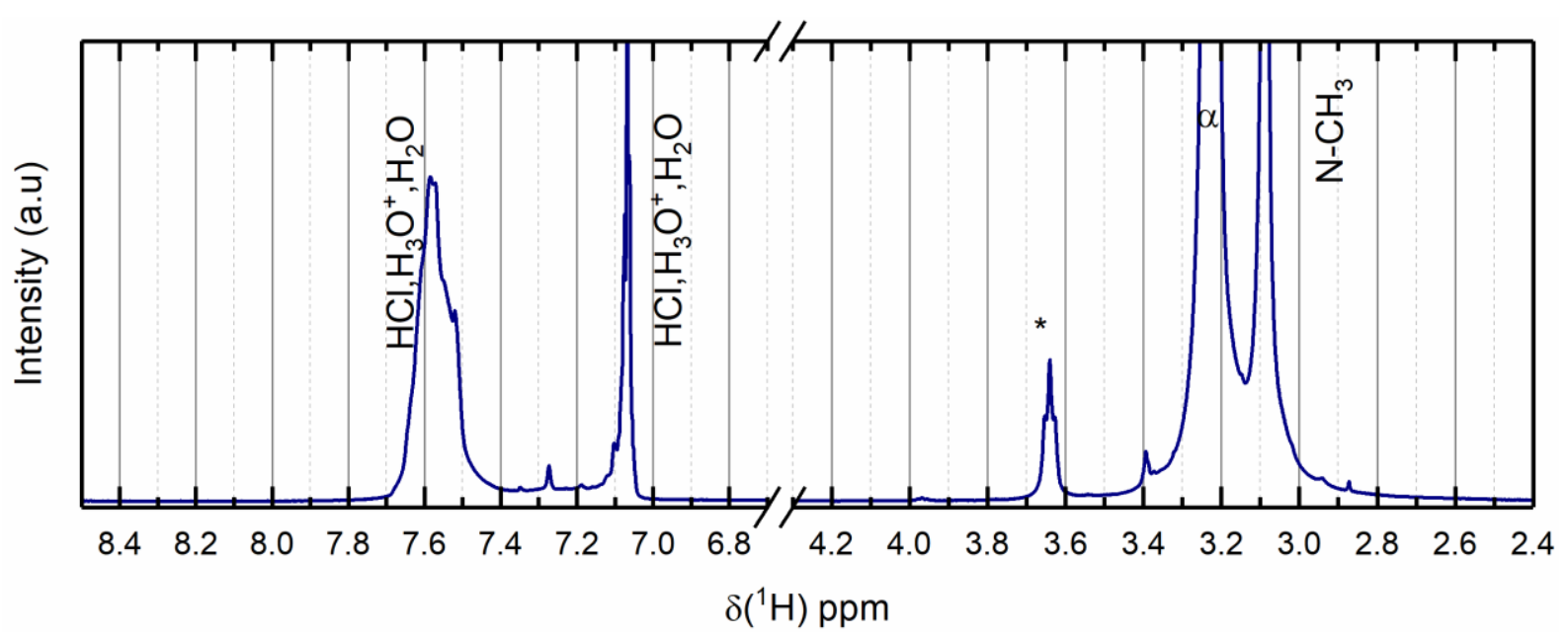

Figure $6.17^{1} \mathrm{H}$-NMR spectrum of the organic phase $\mathrm{A336Cl}$ heated to $50^{\circ} \mathrm{C}$ after extraction from a liquid phase containing $\mathrm{CdCl}_{2}$ and a concentrated $\mathrm{HCl}$ solution.

Figure 6.18 shows the ${ }^{1} \mathrm{H}$ spectra of $\mathrm{A} 336$ in toluene after contact with $37 \mathrm{wt} \% \mathrm{HCl}$. The aqueous peak is now shifted high up to $9.6-9.4 \mathrm{ppm}$. The sample in Figure 6.19 is comparable to the samples in the titration experiment. By integrating and comparing the peak position, it should be possible to estimate the amount of acid in the organic phase [101] (for the calculations, see appendix A.3 or article III). The ratio between molecular hydrochloric acid $(\mathrm{HCl})$ and disassociated acid in the organic phase was calculated to between 0.966 and 1.05. That both molecular and disassociated acid can occur in the organic phase can explain why there can be a factor of 2 to 1 between acid and A336.

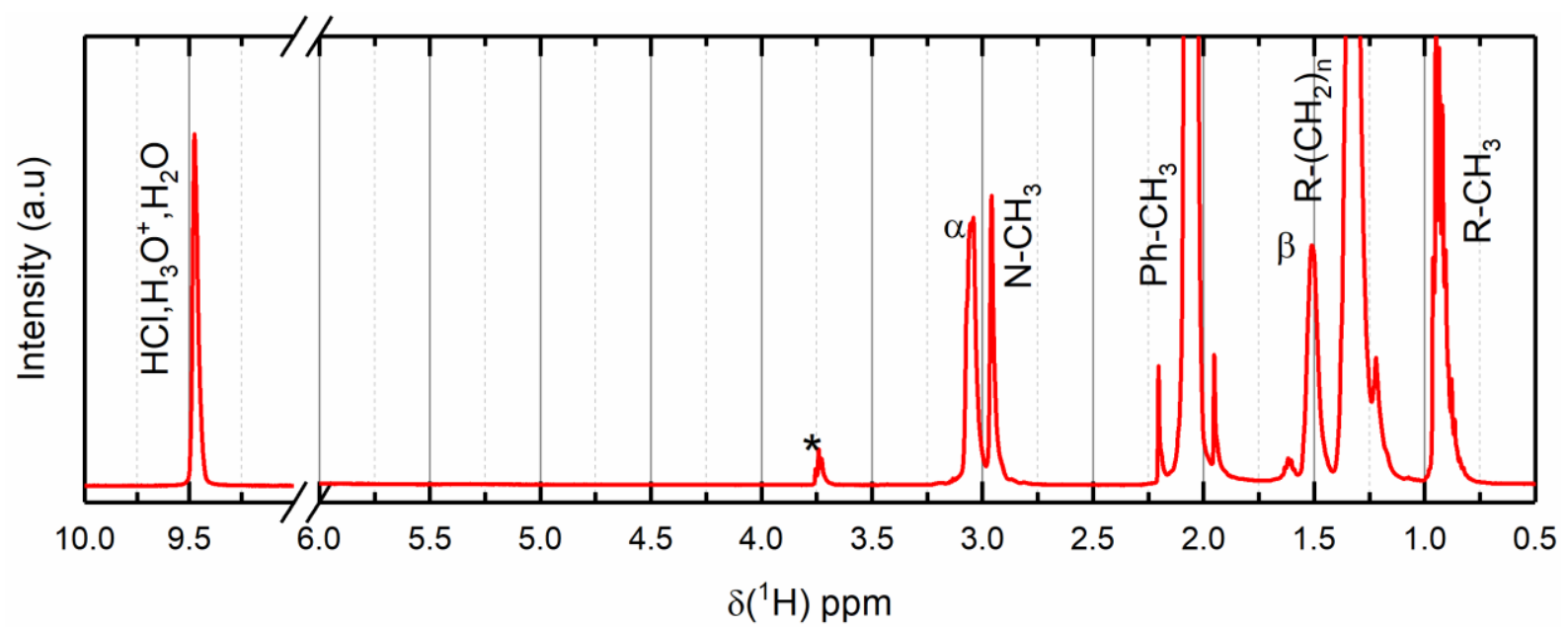

Figure $6.18^{1} \mathrm{H}-\mathrm{NMR}$ spectrum of the organic phase (A336 in toluene) after contact with $37 \mathrm{wt} \% \mathrm{HCl}$. 


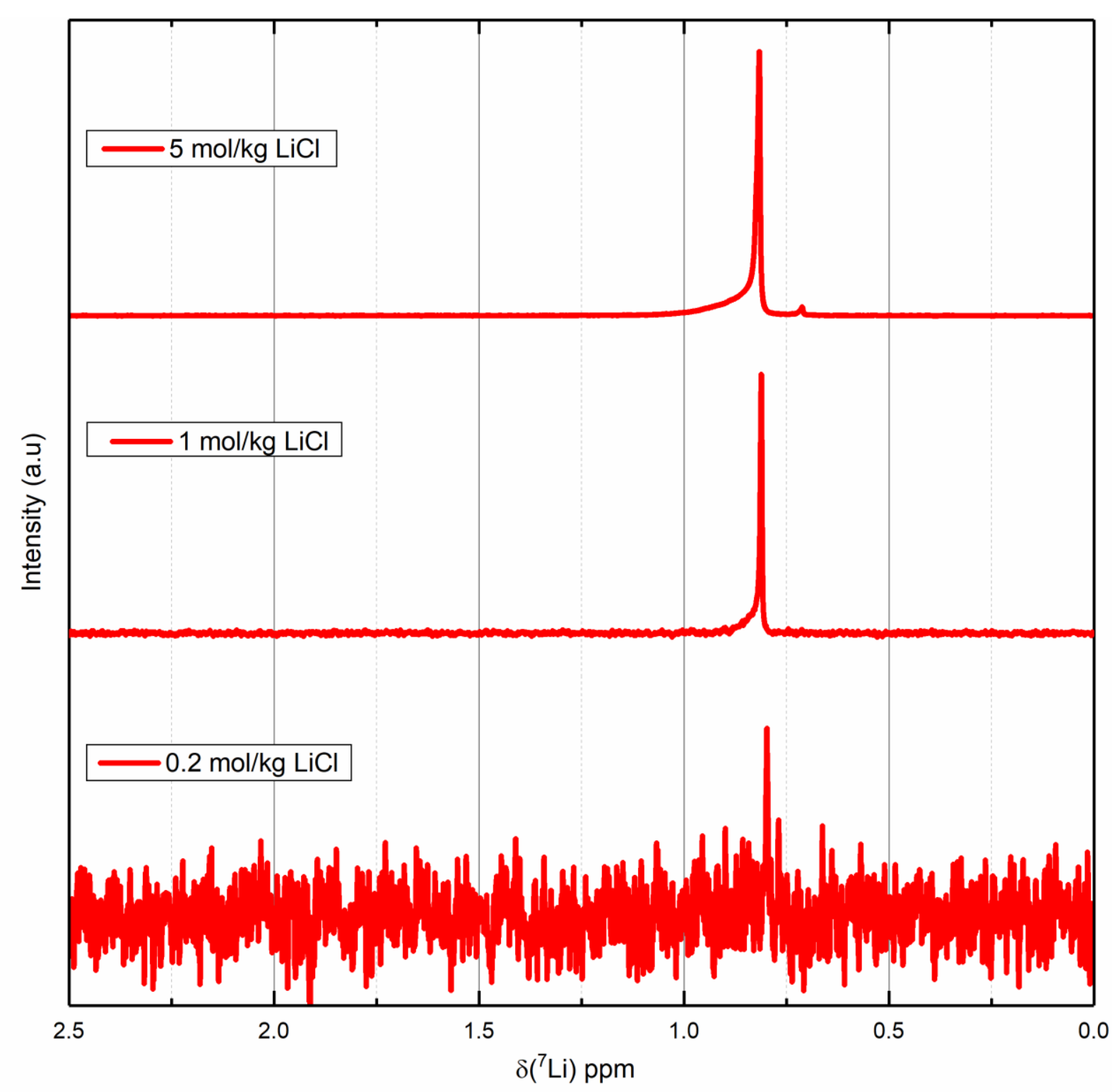

Figure $6.19^{7} \mathrm{Li}$-NMR spectra as a function of added LiCl (organic phase) after extraction with $0.2 \mathrm{~mol} / \mathrm{kg}$ A336 in toluene.

Figure 6.19 shows ${ }^{7} \mathrm{Li}$ NMR spectra of the organic phase after $\mathrm{Li}$ extraction. The bottom spectrum shows the presence of $\mathrm{Li}$ in the organic phase after extraction with $0.2 \mathrm{~mol} / \mathrm{kg} \mathrm{A} 336$ from an aqueous solution containing $0.2 \mathrm{~mol} / \mathrm{kg} \mathrm{LiCl}$. The middle spectrum shows the ${ }^{7} \mathrm{Li}-$ NMR spectrum of organic phase after contact with $1 \mathrm{~mol} / \mathrm{kg} \mathrm{LiCl}$. The top spectrum shows the organic ${ }^{7} \mathrm{Li}-\mathrm{NMRspectrum}$ phase after extraction with $5 \mathrm{~mol} / \mathrm{kg}$ lithium and reveals two peaks, the second-highest field peak is however, quite small. The fact that $\mathrm{Li}^{+}$was found in the organic phase was a welcome surprise. It was easily detectable at rather low aqueous concentrations of $0.2 \mathrm{~mol} / \mathrm{kg}$. It should be tested with other salts present such as $\mathrm{NaCl}$ to see if it can be extracted at lower concentrations.

As explained above, the lithium spectra only differ in the size of the ${ }^{7} \mathrm{Li}$ NMR-peak but the peak position is not altered. The proton spectra for the same solutions and conditions are much more informative: 


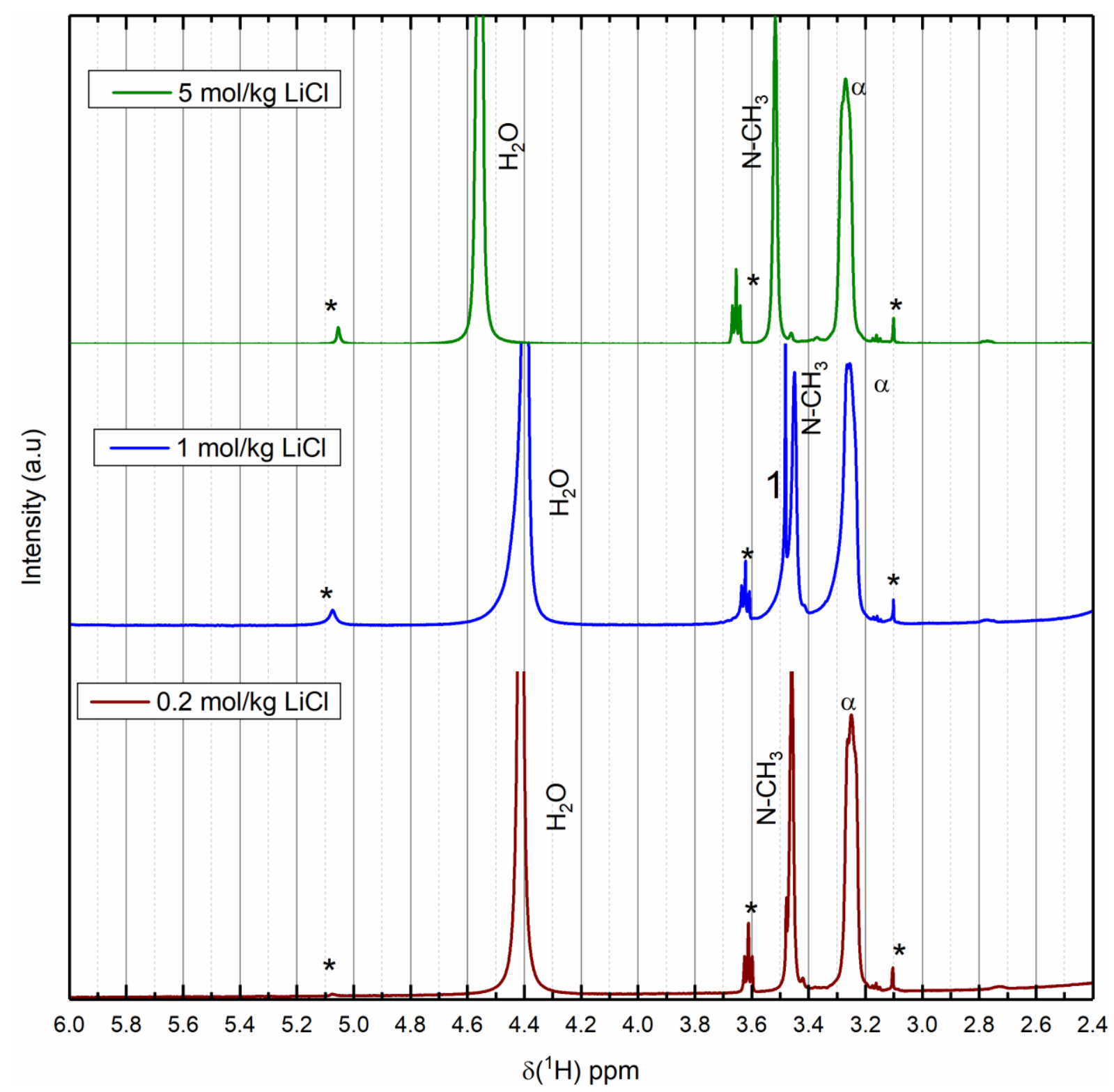

Figure $6.20^{1} \mathrm{H}$-NMR spectra as a function of added LiCl (organic phase) after extraction with $0.2 \mathrm{~mol} / \mathrm{kg}$ A336 in toluene.

Figure 6.20 shows the different ${ }^{1} \mathrm{H}-\mathrm{NMR}$ spectra of the same organic solutions as in figure 6.19 . Important to observe is the movement of the water peak, which is a little below $4.5 \mathrm{ppm}$ at the lowest concentration and moves to a less-shielded position as the ion concentration increases. The $\mathrm{N}-\mathrm{CH}_{3}$ peak switches from under $3.5 \mathrm{ppm}$ to a position right above and it appears to change by interacting with more than one species. It seems to be two peaks present in the middle spectrum. There is also a small peak above 5 ppm that shows up only in these spectra. 


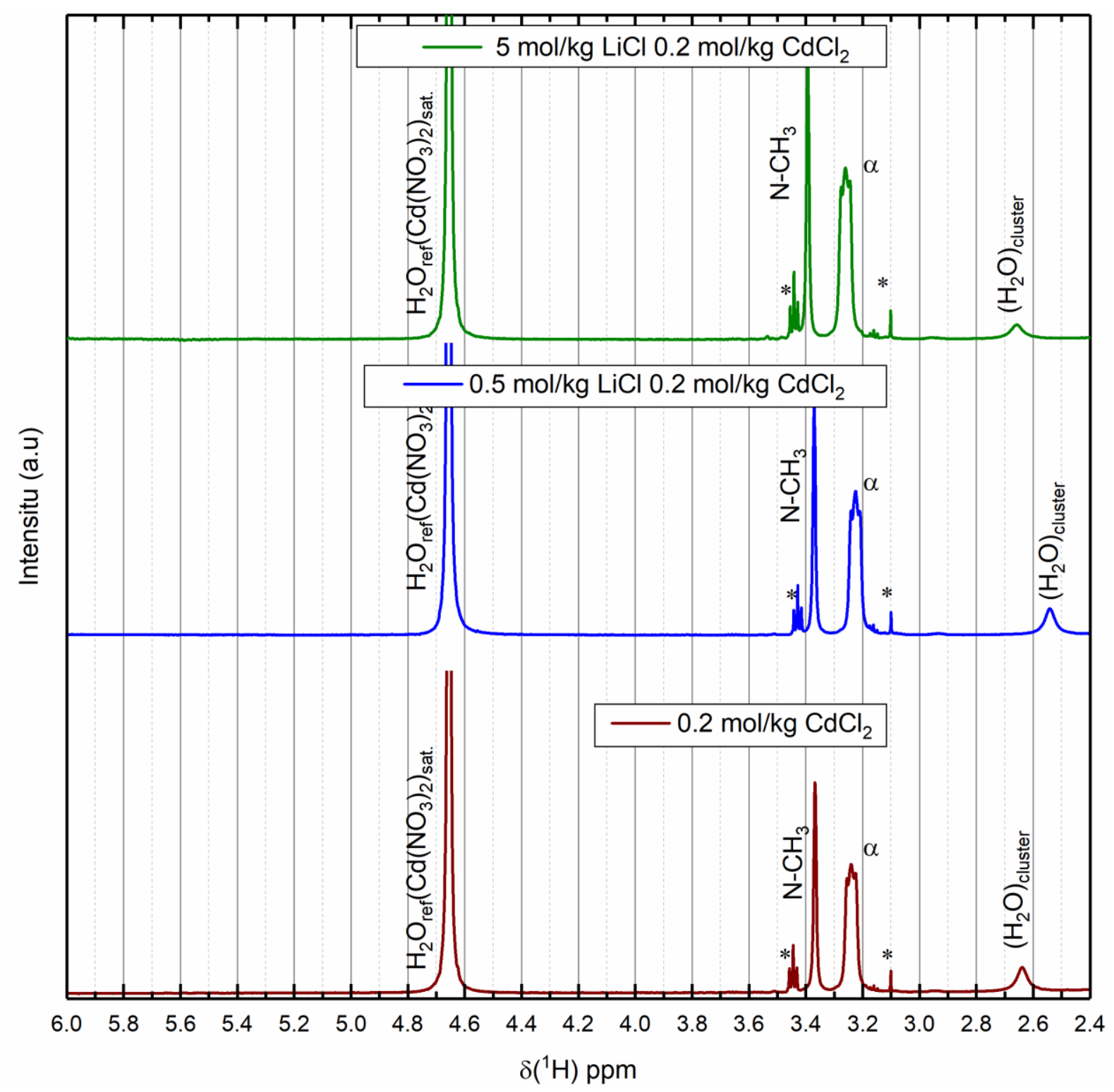

Figure $6.21{ }^{1} \mathrm{H}$-NMR spectra of $0.2 \mathrm{~mol} / \mathrm{kg}$ A336 in toluene after contact with three different aqueous solutions. The peak at 4.65 is the proton resonance from a saturated $\mathrm{Cd}\left(\mathrm{NO}_{3}\right)_{2}$ reference in a capillary tube. The peaks marked with $a *$ are unassigned peaks. The low wide peak at roughly 2.6 is tentatively assigned to water trapped as clusters [102].

Figure 6.21 shows the NMR spectra of the organic phase after contact with aqueous phases of increasing $\mathrm{LiCl}$ concentration and constant $\mathrm{Cd}$ (II) concentration. The water peak right over 4.5 ppm is the water reference used to determine the amount of $\mathrm{Cd}(\mathrm{II})$ extracted. There is little to no difference for the $\alpha$ and $\mathrm{N}-\mathrm{CH}_{3}$ peaks. There is a new peak between the methylated benzene and the $\alpha$-peak which appears to be affected by the concentration. Much less water is apparent in the organic spectrum compared to the spectra where there is only lithium and no $\mathrm{Cd}$ (II). From the literature, there is experimental data that indicate which $\mathrm{Cd}(\mathrm{II})$ and $\mathrm{Zn}$ (II) can force water away from A336 [103]. In addition the small peak at 2.6 to 2.8 can tentatively be assigned to clusters of water under the assumption that benzene and toluene have similar behaviour [104]. This agrees with what was observed in the work presented here. 


\section{Conclusion and Future Perspective}

Extracting $\mathrm{Cd}(\mathrm{II})$, and $\mathrm{Zn}(\mathrm{II})$, from chloride containing solutions, is straight forward using A336, even in solutions containing multiple metals. Adduct formation with sulfate will backextract the metal from the organic phase. The back-extraction is more efficient the higher the sulfate concentration is compared to the chloride and A336 concentration.

There were several different species co-extracted along with the metallic species. Several of these species do not follow our definition of contaminant, but they could still hinder the extraction. Several methods were needed to determine and quantify the co-extracted species. Potentiometric titration can efficiently quantify the acid extracted to the organic phase. ${ }^{1} \mathrm{H}$ NMR quantifies the extraction of water, ${ }^{7} \mathrm{Li} \mathrm{NMR}$ quantifies the extraction of $\mathrm{Li}^{+}$and ${ }^{14} \mathrm{~N} \mathrm{NMR}$ quantifies the extraction of nitrate and other symmetric nitrogen compounds. Raman shows the extraction of molecular species. Raman was the most efficient at discovering unexpected changes in the organic phase. Radiotracers, ICP-MS and ICP-OES was used to quantify the extraction.

Speciation of the various cadmium chlorides and the concentrations of them were straight forward in the aqueous phase using ${ }^{113} \mathrm{Cd} \mathrm{NMR}$. The aqueous NMR experiments also showed that on an NMR timescale there seems to be no measurable interaction between $\mathrm{Cd}(\mathrm{II})$ and $\mathrm{ClO}_{4}{ }^{-}$or $\mathrm{NO}_{3}{ }^{-}$, when $\mathrm{Cl}^{-}$is present. The species in the organic phase were harder to determine. The range of the chemical shift was small, and independent of chloride and A336 concentration. The different chemical shift observed between organic and aqueous phases could be due to changes in the dielectric constant and not due to changes in species [99]. It was then difficult to conclude if the organic species was $\mathrm{CdCl}_{4}{ }^{-2}$ or $\mathrm{CdCl}_{3}{ }^{-}$or some other species. Attempts to determine the species by measuring the amount of chloride extracted was not possible, because both $\mathrm{HCl}$ and $\mathrm{LiCl}$ was extracted into the organic phase. Therefore, the chloride could be bound to other species than $\mathrm{Cd}$ (II). Due to ${ }^{37} \mathrm{Cl}$ large quadrupole moment chloride NMR could not be used to determine what it was bound to.

With the high ionic strength and extractant used in this thesis liquid-liquid extraction had difficulty in determining the species. Especially in solutions with three or more matrix ions. With A336 the speciation was determined by the chemical equilibrium which could explain the results. Extractions with TOPO shows that quick equilibrium will lessen the impact of the expected dominating metallic specie. With the unexpected result that higher chloride concentrations gave higher D-ratios.

It was clear that the binary salt solutions became much easier to explain when the concentrations were expressed as a fraction between the two salts present. In addition, while the speciation diagrams did not fit perfectly, they predicted a sudden shift in the dominating aqueous species.

Being able to tell the difference between the raffinate and the feed is the most important part of single-phase extraction. A single tailed t-test ensure that the difference observed are real, and it is a helpful tool in planning the needed amount of replicas.

Toluene was used as a solvent, for ease of dissolution of the extractant and for its benefit properties for LSS measurements. Its high polarizability and relatively high dielectric constant 
had a high synergy with the extractant which gave rise to a high D-ratio. However, its synergy challenged the speciation as several other species were co-extracted. The complication of this increased due to $\mathrm{LiCl}$. $\mathrm{LiCl}$ and $\mathrm{HCl}$ were chosen as the chloride sources as these where the salts and acids that had a high enough aqueous solubility for the concentrations used. Especially in the binary mixtures heavier alkalines would precipitate. $\mathrm{LiCl}$ would be co-extracted and extract additional water, and $\mathrm{HCl}$ would change the acid concentration drastically in the organic phase.

\subsection{CONCLUSIONS FROM THE ARTICLES Article I}

Here we discuss the effect of low ionic strength solutions $0.002 \mathrm{~mol} / \mathrm{kg}$ to $6.5 \mathrm{~mol} / \mathrm{kg}$ and different counter ions.

It is only possible to determine the equilibrium constant for a limited range. The reason is most likely due to a mechanistic change. We show that it is possible to measure that $\mathrm{ClO}_{4}{ }^{-}$and $\mathrm{NO}_{3}{ }^{-}$ is bound to A336 strongly. We can quantify the nitrate extraction with NMR. We also show that sulfate is extracted to a lesser extent than nitrate and perchlorate. We also show that perchlorate and nitrate binds so strongly to the A336 that it hinders Cd(II) extraction.

\section{Article II}

We show that the extraction properties of A336 depend on the amount of acid used. Cd(II) drops in extraction while all other elements increase. A336 is still in surplus compared to the metals concentration. We calculate that single-phase is more uncertain than two-phase measurement and we show that ICP-MS gives higher D-ratios than radiotracers. We also show that sulfate can function as a stripping agent for $\mathrm{Cd}(\mathrm{II}), \mathrm{Zn}(\mathrm{II})$ and $\mathrm{Co}$ (II) from a chloride environment when the extractant is A336 in toluene.

\section{Article III}

Using NMR to detect water demonstrates how much water is extracted, in addition the chemical shift of the water peak indicates whether there is something affecting the water. We reveal that the chemical shift of water in the organic phase is strongly affected by the amount of acid. We show that the hydrophilic part is the one most affected by the ions. We show that it is possible to measure the amount of $\mathrm{LiCl}$ in the organic phase, and that $\mathrm{LiCl}$ is extracted into the organic phase. We can tentatively calculate the amount of acid and the amount of $\mathrm{LiCl}$. It is also possible to assess the ratio of disassociated and molecular acid assuming there were two acidic species.

\subsection{Future Perspectives}

Using sulfate as a stripping step for $\mathrm{Zn}$ (II) and $\mathrm{Cd}(\mathrm{II})$ could potentially remove these cheaply and easily. However, it should be checked how much chloride enter the stripping solution as this would lower its efficiency. This thesis has shown that Lithium sulfate can be used as a back-extraction agent for A336. Eq. 6.12 is a suggested mechanism for how the sulfate reduces the extraction. To determine if there is some sulfate extracted using the radiotracer ${ }^{35} \mathrm{SO}_{4}{ }^{2-}$ would conclude whether the extraction is within acceptable limits. High extraction of sulfate would make it unsuited for industrial purposes. Marcus and Kertes [97] argue that the distribution of sulfate between organic and aqueous is challenging to determine. However, they do not show quaternary amines in their discussion. Precipitation experiments with $\mathrm{BaCl}_{2}$ could 
also be performed but the amount of the precipitated mass that is the extractant must be determined.

With the increased importance of lithium for batteries, extraction of lithium is important. Determining if $\mathrm{Li}$ is extracted into the organic phase in lower concentrations where the ionic strength is dominated by $\mathrm{NaCl}$ would reveal if it could be used. Flame absorption analysis should be able to measure both $\mathrm{Li}$ in the aqueous and in the organic phase. If sodium extraction occurs, it can be determined using the radionuclide ${ }^{24} \mathrm{Na}$.

NMR and Raman spectroscopy have been shown to be efficient tools to measure co-extraction and could be used to measure the effect of different aqueous solutions on the organic phase. Raman can easily measure if molecular ions (such as $\mathrm{NO}_{3}{ }^{-}, \mathrm{PO}_{4}{ }^{3-}$ in all its forms, $\mathrm{ClO}_{4}{ }^{-}$or $\left.\mathrm{SO}_{4}{ }^{2-}[96,105,106]\right)$ are extracted into the organic phase. Performing quantitative measurements of molecular ions in the organic phase would help to determine how much is extracted and thus help us understand how that affects the extraction.

NMR is excellent at measuring proton-containing species. Protons close to the binding site of the extractant are those most strongly affected. Extraction of different species should then affect these protons in different ways. A series of extractions could then be performed to study how these protons are affected by different ligand concentrations, or different types of metals.

More effort is needed to study the effect on the organic solvent before and after extraction. NMR, infrared and Raman spectroscopy are techniques suitable for studying the change in the organic solvent. For instance, it is possible to have more acid extracted into the organic phase than there is extractant present. For an anion exchanger such as A336, this can only be explained if neutral species are somehow extracted as well. These species may be trapped in aggregates or micelles of various sizes. It should be possible to determine the presence, size and amount of such aggregates by osmometric measurements, or by neutron diffraction of the organic phase. If micelles are being formed, it would be important to understand how these are affected by a change in the ionic strength and by the presence of other ions in the aqueous phase.

In addition if liquid-liquid extractions are to be performed at similar concentrations it is recommended to perform the extractions with a radiotracers such as THO as this could help determine the amount of water co-extracted. In addition, utilizing NMR enables to study the effect different extractants and metals have on the water in the organic phase.

Further, the greatest challenges for ICP-MS was not the high-salinity in the aqueous solutions, but the need to develop a method that could quantify in the organic phase. It is probably possible to push the LOQ of the ICP-MS to such an extent that higher D-ratios can be determined. However, it is suggest that developing good methods for the organic phase would be more valuable. 


\section{REFERENCES}

1. IUPAC (Online 2019-) Compendium of Chemical Terminology, 2nd ed. (the "Gold Book"). Blackwell Scientific Publications, Oxford doi:https://doi.org/10.1351/goldbook. ISBN: 0967855098

2. G. M. Mudd (2010) The Environmental Sustainability of Mining in Australia: Key Mega-trends and Looming Constraints. Resour Policy 35:98-115

3. K. Nakajima, I. Daigo, K. Nansai, K. Matsubae, W. Takayanagi, M. Tomita, Y. Matsuno (2018) Global Distribution of Material Consumption: Nickel, Copper and Iron. Resour Conserv Recycling 133:369-374

4. S. Brihngezu, A. Ramaswami, M. O'Brien, R. Pelton, J. Acquatella, E. T. Ayul, A.

S. F. Chiu, R. Flanegin, J. Fry, S. Giljum, S. Hashimoto, S. Hellweg, K. Hosking, Y.

$\mathrm{Hu}$, M. Lenzen, M. Lieber, S. Lutter, A. Miatto, A. S. Nagpure, M. Obersteiner, L.

Van Oers, S. Pfister, P.-P. Pichler, A. Russell, L. Spini, H. Tanikawa, E. van der Voet,

H. Weisz, J. West, A. Wiijkman, B. Zhu, R. Zivy (2017) Assessing Global Resource

Use: A Systems Approach to Resource Efficiency and Pollution Reduction.

5. Economic and Social Council (2019) Sustainable Development Goals. E/2019/68.

Unitet Nations.

6. M. L. C. M. Henckens, E. C. Van Ierland, P. P. J. Driessen, E. Worrell (2016)

Mineral Resources: Geological Scarcity, Market Price Trends, and Future Generations. Resour Policy 49:102-111

7. M. L. C. M. Henckens, P. P. J. Driessen, E. Worrell (2014) Metal Scarcity and Sustainability, Analyzing the Necessity to Reduce the Extraction of Scarce Metals.

Resour Conserv Recycling 93:1-8

8. M. L. Free (2013) Hydrometallurgy: Fundamentals and Applications.

Wiley.ISBN:97811182230770

9. C. M. Starks, R. M. Owens (1973) Phase-Transfer Catalysis. II Kinetic Detail of Cyanide Displacement on 1-Halooctanes. J Am Chem Soc 95:3613-3617

10. M. Arashmid, G. V. Jeffreys (1980) Analysis of the Phase Inversion

Characteristics of Liquid-liquid Dispersions. AIChe J 26 (1):51-55

11. D. M. Muir The Application of Thermodynamic to Extractive Metallurgy with Chloride Solutions - a Review. Warren Spring Laboratory

12. P. Debye, E. Hückel (1923) De La Theorie des Electrolytes. I. Abaissement du

Point de Congelation et Phenomenes Associes. Physickalische Zeitschrift 24 (9):185206

13. J. N. Brønsted (1922) Studies on Solubility. IV. The Principle of the Specific Interaction of Ions. J Am Chem Soc 44 (5):877-897

14. J.-P. Simonin (2017) Thermodynamic Consistency in the Modeling of Speciation in Self-Complexing Electrolytes. Ind Eng Chem Res 56:9721-9733.

doi:10.1021/asc.iecr.7b01965

15. B. Maribo-Morgensen, G. M. Kontogeorgis, K. Thomsen (2013) Modeling of Dielectric Properties of Aqueous Salt Solutions with an Equation of State. J phys Chem B 117:10523-10533

16. E. A. Guggenheim, J. C. Turgeon (1955) Specific Interaction of Ions. Trans

Faraday Soc 51:747-761 
17. C. L. Kusik, H. P. Meissner (1975) Calculating Activity Coefficients in Hydrometallurgy- A review. Int J Miner Process 2:105-115

18. K. J. Powell, P. L. Brown, R. H. Byrne, T. Gajda, G. Hefter, A.-K. Leuz, S. Sjöberg, H. Wanner (2011) Chemical Speciation of Environmentally Significant Metals with Inorganic Ligands. Part 4: The $\mathrm{Cd}^{2+}+\mathrm{OH}^{-}, \mathrm{Cl}^{-}, \mathrm{CO}_{3}{ }^{2-}, \mathrm{SO}_{4}{ }^{2-}$, and $\mathrm{PO}_{4}{ }^{3-}$ Systems (IUPAC Technical Report) Pure Appl Chem 83 (5):1163-1214. doi:10.1351/PAC-REP-10-08-09

19. K. J. Powell, P. L. Brown, R. H. Byrne, T. Gajda, G. Hefter, A.-K. Leuz, S. Sjöberg, H. Wanner (2013) Chemical Speciation of Environmentally Significant Metals with Inorganic Ligands. Part 5: The $\mathrm{Zn}^{2+}+\mathrm{OH}^{-}, \mathrm{Cl}^{-}, \mathrm{CO}_{3}{ }^{2-} \mathrm{SO}_{4}{ }^{2-}$. and $\mathrm{PO}_{4}{ }^{3-}$ systems (IUPAC Technical Report). Pure Appl Chem 85 (12):2249-2311. 20. K. J. Powell, P. L. Brown, R. H. Byrne, T. Gajda, G. Hefter, A-K. Leuz, S. Sjöberg, H. Wanner (2009) Chemical Speciation of Environmentally Significant Metals with Inorganic Ligands. Part 3: The $\mathrm{Pb}^{2+}+\mathrm{OH}^{-}, \mathrm{Cl}-, \mathrm{CO}_{3}{ }^{2-}, \mathrm{SO}_{4}{ }^{2-}$ and $\mathrm{PO}_{4}{ }^{3-}$ Systems (IUPAC Technical Report) Pure Appl Chem 81 (12):2425-2476.

21. K. J. Powell, P. L. Brown, R. H. Byrne, T. Gajda, G. Hefter, S. Sjöberg, H. Wanner (2007) Chemical Speciation of Environmentally Significant Metals with Inorganic Ligands Part 2: The $\mathrm{Cu}^{2+} . \mathrm{OH}^{-}, \mathrm{Cl}^{-}, \mathrm{CO}_{3}{ }^{2-}, \mathrm{SO}_{4}{ }^{2-}$ and $\mathrm{PO}_{4}{ }^{3-}$ Systems. Pure Appl Chem 79 (5):895-950.

22. K. J. Powell, P. L. Brown, R. H. Byrne, T. Gajda, G. Hefter, S. Sjöberg, H. Wanner (2005) Chemical Speciation of Environmentally Significant heavy Metals with Inorganic Ligands part 1: The $\mathrm{Hg}^{2+}-\mathrm{Cl}^{-}, \mathrm{OH}^{-}, \mathrm{CO}_{3}{ }^{2-}, \mathrm{SO}_{4}{ }^{2-}$ and $\mathrm{PO}_{4}{ }^{3-}$ aqueous systems. Pure Appl Chem 77 (4):739-800.

23. K. S. Pitzer (1974) Thermodynamics of Electrolytes. I. Theoretical Basis and General Equations. J Phys Chem 77 (2):268-277

24. K. S. Pitzer, G. Mayorga (1973) Thermodynamics of Electrolytes. II. Activity and Osmotic Coefficient for Strong Electrolytes with One or Both Ions Univalent. J Phys Chem 77 (19):2300-2308

25. K. S. Pitzer, J. J. Kim (1974) Thermodynamics of Electrolytes. IV . Activity and Osmotic Coefficient for Mixed Electrolytes. J Am Chem Soc 96 (18):5701-5707 26. G. G. Manov, R. G. Bates, W. J. Hamer, S. F. Acree (1943) Values of the constants in the Debye-Hückel Equation for Activity Coefficients. J Am Chem Soc 65 (9):1765-1767

27. R. A. Robinson, R. H. Stokes (1959) Properties of Ionizing Solvents(1-22)The Theoretical Interpetation of Chemical Potentials (223-252). Electrolyte Solutions, The Measurement and Interpretation of Conductance, Chemical Potential and Diffusion in Solution of Simple Electrolytes. London,Butterworths Scientific Publications. ISBN:0408184906.

28. M. Kafuman (2002) Principles of Thermodynamics. Undergraduate Chemistry. Taylor \& Francis Group. ISBN:0824706927.

29. J. B. Hasted, D. M. Riston, C. H. Collie (1948) Dielectric Properties of Aqueous Ionic Solutions Parts I and II. J Chem Phys 16 (1):1-21

30. C. G. Malmberg, A. A. Maryott (1956) Dielectric Constant of Water from 0 to 100

${ }^{\circ} \mathrm{C}$. J Research Natl Bur Standards 56 (1):1-8

31. J. A. Schellman (1957) Dielectric Saturation of Associated Liquids. J Chem Phys 26 (5):1225-1230. 
32. H. T. Kim, W. J. Fredercik Jr (1988) Evaluation of Pitzer Ion Interaction Parameters of Aqueous Electrolytes at 25 C. 1. Single Salt Parameters. J Chem Eng Data 33:177-184

33. J. Rydberg, T. Sekine (1992) Solvent Extraction Equilibria. Principles and Practices of Solvent Extraction. Marcel Dekker, Inc. ,

34. G. M. Ritcey (1992) Development of Industrial Solvent Extraction Processes.

Principles and Practices of Solvent Extraction. Marcel Dekker, Inc.,

35. J. N. Miller, J. C. Miller (2005) Significance Test. Statistics and Chemometrics for Analytical Chemistry Fifth Edition. Pearson Education Limited. ISBN:0131291920.

36. B. L. Welch (1947) The Generalization of 'students' Problem when Several Different Population Variances are Involved. Biometrika 34:28-35.

37. C. J. Jameson, J. Mason (1987) The Parameters of NMR Spectroscopy (3-46).

Multinuclear NMR. Plenum Press, New York.ISBN:0306421534.

38. S. K. Bharti, R. Roy (2012) Quantitative ${ }^{1}$ H NMR Spectroscopy. Trends AnalChem 35:5-26

39. D. L. Pavia, G. M. Lampman, G. S. Kriz, J. R. Vyvyan (2009) Introduction to Spectroscopy. Brooks/Cole Cengage Learning. ISBN:9780495114789.

40. H. D. Young, R. A. Freedman, T. R. Sandin, A. L. Ford (1996) Atomic Structure. University Physics. Addison Wesley Publishing Company. ISBN: 978-0201571585

41. R. K. Harris, E. D. Becker, S. M. Cabral De Menezes, R. Goodfellow, P. Granger (2001) NMR Nomenclature. Nuclear Spin Properties and Concretions for Chemical shifts (IUPAC Recommendations 2001). Pure Appl Chem 73:1795-1818

42. K. Nakamoto (1997) Infrared and Raman Spectra of Inorganic and Coordination Compounds Part A: Theory and Applications in Inorganic Chemistry. Wiley ISBN:0471194609

43. J. Lehto, X. Hou (2011) Radionuclides and their Radiometric Measurement. Chemistry and Analysis of Radionuclides. Wiley. ISBN:978352732658.

44. A. L. Gray, R. S. Houk, I. Jarvis, K. E. Jarvis, J. W. McLaren, J. G. Williams (1994) Handbook of Inductively Coupled Plasma Mass Spectrometry. Blackie Academic \& Professional. ISBN: 075140277.

45. R. Thomas (2013) Sample Introduction (11-22). Practical Guide to ICP-MS, a Tutorial for Beginners. Taylor \& Francis Group. ISBN: 9781466555433

46. R. Thomas (2013) Common ICP-MS Applications (217-256). Practical Guide to ICP-MS, a Tutorial for Beginners. Taylor \& Francis Group. ISBN: 9781466555433

47. R. Thomas (2013) Comparing ICP-MS with Other Atomic Spectroscopic Techniques (281-299). Practical Guide to ICP-MS, a Tutorial for Beginners. Taylor \& Francis Group. ISBN: 9781466555433

48. C. M. Starks (1971) Phase-Transfer Catalysis. I. Heterogeneous Reactions Involving Anion Transfer by Quaternary Ammonium and Phosphonioum Salts. J Am Chem Soc 93 (1):195-199

49. K. Grudpan, C. G. Taylor (1984) Use of Aliquat-336 for the extraction of Cadmium from Aqueous Solutions. Analyst 109:585-588

50. R. A. Kumbasar (2008) Transport of Cadmium Ions from Zinc Plant Leach solutions Through Emulsion Liquid membrane-Containing Aliquat 336 as Carrier. Sep Purif Technol 63:592-599 
51. H. V. Lerum, N. H. Andersen, D. Ø. Eriksen, E. W. Hansen, D. Petersen, G. Wibetoe, J. P. Omtvedt (2018) Study of Cadmium Extraction with Aliquat 336 from Highly saline Solutions. J Solution Chem 47 (8):1395-1417

52. J. Paatero (1974) Studies on the System Aliquat 336 in Xylene-Nickel(II) in Aqueous Chloride Solutions Part I. Determination of the Composition and Average Molecular Weight of Aliqaut 336. Acta Acad Aboensis Ser B 34:1-40

53. B. Wassink, D. Dreisinger, J. Howard (2000) Solvent Extraction Separation of Zinc and Cadmium from Nickel and Cobalt using Aliquat 336, a strong Base Anion Exchanger, in the Chloride and Thiocyanate Forms. Hydrometallurgy 57:235-252 54. Z. Li, X. Li, S. Raiguel, K. Binnemans (2018) Separation of Transition Metals from Rare Earths by Non-aqueous Solvent Extraction from Ethylene Glycol Solutions using Aliquat 336. Sep Purif Technol 201:318-326

55. K. Annane, A. Sahmoune, P. Montels, S. Tingry (2015) Polymer Inclusion Membrane Extraction of Cadmium(II) with Aliquat 336 in micro-channel Cell. Chem Eng Res Des 94:605-610

56. V. V. Bagreev, C. Fischer, L. M. Kardivarenko, Yu. A. Zolotov (1982) Mutual Influence of Metals in the Extraction of Their Chloride Complexes with Tri- $n$ Octylamine and Aliquat 336 in Nitrobenzene. Polyhedron 1:623-627

57. V. V. Bagreev, C. Fischer, L. M. Yuduskina, Yu. A. Zolotov (1978) Mutual Influence of Metals in The Extraction of Their Chloride Complexes with Tri-nOctylamine and Aliquat 336 in Benzene. J Inorg Nucl Chem 40:553-557

58. F. de Mendonça Fábrega, M. B. Mansur (2007) Liquid-liquid Extraction of Mercury(II) from Hydrochloric Acid Solutions by Aliquat 336. Hydrometallurgy 87:83-90

59. N. Dalali, H. Habibi (2015) Facilitated Transport of Cadmium by Bulk Liquid Membrane using Aliquat 336 as Carrier: Separation from other Heavy Metal Ions. Desalin Water Treat 56 (6):1601-1609.

60. L. Wang (1998) Extraction study of Cadmium(II) and Copper(II) using Aliquat 336. Victoria University of Technology, Victoria Australia

61. H. Daud, R. W. Cattrall (1982) The Extraction of Zinc(II) from Chloride Solutions by Methyltrioctylammonium and Methyltridecylammonium Chlorides Dissolved in Chloroform and Other Dilutents and a Comparison with Aliquat 336. Aust J of Chem 35:1087-1093

62. H. F. Aly, M. El-Garhy, S. Ek-Reefy (1972) Extraction of Iron, Cobalt, and Manganese from Hydrochloric Acid with Quaternary Amine, Aliquat-336. Microchem J 17:431-435

63. H. Daud, R. W. Cattrall (1980) The Extraction of Cd(II) and Zn(II) from Acidified Lithium Chloride Solutions by Aliquat 336 in Chlorform. J Radioanal Nucl Chem 43:599-601

64. H. Daud, R. W. Cattrall (1981) The Extraction of $\mathrm{Hg}(\mathrm{II})$ from Potassium Iodide Solutions and the Extraction of $\mathrm{Cu}(\mathrm{II}), \mathrm{Zn}(\mathrm{II})$ and $\mathrm{Cd}(\mathrm{II})$ from Hydrochloric Acid Solutions by Aliquat 336 Dissolved in Chloroform. J Radioanal Nucl Chem 43:779785

65. R. Paimin, R. W. Cattrall (1983) The Extraction of Cobalt(II) from Hydrochloric Acid Solutions by Aliquat 336R Dissolved in Chloroform. Aust J of Chem 36:10171020 
66. R. Paimin, R. W. Cattrall (1982) The Extraction of Cobalt(II) from Lithium Chloride Solutions by Aliquat 336R Dissolved in Chloroform. Aust J of Chem 35:2345-2351

67. L. Wang, R. Paimin, R. W. Cattrall, W. Shen, S. D. Kolev (2000) The Extraction of Cadmium(II) and Copper(II) from Hydrochloric Acid Solutions using an Aliquat 336/PVC Membrane. J Membr Sci 176:105-111

68. R.-S. Juang, H.-C. Kao, W.-H. Wu (2004) Analysis of Liquid Membrane

Extraction of Binary $\mathrm{Zn}$ (II) and Cd(II) from Chloride Media with Aliquat 336 Based on Thermodynamic Equilibrium Models. J Membr Sci 228:169-177

69. J.-P. Mikkola, P. Virtanen, R. Sjöholmen (2006) Aliquat 336- a Versatile and Affordable Cation Source for an Entirely new Family of Hydrophobic Ionic Liquids. Green Chem 8:250-255. doi:10.1039/b51289f

70. S. Baidas, B. Gao, X. Meng (2011) Perchlorate Removal by Quaternary Amine Modified Reed. J Hazard Mater 189:54-61. doi:10.1016/j.jhazmat.2011.01.124 71. A. Brändström (1977) Principles of Phase-Transfer Catalysis by Quaternary Ammonium Salts. Adv Phys Org Chem 15:267-330

72. A. Brändstrom, G. Strandlund (1978) Ion Pair Extraction in Preparative Organic Chemistry. XI. Extraction of Sulfonic Acids as Ion Pairs with Amines. Acta Chem Scand 32:489-498

73. A. R. Selmer-Olsen (1966) Solvent Extraction of Chlorocomplexes by Triisooctylamin/Carbon Tetrachloride from Hydrochloric Acid Medium. Acta Chem Scand 20:1621-1625

74. Nations U (2019) Globally Harmonized System of Classification and Labelling of Chemicals (GHS), Eight Revised Edition.

75. Services USDoHaH (1997) Registry of Toxic Effects of Chemical Substances (RTECS). Comprehensive Guide to the RTECS.

76. Fisher (2008) Material Safety Data Sheet Benzene.

77. ThermoFisher Scientific (2018) Safety Data Sheet Toluene.

78. Koppers (2018) Safety Data Sheet Naphthalene.

79. Fisher (2006) Material Safety Data Sheet Cyclohexane.

80. Merck (2017) Safety Data Sheet n-decane

81. Brenntag (downloaded 2019) Solvesso ${ }^{\text {TM }}$ Series Aromatic Hydrocarbons.

82. Chemicals S (2016) Technical Datasheet Shellsol T.

83. Exxon Mobil (2015) Exxsol ${ }^{\mathrm{tm}}$ D80. Product Datasheet.

84. Sigma Aldrich (Downloaded 2019) Physical Properties of Solvents.

85. E. Brown, J. K. Tuli (2013). Nuclear Data Sheets 114

86. E. Brown, J. K. Tuli (2013). Nuclear Data Sheets 111

87. S. Kumar, J. Chen, F.G. Kondev (2016). Nuclear Data Sheets 137

88. H. Kristiansen (2015) Radiochemical Analysis of Cadmium in Nitric and Phosphoric Acid. master thesis, University of Oslo,

89. R. A. Pacer (1991) Liquid Scintillation and Cherenkov-Counting Characteristics of 109 Cd. J Radioanal Nucl Chem, Letters 155 (2):129-140

90. J. Magill, G. Pfennig, R. Dreher, Z. Sóti (2012) Karlsruher Nuklidkarte. 7. edn. European Commission - DG Joint Research Centre - Institute for Transuranium Elements, Karlsruhe, 
91. J. W. Akitt (1987) The Alkali and Alkaline Earth Metals: Lithium, Sodium, Potassium, Rubidium, Cesium, Beryllium, Magnesium, Calcium, Strontium, and Barium. Multinuclear NMR. Plenum Press, New York, 92. J. Mason (1987) Nitrogen. Multinuclear NMR. Plenum Press, New York, 93. R. J. Goodfellow (1987) Post-Transition Metals, Copper to Mercury. Multinuclear NMR.

94. A. D. Cardin, P. D. Ellis, J. D. Odom, J. W. Howard J (1975) Cadmium-113 Fourier Transform Nuclear Magnetic Resonance Spectroscopy. J Am Chem Soc:16721679

95. P. Allain, L. Jaunault, Y. Mauras, Jean-Michel Mermet, T. Delaporte (1991) Signal Enhancemenet of elements Due to the Presence of Carbon-Containing Compounds in Inductively Coupled Plasma Mass Spectrometry. Anal Chem 63:1497-1498 96. W. R. Angus, A. H. Leckie, S. W. Ramsay (1935) Investigations of Raman Spectra Part I - The Raman Spectra of Sulphuric, Nitric and Nitrosylsulphuric Acids. Proc Roy Soc A 149 (867):327-340

97. Y. Marcus, A. S. Kertes (1969) Extraction by Ion-pair Formation (737-814). Ion Exchange and Solvent Extraction of Metal Complexes. Wiley-Interscience. ISBN: 0471568589

98. J. J. H. Ackerman, T. V. Orr, V. J. Bartsuka, G. E. Maciel (1978) Effect of Halide Complexation of Cadmium(II) on Cadmium-113 Chemical Shifts. J Am Chem Soc $101(2): 341-347$

99. R. J. Kostelnik, A. A. Bothner-By (1974) Cadmium-113 Nuclear Magnetic Resonance Studies of Cadmium(II)- Ligand Binding in aqueous solutions. I. The effect of Diverse Ligands on the Cadmium-113 Chemical shift. J Magn Reson 14:141-151 100. H. J. Jakobsen, P. D. Ellis (1981) Solution Structures of Cadmium-glycine Complexes Probed by Cadmium-113 NMR of Supercooled Aqueous Solutions. J phys Chem 85 (23):3367-3369.

101. Y. Yasaka, C. Wakai, N. Matubayasi, M. Nakahara (2009) Water as an in situ NMR Indicator for Impurity Acids in Ionic Liquids. Anal Chem 81:400-407

102. E. K. Gibson (2007) Amine Hydrochloride Salts: a Problem in Polyurethane Synthesis. University of Glasgow,

103. J. D. Miller, M. C. Fuerstenau (1970) Hydration Effects in Quaternary Amines Extraction Systems. Metall Trans B 1:2531-2535

104. K. Oka, T. Shibue, N. Sugiumura, Y. Watabe, B. Winther-Jensen, H. Nishide (2019) Long-Lived Water Clusters in Hydrophobic Solvents Investigated by Standard NMR Techniques. Sci Rep 9:1-5

105. B. Klassen, R. Aroca, M. Nazri, G. A. Nazri (1998) Raman Spectra and Transport Properties of Lithium Perchlorate in Ethylene Carbonate Based Binary Solvent Systems for Lithium Batteries. J Phys Chem B 102:4795-4801 106. W. W. Rudloph, G. Irmer (2007) Raman and Infrared Spectroscopic Investigations on Aqueous Alkali Metal Phosphate Solutions and Density Functional Theory Calculations of Phosphate-water Clusters. Appl Spectrosc 61:1312-1327 107. D. W. Gaylor, F. N. Hopper (1969) Estimating the Degrees of Freedom for Linear Combinations of Mean Squares By Satterthwaite's Formula. Technometrics 11 (4):691-706. 
108. Y. Marcus, A. S. Kertes (1969) Aqueous Solutions of Electrolytes (3-92). Ion Exchange and Solvent Extraction of Metal Complexes. Wiley-Interscience. ISBN: 0471568589 


\section{APPENDiX A1 ChEMiCAL ACTIVITY CALCULATIONS}

$$
\ln \left(\gamma_{M X}\right)=z^{2} f^{\gamma}+\left(m E+m^{2} \mathrm{~F}\right) \quad \text { Eq. A1.1 }
$$

Here $\gamma_{M X}$ is the average activity of the ions of the salt MX, $z$ is the charge of the ions, $f^{\prime}$ is an extended Debye-Hückel term, the E term takes the effect of short range of ions into account, and the F term is needed for mixed salt solutions where one ion is shared between the solutes, and $m$ is the molality of the solution. The Debye-Hückel term is extended as:

$$
f^{\gamma}=A\left(\frac{\sqrt{I}}{1+b \sqrt{I}}+\frac{2}{b} \ln (1+b \sqrt{I})\right) \quad \text { Eq. A } 1.2
$$

Here $A$ is a term needed to determine when the electrostatic interaction is equal to the thermal movement, $I$ is the ionic strength of the solution, and $b$ is the shortest distance between two ions. The electrostatic attraction and thermal movement is described as:

$$
A=\frac{1}{3}\left(\frac{2 \pi N_{o} d_{s}}{1000}\right)\left(\frac{e^{2}}{D k T}\right)^{\frac{3}{2}} \quad \text { Eq. A1.3 }
$$

Here $N_{0}$ is Avogadro's number, $d_{s}$ is the density of the solvent, $\pi$ is $3.14 \ldots, e$ is the elemental charge, $D$ is the dielectric constant of the solvent, $k$ is the Boltzmann constant and $T$ is absolute temperature.

The E term is expanded as:

$$
\begin{gathered}
E=\left(1-Y^{2}\right) B_{m x}^{\gamma}+Y\left(\theta_{m n}+\theta_{x y}\right)+Y(1-Y)\left(B_{m y}^{\phi}+B_{n x}^{\phi}-2 B_{m x}^{\phi}+I \theta_{m n}+I \theta_{x y}\right) \\
+Y^{2}\left(B_{m y}^{\gamma}-B_{m y}^{\phi}+B_{n x}^{\gamma}-B_{n x}^{\phi}+2 B_{n y}^{\phi}-B_{n y}^{\gamma}\right)
\end{gathered}
$$

Where:

$$
B_{n x}^{\gamma}=2 B_{n x}^{o}+\frac{2 B_{n x}^{1}}{\alpha^{2} I}\left(1-e^{-\alpha \sqrt{I}}(1+\alpha \sqrt{I}-0.5 \alpha I)\right)
$$

And:

$$
B_{m x}^{\phi}=\frac{2 B_{m x}^{1}}{\alpha^{2} I^{2}}\left(-1+\left(1+\alpha \sqrt{I}+\frac{1}{2} \alpha I\right) e^{(-\alpha \sqrt{I})}\right)
$$

Here the subscripts $\mathrm{m}$ and $\mathrm{n}$ are for different cations and the subscripts $\mathrm{x}$ and $\mathrm{y}$ are for different anions, $Y$ is the molar fraction of compound $\mathrm{mx}, \theta$ is the interaction coefficient for two opposing ions from different salts, $\alpha$ is the longest range two ions can interact at, $B_{n x}^{o}$ is a constant specific for salt $n x . B_{n x}^{1}$ is another interaction constant for salt $n x$.

Measuring the chemical activity and determining the chemical activity coefficient for mixed salt solutions is complicated. The possible interactions between the ions increases dramatically. For the models used here, the chemical activity is calculated by assuming that one of the salts is dissolved in a solution of the other. The F-term then is introduced to account for how the different salts can interact. The F-term consists of empirically decided values that account for the interaction of equally charged ions from different elements. The estimation is still chiefly based on empirical data and it is therefore 
necessary to find the values. If the values are not found, estimations from homologues are possible but will incur more inaccuracies. If there are only one type of salt in the solution the F term is not needed.

The F-term is expanded as:

$$
\begin{gathered}
F=(1-\mathrm{Y}) \mathrm{C}_{\mathrm{mx}}^{\gamma}+\mathrm{Y}(1-\mathrm{Y})\left(\psi_{m n x}+\psi_{m x y}+C_{m x}^{\phi}+C_{n x}^{\phi}+C_{m y}^{\phi}\right) \\
+\frac{1}{2} Y^{2}\left(\psi_{m n y}+\psi_{n x y}+C_{m y}^{\phi}+C_{n x}^{\phi}+C_{n y}^{\phi}\right)
\end{gathered}
$$

where $\psi$ is the interaction between ions from two is different salts and $C_{m x}^{\phi}$ is the interaction between ions $m$ and $x$ and $C_{n y}^{\phi}$ is the interaction between ions $n$ and $y$ and so forth. The constants are empirically determined.

Chemical activity works best for dilute solutions, and the solutions should in general avoid complications like phase transfers and phase boundaries. The chemical activity will change in solutions that are not continuous, for example, if there are solid particles present or if the solution is emulsified. This is not discussed in this work, but it is important to be aware of. 


\section{APPENDIX A2 T-TEST AND STATISTICS}

To ensure that differences are not due to uncertainty, a t-test for two samples with different uncertainty can be used[36,107,35]:

$$
t=\frac{\left|\left[M_{\text {feed }}\right]-\left[M_{\text {raf }}\right]\right|}{\sqrt{\frac{\sigma_{\text {raf }}^{2}}{N_{\text {raf }}}+\frac{\sigma_{\text {feed }}^{2}}{N_{\text {feed }}}}}
$$

where $\mathrm{N}_{\mathrm{x}}$ is the number of replicas of the given measurement, here $\mathrm{x}$ represents raffinate and feed, respectively. If [ $\left.\mathrm{M}_{\text {feed }}\right]>$ [ $\left.\mathrm{M}_{\mathrm{raf}}\right]$, and if the value of $t$ exceeds the critical $\mathrm{t}$ value, Eq. 4 can be used to calculate the D-ratio. The critical t-value is given from t-tables, which can be found in, for example,[35]. The critical t-value can be read from such tables after the degrees of freedom are calculated as described in Eq. 12[36,107,35].

For ICP-MS, the minimum statistically significant D-ratio that could be measured was determined by rearranging Eq. A2.1:

$$
\left[M_{\text {raf }}\right]=\left[M_{\text {feed }}\right]-t \sqrt{\frac{\sigma_{\text {raf }}^{2}}{N_{\text {raf }}}+\frac{\sigma_{\text {feed }}^{2}}{N_{\text {feed }}}}
$$

Here the $\sigma_{\text {feed }}$ used was the same for all the samples, $\sigma_{\text {raf }}$ will change depending on the system. In these estimations, the highest experimental values were used. The degrees of freedom needed to assign a critical t-value were calculated as:

$$
v=\frac{\left(\frac{\sigma_{\text {raf }}^{2}}{N_{\text {raf }}}+\frac{\sigma_{\text {feed }}^{2}}{N_{\text {feed }}}\right)^{2}}{\frac{\sigma_{\text {raf }}^{4}}{N_{\text {raf }}^{2}\left(N_{\text {raf }}-1\right)}+\frac{\sigma_{\text {feed }}^{4}}{N_{\text {feed }}^{2}\left(N_{\text {feed }}-1\right)}}
$$

$v$ was then rounded to the closest integer, and a $95 \%$ one-tailed confidence interval was used to determine the significant difference. 



\section{APPENDIX A3 FraCtion OF MOLECULAR ACID AND DISASSOCIATED ACID}

To calculate the correct amount of acid species in the organic phase, it was assumed that there were two. To account for this possibility, we introduce a parameter, $a$, defined by:

$$
a=\frac{n(\mathrm{HCl})}{n\left(\mathrm{H}_{3} \mathrm{O}^{+}\right)}
$$

by which the observable chemical shift $\delta_{\text {avg }}$ is giving rise to a 'single' resonance band with chemical shift:

$$
\delta_{\mathrm{avg}}=f_{\mathrm{H}_{2} \mathrm{O}} \delta_{\mathrm{H}_{2} \mathrm{O}}+f_{\mathrm{H}_{3} \mathrm{O}^{+}} \delta_{\mathrm{H}_{3} \mathrm{O}^{+}}+f_{\mathrm{HCl}} \delta_{\mathrm{HCl}}
$$

where $f_{x}$ defines the fraction of component $\mathrm{X}$ (with chemical shift $\square X$ ), for example:

$$
f_{\mathrm{H}_{2} \mathrm{O}}=\frac{n\left(\mathrm{H}_{2} \mathrm{O}\right)}{n\left(\mathrm{H}_{2} \mathrm{O}\right)+n(\mathrm{HCl})+n\left(\mathrm{H}_{3} \mathrm{O}^{+}\right)}
$$

Furthermore, if the total number of exchangeable protons is denoted $n_{\text {tot }}(H)$, the material balance with respect to these protons can be written:

$$
n_{\text {tot }}(\mathrm{H})=3 \cdot n\left(\mathrm{H}_{3} \mathrm{O}^{+}\right)+n(\mathrm{HCl})+2 \cdot n\left(\mathrm{H}_{2} \mathrm{O}\right)
$$

where the $\mathrm{H}_{3} \mathrm{O}^{+}$-species are associated with only a single exchangeable proton. Hence, the number of exchangeable 'acid' protons $n(\mathrm{H})_{\text {acid }}$ in the organic phase can be written:

It follows that:

$$
n(\mathrm{H})_{\text {acid }}=n\left(\mathrm{H}_{3} \mathrm{O}^{+}\right)+n(\mathrm{HCl})
$$

$$
n\left(\mathrm{H}_{3} \mathrm{O}^{+}\right)=\frac{\delta\left(n(H)_{a c i d} \cdot 2+n_{t o t}(H)\right)-n_{t o t}(H) \delta_{H_{2} O}}{\left(\delta_{H_{3} O^{+}}+a \delta_{H C l}\right) \cdot 2-(3+a) \delta_{H_{2} O}+(3+a) \delta_{a v g}}
$$





\section{APPENDIX B1 CONCENTRATION OF MULTI-ELEMENT FEED SOLUTION}

Table B.1. The concentration of elements in the solution used as feed in the extraction tests. Entries that only were measured using ICP-AES are indicated by a star (*). Concentrations at extractions where a factor 10 lower.

\begin{tabular}{|c|c|c|c|c|c|c|c|c|}
\hline & $\mathrm{Al}$ & $\mathrm{Ba}^{*}$ & $\mathrm{Bi}^{*}$ & $\mathrm{Cd}$ & $\mathrm{Cu}$ & $\mathrm{Co}$ & $\mathrm{Cr}$ & $\mathrm{Mn}$ \\
\hline $\begin{array}{l}\text { Starting } \\
\text { mass } \\
\mathrm{g} / \mathrm{kg}\end{array}$ & 1 & 1 & 1 & 0.8 & 0.9 & 0.7 & 1 & 1 \\
\hline \multirow{2}{*}{$\begin{array}{l}\text { Conc. at } \\
\text { extraction } \\
\mathrm{mg} / \mathrm{kg}\end{array}$} & $4.7 \pm 0.1$ & $>0.2$ & $33.5 \pm 0.2$ & $29.4 \pm 0.1$ & $32.2 \pm 0$ & $22.9 \pm 0.1$ & $19.7 \pm 0.1$ & $37.3 \pm 0.2$ \\
\hline & Mo* & $\mathrm{Ni}$ & $\mathrm{Pb}$ & $\mathrm{Sb}^{*}$ & Sr* & $\mathrm{Te}^{*}$ & $\mathrm{~W}^{*}$ & $\mathrm{Zn}$ \\
\hline $\begin{array}{l}\text { Starting } \\
\text { mass } \\
\mathrm{g} / \mathrm{kg}\end{array}$ & 1 & 1 & 1 & 0.9 & 1 & 1.5 & 1 & 1 \\
\hline $\begin{array}{l}\text { Conc. at } \\
\text { extraction } \\
\mathrm{mg} / \mathrm{kg}\end{array}$ & $31.9 \pm 0.1$ & $36 \pm 1$ & $19.9 \pm 0.1$ & $32.1 \pm 0.2$ & $28.5 \pm 0.1$ & $38 \pm 2$ & $2.4 \pm 0.4$ & $34.0 \pm 0.3$ \\
\hline
\end{tabular}





\section{APPENDIX C1 LiST OF TABLES}

Table 2.1 Exhaustion periods of 60 elements in years after 2050. It is assumed that the extraction of all elements mentioned increases annually by $3 \%$ until 2050 and then levels off. EGR means extractable global resource as defined by Henckens [6] table taken from[7].

Table 4.1 The chloride species and the equilibrium equation for Cd. Stability constants from Powell et al.'s technical IUPAC report[18].

Table 4.2 Some examples of aromatic compounds with their liquid range and their flashpoint.

Table 4.3 Examples of aliphatic solvents with their liquid range and their flashpoint.

Table 4.4 A small sample of commercial solvents with their liquid range and their flashpoint

Table 4.5 Densities, molarities and molalities of various solvents with values taken from the CRC handbook[1].

Table 6.1 List of elements and their extraction properties with A336 from a chloride matrix

Table 6.2 aqueous solutions used for extraction with A336 and TOPO

Table 6.3 Chemical shift of cadmium chloride species. The chemical shift reference peak is $\mathrm{Cd}\left(\mathrm{ClO}_{4}\right)_{2}$ at $0.1 \mathrm{~mol} / \mathrm{kg}[98]$.

Table B.1. The concentration of elements in the solution used as feed in the extraction tests. Entries that only were measured using ICP-AES are indicated by a star (*). Concentrations at extractions where a factor 10 lower. 



\section{APPENDix C2 List OF Figures}

Figure 3.1 Calculated activity coefficients of LiCl where the green line has activity coefficients calculated when the ionic strength is the same as the concentration. The red line calculates the activity coefficients as the ionic strength is kept constant at 4 with $\mathrm{LiNO}_{3}$.

Figure 4.1 The unbroken coloured lines represent the true D-ratio, the stapled coloured lines represent the D-ratios for the same coloured whole line but with increasing entrainment.

Figure 4.2 The red line shows the relative uncertainty D-ratios of single-phase measurements, while the stapled line shows relative uncertainty for two-phase measurements.

Figure 4.3 Minimum D-ratio in single-phase measurement as a function of replicates. The lines show the number of replicas needed to determine a minimum D-ratio at different relative uncertainties, for a one-tailed t-test where the feed relative uncertainty is set to $1 \%$.

Figure 4.4 The coloured lines show the relative deviation possible for Eq. 4.10 estimated with different amount of replicates, for a one-tailed t-test where the feed relative uncertainty is set to $1 \%$.

Figure 4.5the uppermost panel shows how the external magnetic field forces the average magnetic momentum of the nuclei to align with it. The 90-degree pulse forces some of the nuclei to change their magnetic moment perpendicular to the external magnetic field. The bottom half shows the pulse width, the acquisition time and the repetition timeFigure 4.6 Speciation of $C d$ with both chloride and sulfate present. Total ionic strength kept at $6.5 \mathrm{~mol} / \mathrm{kg}$. The right side shows the speciation when the activity was accounted for.

Figure 4.6 Left side of the figure shows the speciation of Cd(II) in chloride solutions as a function of the nominal concentration (disregarding the chemical activity). The right side shows the speciation when the activity is considered.

Figure 4.7 Left side of the figure shows the speciation of Cd(II) in chloride solutions as a function of the nominal concentration (disregarding the chemical activity). The right side shows the speciation when the activity is considered. Total ionic strength kept at $6.5 \mathrm{~mol} / \mathrm{kg}$.

Figure 4.8 Aliquat 336 with $\alpha$-carbon and $\beta$-carbon marked, as well as the end point for the chain. The $\mathrm{n}$ can vary from 6-9 as drawn here. No charge or counter ion added to the molecule for simplicity.

Figure 5.1 Spectrum of ${ }^{109} \mathrm{Cd}$ from Liquid-scintillation counting. The spectra are not energy calibrated. Decay scheme redrawn from [85].

Figure 5.2 Spectrum of ${ }^{65} \mathrm{Zn}$ resolved with a high purity germanium detector [86].

Figure 5.3 Spectrum of ${ }^{60}$ Co resolved with a high-purity germanium detector [87]

Figure 6.1 Extraction data of Cd(II), Zn(II), Co(II) and Cu(II) using ICP-MS as a function of A336 concentration and two different $\mathrm{HCl}$ concentrations. Error bars represent one standard deviation. In some cases, the error is so small that the error bars are masked by the symbol showing the measurement point. Arrows represent values exceeding the measurable D-ratio.

Figure 6.2 D-ratios for $\mathrm{Cd}(\mathrm{II}), \mathrm{Zn}(\mathrm{II})$ and $\mathrm{Co}(\mathrm{II})$ as a function of A336 concentration and two different $\mathrm{HCl}$ concentrations using radiotracers. The error bars represent one standard deviation. Arrows represent values exceeding the measurable D-ratio.

Figure 6.3 D-ratios of cadmium from various LiCl solutions as a function of A336 concentration. Error bars represent one standard deviation.

Figure 6.4 D-ratios of Cd(II) as a function of chloride concentration, A336 in toluene as extractant. Three different aqueous solutions with constant ionic strength were used: $\mathrm{LiCl}$ blue dots, $\mathrm{LiCl}$ and $\mathrm{LiNO}_{3}$ green triangles with ionic strength $6.6 \mathrm{~mol} / \mathrm{kg}, \mathrm{LiCl}$ and $\mathrm{NaClO}_{4}$ black squares with an ionic strength of $6.6 \mathrm{~mol} / \mathrm{kg}$. Lines to guide the eye, error bars are one standard deviation. 
Figure 6.5 D-ratios of $\mathrm{Cd}(\mathrm{II})$ with increasing $\mathrm{LiCl} / \mathrm{LiNO}_{3}$ ratio. The blue line represents a linear regression for the blue triangles. The blue triangles represent $0.001 \mathrm{~mol} / \mathrm{kg}$ A336, red rings represent $0.002 \mathrm{~mol} / \mathrm{kg}$ A336 and black squares represent $0.01 \mathrm{~mol} / \mathrm{kg}$ A336. A constant ionic strength of $6.6 \pm 0.1 \mathrm{~mol} / \mathrm{kg}$ was held by controlling the ratio of $\mathrm{LiCl}$ and $\mathrm{LiNO}_{3}$. Error bars represent one standard deviation. Linear fit $y=a+b x, a=0.29 \pm 0.06$ and $b=0.93 \pm 0, r^{2}=98$.

Figure 6.6 D-ratios of $C d(I I)$ as a function of chloride concentration, TOPO in toluene as extractant. Three different aqueous solutions with constant ionic strength were used: LiCl blue dots, LiCl and $\mathrm{LiNO}_{3}$ green triangles with ionic strength $6.6 \mathrm{~mol} / \mathrm{kg}, \mathrm{LiCl}$ and $\mathrm{NaClO}_{4}$ black squares with an ionic strength of $6.6 \mathrm{~mol} / \mathrm{kg}$. Lines to guide the eye, error bars are one standard deviation.

Figure 6.7 The D-ratio of $\mathrm{Cd}(\mathrm{II})$ in a mixed solution of $\mathrm{LiCl}$ and $\mathrm{Li}_{2} \mathrm{SO}_{4}$ as a function of the concentration ratio of $\mathrm{LiCl} / \mathrm{Li}_{2} \mathrm{SO}_{4}$ with varying $\mathrm{A} 336$ concentrations used. The small panel shows the speciation diagram for Cd(II) with an increasing $\mathrm{LiCl}_{2} \mathrm{Li}_{2} \mathrm{SO}_{4}$ ratio. In the small panel $\mathrm{CdCl}_{4}^{-}$is assumed to not form, activity coefficients are calculated using Pitzer equations [32,23,25,24] and the ionic strength is kept at 6.5. Linear fit $y=a+b x, a=6.2 \pm 0.4$ $b=2.2 \pm 0.12 r^{2}=99$.

Figure 6.8 Example of back-extraction of Cd(II), $\mathrm{Zn}(I I)$ and $\mathrm{Co}(\mathrm{II})$ using lithium sulfate, from organic phases with A336 as extractant.

Fig 6.9 Raman spectra of A336 in toluene after contact with nitrate-and perchlorate-containing solution. In the left panel, the top line shows A336 prior to contact with nitrate solution, the dotted line shows A336 after contact with a nitrate solution and the bottom line shows a nitrate solution before contact with A336. The right panel the top line shows A336 before contact with a perchlorate solution, the dotted line shows A336 after contact with a perchlorate solution and the bottom line shows a perchlorate solution before contact with A336.

Figure $6.10 \mathrm{HCl}$ extraction with A336. The left panel shows extraction as a function of $\mathrm{HCl}$ concentration. The black open squares are from Marcus and Kertes book[97]. The right side shows the extraction as a function of increasing A336 concentration. Red error bars represent one standard deviation, black error bars are $10 \%$ of the value. Linear fit left graph $y=a+b x$ a $0.004 \pm 0.012 b=0.026 \pm 0.0011 r^{2}=98$ right graph $y=a+b x a=0.09 \pm 0.02 b$ $1.8 \pm 0.12 r^{2}=98$.

Figure 6.11 The chemical shift of $C d(I I)$ as a function of the chloride. The chemical shift reference peak is $\mathrm{Cd}\left(\mathrm{ClO}_{4}\right)_{2}$ at $0.1 \mathrm{~mol} / \mathrm{kg}$.

Figure 6.12 The resonance bands of Cd(II) in A336 saturated with 37 wt\% $\mathrm{HCl}$. The red signal shows the sample before heating, the blue line shows the signal during heating and the green line shows the signal after cooling down to room temperature.

Figure 6.13 Drawing of A336 with terms on the different carbon atoms to help identify their positions in the spectrum.

Figure $6.14{ }^{1} \mathrm{H}-\mathrm{NMR}$ spectrum of A336 in toluene, bands marked with * were not assigned.

Figure $6.15^{1} \mathrm{H}$-NMR spectrum of A336 NMR without any solvent present.

Figure $6.16^{1} \mathrm{H}-\mathrm{NMR}$ spectrum of the organic phase A336 without any solvent after extraction from a liquid phase containing $\mathrm{CdCl}_{2}$ and a concentrated $\mathrm{HCl}$ solution, measured at room temperature.

Figure $6.17^{1} \mathrm{H}-\mathrm{NMR}$ spectrum of the organic phase $\mathrm{A336Cl}$ heated to $50^{\circ} \mathrm{C}$ after extraction from a liquid phase containing $\mathrm{CdCl}_{2}$ and a concentrated $\mathrm{HCl}$ solution.

Figure $6.18^{1} \mathrm{H}$-NMR spectrum of the organic phase (A336 in toluene) after contact with $37 \mathrm{wt} \% \mathrm{HCl}$.

Figure $6.19^{7} \mathrm{Li}$-NMR spectra as a function of added LiCl (organic phase) after extraction with $0.2 \mathrm{~mol} / \mathrm{kg}$ A336 in toluene.

Figure $6.20^{1} \mathrm{H}$-NMR spectra as a function of added LiCl (organic phase) after extraction with $0.2 \mathrm{~mol} / \mathrm{kg}$ A336 in toluene.

Figure $6.21{ }^{1} \mathrm{H}$-NMR spectra of $0.2 \mathrm{~mol} / \mathrm{kg}$ A336 in toluene after contact with three different aqueous solutions. The peak at 4.65 is the proton resonance from a saturated $\mathrm{Cd}\left(\mathrm{NO}_{3}\right)_{2}$ reference in a capillary tube. The peaks 
marked with a* are unassigned peaks. The low wide peak at roughly 2.6 is tentatively assigned to water trapped as clusters [102]. 

I 



\section{Study of Cadmium Extraction with Aliquat 336 from Highly Saline Solutions}

\section{Hans Vigeland Lerum, Niels Højmark Andersen, Dag Øistein Eriksen, Eddy Walther Hansen, Dirk Petersen, Grethe Wibetoe, et al.}

\section{Journal of Solution Chemistry}

ISSN 0095-9782

Volume 47

Number 8

J Solution Chem (2018) 47:1395-1417 DOI 10.1007/s10953-018-0795-z

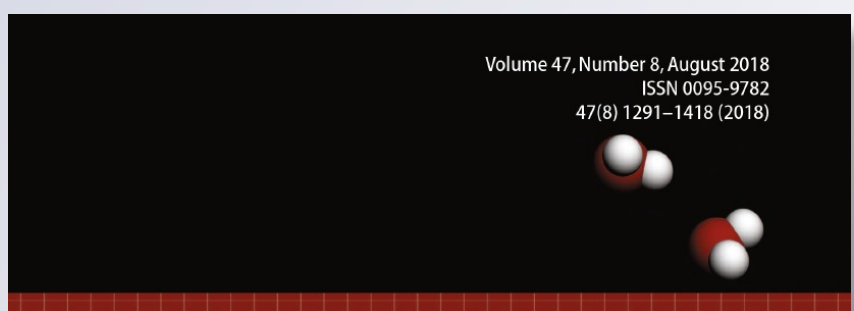

\section{Journal of Solution Chemistry}

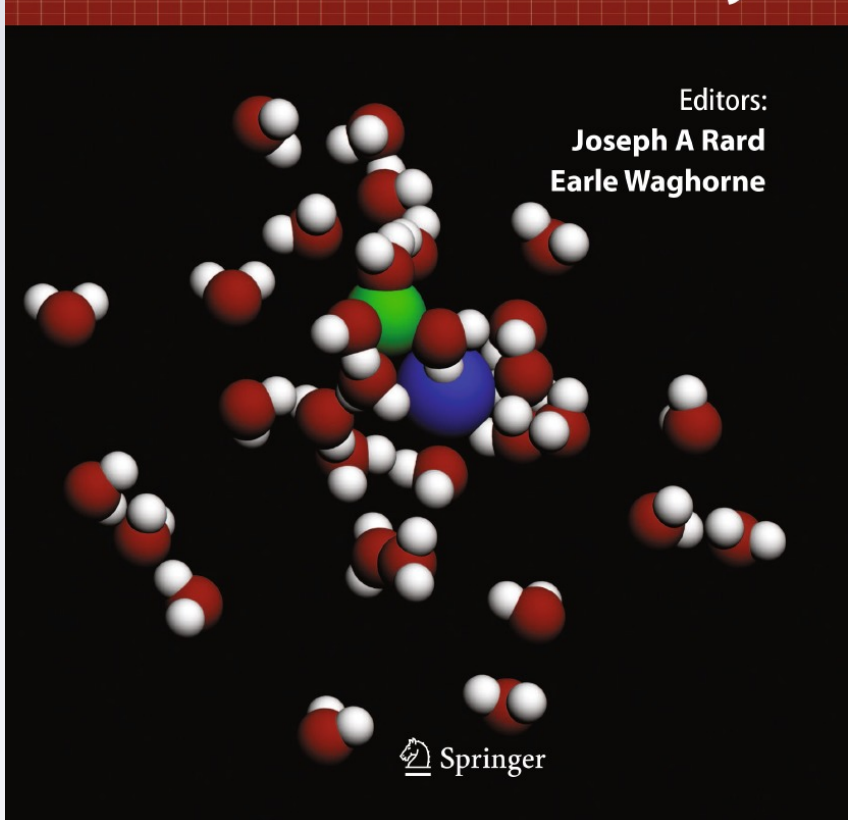


Your article is protected by copyright and all rights are held exclusively by Springer Science+Business Media, LLC, part of Springer Nature. This e-offprint is for personal use only and shall not be self-archived in electronic repositories. If you wish to selfarchive your article, please use the accepted manuscript version for posting on your own website. You may further deposit the accepted manuscript version in any repository, provided it is only made publicly available 12 months after official publication or later and provided acknowledgement is given to the original source of publication and a link is inserted to the published article on Springer's website. The link must be accompanied by the following text: "The final publication is available at link.springer.com". 


\title{
Study of Cadmium Extraction with Aliquat 336 from Highly Saline Solutions
}

\author{
Hans Vigeland Lerum ${ }^{1}$ • Niels Højmark Andersen ${ }^{1}$. Dag Øistein Eriksen ${ }^{1}$. \\ Eddy Walther Hansen ${ }^{1}$. Dirk Petersen ${ }^{1}$. Grethe Wibetoe ${ }^{1}$. Jon Petter Omtvedt ${ }^{1}$
}

Received: 22 August 2017 / Accepted: 25 July 2018 / Published online: 6 August 2018

(c) Springer Science+Business Media, LLC, part of Springer Nature 2018

\begin{abstract}
A large number of model solutions with high ionic strength were synthesised to mimic industrial conditions and were used as a first approach to study Cd extraction in the presence of chloride at high salinity, as experienced in real industrial solutions. The extractant used throughout in this work was Aliquat 336, a quaternary ammonium salt well known to the hydrometallurgical industry. The effects of some selected anions in addition to chloride (i.e., perchlorate, nitrate, and sulfate) were studied. The distribution of cadmium was measured using ${ }^{109} \mathrm{Cd}$ as a tracer. Liquid-scintillation spectroscopy quantified the concentration of ${ }^{109} \mathrm{Cd}$ in both phases. Raman and NMR spectroscopy were employed to gain further insight into the extraction chemistry. A careful analysis of all Cd extraction data showed that within specific windows of the reactant concentrations the chemical reactions could be represented by simplified equations, as discussed thoroughly in the text. Equilibrium constants for the extraction of $\mathrm{CdCl}_{3}^{-}$from chloride and chloride/sulfate media were determined to be $\log _{10} K_{\text {ext }}=4.9 \pm 0.8$ and $\log _{10} K_{\text {ext }}=5.7 \pm 0.5$, respectively. For the nitrate environment, an exchange reaction involving a $\mathrm{LiNO}_{3}$ ion pair is proposed and agrees with the experimental data, but was not proven. ${ }^{14} \mathrm{~N}-\mathrm{NMR}$ and Raman spectroscopy confirmed that the relative affinity of Aliquat 336 for the relevant anions followed the order: perchlorate $>$ nitrate $>$ chloride $>$ sulfate. Finally, ${ }^{14} \mathrm{~N}-\mathrm{NMR}$ enabled the equilibrium constant of the exchange reaction between nitrate and chloride for Aliquat 336 to be determined.
\end{abstract}

Keywords Liquid-liquid extraction $\cdot$ NMR $\cdot$ Raman spectroscopy $\cdot$ Cadmium $\cdot$ High salinity $\cdot$ Radiotracers

\section{Introduction}

Cadmium is a toxic metal that normally occurs at low concentrations in raw materials used for the recovery of metals and fertilizer production. Therefore, low concentrations of this unwanted metal occur in industrial process streams and may disturb the process. It may also end up in the final product in too high a concentration. Environmental and/or health concerns

$\triangle$ Hans Vigeland Lerum hansvl@kjemi.uio.no

1 Department of Chemistry, University of Oslo, Blindern, P.O. Box 1033, 0315 Oslo, Norway 
will then require removal of this cadmium. From an economic point of view, the future appears challenging as tighter legislative control and stricter limits for release from industrial plants are expected. Simultaneously, the quality of available ores is decreasing [1], i.e. exploited minerals will become more complex and contain higher amounts of unwanted elements such as cadmium. This will increase the cost of processing in the future. For these reasons, it will be necessary to enforce efficient control on the amounts of $\mathrm{Cd}$ in many of today's industrial processes. Clearly, effective methods to remove even low concentrations of $\mathrm{Cd}$ from the solutions will be needed.

In the present work, synthetic industrial solutions, i.e. of high salinity, based on chloride media were used as a starting point for studying the extraction chemistry of trace amounts of $\mathrm{Cd}$. The effects of high salinity and the presence of some selected anions (perchlorate, nitrate, and sulfate) were studied. Radioactive Cd-tracer was used to measure the distribution of cadmium. However, selective removal of metal(s) in low concentration(s) from complex and concentrated solutions is challenging. In order to approach this challenge, the mechanics of the extraction processes needs to be better understood. To achieve this, Raman and NMR spectroscopy were combined to gain further insight into other species' influence on the extraction chemistry.

The goal of this work was to study extraction of $\mathrm{Cd}$ from aqueous solutions with high salinity. Aliquat 336 (A336) was chosen as the extractant as its extraction of Cd from chloride media has been studied before and is well known to industry. Safarzadeh et al. have made a comprehensive review of Cd recovery from various sources [2] while various extraction and separation methods were given by Jha et al. [3]. Quaternary amines have been shown to have selectivity for Cd-chloro complexes compared to those of other metal ions that form anionic chloride complexes such as $\mathrm{Hg}(\mathrm{II}), \mathrm{Zn}$ (II), $\mathrm{Cu}$ (II), and $\mathrm{Co}(\mathrm{II})[4,5]$.

A key point in understanding the extraction efficiency for metal ions from brine solutions using the extractant A336 relates to the relative affinity of A336 for the different anions. Changing the anion bound to A336 will change its extraction properties [6]. Subsequently, Cd can be stripped from the organic solution using several different anions (perchlorate, nitrate, sulfate, phosphate) [7]. It has been suggested that $\mathrm{A} 336$ extracts both $\mathrm{CdCl}_{3}^{-}$and $\mathrm{CdCl}_{4}^{2-}$ from solutions with chloride [8]. A336 can be dissolved in several different organic solvents and gives a high extraction of $\mathrm{Cd}$ from chloride environments [9]. Miller and Fuerstenau have proposed that A336 will replace water when $\mathrm{Cd}$ is extracted and that there will be a low concentration of water in the organic solution [10].

In the first part of this work, a radioactive ${ }^{109} \mathrm{Cd}$ tracer, measured using liquid scintillation spectroscopy, was used to determine extraction distribution ratios. Experimental data on the distribution of $\mathrm{Cd}$ between the organic phase and the aqueous phase using different anions, covering a broad range of concentrations, is presented.

In the second part, Raman and NMR spectroscopy are used to study how various anions affect the extraction of $\mathrm{Cd}$, e.g., perchlorate, sulfate and nitrate. These have well known Raman spectra [11, 12] so that tracking the transport of these anions from the aqueous phase to the organic phase is possible. Using NMR, it has been shown that $\mathrm{Cd}$ affects the position and width of the ${ }^{31} \mathrm{P}$ peak when pre- and post-extraction spectra are compared [13]. Thus, NMR spectra provide information on $\mathrm{Cd}$ binding. 


\section{Equilibrium Modelling}

$\mathrm{Cd}(\mathrm{II})$ readily forms aqueous complexes with several different ligands including chloride and sulfate [14]. The kinetics of ligand exchange is fast [15]. Table 1 lists recommended equilibrium constants (when available) and equilibrium reactions, relevant for this work. $K_{i \mathrm{Cl}}$ is the equilibrium constant for consecutive addition of chloride ligands to cadmium.

Note that the fourth consecutive stability constant, $K_{4 \mathrm{Cl}}$, for cadmium-chloro complex formation in Table 1 is rather uncertain [14]. Equation 1 connects the concentration of free $\mathrm{Cd}^{2+}$ with that of any of its corresponding chloro complexes:

$$
\begin{aligned}
& \mathrm{Cd}^{2+}+m \mathrm{Y}^{-q} \rightleftharpoons \mathrm{CdY}_{m}^{(2-m q)} \\
& \log _{10} \beta_{m Y}=\sum_{i=1}^{u} \log _{10} K_{i Y}
\end{aligned}
$$

Equation 2, the more general form of Eq. 1, takes into account anions with a higher charge.

Below, chemical equations relevant for the liquid-liquid extractions studied in this work are listed. Aliquat 336 (without its anion) is represented as A336 in the equations, $m$ and $n$ are positive integers (with $n-2+q m>0$ ) and $q$ is a positive integer representing the (negative) charge of anion Y. Organic phase constituents are indicated with a bar above the species.

The direct anion exchange with A336 in the organic phase when equilibrated with the aqueous phase can be described as

$$
q \overline{\mathrm{A} 336 \cdot \mathrm{Cl}}+\mathrm{Y}^{-q} \rightleftharpoons \overline{\mathrm{A}_{336} \cdot \mathrm{Y}}+q \mathrm{Cl}^{-}
$$

Importantly, this is valid, with or without $\mathrm{Cd}$ being present.

Equation 4 describes the balance between Cd species in the two phases, when A336 is present:

$$
\overline{\mathrm{A}_{3} 36_{n} \cdot \mathrm{CdCl}_{n+2-q m} \mathrm{Y}_{m}} \rightleftharpoons n \overline{\mathrm{A} 336 \cdot \mathrm{Cl}}+\mathrm{Cd}^{2+}+(2-q m) \mathrm{Cl}^{-}+m \mathrm{Y}^{-q}
$$

Equation 5 illustrates the balance between aqueous cadmium-chloro complex species, free chloride, organic cadmium-chloro complexes bound to A336, and A336 bound to chloride:

$$
n \overline{\mathrm{A} 336 \cdot \mathrm{Cl}}+\mathrm{CdCl}_{m}^{(2-m)} \rightleftharpoons \overline{\mathrm{A}_{3} 36_{n} \cdot \mathrm{CdCl}_{n+m}}+(m-2) \mathrm{Cl}^{-}
$$

Table 1 Formation of $\mathrm{Cd}$ chloride and sulphate complexes

\begin{tabular}{lll}
\hline Equation & Equilibrium constant & Label \\
\hline $\mathrm{Cd}^{2+}+\mathrm{Cl}^{-} \rightleftharpoons \mathrm{CdCl}^{+}$ & $\log _{10} K_{1 \mathrm{Cl}}=1.98$ & \\
$\mathrm{CdCl}^{+}+\mathrm{Cl}^{-} \rightleftharpoons \mathrm{CdCl}_{2}$ & $\log _{10} K_{2 \mathrm{Cl}}=0.664$ & \\
$\mathrm{CdCl}_{2}+\mathrm{Cl}^{-} \rightleftharpoons \mathrm{CdCl}_{3}^{-}$ & $\log _{10} K_{3 \mathrm{Cl}}=-0.34$ & \\
$\mathrm{CdCl}_{3}^{-}+\mathrm{Cl}^{-} \rightleftharpoons \mathrm{CdCl}_{4}^{2-}$ & $\log _{10} K_{4 \mathrm{Cl}}=-0.6$ & \\
$\mathrm{Cd}^{2+}+n \mathrm{Cl}^{-} \rightleftharpoons \mathrm{CdCl}_{n}^{(2-n)}$ & $\log _{10} \beta_{n \mathrm{Cl}}=\sum_{i=1}^{n} \log _{10} K_{i \mathrm{Cl}}$ & Eq. 1 \\
$\mathrm{Cd}^{2+}+\mathrm{SO}_{4}^{2-} \rightleftharpoons \mathrm{CdSO}_{4}$ & $\log _{10} K_{1 \mathrm{SO} 4}=2.36$ & \\
$\mathrm{CdSO}_{4}+\mathrm{SO}_{4}^{2-} \rightleftharpoons{\mathrm{Cd}\left(\mathrm{SO}_{4}\right)_{2}^{2-}}$ & $\log _{10} K_{2 \mathrm{SO} 4}=0.96$ & \\
\hline
\end{tabular}

Equilibrium constants measured at an ionic strength of $4.0 \mathrm{~mol} \cdot \mathrm{kg}^{-1}$ are taken from Powell et al. [14] 


\section{Author's personal copy}

Equation 6 relates the organic cadmium-chloro complexes bound to A336 to the more complicated organic complex that might be dominant:

$$
\overline{\mathrm{A} 336_{n} \cdot \mathrm{CdCl}_{n+2-q m} \mathrm{Y}_{m}}+q m \mathrm{Cl}^{-} \rightleftharpoons \overline{\mathrm{A}_{3} 36_{n} \cdot \mathrm{CdCl}_{n+2}}+m \mathrm{Y}^{-q}
$$

By careful addition and/or subtraction of these equations, any organic complex species can be balanced towards any possible complex formed in the water phase. Further, by assuming domination of certain species over the rest, a simple approximate expression involving the phase distribution ratio (explained below) can be obtained. Of course, an exact expression can be derived, but this is not necessary if the dominant species can be pinpointed.

Speciation diagrams for $\mathrm{Cd}$ were calculated as a function of sulfate and chloride concentrations based on data from Table 1 . For these calculations, the chemical activity coefficient was set to 1, i.e., by assuming ideal solutions. Figure 1 shows the speciation when only one anion, either sulfate or chloride, is present.

Figure 2 shows a similar diagram but for a mixture of sulfate and chloride ions. Here it was assumed that mixed ligand species, such as $\mathrm{CdCl}_{2}\left(\mathrm{SO}_{4}\right)^{2-}$, will not occur and that $\mathrm{Li}_{2} \mathrm{SO}_{4}$ and $\mathrm{LiCl}$ are strong electrolytes. If ideal solutions (chemical activity coefficient set to 1) are assumed, then speciation as shown in panel A results. A more realistic calculation that takes into account chemical activity is shown in panel B. Here, the chemical activities were calculated using Pitzer equations according to [16-19]. Clearly, the deviations from ideal solutions will increase with the ionic concentration. It is important to note that in both simulations (see Fig. 2) there is a drastic shift in the dominant species of $\mathrm{Cd}$ at approximately $1 \mathrm{~mol} \cdot \mathrm{kg}^{-1}$ sulfate. However, if the sulfate concentration is below $1 \mathrm{~mol} \cdot \mathrm{kg}^{-1}$ then cadmium chloride complexes will dominate. Details about the calculation are given in Appendix B.

The curves presented in Figs. 1 and 2 aid in predicting at which concentrations the extraction will be most efficient. As there are several different possible species present, a general equilibrium expression for extraction of cadmium with $\mathrm{A} 336 \cdot \mathrm{Cl}$ is presented. This is given by Eq. 4, where $n$ and $m$ are integers satisfying certain constraints $(n+m q>2$ and $1 \leq n)$ and hence define the stoichiometric constants of the finite number of possible reactions.
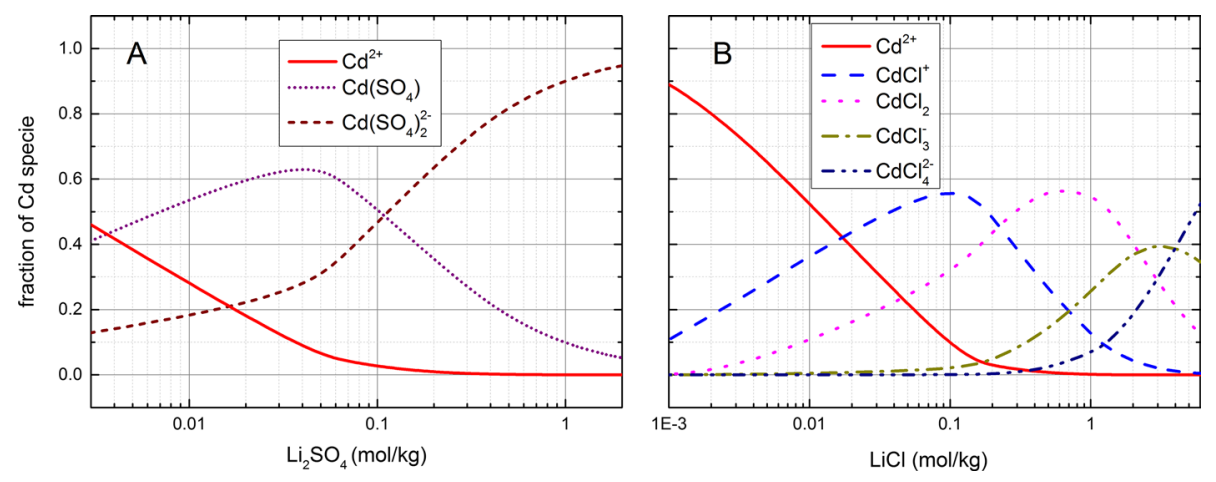

Fig. 1 Panel A shows the speciation of Cd with sulfate estimated using Eqs. B3 and B5 (Appendix B). Panel $\mathbf{B}$ is the speciation of Cd with chloride using Eqs. B2 and B4 (Appendix B). For both panels, equilibrium constants from Table 1 were used and the activity coefficients were set to unity 


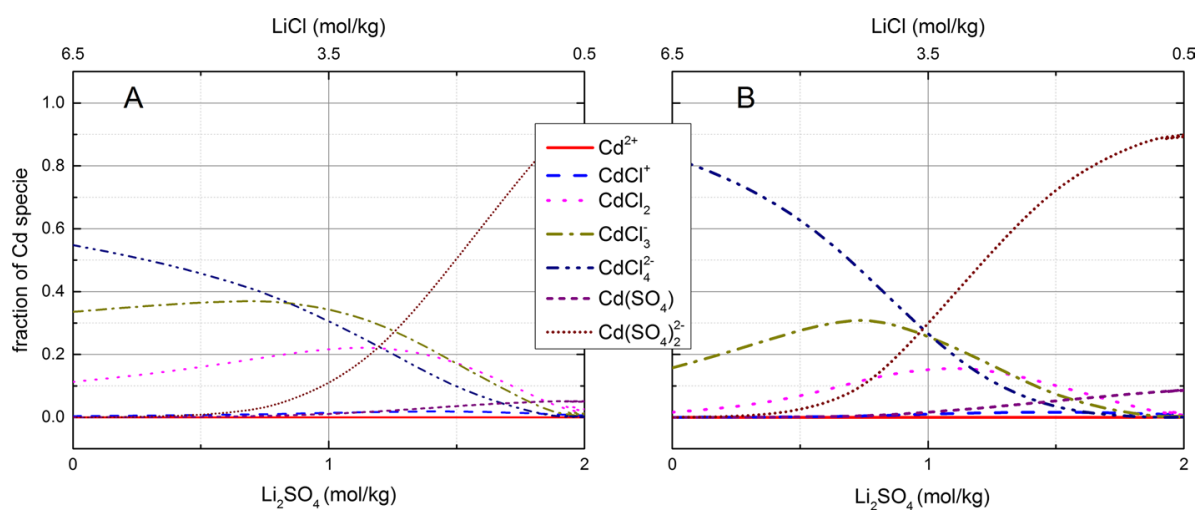

Fig. 2 Speciation of $\mathrm{Cd}$ in a mixture of sulfate and chloride ions. Panel $\mathbf{A}$ shows results for ideal solutions with activity coefficients set to unity. Here the speciation was calculated using Eqs. B4, B5 and B6 in Appendix B. Panel B shows results when chemical activities are taken into account and calculated with the Pitzer equations [16-19]

The distribution ratio $(D)$ of $\mathrm{Cd}$ in the liquid-liquid extraction is defined as the total concentration of all $\mathrm{Cd}$ species in the organic phase divided by that of all $\mathrm{Cd}$ species in the aqueous phase:

$$
D=\frac{\left[\overline{\mathrm{Cd}_{\mathrm{org}}}\right]}{\left[\mathrm{Cd}_{\mathrm{aq}}\right]}
$$

$D$ can be inserted into Eq. 5, with the assumption that the $D$ value is limited to one species dominating in the aqueous phase and one species dominating in the organic phase, leading to:

$$
K_{\mathrm{ex}}=\frac{D}{[\overline{\mathrm{A} 336 \cdot \mathrm{Cl}}]^{n}\left[\mathrm{Cl}^{-}\right]^{2-m}}
$$

Plotting $\log _{10} D$ against $\log _{10}$ of the variables (e.g. $\left[\mathrm{Cl}^{-}\right]$) will give a slope that should represent the stoichiometry of the reaction. If several species are present in the solution, then the extraction data can be used to determine the dominant species interacting with the extractant. Assumption of a dominant cadmium species can then be used to estimate an equilibrium value of the extraction.

\section{Experimental Procedure}

\subsection{Chemicals}

Toluene was selected as organic solvent for the liquid-liquid extraction experiments even though it is not used in industrial processes due to its carcinogenic and flammable nature. The reason for using it in this work is that it is well defined and "pure", contrary to other industrial solvents that frequently are a mixture of different organic compounds. More important was the fact that toluene will not quench the light transfer process of the 
liquid-scintillation spectroscopy measurements. Thus, high quality spectra from ${ }^{109} \mathrm{Cd}$ could be obtained. In addition, toluene has a well-known Raman spectrum with clear sharp signals.

Toluene used for the extraction experiments was of technical grade (from Univar) while p.a. grade quality (from VWR) was used for the Raman spectroscopy measurements. LiCl (99\%), $\mathrm{CdCl}_{2}$ (99.5\%), $\mathrm{Li}_{2} \mathrm{SO}_{4}(99 \%), \mathrm{NaClO}_{4}(99.0 \%)$, and $\mathrm{HCl}$ (37\% fuming) were all of p.a. grade. Due to the hygroscopic nature of $\mathrm{LiNO}_{3}(99 \%)$, a saturated solution was made. The solution was gently stirred for a couple of days to ensure equilibrium. The saturated aqueous phase was used in the experiments. A carrier free, aqueous solution of ${ }^{109} \mathrm{Cd}$ was supplied by Ecker and Ziegler. Aliquat 336 (assay 88-90\%) was supplied by Alfa Aesar and used as supplied.

The liquid scintillator cocktail was Ultima Gold XR, produced by Packard and used as supplied.

\subsection{Liquid-Liquid Extraction}

Extractions were performed at ambient temperature $\left(21 \pm 2{ }^{\circ} \mathrm{C}\right)$ using equal volumes of the organic and aqueous phases. The phases were prepared by adding the radioactive tracer ${ }^{109} \mathrm{Cd}$ to the inactive aqueous Cd-solution of selected composition and the A336 was diluted with toluene. The two phases were then mixed and shaken for at least 25 min using a vortex shaker. Measurements of $D$ values at various shaking times had beforehand shown that $20 \mathrm{~min}$ was sufficient to obtain equilibrium for the distribution of $\mathrm{Cd}$ between the two phases. Separation between the aqueous and the organic phases was performed by centrifugation at $4000 \mathrm{rpm}$ for a minimum of $2 \mathrm{~min}$.

Subsequently, the equal volumes of the two phases were sampled and transferred to $20 \mathrm{~mL}$ scintillation vials. To avoid organic entrainment in the aqueous phase (the bottom one), the organic and the interphase were removed before sampling of the aqueous phase.

Table 2 shows the concentrations selected for the four systems studied. System 1 was designed to determine the extraction with chloride as the only anion present. System 2 was designed to study the impact of increase in ionic strength on the extraction using $\mathrm{LiNO}_{3}$. Systems 3 and 4 used $\mathrm{Li}_{2} \mathrm{SO}_{4}$ and $\mathrm{NaClO}_{4}$, respectively. $\mathrm{LiCl}$ was used to vary the chloride concentration for all four systems.

All experiments were performed at a minimum in triplicate.

\subsection{Liquid Scintillation Spectroscopy}

Scintillation spectroscopy with a Hidex 900 liquid scintillator spectrometer was used to measure the conversion-electron spectrum from the $88 \mathrm{keV}$ transition following decay of ${ }^{109} \mathrm{Cd}$. The amount of ${ }^{109} \mathrm{Cd}$ in each sample was then determined by integrating the appropriate peak in the spectrum. An efficiency calibration, measuring quenching of the liquid scintillation process as $\mathrm{s}$ function of the position of the $88 \mathrm{keV}$ electron conversion line of ${ }^{109 m} \mathrm{Ag}$ [20], was determined by measuring the shift in peak position when $\mathrm{CCl}_{4}$ was added as quencher [21].

The spectra were analyzed using the peak-fit function in the Origin software package version 9.1 from OriginLab Corporation. $D$ values were determined provided the peak in the spectra for both phases had an area of at least 10 times as high as the background. 


\section{Author's personal copy}

Table 2 The aqueous systems used for Cd extraction with Aliquat 336 in toluene as an extractant

\begin{tabular}{llllll}
\hline System \# & {$[\mathrm{LiCl}] \mathrm{mol} \cdot \mathrm{kg}^{-1}$} & $\begin{array}{l}\text { Ionic strength } \\
\mathrm{mol} \cdot \mathrm{kg}^{-1}\end{array}$ & Matrix salt & Matrix ion mol $\cdot \mathrm{kg}^{-1}$ & $\mathrm{~A} 336 \mathrm{mmol} \cdot \mathrm{kg}^{-1}$ \\
\hline 1 & $0.01-5$ & $0.01-5$ & - & - & $0.6-750$ \\
2 & $0.1-5$ & 6.5 & $\mathrm{LiNO}_{3}$ & $1.5-6.4$ & $1-20$ \\
3 & $0.01-1$ & 6.5 & $\mathrm{Li}_{2} \mathrm{SO}_{4}$ & $1.8-2.2$ & $1-10$ \\
4 & $0.1-2$ & 7 & $\mathrm{NaClO}_{4}$ & $4.5-6.8$ & $1-10$ \\
\hline
\end{tabular}

All solutions have $0.1 \mathrm{mmol} \cdot \mathrm{kg}^{-1} \mathrm{Cd}$ and $0.1 \mathrm{mmol} \cdot \mathrm{kg}^{-1} \mathrm{HCl}$

\subsection{Raman Spectroscopy}

The anions under consideration in this study are characterized by having $T_{\mathrm{d}}\left(\mathrm{ClO}_{4}^{-}\right.$, $\left.\mathrm{SO}_{4}^{2-}\right)$ or $D_{3 \mathrm{~h}}\left(\mathrm{NO}_{3}^{-}\right)$symmetry, with the exception of $\mathrm{HSO}_{4}^{-}$that is expected only to have $C_{s}$ symmetry if any at all. The vibrational modes of the two first symmetry classes fall into the groups $\left(\Gamma=A_{1}+E+2 T\right)$ and $\left(\Gamma=A_{1}{ }^{\prime}+A_{2}{ }^{\prime}+2 E^{\prime}\right)$, respectively, while the vibrational modes of $\mathrm{HSO}_{4}^{-}$belong to the group $\left(\Gamma=8 A^{\prime}+4 \mathrm{~A}^{\prime \prime}\right)$. However, what these anions have in common is that their most intense Raman active modes $\left(A_{1}, A_{1}{ }^{\prime}\right.$ and $\left.A^{\prime}\right)$ are nondegenerate and strongly polarized. Hence, the wavenumber positions of these Raman bands, characterized by being 'breathing' modes, all appear as single bands unless they fall exactly at the same place as Raman bands of other species. Therefore, detection of these in a Raman spectrum will serve as an efficient tool for identification of specific anions, both in the water and the organic phases. In principle, infrared spectroscopy can provide similar information, but here band degeneracies and possible splitting may complicate the picture, and for the case of aqueous solutions, the most interesting spectral ranges would be very difficult to deal with because of strong absorption. The 'breathing mode' Raman bands contain valuable information about local molecular surroundings, reflected in characteristics of the bandwidths as well as their absolute position and intensities. Molecular association between anions and species can be revealed by studying model solutions [11, 12, 22].

The Raman spectra were recorded with a Horiba Jobin-Yvon T64000 multichannel spectrometer adjusted to work in the triple subtractive mode using three gratings with 1800 rules $/ \mathrm{mm}$. The liquid samples were kept in glass vials illuminated in a $90^{\circ}$ macro-chamber setup at room temperature $\left(20^{\circ} \mathrm{C}\right)$. The light source for excitation was a Spectra-Physics Millennia Pro 12SJ, Nd: $\mathrm{YVO}_{4}$ laser emitting $200 \mathrm{~mW}$ at $532.1 \mathrm{~nm}$, leading to a power of $\sim 40 \mathrm{~mW}$ at the sample. Both the entrance and the second intermediate slits of T64000 were set to $300 \mu \mathrm{m}$. Scattered light was collected by a BIDD CCD cooled to $-125{ }^{\circ} \mathrm{C}$. These settings lead to a spectral width of $6.8 \mathrm{~cm}^{-1}$. No attempt was made to control polarization within these runs. The wavenumber position was calibrated against paracetamol [23].

Table 3 lists the Raman samples with concentration and composition. The organic phases have been in contact with the aqueous phases as described in Sect. 3.2. Aqueous phases were measured without contact with the organic phase. 


\section{Author's personal copy}

\subsection{NMR Spectroscopy}

${ }^{14} \mathrm{~N}-\mathrm{NMR}$ can be used to identify the nitrogen species present in both the organic and the aqueous phases. For instance, the chemical shift $\delta$ at $-320 \mathrm{ppm}$ is assigned to the quaternary nitrogen in A336, which is only present in the organic phase. Likewise, the ${ }^{14} \mathrm{~N}$-chemical shift at $\delta=0$ is assigned to the nitrate anion in the aqueous phase as well as to the nitrate anion associated with A336 in the organic phase. An underscore will be used to specify which nitrogen is being referred to by writing $\overline{\underline{\mathbf{A 3 3 6}} \cdot \mathbf{N O}_{3}}$ or $\overline{\mathbf{A 3 3 6} \cdot \mathbf{N O}_{3}}$ (the bar above the compound indicates that it is present in the organic phase).

Since the ${ }^{14} \mathrm{~N}$-signal intensity is directly proportional to the number of ${ }^{14} \mathrm{~N}$ nuclei,

$$
I_{0}[\overline{\overline{\mathrm{A} 336 \cdot \mathrm{Cl}}}]_{0}=I([\overline{\mathrm{A} 336 \cdot \mathrm{Cl}}])+I\left(\left[\overline{\overline{\mathrm{A} 336} \cdot \mathrm{NO}_{3}}\right]\right)
$$

where $I$ denotes the ${ }^{14} \mathrm{~N}-\mathrm{NMR}$ signal intensity of A336 and $I_{0}(\overline{\mathrm{A} 336 \cdot \mathrm{Cl}})$ represents the initial NMR signal intensity of $\mathrm{A} 336 \cdot \mathrm{Cl}$ within the organic phase, before any extraction has taken place.

Since the ${ }^{14} \mathrm{~N}-\mathrm{NMR}$ chemical shift of $\mathrm{NO}_{3}^{-}$is significantly different from the chemical shift of $\mathrm{A} 336 \cdot \mathrm{Cl}$, it is possible to quantitatively differentiate between $\overline{\mathrm{A} 336 \cdot \mathrm{Cl}}$ and $\overline{\mathrm{A} 336 \cdot \mathrm{NO}_{3}}$. The equilibrium constant $K$ for the ion exchange reaction between $\mathrm{A} 336 \cdot \mathrm{Cl}$ and nitrate is:

$$
K=\frac{\left.\overline{\mathrm{A} 336 \cdot \mathrm{NO}_{3}}\right]\left[\mathrm{Cl}^{-}\right]}{[\overline{\mathrm{A} 336 \cdot \mathrm{Cl}}]\left[\mathrm{NO}_{3}^{-}\right]}
$$

Hence, combining Eqs. 9 and 10 and noting that $\left[\overline{\mathrm{A} 336 \cdot \mathrm{NO}_{3}}\right]_{0}=0$ and $[\overline{\mathrm{A} 336 \cdot \mathrm{Cl}}]_{0} \ll\left[\mathrm{LiNO}_{3}\right]_{0}$ (see Table 4 ) yields:

$$
f_{\mathrm{eq}}=\frac{\left[\overline{\mathrm{A} 336 \cdot \mathrm{NO}_{3}}\right]_{\mathrm{eq}}}{[\overline{\mathrm{A} 336 \cdot \mathrm{Cl}}]_{0}}=\frac{I \overline{\left(\underline{\mathrm{NO}_{3}^{-}}\right)}}{I\left(\underline{\underline{\mathrm{A} 336} \cdot \mathrm{Cl}+\underline{\mathrm{A} 336} \cdot \mathrm{NO}_{3}}\right)}=\frac{K}{K+\frac{[\mathrm{LiCl}]_{0}}{\left[\mathrm{LiNO}_{3}\right]_{0}}}
$$

Table 3 List of Raman samples

\begin{tabular}{lllll}
\hline Sample & Phase measured & Org. conc. mol $\cdot \mathrm{kg}^{-1}$ & Aq. conc. & \\
\cline { 5 - 5 } & & & $\mathrm{mol} \cdot \mathrm{kg}^{-1}$ & $\mathrm{~mol} \cdot \mathrm{kg}^{-1}$ \\
\hline System 1 & Org. & $0.25 \mathrm{~A} 336$ & & \\
System 2 & Org. & $0.25 \mathrm{~A} 336$ & $0.09 \mathrm{LiCl}$ & $6.41 \mathrm{LiNO}_{3}$ \\
System 3 & Org. & $0.25 \mathrm{~A} 336$ & $0.01 \mathrm{LiCl}$ & $2.17 \mathrm{Li}_{2} \mathrm{SO}_{4}$ \\
System 4 & Org. & $0.25 \mathrm{~A} 336$ & $0.12 \mathrm{LiCl}$ & $6.81 \mathrm{NaClO}_{4}$ \\
System 2 & Aq. & & $0.09 \mathrm{LiCl}$ & $6.41 \mathrm{LiNO}_{3}$ \\
System 4 & Aq. & & $0.12 \mathrm{LiCl}$ & $6.81 \mathrm{NaClO}_{4}$ \\
\hline
\end{tabular}

Samples with both organic (org.) and aqueous (aq.) components, Org. was contacted with written Aq. phases 


\section{Author's personal copy}

Table 4 Sample characteristics of the three solutions studied by ${ }^{14} \mathrm{~N}-\mathrm{NMR}$

\begin{tabular}{llll}
\hline Sample & {$\left[\mathrm{Cl}^{-}\right]$} & {$\left[\mathrm{NO}_{3}^{-}\right]$} & $f_{\mathrm{eq}}=\frac{\left[\overline{\mathrm{A} 336 \cdot \underline{\underline{\mathrm{NO}}}]_{\mathrm{eq}}}\right.}{[\underline{\underline{\mathrm{A} 336 \cdot \mathrm{Cl}}}]_{0}}$ \\
& $\mathrm{~mol} \cdot \mathrm{kg}^{-1}$ & $\mathrm{~mol} \cdot \mathrm{kg}^{-1}$ & \\
\hline 1 & 5.00 & 1.50 & 1.03 \\
2 & 1.01 & 5.50 & 0.98 \\
3 & 0.09 & 6.41 & 0.86 \\
\hline
\end{tabular}

The initial concentration $[\overline{\mathbf{A 3 3 6 \cdot \mathbf { C l }}}]_{0}$ was the same in all samples and equal to $0.1 \mathrm{~mol} \cdot \mathrm{kg}^{-1}$

here $f_{\text {eq }}$ shows how much of the total $\overline{A 336 \cdot \mathrm{Cl}}$ has reacted with nitrate and formed $\overline{A 336 \cdot \mathrm{NO}_{3}}$. The $[\overline{A 336 \cdot \mathrm{Cl}}]_{0},[\mathrm{LiCl}]_{0}$ and $\left[\mathrm{LiNO}_{3}\right]_{0}$ represent the initial concentrations of $\overline{\mathrm{A} 336 \cdot \mathrm{Cl}}, \mathrm{LiCl}$ and $\mathrm{LiNO}_{3}$, before any extraction was initiated, and $I$ describes the ${ }^{14} \mathrm{~N}-\mathrm{NMR}$ signal intensity.

${ }^{14} \mathrm{~N}-\mathrm{NMR}$ spectra were acquired using a Bruker DRX 500 spectrometer operating at $11.74 \mathrm{~T}$, equipped with a $5 \mathrm{~mm} \mathrm{BBO}\left(\mathrm{BB} /{ }^{1} \mathrm{H} /{ }^{2} \mathrm{H}\right)$ probe with Z-gradient. 5 vol\% deuterium oxide (D 99.9\%, Cambridge Isotope Laboratories, Inc.) was added to the aqueous phases and 5 vol\% benzene- $\mathrm{d}_{6}$ (D 99.6\%, Cambridge Isotope Laboratories, Inc.) to the organic phases in order to achieve lock. Spectra were recorded using a single-pulse program with a RF-pulse duration of $13.25 \mu \mathrm{s}\left(90^{\circ}\right.$ pulse), a repetition time of $5.0 \mathrm{~s}$ between pulses and an acquisition time of $1.5 \mathrm{~s}$. An exponential apodization of $10 \mathrm{~Hz}$ and a zero filling from $32 \mathrm{~K}$ to $128 \mathrm{~K}$ were applied before the Fourier transformation. The frequency spectrum was base-line corrected before further analysis. All spectra were acquired at $25{ }^{\circ} \mathrm{C}$. The intensity (integrated area) of an NMR peak was determined by fitting certain spectral functions (a linear combination of a Gaussian and a Lorentzian peak function) to the observed NMR spectra by a non-linear least-squares technique.

\section{Experimental Results}

Experimental data is provided in this chapter. First, the general results of the extraction experiments with the Cd radiotracer will be presented. Then the NMR and Raman results that provide insight into the speciation of the extraction chemistry will be given. A detailed discussion of the results from the different extraction systems will be presented in Sect. 5 .

\subsection{Liquid-Liquid Extraction}

Liquid-liquid extraction experiments were performed at several aqueous conditions as defined in Table 2 (systems 1-4). Figure 3 illustrates how the $D$ values for extraction of Cd from chloride solutions vary for:

- System 1; with no other anions present (panel A)

- System 2; in the presence of nitrate (panel B), and 


\section{Author's personal copy}
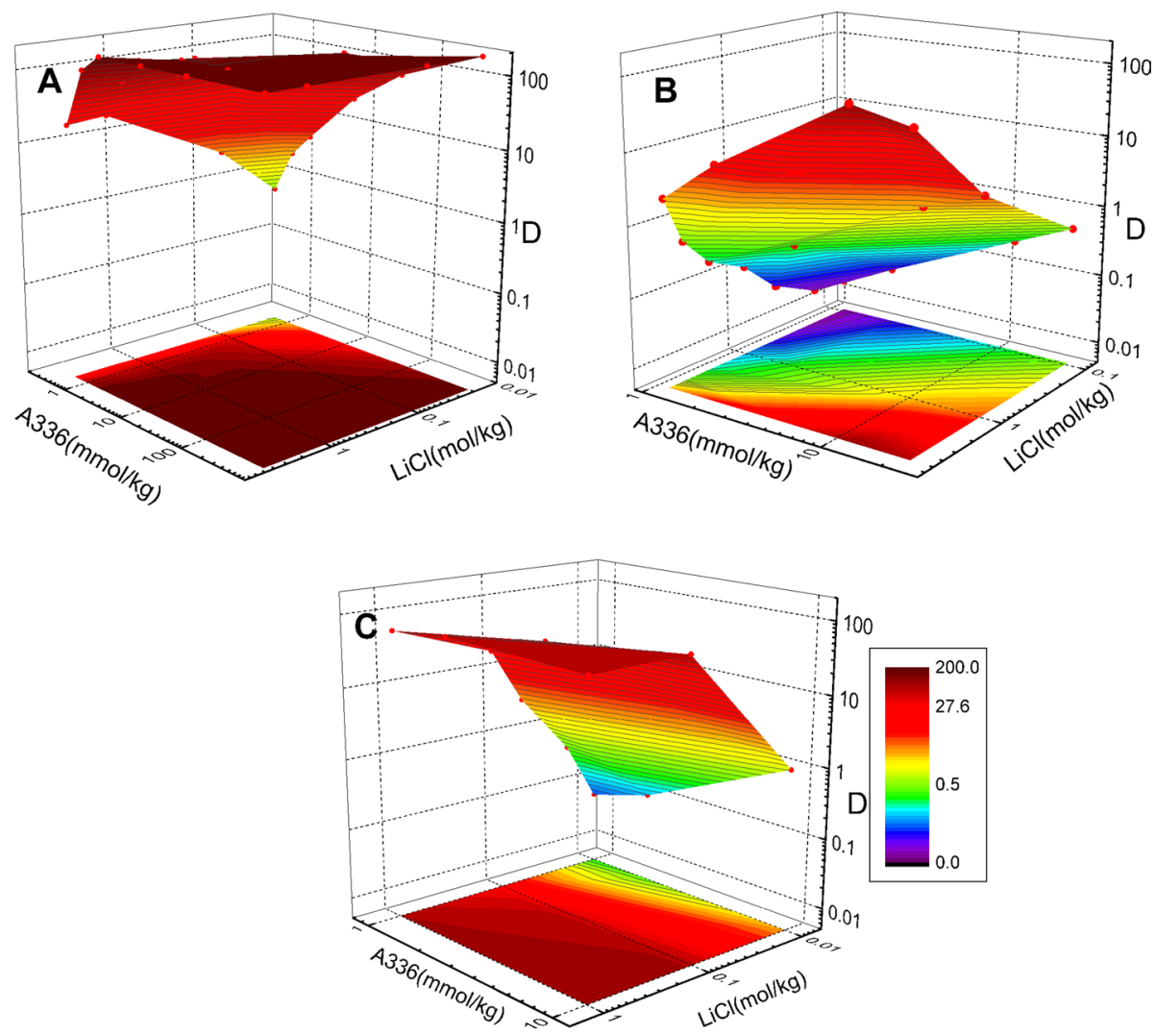

Fig. 3 Combined 3D and contour plots fitted to the measured $D$-values as functions of the various aqueous conditions for extraction of $\mathrm{Cd}$ into toluene using Aliquat 336 as extractant. Panel A shows extraction when chloride is used to vary the ionic strength between 0.02 and $5 \mathrm{~mol} \cdot \mathrm{kg}^{-1}$. Panel $\mathbf{B}$ shows the extraction when $\mathrm{LiNO}_{3}$ is used to keep the ionic strength equal to $6.5 \mathrm{~mol} \cdot \mathrm{kg}^{-1}$ and $\mathrm{LiCl}$ is varied from 0.1 to $5 \mathrm{~mol} \cdot \mathrm{kg}^{-1}$. Panel $\mathbf{C}$ shows the extraction of $\mathrm{Cd}$ where $\mathrm{Li}_{2} \mathrm{SO}_{4}$ is used to keep the ionic strength constant at $6.5 \mathrm{~mol} \cdot \mathrm{kg}^{-1}$ and the $\mathrm{LiCl}$ concentration is varied from 0.01 to $1 \mathrm{~mol} \cdot \mathrm{kg}^{-1}$

- System 3; in the presence of sulfate (panel C).

The surfaces in Fig. 3 are computer fitted to the experimentally measured $D$ values, which are tabulated in Appendix A. System 4 was not plotted, as the association between perchlorate and A336 was stronger than for the $\mathrm{Cd}$-chloro complexes and therefore extraction was not viable.

As seen in Fig. 3, adding other anions such as nitrate or sulfate perturbs the extraction behaviour quite significantly. This is especially noticeable for nitrate. The reason is most likely because either the extractant is saturated with species having stronger affinity to the A336 extractant than Cd chloro-complexes, or a different and less extractable Cd complex is created.

In order to determine exactly in which way nitrate and sulfate influence the extraction, Raman and NMR spectroscopy were used to gain more detailed insight into the systems. Below, the details of the Raman and NMR spectroscopy will be presented. 
Afterwards, using the Raman and NMR results, a detailed discussion of the extraction data is provided.

\subsection{Raman Spectroscopy}

Raman spectroscopy can identify specific anions both in aqueous and organic phase. For the present study the detectable anions of interest are $\mathrm{ClO}_{4}^{-}, \mathrm{SO}_{4}^{2-}$, and $\mathrm{NO}_{3}^{-}$. Below, the experimental results from the Raman spectroscopy are presented.

Figure 4 shows the Raman spectra of nitrate (panel A) and perchlorate (panel B) in the organic and the aqueous phase.

For water, the spectral range from 850 to $1100 \mathrm{~cm}^{-1}$ is Raman silent. Toluene has a strong $\mathrm{A}_{1}$ band at $1003.6 \mathrm{~cm}^{-1}$ and a medium intensity band following the same symmetry at $1030.6 \mathrm{~cm}^{-1}$. In water, the $\mathrm{A}_{1}{ }^{\prime}$ stretching band of nitrate falls at $1049 \mathrm{~cm}^{-1}$ as expected, but is found to be shifted to $1040 \mathrm{~cm}^{-1}$ in the organic phase. Comparison with the $\mathrm{A} 336 \cdot \mathrm{Cl}$ spectrum leaves no doubt that this is specific for nitrate occurring in some form. For the perchlorate experiment (Fig. 4, panel B), the picture is similar, but the shift is smaller. Here the $\mathrm{A}_{1}$ mode of perchlorate in the organic phase appears at $930 \mathrm{~cm}^{-1}$, a clear sign that anion exchange with the organic phase by A336 again has happened. However, the observed shift is smaller than for nitrate, as the perchlorate $A_{1}$ band falls at $936 \mathrm{~cm}^{-1}$ in the aqueous phase. The $A_{1}$ bandwidths of perchlorate and nitrate both decrease upon transfer to the organic phase. The decrease is most prominent for perchlorate. An explanation for this could be that the affinity of perchlorate to A336 is stronger and better defined than for nitrate, and that perchlorate is less susceptible to changes in molecular surroundings in the aqueous phase. Also, a weaker binding of nitrate to A336 will lead to an increase in the number of possible conformations and, hence, a larger spectral broadening. Experiments with sulfate solutions were carried out, but here no $A_{1}$ peak could be detected in the Raman spectra of the organic phases. This indicates that the affinity of sulfate to A336 is very weak, or at least so weak that the concentration remains below the detection limit of Raman spectroscopy, which under this framework is assumed to be around $1 \mathrm{mmol} \cdot \mathrm{kg}^{-1}$. A qualitative estimate of the
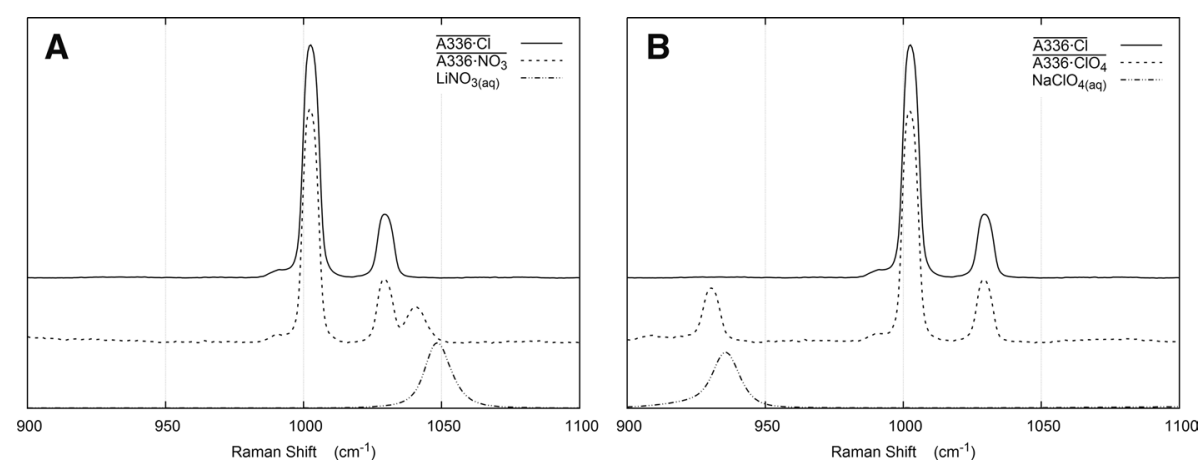

Fig. 4 Panel A: the Raman spectrum of toluene containing only Aliquat 336 (A336) (full line), the organic phase in an equilibrium mixture with $\overline{\mathbf{A 3 3 6} \cdot \mathbf{C l}}$ and $\mathbf{L i N O}_{3}$ nitrate (dotted) revealed by the $\mathrm{A}_{1}{ }^{\prime}$ band at $1040 \mathrm{~cm}^{-1}$, and the spectrum of aqueous $\mathrm{LiNO}_{3}$ (dot dash). Panel $\mathbf{B}$ : the Raman spectrum of toluene containing only Aliquat 336 (A336) (full line), the organic phase in an equilibrium mixture with $\overline{\mathbf{A 3 3 6} \cdot \mathbf{C l}}$ and $\mathrm{NaClO}_{4}$ (dotted) showing the $\mathrm{A}_{1}$ mode of perchlorate at $930 \mathrm{~cm}^{-1}$ and finally the spectrum of aqueous $\mathrm{NaClO}_{4}$ (dot dash) 
sulfate band position, based on the nitrate and perchlorate properties, indicates that the $A_{1}$ band in the organic phase should be found $5-10 \mathrm{~cm}^{-1}$ below $981 \mathrm{~cm}^{-1}$ that is typical for aqueous solutions.

\subsection{NMR Spectroscopy}

${ }^{14} \mathrm{~N}-\mathrm{NMR}$ can be used to study the extraction of nitrate between the phases. This was explored to gain insight into the extraction systems presented in this work. The experimental details from the NMR experiments are presented below.

Figure 5 presents the ${ }^{14} \mathrm{~N}-\mathrm{NMR}$ spectra for:

- organic phase containing only $\mathrm{A} 336 \cdot \mathrm{Cl}$,

- aqueous phase in an equilibrium mixture of $\mathrm{A} 336 \cdot \mathrm{Cl}$ and $\mathrm{LiNO}_{3}$, and

- organic phase in an equilibrium mixture of $\mathrm{A} 336 \cdot \mathrm{Cl}(\mathrm{org})$ and $\mathrm{LiNO}_{3}(\mathrm{aq})$.

As can be inferred from Fig. 5, $\overline{\mathrm{A} 336} \cdot \mathrm{Cl}$ reveals two distinct peaks in the ${ }^{14} \mathrm{~N}-\mathrm{NMR}$ spectrum (green broken line), a narrow peak at a chemical shift $\delta \approx-320$ ppm with a halfwidth of less than $35 \mathrm{~Hz}$ and a much broader peak at $\delta \approx-330 \mathrm{ppm}$ with a half width of the order of $400 \mathrm{~Hz}$. The narrow peak is the response from A336 and the broad peak is the response of triethylamine used as a reference.

Generally, the ${ }^{14} \mathrm{~N}-\mathrm{NMR}$ spectrum of the aqueous phase (blue dotted curve) reveals only a single peak, which is consistent with the presence of $\mathrm{NO}_{3}^{-}$. No ${ }^{14} \mathrm{~N}$-peak from $\mathrm{A} 336 \cdot \mathrm{Cl}$ or $\mathrm{NO}_{3}$ is observed and this simply confirms the lack of any significant solubility of $\mathrm{A} 336$ in the aqueous phase. In contrast, the ${ }^{14} \mathrm{~N}-\mathrm{NMR}$ spectrum (red solid curve) of the organic phase, which was formed after a thorough mixing of the organic solution, $\overline{\mathrm{A} 336 \cdot \mathrm{Cl}}$ and the aqueous solution $\left(\mathrm{LiNO}_{3}\right)$, revealed the presence of both $\overline{\mathrm{A} 336 \cdot \mathrm{Cl}}$ and $\overline{\mathrm{A} 336 \cdot \mathrm{NO}_{3}}$. The presence of $\overline{\mathrm{A} 336 \cdot \mathrm{Cl}}$ was indirectly confirmed by noting the difference between the

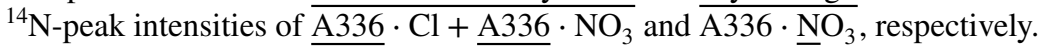

Fig. $5{ }^{14} \mathrm{~N}-\mathrm{NMR}$ spectra of toluene containing only $\overline{\mathbf{A 3 3 6} \cdot \mathbf{C l}}$ (green broken line), the aqueous phase in an equilibrium mixture of $\overline{\mathbf{A 3 3 6} \cdot \mathbf{C l}}$ and $\mathrm{LiNO}_{3}$ (blue dotted line) and the organic phase in the equilibrium mixture of $\overline{\mathbf{A 3 3 6} \cdot \mathbf{C l}}$ and $\mathrm{LiNO}_{3}$ (red solid line) (Color figure online)

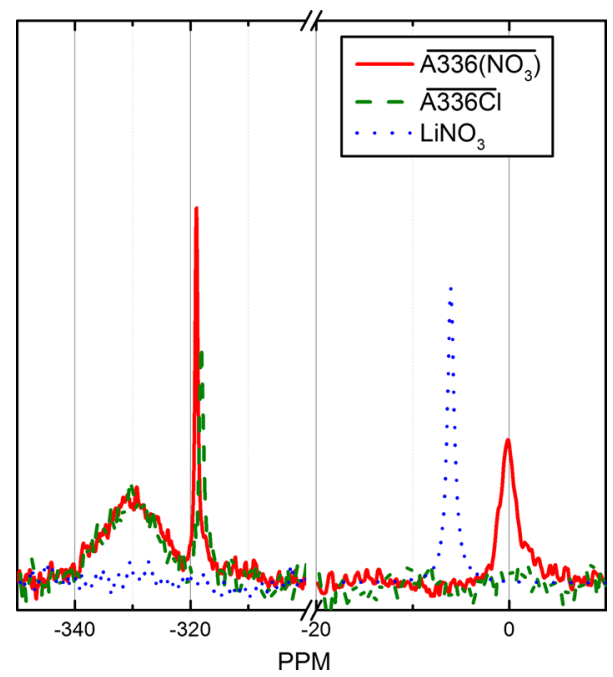


Moreover, the ratio $\left[\overline{\mathrm{A} 336 \cdot \underline{\mathrm{NO}}_{3}}\right]_{\mathrm{eq}} /[\overline{\mathrm{A} 336 \cdot \mathrm{Cl}}]_{0}$ is easily determined from the ${ }^{14} \mathrm{~N}-\mathrm{NMR}$ spectrum of the organic phase as it is simply represented by the signal intensity ratio between the ${ }^{14} \mathrm{~N}-\mathrm{NMR}$ resonance peak at $\delta \approx 0$ and the resonance peak within the region $-320 \mathrm{ppm}<\delta<-310 \mathrm{ppm}$ (Fig. 5), at equilibrium. Table 4 summarizes the sample characteristics of the three samples investigated by ${ }^{14} \mathrm{~N}-\mathrm{NMR}$. A plot of $\left[\overline{\mathrm{A} 336 \cdot \underline{\mathrm{NO}_{3}}}\right]_{\mathrm{eq}} /[\overline{\mathrm{A} 336 \cdot \mathrm{Cl}}]_{0}$ against $[\mathrm{LiCl}]_{0} /\left[\mathrm{LiNO}_{3}\right]_{0}$ is presented in Fig. 6. The solid curve represents the non-linear least-squares fit of Eq. 11 to the observed data and results in an equilibrium value of $K_{\text {ex } 0}=(18 \pm 5)$. The large uncertainty (28\%) stems partly from the large distance between the second and third data point, but also from the uncertainty in each data point (15\%).

Although the number of data points is small and the relative error is high, it can be concluded that the association between nitrate and A336 is stronger than the corresponding association between $\mathrm{Cl}^{-}$and A336. This is supported by previous work [24]. For instance, by considering extraction of nitrate and applying Eq. 11 with $K_{\mathrm{ex} 0}=18 \pm 5$ $\left(\log _{10} K_{\mathrm{ex} 0}=1.26 \pm 0.12\right)$ on a solution containing initially only $\overline{\mathrm{A} 336 \cdot \mathrm{Cl}}$ and $\mathrm{NO}_{3}^{-}$with $\left[\overline{\mathrm{A} 336 \cdot \mathrm{Cl}}_{0}=\left[\mathrm{NO}_{3}^{-}\right]_{0} \gg[\mathrm{A} 336 \cdot \mathrm{Cl}]\right.$, it can be shown that more than $90 \%$ of $\overline{\mathrm{A} 336 \cdot \mathrm{Cl}}$ will be converted to $\overline{\mathrm{A} 336 \cdot \mathrm{NO}_{3}}$.

\section{Discussion}

In this chapter, the three extraction systems that were measured and presented in Fig. 3 will be discussed in detail, using the results from the NMR and Raman spectroscopy to gain insight into the speciation and extraction mechanisms.

\subsection{System with Chloride as the Only Anion}

Here an analysis of system 1 (defined in Table 2) with variable chloride concentration and variable ionic strength is presented.

Fig. 6

$\left[\overline{\mathrm{A336} \cdot \underline{\mathbf{N O}_{3}}}\right]_{\mathrm{eq}} /[\overline{\mathrm{A336} \cdot \mathrm{Cl}}]_{0}$ versus $[\mathbf{L i C l}]_{0} /\left[\mathbf{L i N O}_{3}\right]_{0}$ as derived from ${ }^{14} \mathrm{~N}-\mathrm{NMR}$ spectral analysis (see Fig. 5). The standard error in NMR intensity measurements is of the order of $\pm 10 \%$, resulting in a standard error in $f_{\text {eq }}$ of approximately $\pm 15 \%$ (see error bars). The solid curve represents a non-linear least-squares fit of Eq. 11 to the observed data (red circle) (Color figure online)

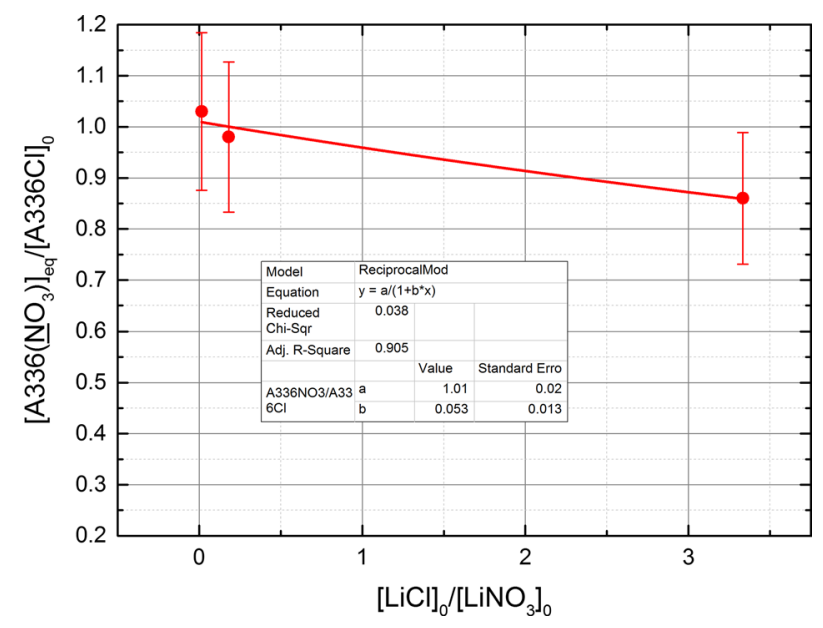

Springer 


\section{Author's personal copy}
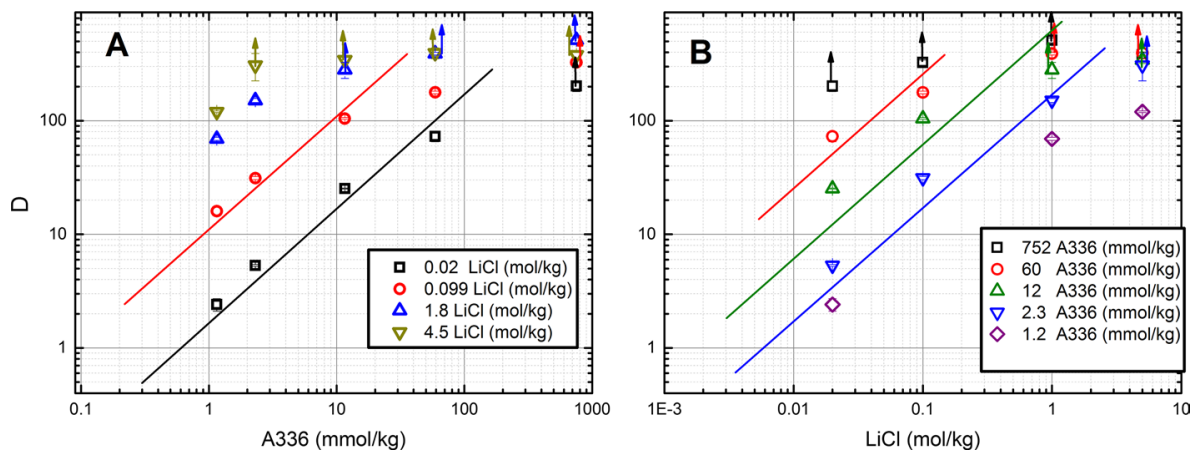

Fig. 7 Extraction of aqueous phase with $0.1 \mathrm{~mol} \cdot \mathrm{kg}^{-1} \mathrm{Cd}$ extracted from a $\mathrm{LiCl}$ solution using Aliquat 336. Panel A shows the $D$ values as a function of A336 concentration. Panel B shows the $D$ values as a function of the chloride concentration. For both panels, straight lines with slope +1 are drawn through the datasets. The straight lines represent a one-to-one stoichiometric ratio. $D$ values with arrows indicate that the real $D$ value should be higher due to the concentration of $\mathrm{Cd}$ in the aqueous phase being below the limits of detection

Figure 7 shows the extraction of $\mathrm{Cd}$ from a pure chloride media. Panel A presents $D$ values as function of the A336 concentration, panel B presents $D$ values as a function of chloride concentration. These data can be discussed in the contexts of Eq. 5: Panel A (Fig. 7) shows that one mole of A336 is needed to extract one mole of $\mathrm{Cd}$. Since it is only chloride that participates in the equilibrium. Eq. 5 becomes:

$$
\overline{\mathrm{A} 336 \cdot \mathrm{Cl}}+\mathrm{Cd}^{2+}+2 \mathrm{Cl}^{-} \rightleftharpoons \overline{\mathrm{A} 336 \cdot \mathrm{CdCl}_{3}}
$$

$\mathrm{A} 336$ is an anion exchanger, meaning that to extract $\mathrm{Cd}$ the $\mathrm{Cd}$-chloro complex must be negatively charged, i.e., contain at least three chloride ions. Therefore, $m$ in Eq. 5 must be 2 (the third chloride is delivered by the A336. $\mathrm{Cl}$ complex). If this model is correct then the slope of $\log _{10} D$ versus $\log _{10}\left[\mathrm{Cl}^{-}\right]$should be approximately 2 . This is not in agreement with the experimental data (Fig. 7).

Figure 1 (panel B) suggested that between chloride concentrations of 0.1 and $1 \mathrm{~mol} \cdot \mathrm{kg}^{-1}$ the species of $\mathrm{CdCl}^{+}$and $\mathrm{CdCl}_{2}$ dominate. This could imply that that there is no free $\mathrm{Cd}^{2+}$ present and therefore Eq. 12 can be written as:

$$
\overline{\mathrm{A} 336 \cdot \mathrm{Cl}}+\mathrm{CdCl}^{+}+\mathrm{Cl}^{-} \rightleftharpoons \overline{\mathrm{A} 336 \cdot \mathrm{CdCl}_{3}}
$$

i.e., the stoichiometric ratio between $\mathrm{A} 336 \cdot \mathrm{Cl}$, free $\mathrm{Cl}^{-}$and $\mathrm{CdCl}^{+}$should be $1: 1: 1$, in fair agreement with the experimental data shown in Fig. 7. Equation 7 takes into account all possible organic species and aquatic species for the extraction, the assumption is then that it can be written as:

$$
D=\frac{\overline{\left[A 336 \cdot \mathrm{CdCl}_{3}\right]}+\overline{\left[A 336_{2} \cdot \mathrm{CdCl}_{4}\right]}+\overline{\left[\mathrm{CdCl}_{2}\right]}}{\sum_{0}^{n}\left[\mathrm{CdCl}_{n}\right]} \approx \frac{\overline{\left[A 336 \cdot \mathrm{CdCl}_{3}\right]}}{\left[\mathrm{CdCl}^{+}\right]}
$$

If Eq. 13 is combined with Eq.14 the equilibrium constant can be estimated as:

$$
K_{\mathrm{ext} 1}=\frac{D}{[\overline{\mathrm{A} 336 \cdot \mathrm{Cl}}]_{0}\left[\mathrm{Cl}^{-}\right]_{0}}
$$


If Eq. 14 is assumed to hold, then the equilibrium constant $K_{\text {ext1 }}$ can be calculated using Eq. 15. This results in $\log _{10} K_{\text {ext1 }}=4.9 \pm 0.8$. If chemical activities are taken into account then the resulting value is $\log _{10} K_{\mathrm{p} 1}=5.1 \pm 0.4$

\subsection{System with Chloride and Nitrate}

Here an analysis of system 2 (defined in Table 2) is presented. The ionic strength was kept constant at $6.5 \mathrm{~mol} \cdot \mathrm{kg}^{-1}$ by using $\mathrm{LiNO}_{3}$ and $\mathrm{LiCl}$.

Figure 8 shows the extraction of $\mathrm{Cd}$ with both nitrate and chloride present. From the Raman and NMR experiments there is clear evidence that nitrate replaces chloride in the A336 complex. The extraction curves show that roughly $1 \mathrm{~mol}$ of chloride is extracted per mole of $\mathrm{Cd}$, as indicated by fitting the extraction data in the double logarithmic plot with a straight line with slope +1 (Fig. 8, panel B).

Nitrate hinders extraction: i.e., a high nitrate concentration will exchange nitrate with chloride (Eq. 3, $\mathrm{Y}^{-q}$ equal to $\mathrm{NO}_{3}^{-}$) and more $\mathrm{Cd}$ will remain in the aqueous phase.
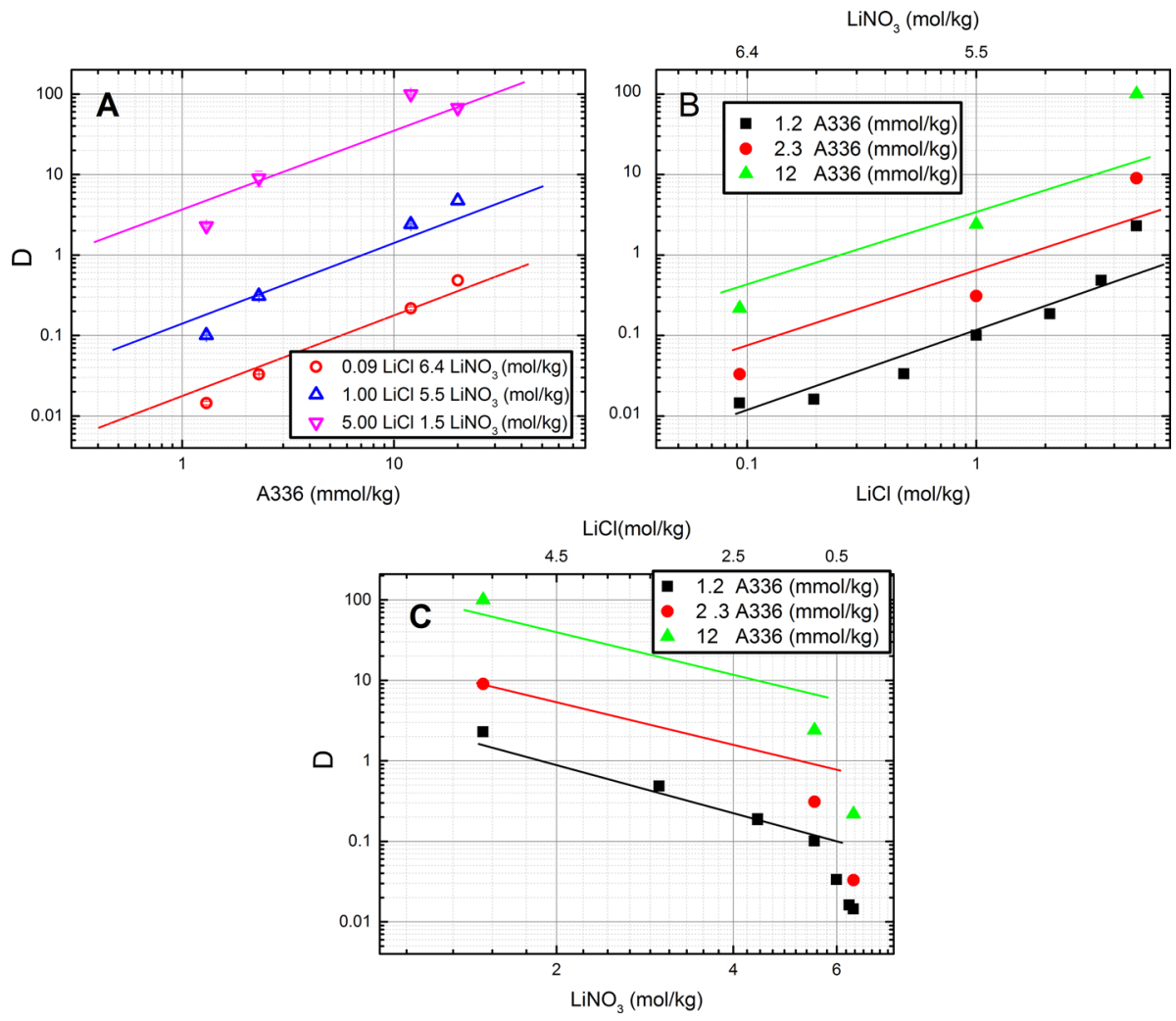

Fig. 8 Extraction of the aqueous phase with $0.1 \mathrm{mmol} \cdot \mathrm{kg}^{-1} \mathrm{Cd}$ with an ionic strength of $6.5 \mathrm{~mol} \cdot \mathrm{kg}^{-1}$. Panel A shows the $D$ values as function of the A336 concentration, panel B shows $D$ as function of increasing chloride (and decreasing nitrate) concentration, and panel $\mathbf{C}$ shows $D$ as function of increasing nitrate (and decreasing chloride) concentration. The straight lines (slope $=+1$ ) in panels $\mathbf{A}$ and $\mathbf{B}$ represent a oneto-one stoichiometric ratio. The straight lines (slope -2) in panel $\mathbf{C}$ represent a one-to-two stoichiometric ratio between cadmium and nitrate 
Remember that the NMR results (Sect. 4.3) indicated that nitrate will replace chloride ions in A336. Cl to a large extent (>90\%). Based on panel A (Fig. 8) it can be assumed that one A336 is required per Cd extracted. Each $\mathrm{Cd}$ will be complexed by one chloride ion, in accordance with panel $\mathrm{B}$. From panel $\mathrm{C}$ it can be deduced that two nitrate ions are needed to "inhibit" one A336 ion. Therefore, a suggested chemical equation that fits these parameters can be written as:

$$
\begin{gathered}
\overline{\mathrm{A} 336 \cdot \mathrm{NO}_{3} \cdot \mathrm{LiNO}_{3}}+\mathrm{CdCl}_{2}+\mathrm{Cl}^{-} \rightleftharpoons \overline{\mathrm{A} 336 \cdot \mathrm{CdCl}_{3}}+\mathrm{Li}^{+}+2 \mathrm{NO}_{3}^{-} \\
K_{\mathrm{ext} 2}=\frac{D\left[\mathrm{Li}_{0}^{+}\right]_{0}\left[\mathrm{NO}_{3}^{-}\right]_{0}^{2}}{\left.\overline{A 336 \cdot \mathrm{NO}_{3} \cdot \mathrm{LiNO}_{3}}\right]_{0}[\mathrm{Cl}]_{0}}
\end{gathered}
$$

Using Eq. 16 and data from Fig. 8, and assuming that all $\mathrm{A} 336 \cdot \mathrm{Cl}$ have been replaced, a corresponding equilibrium constant $K_{\text {ext2 }}$ can be calculated. This results in $\log _{10} K_{\text {ext }}=4.2 \pm 0.3$. If chemical activity is taken into account the result becomes $\log _{10} K_{\text {ext }}=4.7 \pm 0.3$. Wang and Hemmes [25] suggest that $\mathrm{LiNO}_{3}$ will readily form in tetrahydrofuran with an equilibrium constant larger than $\log _{10} K_{\text {ext }}=9$. In addition, Ref. [26] suggests that the equilibrium constants for $\mathrm{LiNO}_{3}$ in tetramethylurea, methylcyanate and isopentyl alcohol are $\log _{10} K_{\text {ext }}=2.22, \log _{10} K_{\text {ext }}=3.35$ and $\log _{10} \log _{10}$ $K_{\text {ext }}=0.58$, respectively. It should be noted that Eq. 15 is only presented as a hypothesis. The equation agrees with the experimental data, but it does not prove that the hypothesis necessarily is correct. Further investigations are needed and will be carried out in future work.

\subsection{System with Chloride and Sulfate}

Here an analysis of system 3 (defined in Table 2) is presented. The ionic strength was kept fixed at $6.5 \mathrm{~mol} \cdot \mathrm{kg}^{-1}$ by using $\mathrm{LiCl}$ and $\mathrm{Li}_{2} \mathrm{SO}_{4}$.

Figure 9 shows the extraction of $\mathrm{Cd}$ with both sulfate and chloride present. Notice that for low chloride concentration the sulfate concentration will be high and vice versa. From the Raman experiments there is no evidence of sulfate occurring in the organic phase, and Figs. 1 and 2 show that sulfate has a high affinity for Cd. This indicates that sulfate interacts with $\mathrm{Cd}$ rather than with the extractant. From Fig. 9 it seems that the change from an easily extractable chloride species to a less extractable (by A336) sulfate species starts to dominate when the chloride concentration is below $0.1 \mathrm{~mol} \cdot \mathrm{kg}^{-1}$. Based on this the following extraction equation is proposed:

$$
\overline{\mathrm{A} 336 \cdot \mathrm{Cl}}+\mathrm{Cd}^{2+}+2 \mathrm{Cl}^{-} \rightleftharpoons \overline{\mathrm{A} 336 \cdot \mathrm{CdCl}_{3}}
$$

This formula dictates that $\log _{10} D$ versus $\log _{10}\left[\mathrm{Cl}^{-}\right]$should follow a straight line with slope of +2 , as indeed it does (Fig. 9, panel A). Similarly, a slope of +1 is expected for $\log _{10} D$ versus $\log _{10}$ [A336], which is also in agreement with the experimental data (Fig. 9, panel B). Expressing the equilibrium constant from Eq. 12 can then be done as:

$$
K_{\mathrm{ext} 3}=\frac{D}{[\overline{\mathrm{A} 336 \cdot \mathrm{Cl}}]_{0}\left[\mathrm{Cl}^{-}\right]_{0}^{2}}
$$



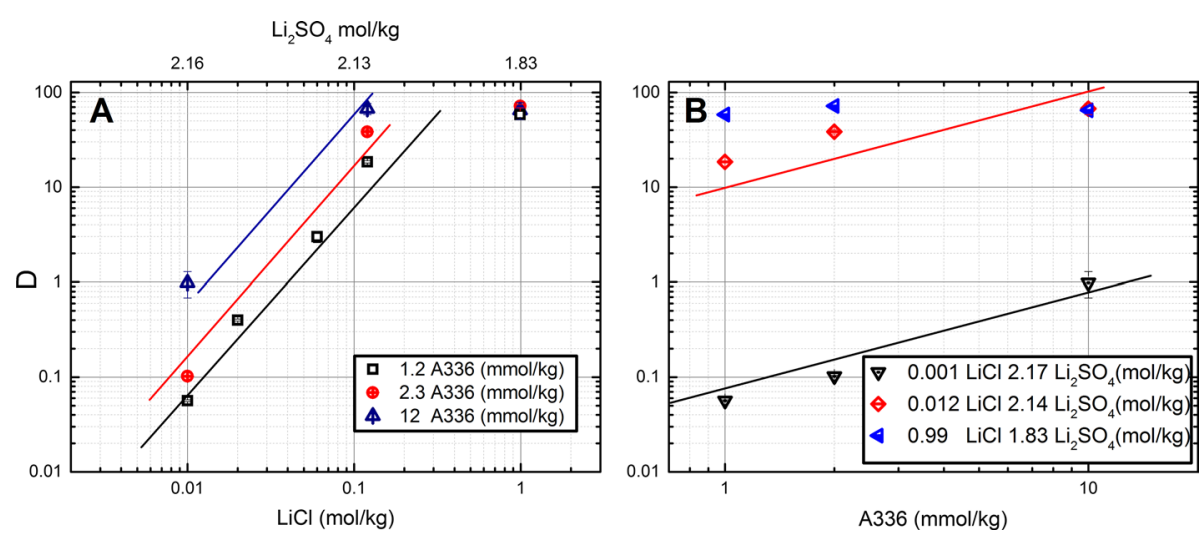

Fig. 9 Extraction of aqueous phase with $0.1 \mathrm{mmol} \cdot \mathrm{kg}^{-1} \mathrm{Cd}$ with an ionic strength of $6.5 \mathrm{~mol} \cdot \mathrm{kg}^{-1} . D$ values shown as a function of increasing chloride concentration (and decreasing sulfate) (panel A), and of A336 concentration (panel B). Lines in panel $\mathbf{A}$ have been drawn with a slope of +2 and lines in panel $\mathbf{B}$ have been drawn with a slope of +1

Using Eq. 17 to calculate the equilibrium constant for the chloride/sulfate system results in $\log _{10} K_{\text {ext3 }}=5.7 \pm 0.3$ and, by taking chemical activity into account, the result is $\log _{10} K_{\mathrm{p} 3}=6.5 \pm 0.5$.

\subsection{Comparison of $K$ Values}

As a check of consistency in our data and the validity of the assumptions leading to Eqs. 14, 16, and 17, the equilibrium constants calculated from the $D$ values to each individual extraction in Figs. 7, 8, and 9 are plotted in Fig. 10. Ideally, the equilibrium constants should show no trends. Figure 10 shows the different equilibrium constants as a function of $D$ ratio. The equilibrium constants have been calculated both with the assumption that the chemical activity coefficient is unity and by using Pitzer equations to estimate the real activity coefficient $(\gamma)$ [17-19]. Panel A shows the values when only chloride was present and the ionic strength was varied. The results suggest that Eq. 13 is valid for 0.02 and $0.5 \mathrm{~mol} \cdot \mathrm{kg}^{-1}$ chloride concentrations and A336 concentrations from 1 up to $60 \mathrm{mmol} \cdot \mathrm{kg}^{-1}$. The validity was checked using the student's $t$ test. Panel B shows the extraction as the ionic strength is kept constant using nitrate. In that system the equilibrium constants does not diverge significantly. Panel $\mathrm{C}$ shows the equilibrium constant for the sulfate system. No significant change is observed for $D$ values below 40, which suggest that Eq. 12 fits until the chloride concentration approaches $1 \mathrm{~mol} \cdot \mathrm{kg}^{-1}$, where a different mechanism starts to dominate.

Table 5 summarizes the equilibrium constants for $\mathrm{Cd}$ extraction. Extraction from a perchlorate matrix (System 4 in Table 2) was measured, but as noted in Sect. 4.1 no extraction was observed as perchlorate has a stronger affinity to A336 than the Cd species. This is in accordance with the observation of De et al. [24] who reported that nitrate's affinity for A336 is lower than perchlorate's. 


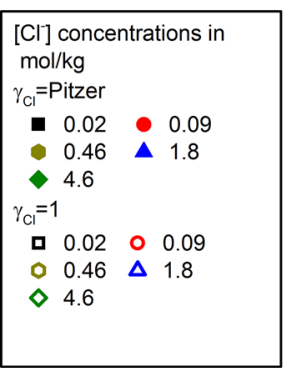

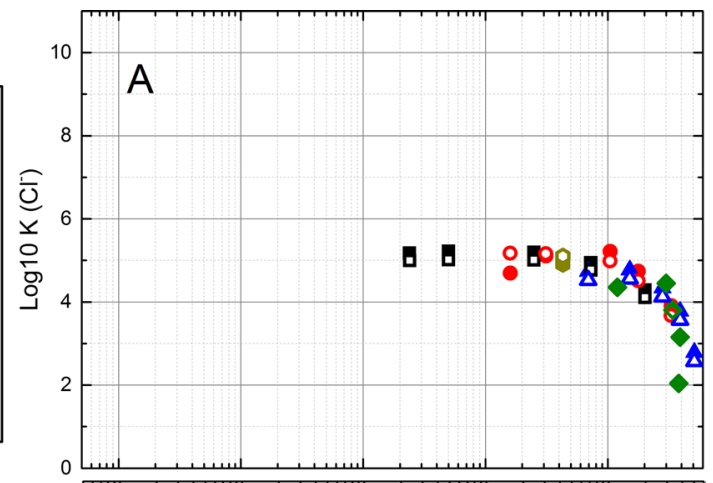

\begin{tabular}{|c|c|c|}
\hline \multirow{2}{*}{\multicolumn{3}{|c|}{$\begin{array}{l}{[\mathrm{Cl}] \text { concentrations in }} \\
\mathrm{mol} / \mathrm{kg} \\
\gamma_{\mathrm{NO} 3} \gamma_{\mathrm{Cl}}=\text { Pitzer }\end{array}$}} \\
\hline & & \\
\hline - 0.09 & - & 0.99 \\
\hline$\Delta 5.0$ & 4 & 0.2 \\
\hline$>0.5$ & $\bullet$ & 2.0 \\
\hline$\nabla 3.5$ & & \\
\hline \multicolumn{3}{|l|}{$\gamma_{\mathrm{NO} 3} \gamma_{\mathrm{Cl}}=1$} \\
\hline 口 0.09 & 0 & 0.99 \\
\hline$\Delta 5.0$ & $\triangleleft$ & 0.2 \\
\hline$\triangleright 0.5$ & $\diamond$ & 2.0 \\
\hline$\nabla 3.5$ & & \\
\hline
\end{tabular}

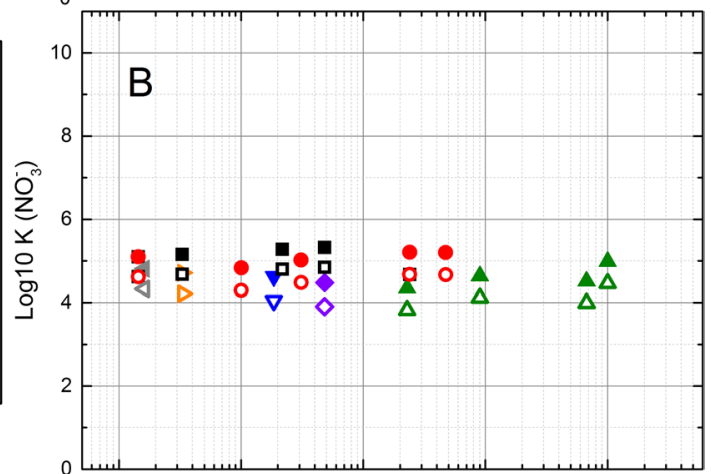

\begin{tabular}{|c|c|c|c|}
\hline \multicolumn{4}{|c|}{$\begin{array}{l}{[\mathrm{Cl}] \text { concentrations in }} \\
\mathrm{mol} / \mathrm{kg}\end{array}$} \\
\hline \multicolumn{4}{|c|}{$\gamma_{C 1}=$ Pitzer } \\
\hline a & 0.01 & $\bullet$ & 0.02 \\
\hline v & 0.06 & - & 0.12 \\
\hline$\Delta$ & 0.99 & & \\
\hline \multicolumn{4}{|c|}{$\gamma_{C I}=1$} \\
\hline 口 & 0.01 & $\diamond$ & 0.02 \\
\hline$\nabla$ & 0.06 & 0 & 0.12 \\
\hline$\Delta$ & 0.99 & & \\
\hline
\end{tabular}

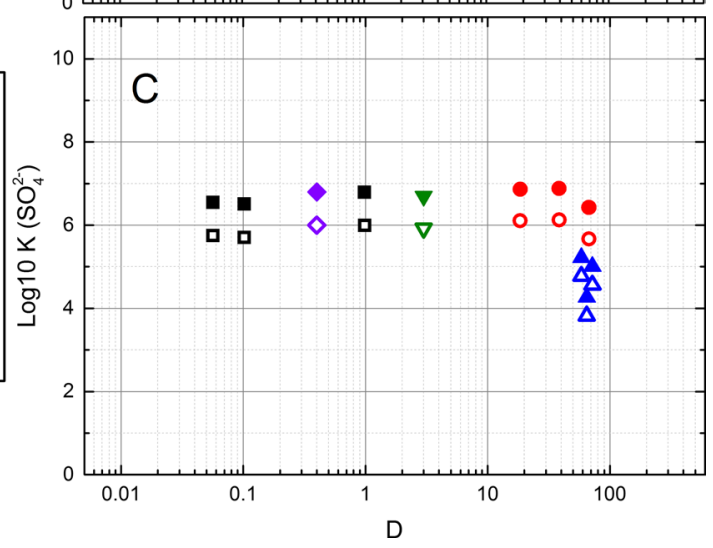

Fig. 10 Calculation of the equilibrium constants for the extractions from various media versus $D$ ratios. Panel $\mathbf{A}$ is for the $\mathrm{LiCl}$ medium, panel $\mathbf{B}$ is for the $\mathrm{LiCl}, \mathrm{LiNO}_{3}$ mixture and panel $\mathbf{C}$ is for the $\mathrm{LiCl}, \mathrm{Li}_{2} \mathrm{SO}_{4}$ mixtures

\section{Conclusions}

Solutions of the quaternary amine A336 dissolved in toluene were used to extract $\mathrm{Cd}$ from a large number of different aqueous solutions containing (1) chloride of different concentrations (and hence different ionic strengths), and mixed Li salts of: (2) chloride and nitrate, (3) chloride and sulfate, and (4) chloride and perchlorate, respectively. Notably, solutions (2), (3), (4) were all constrained at the same high ionic strength of $6.5 \mathrm{~mol} \cdot \mathrm{kg}^{-1}$. 
Table 5 the concentration ranges where the calculated equilibrium values are valid

\begin{tabular}{lllll}
\hline System & {$\left[\mathrm{Cl}^{-}\right] \mathrm{mol} \cdot \mathrm{kg}^{-1}$} & {$[\mathrm{~A} 336] \mathrm{mol} \cdot \mathrm{kg}^{-1}$} & $K_{\text {extn }} \mu=[] \cdot 1$ & $K_{\mathrm{pn}} \mu=[] \cdot \gamma$ \\
\hline $1\left[\mathrm{Cl}^{-}\right] K_{\text {ext1 }}$ & $0.02-0.5$ & $1-50$ & $4.9(0.8)$ & $5.1(0.4)$ \\
$2\left[\mathrm{Cl}^{-}, \mathrm{NO}_{3}^{-}\right] K_{\text {ext2 }}$ & $0.1-5$ & $1-12$ & $4.2(0.3)$ & $4.7(0.3)$ \\
$3\left[\mathrm{Cl}^{-}, \mathrm{SO}_{4}^{2-}\right] K_{\text {ext3 }}$ & $0.01-0.12$ & $1-12$ & $5.7(0.4)$ & $6.5(0.5)$ \\
\hline
\end{tabular}

Values are shown both for ideal solutions $(\gamma=1)$ and when the chemical potentials were calculated using the Pitzer equations

One objective of the present work was to identify any simple reaction scheme that may describe the extraction of $\mathrm{Cd}$ within certain concentration "windows" of the reactants. In order to accomplish this, the three-dimensional data matrices (characterized by the distribution ratio, the A336 concentration, and the salt concentrations) were converted into twodimensional matrices by simply keeping one of the concentration variables fixed.

Notably, it was found that NMR spectroscopy provided quantitative information on the distribution of anions between phases as well as giving insight into the association property or affinity of A336 for various anions, i.e.: perchlorate $>$ nitrate $>$ chloride $>$ sulfate, an observation which was found useful in explaining the extraction properties within the different systems.

Moreover, ${ }^{14} \mathrm{~N}-\mathrm{NMR}$ spectroscopy allowed the equilibrium constant $K_{\text {ex } 0}$ of the reaction: $\overline{\mathrm{A} 336 \cdot \mathrm{NO}_{3}}+\mathrm{Cl}^{-} \rightleftharpoons \overline{\mathrm{A} 336 \cdot \mathrm{Cl}}+\mathrm{NO}_{3}^{-}$to be determined as $K_{\mathrm{ex} 0}=18 \pm 5$ (or $\log _{10}$ $K_{\text {ex } 0}=1.26 \pm 0.12$ ).

Based on the two-dimensional data reduction analysis approach, it was concluded that for chloride concentrations within the concentration range of $0.01-0.5 \mathrm{~mol} \cdot \mathrm{kg}^{-1}$ and with no other anions present in the solution, the species $\mathrm{CdCl}^{+}$dominated in the extraction reaction. Hence, the following simplified reaction scheme: $\overline{\mathrm{A} 336 \cdot \mathrm{Cl}}+\mathrm{CdCl}^{+}+\mathrm{Cl}^{-} \rightleftharpoons \overline{\mathrm{A} 336 \cdot \mathrm{CdCl}_{3}}$ (dominated).

If both sulfate and chloride were present at high ionic strength $\left(6.5 \mathrm{~mol} \cdot \mathrm{kg}^{-1}\right)$ and the sulfate concentration increased (at the expense of the chloride concentration, which decreased correspondingly at constant ionic strength), then a significant drop in the $D$ values of $\mathrm{Cd}$ was observed. This was found not to be caused by sulfate being associated to A336, since no sulfate was detected in the organic phase after extraction, as confirmed by Raman spectroscopy. Instead, it seems that formation of sulfate species started to dominate when the chloride concentration decreased below $0.1 \mathrm{~mol} \cdot \mathrm{kg}^{-1}$. If both sulfate and chloride were present at high ionic strength $\left(6.5 \mathrm{~mol} \cdot \mathrm{kg}^{-1}\right)$, then the main reaction taking place was identified as: $\overline{\mathrm{A} 336 \cdot \mathrm{Cl}}+\mathrm{Cd}^{2+}+2 \mathrm{Cl}^{-} \rightleftharpoons \overline{\mathrm{A} 336 \cdot \mathrm{CdCl}_{3}}$. Finally, the extraction of $\mathrm{Cd}$ in the presence of both nitrate and chloride suggested that the following major reaction takes place: $\overline{\mathrm{A} 336 \cdot \mathrm{NO}_{3} \cdot \mathrm{LiNO}_{3}}+\mathrm{CdCl}_{2}+\mathrm{Cl}^{-} \rightleftharpoons \overline{\mathrm{A} 336 \cdot \mathrm{CdCl}_{3}}+\overline{\mathrm{A} 336 \cdot \mathrm{Cl}}+\mathrm{Li}^{+}+2 \mathrm{NO}_{3}^{-}$

The current work demonstrated that both NMR and Raman spectroscopy will be important tools in future characterizations of Cd-extraction from real industrial solutions of high salinity. In particular, the potential of using multinuclear NMR $\left({ }^{7} \mathrm{Li},{ }^{14} \mathrm{~N},{ }^{13} \mathrm{C},{ }^{1} \mathrm{H},{ }^{35} \mathrm{Cl},{ }^{31} \mathrm{P}\right.$ and $\left.{ }^{113} \mathrm{Cd}\right)$ will be considered.

Acknowledgements The authors are grateful for the financial support from the Norwegian Research Council and industry companies Yara International, Glencore Nikkelverk, and Boliden Odda. The support was channelled through the Norwegian Research Council project BIA-KPN, Project No. 2366741. We also appreciate the valuable input and constructive discussions with representatives from our industry partners. Thanks to the University of Oslo NMR laboratory for running the NMR experiments. 


\section{Appendix A: Distribution Ratios}

See Tables 6, 7, 8 and 9.

\section{Appendix B: Speciation Estimation}

Figure 1 shows the speciation of $\mathrm{Cd}$ as functions of sulfate and chloride concentrations. The speciation diagrams were made by calculating the fraction of free $\mathrm{Cd}$ at a given chloride or sulfate concentration:

$$
f\left(\mathrm{Cd}^{2+}\right)=\frac{\left[\mathrm{Cd}^{2+}\right]}{\left[\mathrm{Cd}^{2+}\right]+\left[\mathrm{CdCl}^{+}\right]+\left[\mathrm{CdCl}_{2}\right] \ldots}
$$

Table $6 D$ values of $0.1 \mathrm{mmol} \cdot \mathrm{kg}^{-1} \mathrm{Cd}$ at $21 \pm 2{ }^{\circ} \mathrm{C}$ from aqueous chloride, using A336 in toluene as the extractant

\begin{tabular}{|c|c|c|c|}
\hline $\begin{array}{l}\text { A336 } \\
{\left[\mathrm{mmol} \cdot \mathrm{kg}^{-1}\right]}\end{array}$ & $\mathrm{LiCl}\left[\mathrm{mol} \cdot \mathrm{kg}^{-1}\right]$ & $D$ values & \\
\hline 752 & 0.02 & $2.3 \times 10^{2}$ & (20) \\
\hline 60 & 0.02 & 81 & (8) \\
\hline 12 & 0.02 & 28.5 & $(0.2)$ \\
\hline 2 & 0.02 & 6.1 & $(0.1)$ \\
\hline 1 & 0.02 & 2.7 & $(0.3)$ \\
\hline 0.6 & 0.02 & 0.7 & $(0.1)$ \\
\hline 750 & 0.09 & $3.6 \times 10^{2}$ & (10) \\
\hline 60 & 0.09 & $1.95 \times 10^{2}$ & (6) \\
\hline 12 & 0.09 & $1.15 \times 10^{2}$ & (2) \\
\hline 1 & 0.09 & 18 & (1) \\
\hline 0.6 & 0.09 & 3.45 & $\left(1 \times 10^{-2}\right)$ \\
\hline 1 & 0.46 & 42 & $(0.2)$ \\
\hline 752 & 1.85 & $5.1 \times 10^{2}$ & (30) \\
\hline 60 & 1.85 & $3.9 \times 10^{2}$ & (10) \\
\hline 12 & 1.85 & $2.8 \times 10^{2}$ & $(50)$ \\
\hline 2.3 & 1.85 & $1.51 \times 10^{2}$ & (6) \\
\hline 1.2 & 1.85 & 69 & (2) \\
\hline 0.6 & 1.85 & 21 & (1) \\
\hline 752 & 4.63 & $3.8 \times 10^{2}$ & (20) \\
\hline 60 & 4.63 & $3.9 \times 10^{2}$ & (40) \\
\hline 12 & 4.63 & $3.4 \times 10^{2}$ & (20) \\
\hline 2.3 & 4.63 & $3.0 \times 10^{2}$ & (80) \\
\hline 1 & 4.63 & $1.20 \times 10^{2}$ & (1) \\
\hline 0.6 & 4.63 & 19 & (5) \\
\hline
\end{tabular}

Absolute standard deviations of $D$ values (calculated by the standard formula $\sqrt{ }\left(\frac{\sum x_{i}-\bar{x}}{n-1}\right)$, with $n$ at a minimum of 3$)$ are given in the parenthesis 


\section{Author's personal copy}

Table $7 D$ values of

$0.1 \mathrm{mmol} \cdot \mathrm{kg}^{-1} \mathrm{Cd}$ at $21 \pm 2{ }^{\circ} \mathrm{C}$ with $\mathrm{LiCl}$ and $\mathrm{LiNO}_{3}$ present and the variation of them

\begin{tabular}{lllll}
\hline $\begin{array}{l}\mathrm{A} 336 \\
{\left[\mathrm{mmol} \cdot \mathrm{kg}^{-1}\right]}\end{array}$ & $\mathrm{LiCl}\left[\mathrm{mol} \cdot \mathrm{kg}^{-1}\right]$ & $\begin{array}{l}\mathrm{LiNO}_{3} \\
{\left[\mathrm{~mol} \cdot \mathrm{kg}^{-1}\right]}\end{array}$ & $D$ values & \\
\hline 12 & 0.09 & 6.41 & 0.218 & $\left(9 \times 10^{-3}\right)$ \\
2.3 & 0.09 & 6.41 & $3.30 \times 10^{-2}$ & $\left(2 \times 10^{-4}\right)$ \\
1.2 & 0.09 & 6.41 & $1.44 \times 10^{-2}$ & $\left(7 \times 10^{-4}\right)$ \\
0.6 & 0.09 & 6.41 & $5.6 \times 10^{-3}$ & $\left(2 \times 10^{-4}\right)$ \\
12 & 1.01 & 5.50 & 2.39 & $\left(6 \times 10^{-2}\right)$ \\
2.3 & 1.01 & 5.50 & 0.310 & $\left(6 \times 10^{-3}\right)$ \\
1.2 & 1.01 & 5.50 & 0.102 & $\left(2 \times 10^{-3}\right)$ \\
23 & 5.00 & 1.50 & 67 & $(1)$ \\
12 & 5.00 & 1.50 & $1.00 \times 10^{2}$ & $(2)$ \\
2.3 & 5.00 & 1.50 & 9 & $(2)$ \\
1.2 & 5.00 & 1.50 & 2.29 & $\left(8 \times 10^{-2}\right)$ \\
1.2 & 0.50 & 6.00 & $3.34 \times 10^{-2}$ & $\left(5 \times 10^{-4}\right)$ \\
\hline
\end{tabular}

Standard deviations for the D values are provided as described for Table 6
Table $8 D$ values of

$0.1 \mathrm{mmol} \cdot \mathrm{kg}^{-1} \mathrm{Cd}$ at $21 \pm 2{ }^{\circ} \mathrm{C}$ with both $\mathrm{LiCl}$ and $\mathrm{Li}_{2} \mathrm{SO}_{4}$ present the variation of them

\begin{tabular}{lllll}
\hline $\begin{array}{l}\text { A336 } \\
{\left[\mathrm{mmol} \cdot \mathrm{kg}^{-1}\right]}\end{array}$ & $\mathrm{LiCl}\left[\mathrm{mol} \cdot \mathrm{kg}^{-1}\right]$ & $\begin{array}{l}\mathrm{Li}_{2} \mathrm{SO}_{4} \\
{\left[\mathrm{~mol} \cdot \mathrm{kg}^{-1}\right]}\end{array}$ & $D$ values & \\
\hline 12 & 0.01 & 2.17 & 1.0 & $(0.3)$ \\
2.3 & 0.01 & 2.17 & 0.102 & $\left(1 \times 10^{-3}\right)$ \\
1.2 & 0.01 & 2.17 & $5.6 \times 10^{-2}$ & $\left(1 \times 10^{-3}\right)$ \\
1.2 & 0.02 & 2.17 & 0.39 & $\left(1 \times 10^{-2}\right)$ \\
1.2 & 0.06 & 2.16 & 3.1 & $(0.4)$ \\
12 & 0.12 & 2.14 & 63 & $(9)$ \\
2.3 & 0.12 & 2.14 & 38 & $(2)$ \\
1.2 & 0.12 & 2.14 & 18.0 & $(0.5)$ \\
12 & 0.99 & 1.8 & 60 & $(1)$ \\
2.3 & 0.99 & 1.8 & 71 & $(4)$ \\
1.2 & 0.99 & 1.8 & 58 & $(2)$ \\
\hline
\end{tabular}

Standard deviations for the $D$ values is provided as described for Table 6

\begin{tabular}{lllll}
\hline $\begin{array}{l}\mathrm{A} 336 \\
{\left[\mathrm{mmol} \cdot \mathrm{kg}^{-1}\right]}\end{array}$ & $\mathrm{LiCl}\left[\mathrm{mol} \cdot \mathrm{kg}^{-1}\right]$ & $\begin{array}{l}\mathrm{NaClO}_{4} \\
{\left[\mathrm{~mol} \cdot \mathrm{kg}^{-1}\right]}\end{array}$ & $D$ values & \\
\hline 60 & 0.25 & 6.80 & 0.5 & $(0.3)$ \\
60 & 0.75 & 5.90 & $6 \times 10^{-2}$ & $\left(3 \times 10^{-2}\right)$ \\
60 & 2.55 & 4.11 & 0.2 & $(0.2)$ \\
\hline
\end{tabular}

Standard deviations for the $D$ values is provided as described for Table 6
Table $9 D$ values for $0.1 \mathrm{mmol} \cdot \mathrm{kg}^{-1} \mathrm{Cd}$ at $21 \pm 2{ }^{\circ} \mathrm{C}$ with perchlorate present the variation of them 



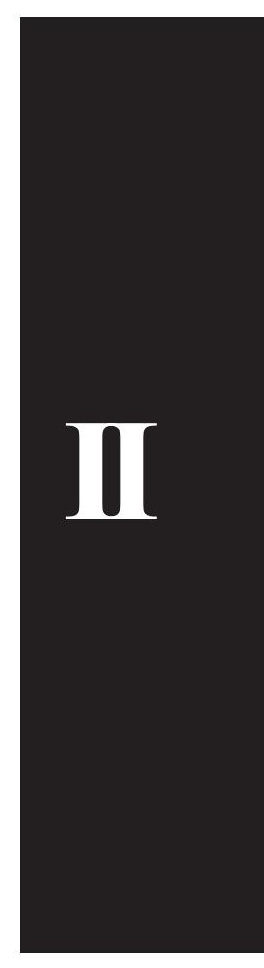





\title{
Comparison of distribution ratios using
}

\section{single-phase and two-phase}

\section{measurements.}

\section{Extraction of Cd, $\mathrm{Zn}$ and Co with Aliquat 336 from a multi- element chloride matrix}

Hans Vigeland Lerum ${ }^{1}$, Svetlana Sand, Dag Øistein Eriksen, Grethe Wibetoe, Jon Petter Omtvedt

Department of Chemistry, University of Oslo, PO Box 1033 - Blindern, NO-0315 Oslo, Norway

${ }^{1}$ Corresponding author, e-mail: hansvl@kjemi.uio.no

\begin{abstract}
$\mathrm{Cd}$ and $\mathrm{Zn}$ were separated from $\mathrm{Co}$, from chloride solutions containing 16 different metal ions. The separation method used was liquid-liquid extraction. Two different chloride concentrations, 0.5 and $5 \mathrm{~mol} / \mathrm{kg}$, were tested. Aliquat 336 in toluene was used as extractant. It is shown that $\mathrm{Li}_{2} \mathrm{SO}_{4}$ can back-extract the metals. Distribution ratios were determined using radiotracers or inductively coupled plasma mass spectrometry. The results of these methods are compared. In particular, we demonstrate that the determination of low distribution ratios are limited by the uncertainty of the measured concentration of the feed solution.
\end{abstract}

\section{Keywords}

Cadmium, zinc, cobalt, separation, extraction, statistics

\section{Introduction}

Industrial plants converting minerals to elemental products will preferably select ores as rich as possible in the wanted element(s). Due to the continuous consumption of mineral ores, the richest ores are gradually consumed [1]. Therefore, ores with lower concentration gradually replaces what is currently being used. Hence, in the future, industry is forced to use minerals 


\section{Journal of Radioanalytical and Nuclear Chemistry}

with lower concentration of wanted elements and with more unwanted constituents. In the worst case, this can seriously interfere with the production process. For example, the impurities can react with the extractant and thus inhibit it. This is a concern when e.g. Co needs to be removed in $\mathrm{Ni}$ production, because $\mathrm{Zn}$ and $\mathrm{Cd}$ will bind stronger to the $\mathrm{Co}$ extractant $[2,3]$.

This work had 3 goals:

(1) Investigation of the separation of $\mathrm{Cd}$ and $\mathrm{Zn}$ from $\mathrm{Co}$ in a complex chloride matrix with 13 other metallic elements present;

(2) Investigation of back-extraction of $\mathrm{Cd}$ and $\mathrm{Zn}$ from the organic phase (from (1)) using lithium sulfate.

(3) Comparison of distribution ratios measured using single-phase measurement and twophase measurements.

Aliquat 336 (A336) is a commercial trade name that describes a mixture of quaternary amines, where the nitrogen is bound to three carbon chains with variable length (8-10 carbons), and one methyl group. A336 is sold with chloride as the counter ion. In chloriderich media A336 extracts $\mathrm{Cd}$ and $\mathrm{Zn}$ better than Co [4-13]. However, in these studies the elements were not simultaneously present in the solution $[4-9,13]$. In a few works simultaneous extraction of several elements were performed $[14,15,11,10]$. The efficeincy of A336 extraction is known to drop when there are several elements present $[14,15]$.

In all of the works mentioned above, except four $[7,12,14,15]$, only the content in the aqueous phase was measured when determining the distribution ratios of the extractions. In this work we refer to such a procedure as "single-phase measurement". I.e. instead of measuring the concentration in both phases directly, the amount in one of the phases is determined indirectly by measuring the other phase before and after extraction. In one study both single-phase measurements and two-phase measurements (implying that the content of both the aqueous and organic phase were measured) were performed [12]. Furthermore, there was no discussion if one-phase and two-phase measurements would give the same result. Unfortunately, most of the literature mentioned above has omitted this. In addition there was no published standard deviation in the following articles [3-8,12,16-21]. There is even some cases where more than 100 percent extraction are reported [22]. From this we deduce that there is a need to clarify how to assess uncertainty in measuring distribution ratios in liquid- 
57 liquid extraction. In general it is prudent to discuss the validity and uncertainty of

58 measurements. In particular, it is a clear need to understand uncertainty and limitations when only the metal concentration in a single phase is measured. For this reason, we include a discussion and comparison of D-ratios determined using single- and two-phase measurements. In addition, it has been shown that sulfate lowers the distribution ratio of $\mathrm{Cd}$, it is therefore

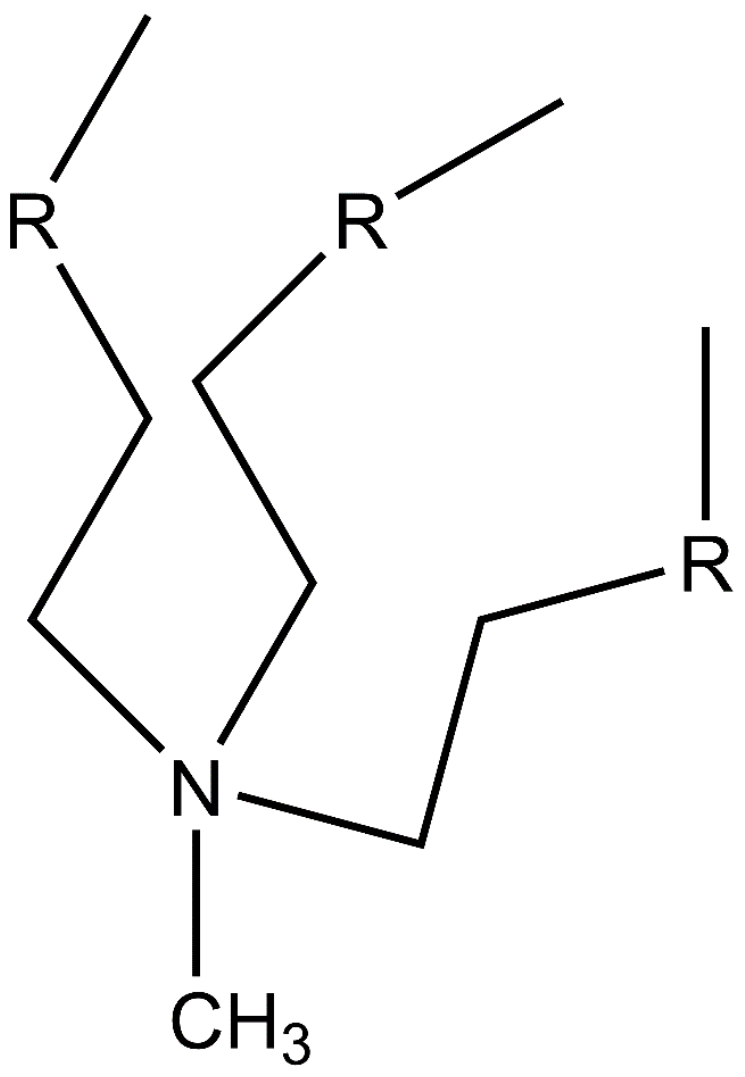

Fig. 1 simplified drawing of A336, for simplicity no positive charge is added and the interchangable counter ions is not drawn. The $R$ in the figure represent the variable length of the carbon chains

Fig. 1 shows a simplified drawing of A336.

69

Since it is commonly depicted as an anion exchanger there are several extraction mechanism possible but a suggested general form can be:

$$
n A 336 \cdot C l_{\text {org }}+M C l_{i}^{p-i} \rightleftharpoons A 336_{n} \cdot\left(M C l_{i}\right)_{\text {org }}+n C l^{-} a q
$$


Here $p$ is the positive charge of the metal ion, $i$ is the number of chloride ions needed to form a negative complex, and $n$ is equal to the negative charge of the metal species.

In this work there were several extraction steps with several different solutions used. The naming convention used in this work is defined in Fig. 2.

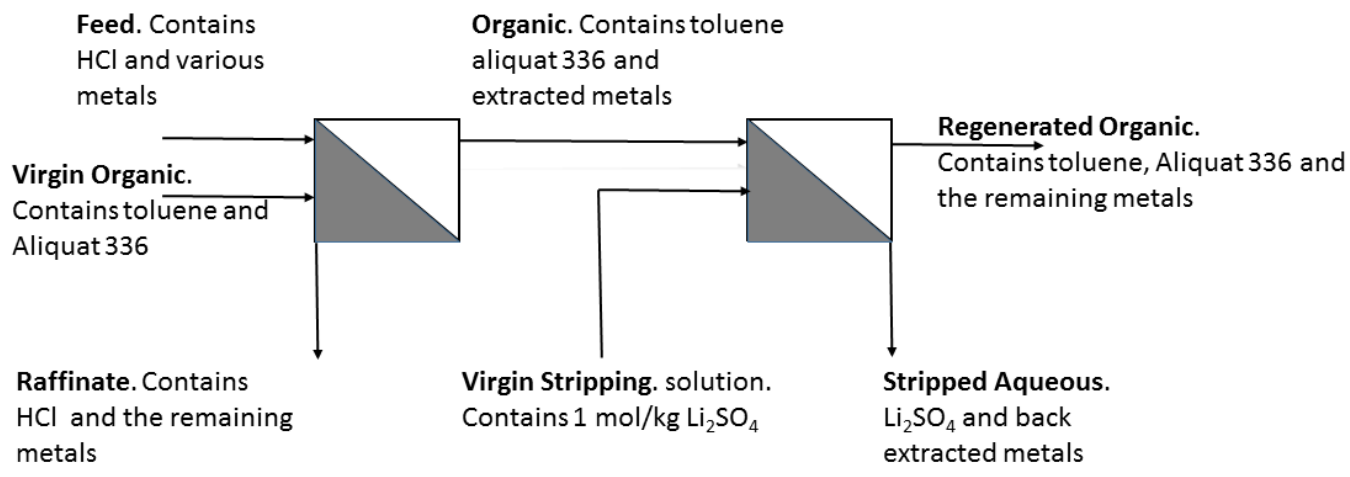

\section{Fig. 2 Naming convention for extraction steps and phases used in this work}

In the following discussion feed, raffinate, organic, stripped aqueous and regenerated organic are indexed as feed, raf, org, stripaq and regorg. In a continous process regenerated organic will replace virgin organic.

\section{Uncertainty in two-phase measurements}

Liquid-liquid extraction is a well-established separation process based on the distribution of an analyte, e.g. a metal cation, between two immiscible phases. The definition of the distribution ratio, as used in this work, is:

$$
D=\frac{\left[M_{\text {org }}\right]}{\left[M_{\text {raf }}\right]}
$$

Here $\left[M_{\text {org }}\right]$ is the concentration of analyte in the organic phase and $\left[\mathrm{M}_{\mathrm{raf}}\right]$ is the total concentration of analyte in aqueous phase.

Using the standard equation for propagation of errors and assuming no correlation, for Eq. 2 we get: 


$$
\sigma_{D}=D \sqrt{\left(\frac{\sigma_{\text {org }}}{\left[M_{\text {org }}\right]}\right)^{2}+\left(\frac{\sigma_{\text {raf }}}{\left[M_{\text {raf }}\right]}\right)^{2}}
$$

Where $\sigma_{\mathrm{x}}$ is the uncertainty of the measurement, here $\mathrm{x}$ describes the index.

\section{Uncertainty in single-phase measurements}

When only one of the phases can be measured, the amount of the metal in the other phase must be calculated indirectly. The normal reason for only measuring metal content in one of the phases is that measurement of the content in the other phase can be challenging, therefore single-phase measurements are convenient and even necessary [28]. In principle, single-phase and two-phase measurements should result in equal D-ratios. However, this is not always the case, as demonstrated and discussed below.

In the following discussion it is assumed that the phase to be analysed for metal content is the aqueous phase, as is normally the case. The same method, and limitations, will of course apply if only the organic phase was measured. The assumption for single phase measurements is that the content of the organic phase can be calculated as the difference between the feed and raffinate solution:

$$
\left[M_{\text {org }}\right]=\left[M_{\text {feed }}\right]-\left[M_{\text {raf }}\right]
$$

where $\left[\mathrm{M}_{\mathrm{feed}}\right]$ is the aqueous concentration of analyte prior to extraction. It is assumed that the volume of organic and raffinate is equal.

Inserting Eq. 3 into Eq. 1 provides the following formula to calculate the distribution ratio:

$$
D=\frac{\left[M_{\text {feed }}\right]-\left[M_{\text {raf }}\right]}{\left[M_{\text {raf }}\right]}
$$

Applying the normal propagation of error to Eq. 5 gives:

$$
\begin{aligned}
\sigma_{D}=\frac{\left[M_{\text {feed }}\right]}{\left[M_{\text {raf }}\right]} \sqrt{\left(\frac{\sigma_{\text {feed }}}{\left[M_{\text {feed }}\right]}\right)^{2}+\left(\frac{\sigma_{\text {raf }}}{\left[M_{\text {raf }}\right]}\right)^{2}} \\
=(D+1) \sqrt{\left(\frac{\sigma_{M_{\text {feed }}}}{\left[M_{\text {feed }}\right]}\right)^{2}+\left(\frac{\sigma_{M_{\text {raf }}}}{\left[M_{\text {raf }}\right]}\right)^{2}}
\end{aligned}
$$

When there is little to no extraction, [ $\left.\mathrm{M}_{\mathrm{raf}}\right]$ will approach $\left[\mathrm{M}_{\mathrm{feed}}\right]$. Thus, it becomes impossible to tell if the difference between $\left[\mathrm{M}_{\mathrm{raf}}\right]$ and $\left[\mathrm{M}_{\text {feed }}\right]$ is real or due to statistical fluctuations. To 
ensure that the difference is not due to uncertainty the t-test for two samples with different uncertainty can be used [29-31]:

$$
t=\frac{\left[M_{\text {feed }}\right]-\left[M_{\text {raf }}\right]}{\sqrt{\frac{\sigma_{\text {raf }}^{2}}{N_{\text {raf }}}+\frac{\sigma_{\text {feed }}^{2}}{N_{\text {feed }}}}}
$$

where $\mathrm{N}_{\mathrm{x}}$ is the number of replicas of the given measurement, here $\mathrm{x}$ represents raffinate and feed, respectively. If [ $\left.\mathrm{M}_{\text {feed }}\right]>\left[\mathrm{M}_{\text {raf }}\right]$, and if the value of $t$ exceeds the critical $t$ value Eq. 5 can be used to calculate the D-ratio. The critical t-value is given from t-tables which can be found in e.g [31]. The critical t-value can be read from such tables after the degrees of freedom is calculated as described in Eq. 12 [29-31].

Calculating the uncertainty for back extraction can also be done with taylor expansion and it will result in a longer and more complex equation.

\section{Comparison of single-phase and two-phase measurements}

First we look at the main extraction-stage: Comparing the equations for the uncertainty in the distribution ratio calculated by measuring both phases (Eq. 3) or only one (Eq. 6), it is clear that two-phase measurements gives a lower uncertainty than single-phase measurements due to the D+1 multiplication term in Eq. 6 for single phase measurements. Of course, this factor will affect the uncertainty for low distribution ratios in particular. Notice that in real situations the uncertainties in aqueous and organic phase are not necessarily of the same magnitude, this can affect the validity of the above statement.

The main advantage of single-phase measurement is that it generally is much quicker. The reason for this is that it is generally much easier to find a suitable method for aqueous phase measurements than for organic phase measurements. Thus, one-phase measurements is e.g. suitable for screening purposes and situations where a large number of measurements needs to be performed quickly (or cheaply). On the other hand, if very high or low distribution ratios need to be determined accurately, measuring both phases is most likely necessary to obtain an acceptable statistical accuracy. 
133

134

135

\section{Separation factor}

The separation factor $\alpha$ is defined as:

$$
\alpha_{D_{m 2}}^{D_{m 1}}=\frac{D_{m 1}}{D_{m 2}}
$$

Here $D_{m 1}$ is the D-ratio of one of the analytes and $D_{m 2}$ is the D-ratio of a different one.

\section{Determination of minimum and maximum measurable D-ratio}

For ICP-MS the minimum statistical significant D-ratio that could be measured were determined by rearranging eq. 7 :

$$
\left[M_{\text {raf }}\right]=\left[M_{\text {feed }}\right]-t \sqrt{\frac{\sigma_{\text {raf }}^{2}}{N_{\text {raf }}}+\frac{\sigma_{\text {feed }}^{2}}{N_{\text {feed }}}}
$$

Here the $\sigma_{\text {feed }}$ used was the same for all the samples, $\sigma_{\text {raf }}$ will change depending on with the system, in these estimations the highest experimental values were used. The degrees of freedom needed to assign a critical t-value was calculated as:

$$
v=\frac{\left(\frac{\sigma_{\text {raf }}^{2}}{N_{\text {raf }}}+\frac{\sigma_{\text {feed }}^{2}}{N_{\text {feed }}}\right)^{2}}{\frac{\sigma_{\text {raf }}^{4}}{N_{\text {raf }}^{2}\left(N_{\text {raf }}-1\right)}+\frac{\sigma_{\text {feed }}^{4}}{N_{\text {feed }}^{2}\left(N_{\text {feed }}-1\right)}}
$$

$v$ was then rounded to the closest integer, and $95 \%$ one-tailed confidence interval was used to determine the significant difference.

The maximum D-ratio was determined using the limit of quantification (LOQ). D-ratios measured using ICP-MS were determined by taking the average of the replicas of the raffinate over the concentration of the feed.

For radiotracers the minimum and maximum D-ratios were mainly limited by counting statistics, i.e. measurement time. However, at some point entrainment and operational errors in separating the phases and sampling them will limit the minimum/maximum determinable values. Based on experience the practical limit for the range of D-values that could be determined, using radiotracers, where therefore set to be between 0.006 and 300. This holds true also for single-phase measurements using ICP-MS, but here the limit is reached before issues about entrainment becomes a factor. 


\section{Journal of Radioanalytical and Nuclear Chemistry}

\section{Experimental methods}

Liquid-liquid extraction was used to separate metals from mixed solutions, as this is the separation technique preferred and commonly used by industry. If ionic strength is applied to typical industrial hydrometallurgical solutions they will have an ionic strength in excess of 5 $\mathrm{mol} / \mathrm{kg}$ [2]. However, in order to keep the solutions reproducible in the lab, we used artificial feed-solutions with 5 molal chloride concentration. Such solutions have high enough concentrations to represent many of the challenges encountered in industry and enables investigation of their frequently very none-ideal behaviour. For comparison with data more commonly reported from laboratory experiments, we included measurements on feed solutions of 0.5 molal in chloride. Due to the complexity and high concentration of the industrial solutions, the accuracy in calculating ionic strengths and activity coefficients is low $[24,25]$. Therefore, comparisons between work performed in solutions with concentrations below 1 molal and work performed with concentrations higher than 1 molal is quite challenging and must be treated with great care.

\section{Chemicals}

Aliquat 336 (assay 90\%) was supplied from Alfa Aesar and used as supplied. The toluene used was AnalR NormaPur supplied from VWR international and used as is. Salts used to prepare feed solutions were of purum grade.

Nitric acid $65 \%$ (mass/volume), Suprapur®, was purchased from Merck KGaA (Darmstadt, Germany). Water Type I (18.2 M $\Omega \mathrm{cm})$, tapped from Milli-Q® Integral Water Purification System produced by Merck Millipore (Darmstadt, Germany), was used to prepare all solutions analysed by inductive coupled plasma mass spectrometry and inductive coupled plasma atomic emission spectroscopy. For radiotracer experiments, Type II water (15 $\mathrm{M} \Omega \mathrm{cm})$ delivered by a PureLab Option Elga filter plant, was used.

Internal standard (IS) feed solution was prepared from single element standard solution of In $(1000 \mu \mathrm{g} / \mathrm{mL})$ for atomic spectroscopy purchased from Teknolab AS (Ski, Norway).

Calibration standards for were prepared from Multielement standard solution IV for ICP, TraceCERT®, in $10 \%$ nitric acid, purchased from Sigma-Aldrich Co. LLC (St. Louis, MO, USA). For the additional elements single element standards were used $(1000 \mu \mathrm{g} / \mathrm{mL})$. 


\section{Journal of Radioanalytical and Nuclear Chemistry}

\section{Liquid-liquid extraction procedure}

All measurements were performed at a minimum in triplicates. Extractions were performed at ambient temperature $\left(21(2)^{\circ} \mathrm{C}\right)$ using equal volumes of the organic and aqueous phases. 25 min shaking time was determined experimentally to be sufficient to reach equilibrium for the experimental conditions investigated in this work, i.e. the distribution-ratios had reached a stable value [23]. After shaking, the solutions were centrifuged at $4000 \mathrm{rpm}$ for $5 \mathrm{~min}$. To minimize the possibility of entrainment, the organic sample was transferred to a separate vessel for later analysis. The remaining organic phase bordering the interphase was subsequently discarded. Equal amount of aqueous phase bordering the interphase was discarded and the aqueous sample was transferred to a separate vessel for later analysis.

For back extraction measurements, the organic phase was contacted with aqueous lithium sulfate solutions and shaken for 20 minutes using a vortex shaker. As for the back extraction experiments, shaking for longer than 20 minutes showed no change in distribution ratios.

\section{ICP-MS and ICP-AES}

Concentrations of the target elements ( $\mathrm{Co}, \mathrm{Zn}$, and $\mathrm{Cd})$ was determined by using an Inductively Coupled Plasma-Mass Spectrometer (ICP-MS); model NexION® 300D, manufactured by PerkinElmer Inc. (Waltham, MA, USA). The instrument's software was NexION® ICP-MS Software (version 1.2), from the same manufacturer. The following isotopes were selected for determination with ICP-MS: ${ }^{27} \mathrm{Al},{ }^{114} \mathrm{Cd},{ }^{63 / 65} \mathrm{Cu},{ }^{59} \mathrm{Co},{ }^{52 / 53} \mathrm{Cr}$, ${ }^{55} \mathrm{Mn},{ }^{60 / 62} \mathrm{Ni},{ }^{207 / 208} \mathrm{~Pb},{ }^{66} \mathrm{Zn}$.

While the following elements were determined using inductive coupled plasma atomic emission spectroscopy (Vista Ax CCD simultaneous ICP-AES): $\mathrm{Sr}$ (407.771 nm), Te (238.579 nm), Sb (206.834 nm), W (220.449 nm),Ba (389 nm), Bi (298 nm) and Mo (379 $\mathrm{nm}$ ) with the excitations bands in parenthesis.

Sterile polypropylene tubes of $15 \mathrm{~mL}(120 \times 17 \mathrm{~mm})$ and $50 \mathrm{~mL}(115 \times 28 \mathrm{~mm})$, purchased from Sarstedt AG \& Co (Nümbrecht, Germany), were used as solution vessels during extraction-, back extraction-, and ICP-MS procedures.

For the samples analysed using ICP-MS $0.5 \mathrm{~g}$ of the aqueous solution was added to $10 \mathrm{~g}$ of $2 \%$ nitric acid $\left(\mathrm{HNO}_{3}\right)$ before they were injected into the ICP-MS. 
Limits of quantification (LOQ) were made based on two solutions: A blank solution of 5 $\mathrm{mol} / \mathrm{kg} \mathrm{HCl}$ and a blank made of $1 \mathrm{~mol} / \mathrm{kg}$ lithium sulfate solution. The LOQ was defined from the standard deviations of 10 repeated measurements of these two solutions.

\section{Radiotracers}

${ }^{65} \mathrm{Zn}$ was produced in the JEEP II reactor at Institute for Energy Technology, Kjeller, Norway. ${ }^{60} \mathrm{Co}$ was purchased from Amersham, England. Carrier free, aqueous solution of ${ }^{109} \mathrm{Cd}$ was supplied by Ecker and Ziegler, Germany.

\section{Liquid scintillation Spectroscopy}

Liquid scintillation spectroscopy using a Hidex 300 liquid-scintillation spectrometer was used to determine the amount of ${ }^{109} \mathrm{Cd}$-tracer in the solutions. This was based on measurement of the conversion-electron spectrum of ${ }^{109} \mathrm{Cd}$. The liquid scintillator cocktail used was Ultima Gold XR produced by Packard and used as supplied. The amount of ${ }^{109} \mathrm{Cd}$ in each sample was then determined by integrating the appropriate peak in the spectrum. Varying degrees of quenching of the light-transfer process by the constituents of the different solutions were compensated ("efficiency calibration") by measuring the shift in peak position of the 88-keV electron conversion line of the ${ }^{109 \mathrm{~m}} \mathrm{Ag}$ daughter from ${ }^{109} \mathrm{Cd}$-decay [26]. The quench correction curve was determined by adding $\mathrm{CCl}_{4}$, as a deliberate quencher, to known amounts of ${ }^{109} \mathrm{Cd}$ solutions [27].

The spectra were analysed using the peak-fit function of the Origin software package version 9.1 from OriginLab Corporation.

\section{High Resolution Gamma Spectroscopy}

Gamma rays were detected with a Coaxial $80 \%$ High Purity Germanium detector (HPGe) supplied from Canberra. For ${ }^{65} \mathrm{Zn}$ the area in the $1115-\mathrm{keV}$ peak was used and for ${ }^{60} \mathrm{Co}$ the area sum of the peaks from the 1173-keV and 1332-keV transitions was used. The spectra were recorded and analysed using the Maestro software suite (version 6.08) developed and supplied by Ortec, Oak Ridge, Tennessee, USA.

\section{Preparation of feed solution}

A feed solution was generated by dissolving 10 chloride metal salts and aluminium oxide, tungsten oxide, tellurium oxide, molybdenum oxide, barium oxide and bismuth oxide using 4 $\mathrm{mol} / \mathrm{kg}$ hydrochloric acid made from a $37 \% \mathrm{HCl}$ analytical grade acid. The solution was then used to generate two feed solutions with the concentrations described in Table 1. ICP-AES 
was used as a preliminary analysis of the feed, before it became clear that the accuracy of the ICP-MS was needed.

Table 1. The concentration of elements in the solution used as feed in the extraction tests. Entries

that only were measured using ICP-AES are indicated by a star (*)

\begin{tabular}{|c|c|c|c|c|c|c|c|c|}
\hline & $\mathrm{Al}$ & $\mathrm{Ba}^{*}$ & $\mathrm{Bi}^{*}$ & $\mathrm{Cd}$ & $\mathrm{Cu}$ & $\mathrm{Co}$ & $\mathrm{Cr}$ & $\mathrm{Mn}$ \\
\hline $\begin{array}{l}\text { Starting } \\
\text { mass } \\
\mathrm{g} / \mathrm{kg}\end{array}$ & 1 & 1 & 1 & 0.8 & 0.9 & 0.7 & 1 & 1 \\
\hline \multirow{2}{*}{$\begin{array}{l}\text { Conc. at } \\
\text { extraction } \\
\mathrm{mg} / \mathrm{kg}\end{array}$} & $4.71(9)$ & $>0.2$ & $33.5(2)$ & $29.4(6)$ & $32.22(21)$ & $22.86(9)$ & 19.64(5) & $37.35(17)$ \\
\hline & Mo* & $\mathrm{Ni}$ & $\mathrm{Pb}$ & $\mathrm{Sb}^{*}$ & $\mathrm{Sr}^{*}$ & $\mathrm{Te}^{*}$ & $\mathrm{~W}^{*}$ & $\mathrm{Zn}$ \\
\hline $\begin{array}{l}\text { Starting } \\
\text { mass } \\
\mathrm{g} / \mathrm{kg}\end{array}$ & 1 & 1 & 1 & 0.9 & 1 & 1.5 & 1 & 1 \\
\hline $\begin{array}{l}\text { Conc. at } \\
\text { extraction } \\
\mathrm{mg} / \mathrm{kg}\end{array}$ & $31.93(5)$ & $36(5)$ & $14.86(12)$ & $32.11(16)$ & $28.45(11)$ & $38(2)$ & $2.36(4)$ & $34.0(3)$ \\
\hline
\end{tabular}

\section{Results and discussion}

253 Fig. 3shows the D-ratios for extraction and back extraction of $\mathrm{Cd}, \mathrm{Zn}$, and Co radiotracers.

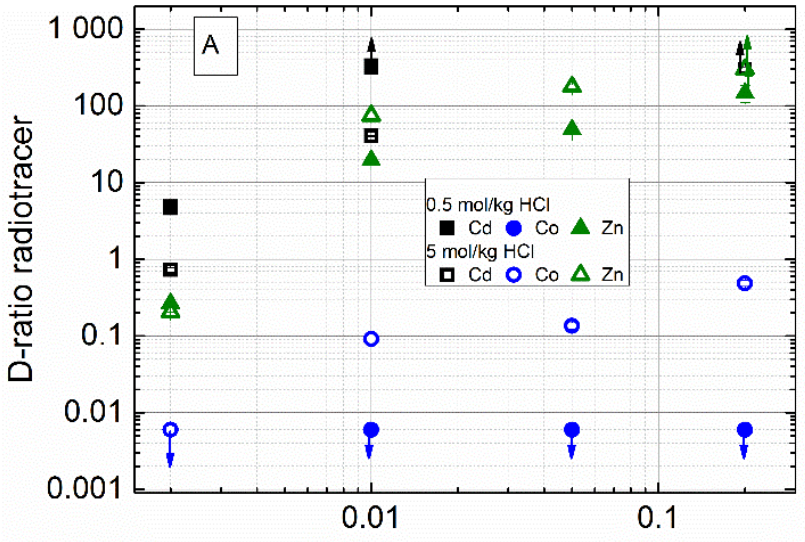

[A336] $\mathrm{mol} / \mathrm{kg}$

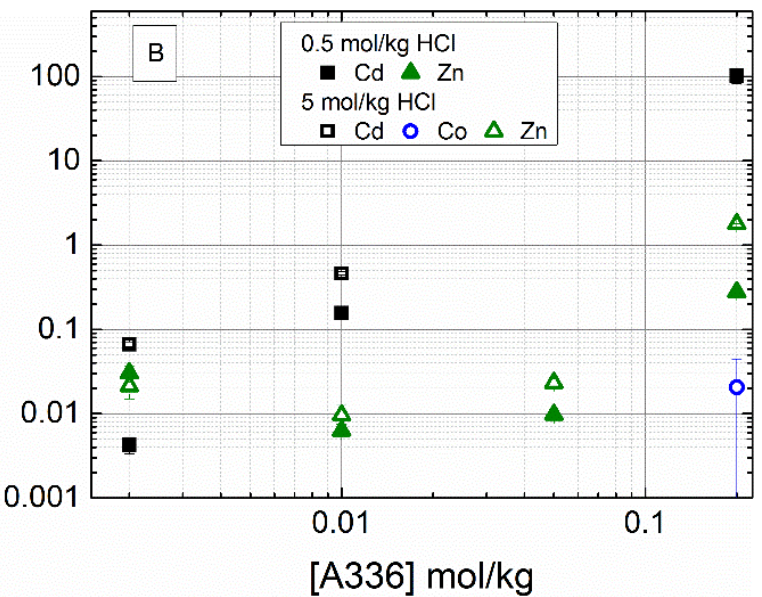

[A336] $\mathrm{mol} / \mathrm{kg}$

Fig. 3D-ratios for extraction (left panel) and D-ratios for back extraction (right panel) of Cd, Co 

and $\mathrm{Zn}$ from 0.5 and $5 \mathrm{~mol} / \mathrm{kg} \mathrm{HCl}$ determined with radiotracers. Back extraction was performed using $1 \mathrm{~mol} / \mathrm{kg}$ lithium sulfate. Error bars show one standard deviation

Co was extracted in measurable quantities for the $5 \mathrm{~mol} / \mathrm{kg}$ acid concentration, but to a lower degree than $\mathrm{Zn}$ and $\mathrm{Cd}$. Cd-extraction decreased when more acid was added. A reasonable explanation for this is that the higher acid- and corresponding chloride concentrations increase the amount of negatively extractable species, which therefore becomes a stronger competitor for the available A336 to form extractable species. Similar to $\mathrm{Cd}$, the extraction of $\mathrm{Zn}$ increases with the increasing acid/chloride concentration. When the concentration of the A336 increases the D-ratio for all three species becomes higher and at some point reaches the limit of how high D-ratios it is possible to determine within the experimental conditions used in this work. The back extraction shows that higher A336 concentrations and higher $\mathrm{HCl}$ concentration lower the amount back extracted. In addition as the organic phase is different from the virgin organic phase the experiments could not be performed using fresh activity but the same samples had to be use for both extraction and back extraction. For Co which had low extraction this increased the uncertainty.

Table 2 shows the separation factors for $\mathrm{Cd}$ and $\mathrm{Zn}$ from Co, based on the data shown in Fig. 3. It is not possible to quantify the highest separation factors since the D-ratios for $0.5 \mathrm{~mol} / \mathrm{kg}$ $\mathrm{HCl} \mathrm{Co} \mathrm{are} \mathrm{too} \mathrm{low} \mathrm{to} \mathrm{measure} \mathrm{accurately.} \mathrm{The} \mathrm{D-ratios} \mathrm{are} \mathrm{limited} \mathrm{by} \mathrm{available} \mathrm{measurement}$ time/instrument capacity. As already mentioned, for very low or high D-ratios entrainment and operational uncertainty will become the limiting factor.

Table 2. Separation ratios between $\mathrm{Cd} / \mathrm{Co}$ and $\mathrm{Zn} / \mathrm{Co}$ measured with radiotracers for two different acid concentrations

\begin{tabular}{|l|l|l|l|l|}
\hline $\mathrm{A} 336(\mathrm{~mol} / \mathrm{kg})$ & $\mathrm{HCl}(\mathrm{mol} / \mathrm{kg})$ & $\mathrm{D}(\mathrm{Co})$ & $\mathrm{D}(\mathrm{Cd})$ & $\alpha_{C o}^{C d}$ \\
\hline 0.2 & 0.5 & $<6 \cdot 10^{-3}$ & $>300$ & $>5 \cdot 10^{4}$ \\
\hline 0.01 & 0.5 & $<6 \cdot 10^{-3}$ & $>300$ & $>5 \cdot 10^{4}$ \\
\hline 0.002 & 0.5 & $<6 \cdot 10^{-3}$ & $4.73(13)$ & $>17$ \\
\hline 0.2 & 5 & $0.48(4)$ & $>300$ & $>1 \cdot 10^{3}$ \\
\hline 0.01 & 5 & $0.136(13)$ & $40.6(9)$ & $300(30)$ \\
\hline 0.002 & 5 & $<6 \cdot 10^{-3}$ & $0.73(5)$ & $>120$ \\
\hline
\end{tabular}




\begin{tabular}{|l|l|l|l|l|}
\hline & & $\mathrm{D}(\mathrm{Co})$ & $\mathrm{D}(\mathrm{Zn})$ & $\alpha_{C o}^{Z n}$ \\
\hline 0.2 & 0.5 & $<6 \cdot 10^{-3}$ & $>300$ & $>5 \cdot 10^{4}$ \\
\hline 0.05 & 0.5 & $<6 \cdot 10^{-3}$ & $50(4)$ & $>8 \cdot 10^{3}$ \\
\hline 0.01 & 0.5 & $<6 \cdot 10^{-3}$ & $19.70(17)$ & $>3 \cdot 10^{3}$ \\
\hline 0.002 & 0.5 & $<6 \cdot 10^{-3}$ & $0.2670(4)$ & $>45$ \\
\hline 0.2 & 5 & $0.48(4)$ & $>300$ & $600(50)$ \\
\hline 0.05 & 5 & $0.136(13)$ & $180(11)$ & $1.32(16) \cdot 10^{3}$ \\
\hline 0.01 & 5 & $0.092(14)$ & $74(8)$ & $800(100)$ \\
\hline 0.002 & 5 & $<6 \cdot 10^{-3}$ & $0.205(7)$ & $>1.2$ \\
\hline
\end{tabular}

The stripping efficiency of lithium sulfate, i.e. how efficiently extracted $\mathrm{Co}, \mathrm{Cd}$, and $\mathrm{Zn}$ can be removed from the organic phase when contacted with an aqueous phase of lithium sulfate, seems to be heavily dependent on two variables: The Aliquat concentration and the initial $\mathrm{HCl}$ concentration of the feed. At A336 concentrations of $0.2 \mathrm{~mol} / \mathrm{kg}$ there seems to be nearly no back extraction of $\mathrm{Cd}$, thus the element is nearly completely retained in the organic phase. However, as the A336 concentration is lowered there is more Cd transported to the aqueous phase. $\mathrm{Zn}$ is similarly affected but is easier to remove from the organic solution. The Co found in the organic phase is easily removed.

The stripping utilizes the equilibrium between the organic and the aqueous phase and it is assumed that the sulfate content in the aqueous phase shift the species to a neutral species. Accordingly, the suggested explanation for sulfate back-extraction is:

$$
\mathrm{MCl}_{3}^{-}+\mathrm{SO}_{4}^{2-} \rightleftharpoons \mathrm{MSO}_{4}+3 \mathrm{Cl}^{-}
$$

where $\mathrm{M}$ is the metal in question. The proposed mechanism is that the sulfate shifts the dominating species from chloride to a neutral species. For the extraction to work it is then important that sulfate dominates and the more chloride there is in the organic phase the less efficient sulfate will be as extractant. Table 3 shows the relevant literature equilibrium- and stability constants for the suggested species. Considering the values listed in Table 3, higher stability constants for the chloride species will lead to more metal being retained, while high stability constants for sulfate species will lead to better stripping. 
Table 3 stability constant for the various metal species with sulfate and chloride

\begin{tabular}{|l|l|l|l|}
\hline Metal & $\mathrm{Cl}^{-}$as a ligand & $\mathrm{SO}_{4}^{2-}$ as a ligand & Ref. \\
\hline $\mathrm{Cd}$ & $\log _{10} \beta_{3}=2.36$ & $\log _{10} \mathrm{~K}_{1}=2.3$ & {$[32]$} \\
\hline $\mathrm{Zn}$ & $\log _{10} \beta_{3}=0.43$ & $\log _{10} \mathrm{~K}_{1}=2.3$ & {$[33]$} \\
\hline $\mathrm{Co}$ & $\log _{10} \beta_{3}=-5.92$ & $\log _{10} \mathrm{~K}_{1}=2.47$ & {$[34]$} \\
\hline
\end{tabular}

Fig. 4 shows the D-ratios of extraction and back extraction measured using ICP-MS. The concentration of $\mathrm{Zn}$ and $\mathrm{Cd}$ is only determinable at $0.002 \mathrm{~mol} / \mathrm{kg} \mathrm{A} 336$.
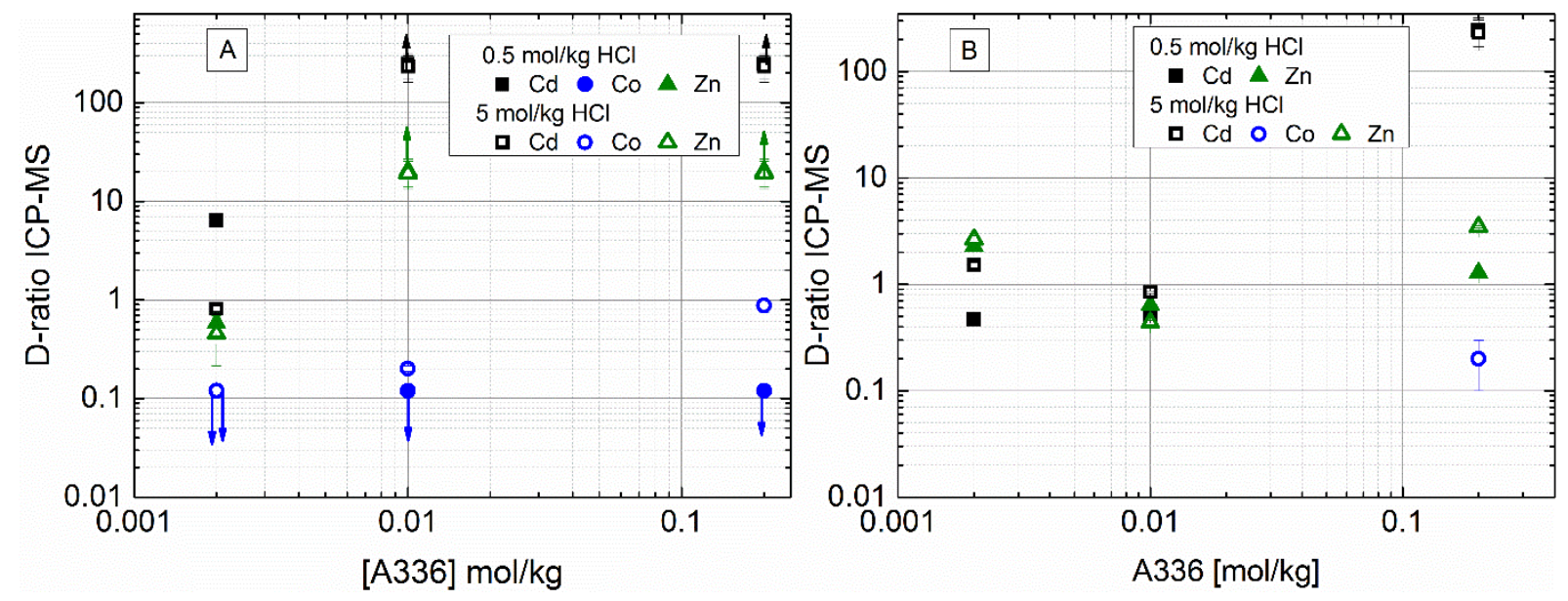

Fig. 4. D-ratio (left panel) and D-ratio back extraction (right panel) of Cd, Co and $\mathrm{Zn}$ from 0.5 and $5 \mathrm{~mol} / \mathrm{kg} \mathrm{HCl}$ as measured with ICP-MS. Back extraction was performed using $1 \mathrm{~mol} / \mathrm{kg}$ lithium sulfate. Error bars represent one standard deviation, arrows indicate that the upper and/or lower standard deviation could not be determined.

When the single-phase data, as obtained in the ICP-MS measurements, is compared to the two-phase data obtained with measurements of the radiotracers, the single-phase data have higher minimum D-ratios and lower maximum D-ratios than the radiotracers. This trend will of course also affect the separation factors, as shown in Table 4. The separation factors obtained from ICP-MS measurements are both lower and less well defined (more uncertain) than for the radiotracer data. 
Table 4. Separation ratio between $\mathrm{Cd} / \mathrm{Co}$ and $\mathrm{Zn} / \mathrm{Co}$ for the different acid concentrations measured with ICP-MS

\begin{tabular}{|l|l|l|l|l|}
\hline A336 mol/kg & $\mathrm{HCl} \mathrm{mol} / \mathrm{kg}$ & $\mathrm{D}(\mathrm{Co})$ & $\mathrm{D}(\mathrm{Cd})$ & $\alpha_{\text {Co }}^{C d}$ \\
\hline 0.2 & 0.5 & $<0.12$ & $>240$ & $>1.2 \cdot 10^{3}$ \\
\hline 0.01 & 0.5 & $<0.12$ & $>240$ & $>1.2 \cdot 10^{3}$ \\
\hline 0.002 & 0.5 & $<0.12$ & $7.2(5)$ & $>23$ \\
\hline 0.2 & 5 & $0.88(13)$ & $>230$ & $>260$ \\
\hline 0.01 & 5 & $0.201(14)$ & $>230$ & $>1.15 \cdot 10^{3}$ \\
\hline 0.002 & 5 & $<0.12$ & $0.81(5)$ & $>4$ \\
\hline A336 mol/kg & $\mathrm{HCl} \mathrm{mol} / \mathrm{kg}$ & $\mathrm{D}(\mathrm{Co})$ & $\mathrm{D}(\mathrm{Zn})$ & $\alpha_{C o}^{Z n}$ \\
\hline 0.2 & 0.5 & $<0.12$ & $>20$ & $>100$ \\
\hline 0.01 & 0.5 & $<0.12$ & $>20$ & $>100$ \\
\hline 0.002 & 0.5 & $<0.12$ & $0.62(15)$ & $>3$ \\
\hline 0.2 & 5 & $0.9(13)$ & $>19$ & $>20$ \\
\hline 0.01 & 5 & $0.201(13)$ & $>19$ & $>3$ \\
\hline 0.002 & 5 & $<0.12$ & $0.46(24)$ & \\
\hline For & & & & \\
\hline
\end{tabular}

319 For a more thorough comparison of single-phase measurement and two-phase measurements

320 Table 5 shows the distribution and extraction percentage for both techniques.

321 Table 5. Comparison of measured D-ratios and \% of $\mathrm{Cd}, \mathrm{Zn}$ or Co extracted (denoted as \% in org) performed with ICP-MS and by applying radiotracers. If the measurements are significantly different (outside the $\mathbf{9 5 \%}$ confidence interval) it is marked with a "Y", otherwise a

\begin{tabular}{|c|c|c|c|c|c|}
\hline \multirow{2}{*}{$\begin{array}{l}\text { A } 336 \\
\text { conc. } \\
\text { mol/kg }\end{array}$} & \multirow{2}{*}{$\begin{array}{l}\text { Significant } \\
\text { difference }\end{array}$} & \multicolumn{2}{|c|}{ Radiotracers } & \multicolumn{2}{|c|}{ ICP-MS } \\
\hline & & D-ratio & $\%$ in org & D-ratio & $\%$ in org. \\
\hline \multicolumn{6}{|c|}{ Extraction of Cd from $0.5 \mathrm{~m} \mathrm{HCl}$} \\
\hline 0.2 & & $>300$ & $>99.7$ & $>250$ & $>99.6$ \\
\hline 0.01 & & $>300$ & $>99.7$ & $>250$ & $>99.6$ \\
\hline
\end{tabular}




\begin{tabular}{|c|c|c|c|c|c|}
\hline 0.002 & Y & $4.74(13)$ & $83(4)$ & $6.6(6)$ & $87(6)$ \\
\hline \multicolumn{6}{|c|}{ Stripping of $\mathrm{Cd}$ after contact with $0.5 \mathrm{~m} \mathrm{HCl}$} \\
\hline 0.2 & & $100(20)$ & $98.70(18)$ & $>250$ & $>99.6$ \\
\hline 0.01 & $\mathrm{Y}$ & $0.157(14)$ & $13.5(11)$ & $0.50(5)$ & $33.2(19)$ \\
\hline 0.002 & & $0.0043(9)$ & $0.35(9)$ & $0.28(5)$ & 19(3) \\
\hline \multicolumn{6}{|c|}{ Extraction of Cd from $5 \mathrm{~m} \mathrm{HCl}$} \\
\hline 0.2 & & $>300$ & $>99.7$ & $>230$ & $>99.5$ \\
\hline 0.01 & $\mathrm{Y}$ & $40.6(9)$ & $97.60(13)$ & $>230$ & $>99.5$ \\
\hline 0.002 & $\mathrm{~N}$ & $0.73(5)$ & 42(3) & $0.82(6)$ & $45.0(18)$ \\
\hline \multicolumn{6}{|c|}{ Stripping of Cd after contact with $5 \mathrm{~m} \mathrm{HCl}$} \\
\hline 0.2 & & $>300$ & $>99.7$ & $>230$ & $>99.5$ \\
\hline 0.01 & $\mathrm{Y}$ & $0.463(19)$ & $30.9(9)$ & $0.848(18)$ & $45.7(5)$ \\
\hline 0.002 & $\mathrm{Y}$ & $0.067(5)$ & $2.6(4)$ & $1.5(11)$ & $27(5)$ \\
\hline \multicolumn{6}{|c|}{ Extraction of $\mathrm{Zn}$ from $0.5 \mathrm{~m} \mathrm{HCl}$} \\
\hline 0.2 & & $>300$ & $>99.7$ & $>20$ & $>95$ \\
\hline 0.01 & & $19.69(17)$ & $95.17(8)$ & $>20$ & $>95$ \\
\hline 0.002 & $\mathrm{Y}$ & $0.267(20)$ & $21.07(4)$ & $0.58(3)$ & $37(3)$ \\
\hline \multicolumn{6}{|c|}{ Stripping of $\mathrm{Zn}$ after contact with $0.5 \mathrm{~m} \mathrm{HCl}$} \\
\hline 0.2 & $\mathrm{Y}$ & $0.278(23)$ & $21.6(14)$ & $1.29(4)$ & $53.8(13)$ \\
\hline 0.01 & $\mathrm{Y}$ & $0.0063(12)$ & $0.59(12)$ & $0.61(4)$ & $36.2(16)$ \\
\hline 0.002 & $\mathrm{Y}$ & $0.030(7)$ & $0.6(6)$ & $2.27(17)$ & $25(5)$ \\
\hline \multicolumn{6}{|c|}{ Extraction of $\mathrm{Zn}$ from $5 \mathrm{~m} \mathrm{HCl}$} \\
\hline 0.2 & & $>300$ & $>99.7$ & $>20$ & $>95$ \\
\hline 0.01 & & 74(8) & $98.7(3)$ & $>20$ & $>95$ \\
\hline 0.002 & $\mathrm{Y}$ & $0.206(7)$ & $16.99(3)$ & $0.46(4)$ & $31(4)$ \\
\hline \multicolumn{6}{|c|}{ Stripping of $\mathrm{Zn}$ after contact with $5 \mathrm{~m} \mathrm{HCl}$} \\
\hline 0.2 & $\mathrm{Y}$ & $1.7920(18)$ & $64(3)$ & $3.51(4)$ & $77.6(5)$ \\
\hline 0.01 & $\mathrm{Y}$ & $0.009(3)$ & $0.88(3)$ & $0.38(3)$ & $26.3(15)$ \\
\hline 0.002 & $\mathrm{Y}$ & $0.021(6)$ & $0.3(5)$ & $2.6(17)$ & $25(5)$ \\
\hline \multicolumn{6}{|c|}{ Co extraction from $5 \mathrm{~m} \mathrm{HCl}$} \\
\hline 0.2 & $\mathrm{Y}$ & $0.49(4)$ & $33(4)$ & $0.80(16)$ & $47(3)$ \\
\hline 0.01 & $\mathrm{Y}$ & $0.096(14)$ & $8.7(8)$ & $0.199(8)$ & $16.7(7)$ \\
\hline \multicolumn{6}{|c|}{ Co Stripping from $5 \mathrm{~m} \mathrm{HCl}$} \\
\hline
\end{tabular}




\begin{tabular}{|l|l|l|l|l|l|}
\hline 0.2 & $\mathrm{~N}$ & $0.020(24)$ & $0.64(23)$ & $0.17(12)$ & $11.6(9)$ \\
\hline
\end{tabular}

326

327

328

329

330

331

332

333

334

335

336

337

338

339

340

341 Based on this, Fig. 5was generated assuming that at a maximum there were $10^{6}$ counts to

Table 5 shows that the measurement techniques gives statistically significantly different Dratios for most concentrations. Direct measurements point-by-point show that single-phase measurements generally overestimate the D-ratio. There is only one single measurement $(0.002 \mathrm{~mol} / \mathrm{kg} \mathrm{A} 336$ and $5 \mathrm{~mol} / \mathrm{kg} \mathrm{HCl})$ where the two-phase measurement gives the highest D-ratio. In addition, when comparing the extraction of Cd at $0.01 \mathrm{~mol} / \mathrm{kg} \mathrm{A} 336$ and $5 \mathrm{~mol} / \mathrm{kg}$ $\mathrm{HCl}$ two phase measurements give a D-ratio of 41 and single-phase measurements suggest that the D-ratio is higher than 230. This implies that using LOQ as the limit to determine the maximum D-ratio probably overestimates the value.

The uncertainty of low D-ratios for single-phase measurements grow faster than for the twophase measurements, as shown for a hypothetical case in Fig. 5 The graph was obtained by assuming the measured concentrations was determined by counts (area of peaks in a spectrum) which obey the Poisson distribution. Therefore, $\sigma_{\text {feed }}, \sigma_{\text {raf }}$, and $\sigma_{\text {org }}$ can be calculated as $\sqrt{\left[M_{\text {feed }}\right]}, \sqrt{\left[M_{\text {raf }}\right]}, \sqrt{\left[M_{\text {org }}\right]}$ since the standiard variation of $\mathrm{N}$ counts equal the square root of $\mathrm{N}$ according to the Poisson distribution statistics. This means that Eq. 2 and Eq. 5 becomes:

$$
\begin{gathered}
\sigma_{D}=D \sqrt{\left(\frac{\sqrt{\left[M_{\text {org }}\right]}}{\left[M_{\text {org }}\right]}\right)^{2}+\left(\frac{\sqrt{\left[M_{\text {raf }}\right]}}{\left[M_{\text {raf }}\right]}\right)^{2}} \\
\sigma_{D}=(D+1) \sqrt{\left(\frac{\sqrt{\left[M_{\text {feed }}\right]}}{\left[M_{\text {feed }}\right]}\right)^{2}+\left(\frac{\sqrt{\left[M_{\text {raf }}\right]}}{\left[M_{\text {raf }}\right]}\right)^{2}}
\end{gathered}
$$

342 distribute between the phases. It clearly shows that at lower D-ratios than 10 the relative 343 uncertainty of single-phase measurements increases rapidly compared to two-phase 344 measurements. 


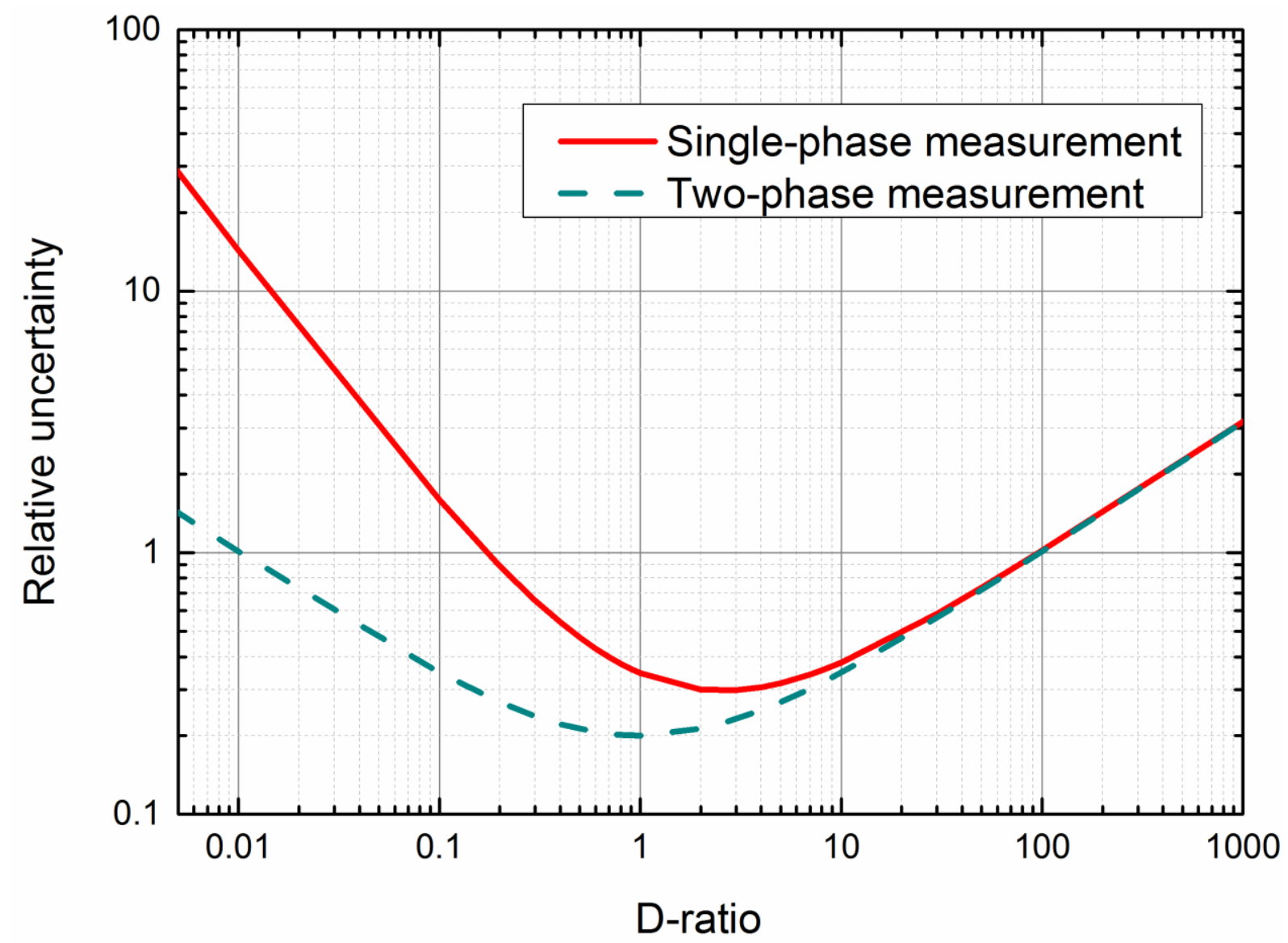

Fig. 5 Hypothetical uncertainty trend in one-phase and two-phase measurements calculated by assuming measurements obey Poisson-distribution statistics

Fig. 6 shows how the minimum determinable D-ratios is dependent on the number of replicas for single-phase measurements. With a higher number of replicas the degrees of freedom increases and thus makes the t-value smaller. The critical concentration difference between feed and raffinate will then decrease and therefore smaller D-ratios can be measured. Eq. 10 was used to determine the degrees of freedom and Eq. 9 was used to calculate the raffinate concentration. 


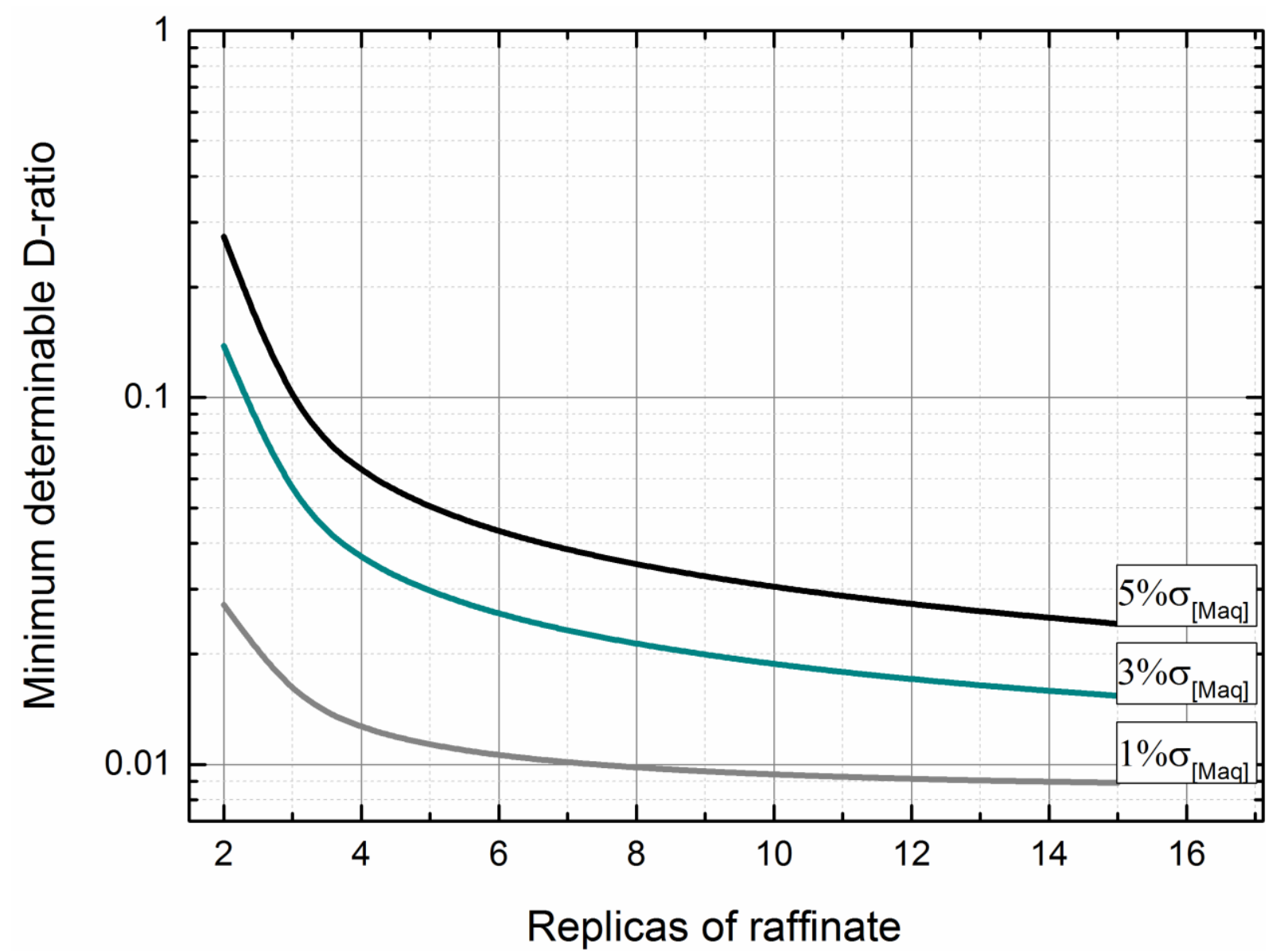

Fig. 6 Minimum measurable D-ratio calculated using a feed solution uncertainty of $1 \%$ and 6 replicas of the feed solution, with a one sided t-test

Figures 4 and 5 provide insight into why reported D-ratios are higher when using one-phase measurements: Firstly, for one-phase measurements the lower D-ratios will have a substantially higher standard deviation and secondly, at low D-ratios the concentrations become impossible do discern from the feed solution.

A different explanation for the higher D-values for single-phase measurement could be related to entrainment and organic material. Carbon is known for increasing the sensitivity of ICPMS [35]. If there is carbon in the raffinate this would result a systematic higher concentration in the raffinate. However, both toluene and A336 have very limited solubility in aqueous solutions with high ionic strength, and all samples were diluted before they were injected in the ICP-MS, thus carbon should not have affected the measurement reported in this work. 
368

369

370

371

372

373

374

375

376

377

378

379

380

381

382

383

384

385

\section{Conclusions}

Separation of $\mathrm{Cd}$ and $\mathrm{Zn}$ from Co more efficient at an acid concentration of $0.5 \mathrm{~mol} / \mathrm{kg} \mathrm{HCl}$ than $5 \mathrm{~mol} / \mathrm{kg} \mathrm{HCl}$. However, it is not possible to properly define the separation factor as the D-ratios for Co are too low. Using an A336 concentration of $0.01 \mathrm{~mol} / \mathrm{kg}$ and an acid concentration of $5 \mathrm{~mol} / \mathrm{kg}$ gives a separation factor of 300(30) for Cd and 1400(200) of $\mathrm{Zn}$ relative to Co. Cd is not satisfactorily stripped when the A336 concentration is $0.2 \mathrm{~mol} / \mathrm{kg}$ in toluene, and the stripping of $\mathrm{Zn}$ is also reduced. The amount of hydrochloric acid in the feed determine the amount of separation and the ease of stripping.

Determination of D-ratios: Low D-ratios are limited by how well the metal concentration in the feed can be determined. The lowest possible D-ratio is determined by the minimum difference between feed and raffinate that can be measured.

The analysis performed also showed that single-phase measurements, as performed using ICP-MS, on average had a higher D-ratio than two-phase measurements performed with the use of radiotracers. Therefore, ICP-MS measurements should be used with care when discussing extraction mechanisms and speciation, as this frequently involve analysing extraction curves obtain from very low and very high D-ratios. This should also be kept in mind when using ICP-MS data from literature.

Extraction of negatively charged chloride complexes is an efficient method to discriminate $\mathrm{Zn}$ and $\mathrm{Cd}$ from $\mathrm{Co}$, but also from $\mathrm{Al}, \mathrm{Cr}, \mathrm{Mn}, \mathrm{Ni}, \mathrm{Pb}, \mathrm{Sb}, \mathrm{Sr}, \mathrm{Te}$, and $\mathrm{W}$.

\section{Acknowledgements}

The authors are grateful for the financial support from the Norwegian Research Council and industry companies Yara International, Glencore Nikkelverk, and Boliden Odda. The support was channelled through Norwegian Research Council project BIA-KPN project number 2366741. Thanks to Eddy Walter Hansen and Ørnulf Borgan for discussion regarding the statistics. 


\section{Journal of Radioanalytical and Nuclear Chemistry}

References

1. Mudd GM (2009) The Sustainability of Mining in Australia: Key Production Trends and Their Environmental Implications for the Future (trans: Engineering DoC). Monash University and Mineral Policy Institute,

2. Stensholt EO, Zachariasen H, Lund JJ (1986) Falconbridge Chlorine Leach Process, . Transactions of the Institution of Mining and Metallurgy 5:10-16

3. Selmer-Olsen AR (1966) Solvent Extraction of Chlorocomplexes by Triisooctylamin/Carbon Tetrachloride from Hydrochloric Acid medium. Acta Chemica Scandinavica 20:1621-1625 4. Rice NM, Smith MR (1975) Recovery of Zinc, Cadmium and Mercury(II) from Chloride and Sulphate Media by Solvent Extraction J Chem Technol Biotechnol 25 (379-402) 5. Sato T, Shimomura T, Murakami S, Maeda T, Nakamura T (1984) Liquid-Liquid Extraction of Divalent Manganese, Cobalt, Copper, Zinc and Cadmium From Aqueous Chloride Solutions by Tricaprylmethylammonium Chloride. Hydrometallurgy 12:245-254

6. Sato T, Adachi K, Kato T, Nakamura T (1982) The Extraction of Divalent Manganese, Cobalt, Copper, Zinc, and Cadmium from Hydrochloric Acid Solutions by Tri-n-Octylamine. Sep Sci Technol $17: 1565-1576$

7. Mahlman HA, Leddicote GW, Moore FL (1954) Separation of Cobalt and Zinc by Liquid-liquid Extraction. Analytical Chemistry 26

8. Wassink B, Dreisinger D, Howard J (2000) Solvent Extraction Separation of Zinc and Cadmium from Nickel and Cobalt using Aliquat 336, a strong Base Anion Exchanger, in the Chloride and Thiocyanate forms. Hydrometallurgy 57:235-252

9. Wang L, Paimin R, Cattrall RW, Shen W, Kolev SD (2000) The Extraction of Cadmium(II) and Copper(II) from Hydrochloric Acid Solutions using an Aliquat 336/PVC Membrane. J Membr Sci 176:105-111 10. Juang R-S, Kao H-C, Wu W-H (2004) Analysis of Liquid Membrane Extraction of Binary Zn(II) and Cd(II) from Chloride Media with Aliquat 336 Based on Thermodynamic Equilibrium Models. J Membr Sci 228:169-177

11. Dalali N, Habibi H (2015) Facilitated Transport of Cadmium by Bulk Liquid Membrane using Aliquat 336 as Carrier: Separation from other Heavy Metal Ions. Desalination and Water Treatment 56 (6):1601-1609. doi:10.1080/19443994.2014.951973

12. Daud H, Cattrall RW (1981) The Extraction of $\mathrm{Hg}(\mathrm{II})$ from Potassium Iodide Solutions and the Extraction of $\mathrm{Cu}(\mathrm{II}), \mathrm{Zn}(\mathrm{II})$ and $\mathrm{Cd}(\mathrm{II})$ from Hydrochloric Acid Solutions by Aliquat 336 Dissolved in Chloroform. J Radioanal Nucl Chem 43:779-785

13. Paimin R, Cattrall RW (1983) The Extraction of Cobalt(II) from Hydrochloric Acid Solutions by Aliquat 336R Dissolved in Chloroform. Aust J of Chem 36:1017-1020 


\section{Journal of Radioanalytical and Nuclear Chemistry}

14. Bagreev VV, Fischer C, Kardivarenko LM, Zolotov YA (1982) Mutual Influence of Metals in the Extraction of Their Chloride Complexes with Tri- $n$-Octylamine and Aliquat 336 in Nitrobenzene. Polyhedron 1:623-627

15. Bagreev VV, Fischer C, Yuduskina LM, Zolotov YA (1978) Mutual Influence of Metals in The Extraction of Their Chloride Complexes with Tri-n-Octylamine and Aliquat 336 in Benzene. J Inorg Nucl Chem 40:553-557

16. Taichi Sato, Hiroshi Watanabe (1970) The Extraction of Zirconium(IV) from Hydrochloric Acid Solutions by Tricaprylmethylammonium Chloride. Anal Chim 49:463-471

17. Sato T, Kato T (1976) The Stability Constants of Chloro Complexes of Copper(II) and Zinc(II) Determined by Tri- $n$-Octylamine Extraction. J Inorg Nucl Chem 39:1205-1208

\section{Sato T, Murakami S (1976) Determination of the Activity Coefficient of}

Tricaprylmethylammonium Chloride and the stability Constants of the Aqueous Complexes formed in the Extraction of Zinc(II) from Hydrochloric Acid Solutions. Anal Chem 82:217-221

19. Daud H, Cattrall RW (1980) The extraction of Cd(II) and Zn(II) from Acidified Lithium Chloride Solutions by Aliquat 336 in Chlorform. J Radioanal Nucl Chem 43:599-601

20. Daud H, Cattrall RW (1982) The Extraction of Zinc(II) from Chloride Solutions by

Methyltrioctylammonium and Methyltridecylammonium Chlorides Dissolved in Chloroform and Other Diluents and a Comparison with Aliquat 336. Australian Journal of Chemistry 35:1087-1093

21. Daud H, Cattrall RW (1982) The Mechanism of Extraction of Zinc(II) from Aqueous Chloride Solutions into Chloroform Solutions of Methyltrioctylammonium Chloride. Aust J of Chem 35:10951103

22. Wei G-T, Yang Z, Chen C-J (2003) Room Temperature Ionic Liquid as a Novel Medium for Liquid/Liquid extraction of Metal Ions. Analytica Chimica Acta 488:183-192

23. Lerum HV, Andersen NH, Eriksen DØ, Hansen EW, Petersen D, Wibetoe G, Omtvedt JP (2018) Study of Cadmium Extraction with Aliquat 336 from Highly saline Solutions. Journal of Solution Chemistry 47 (8):1395-1417

24. Marcus Y, Kertes AS (1969) Aqueous Solutions of Electrolytes. Ion Exchange and Solvent Extraction of Metal Complexes.

25. Muir DM The Application of Thermodynamic to Extractive Metallurgy with Chloride Solutions a Review. Warren Spring Laboratory

26. Kristiansen H (2015) Radiochemical Analysis of Cadmium in Nitric and Phosphoric acid. master thesis, University of Oslo,

27. Pacer RA (1991) Liquid Scintillation and Cherenkov Counting Characteristics of 109 Cd. J

Radioanal Nucl Chem, Letters 155 (2):129-140

28. Ritcey GM (1992) Development of Industrial Solvent Extraction Processes. Principles and Practices of Solvent Extraction. 
466

467

468

469

470

471

472

473

474

475

476

477

478

479

480

481

482

483

484

485

486

487

488

29. Welch BL (1947) the Generalization of 'students' Problem when Several Different Population Variances are Involved. Biometrika 34:28-35. doi:https://doi.org/10.1093/biomet/34.1-2.28

30. Gaylor DW, Hopper FN (1969) Estimating the Degrees of Freedom for Linear Combinations of Mean Squares By Satterthwaite's Formula. Technometrics 11 (4):691-706.

doi:https://doi.org/10,1080/0040176,1969,10490732

31. Miller JN, Miller JC (2005) Significance Test. Statistics and Chemometrics for Analytical

Chemistry Fifth Edition.

32. Powell KJ, Brown PL, Byrne RH, Gajda T, Hefter G, Leuz A-k, Sjöberg S, Wanner H (2011)

Chemical Speciation of Environmentally Significant Metals with Inorganic Ligands. Part 4: The $\mathrm{Cd}^{2+}$ $+\mathrm{OH}^{-}, \mathrm{Cl}^{-}, \mathrm{CO}_{3}{ }^{2-}, \mathrm{SO}_{4}{ }^{2}$-, and $\mathrm{PO}_{4}{ }^{3-}$ Systems (IUPAC Technical Report) Pure Appl Chem 83 (5):1163-

1214. doi:10.1351/PAC-REP-10-08-09

33. Powell KJ, Brown PL, Byrne RH, Gajda T, Hefter G, Leuz A-k, Sjöberg S, Wanner H (2013)

Chemical Speciation of Environmentally Significant Metals with Inorganic Ligands. Part 5: The $\mathrm{Zn}^{2+}+\mathrm{OH}^{-}, \mathrm{Cl}^{-}, \mathrm{CO}_{3}{ }^{2-} \mathrm{SO}_{4}{ }^{2-}$. and $\mathrm{PO}_{4}{ }^{3-}$ systems (IUPAC Technical Report). Pure and Applied Chemistry 85 (12):2249-2311. doi:http://dx.doi.org/10.1351/PAC-REP-13-06-03

34. Sillên LG, Martell AE (1957) Stability Constants, Special Publication No. 17.

35. Allain P, Jaunault L, Mauras Y, Mermet J-M, Delaporte T (1991) Signal Enhancemenet of elements Due to the Presence of Carbon-Containing Compounds in Inductively Coupled Plasma Mass Spectrometry. Anal Chem 63:1497-1498

\section{Appendix}

Table A1. D-ratios of extraction and back extraction for $\mathrm{Cd}, \mathrm{Zn}$, and $\mathrm{Co}$. With radiotracers and ICP-MS

\begin{tabular}{lccccc}
\hline Element & $\begin{array}{c}\text { Measurement } \\
\text { method }\end{array}$ & $\begin{array}{c}\mathrm{A} 336 \\
\text { Conc. }[\mathrm{mol} / \mathrm{kg}]\end{array}$ & $\begin{array}{c}\mathrm{HCl} \text { Conc. } \\
{[\mathrm{mol} / \mathrm{kg}]}\end{array}$ & $\begin{array}{c}\text { D-ratio } \\
\text { extraction }\end{array}$ & $\begin{array}{c}\text { D-ratio } \\
\text { back- } \\
\text { extraction }\end{array}$ \\
\hline $\mathrm{Cd}$ & ICP-MS & 0.2 & 0.5 & $>230$ & $>230$ \\
$\mathrm{Cd}$ & ICP-MS & 0.01 & 0.5 & $>230$ & $0.49(4)$ \\
$\mathrm{Cd}$ & ICP-MS & 0.002 & 0.5 & $6.6(6)$ & $0.28(5)$ \\
$\mathrm{Cd}$ & ICP-MS & 0.2 & 5 & $>250$ & $>250$ \\
$\mathrm{Cd}$ & ICP-MS & 0.01 & 5 & $>250$ & $0.85(5)$ \\
$\mathrm{Cd}$ & ICP-MS & 0.002 & 5 & $0.82(6)$ & $1.5(11)$ \\
$\mathrm{Zn}$ & ICP-MS & 0.2 & 0.5 & $>20$ & $1.29(5)$
\end{tabular}




\begin{tabular}{|c|c|c|c|c|c|}
\hline $\mathrm{Zn}$ & ICP-MS & 0.01 & 0.5 & $>20$ & $0.61(4)$ \\
\hline $\mathrm{Zn}$ & ICP-MS & 0.002 & 0.5 & $0.58(3)$ & $2.27(17)$ \\
\hline $\mathrm{Zn}$ & ICP-MS & 0.2 & 5 & $>20$ & $3.51(4)$ \\
\hline $\mathrm{Zn}$ & ICP-MS & 0.01 & 5 & $>20$ & $0.38(3)$ \\
\hline $\mathrm{Zn}$ & ICP-MS & 0.002 & 5 & $0.46(4)$ & $2.6(17)$ \\
\hline $\mathrm{Co}$ & ICP-MS & 0.2 & 0.5 & $<0.16$ & - \\
\hline $\mathrm{Co}$ & ICP-MS & 0.01 & 0.5 & $<0.16$ & - \\
\hline $\mathrm{Co}$ & ICP-MS & 0.002 & 0.5 & $<0.16$ & - \\
\hline Co & ICP-MS & 0.2 & 5 & $0.80(16)$ & $0.17(12)$ \\
\hline $\mathrm{Co}$ & ICP-MS & 0.01 & 5 & $0.199(8)$ & $<0.16$ \\
\hline $\mathrm{Co}$ & ICP-MS & 0.002 & 5 & $<0.16$ & - \\
\hline $\mathrm{Cu}$ & ICP-MS & 0.2 & 5 & $12.3(12)$ & $0.50(4)$ \\
\hline $\mathrm{Cu}$ & ICP-MS & 0.01 & 5 & $1.04(4)$ & $5.3(16)$ \\
\hline $\mathrm{Cu}$ & ICP-MS & 0.002 & 5 & $<0.16$ & \\
\hline \multirow[t]{2}{*}{$\mathrm{Cd}$} & Liquid & 0.2 & 0.5 & $>300$ & $100(20)$ \\
\hline & Scintillation & & & & \\
\hline \multirow[t]{2}{*}{$\mathrm{Cd}$} & Liquid & 0.01 & 0.5 & $>300$ & $0.157(14)$ \\
\hline & Scintillation & & & & \\
\hline \multirow[t]{2}{*}{$\mathrm{Cd}$} & Liquid & 0.002 & 0.5 & $4.73(13)$ & $0.0043(9)$ \\
\hline & Scintillation & & & & \\
\hline \multirow[t]{2}{*}{$\mathrm{Cd}$} & Liquid & 0.001 & 0.5 & $0.206(3)$ & - \\
\hline & Scintillation & & & & \\
\hline \multirow[t]{2}{*}{$\mathrm{Cd}$} & Liquid & 0.2 & 5 & $>300$ & $>300$ \\
\hline & Scintillation & & & & \\
\hline \multirow[t]{2}{*}{$\mathrm{Cd}$} & Liquid & 0.01 & 5 & $40.6(9)$ & $0.463(19)$ \\
\hline & Scintillation & & & & \\
\hline \multirow[t]{2}{*}{$\mathrm{Cd}$} & Liquid & 0.002 & 5 & $0.73(5)$ & $0.067(5)$ \\
\hline & Scintillation & & & & \\
\hline \multirow[t]{2}{*}{$\mathrm{Cd}$} & Liquid & 0.001 & 5 & $0.046(3)$ & $0.60(3)$ \\
\hline & Scintillation & & & & \\
\hline $\mathrm{Zn}$ & Gamma & 0.2 & 0.5 & $>300$ & $0.278(23)$ \\
\hline & spectroscopy & & & & \\
\hline
\end{tabular}




\begin{tabular}{|c|c|c|c|c|c|}
\hline $\mathrm{Zn}$ & $\begin{array}{c}\text { Gamma } \\
\text { spectroscopy }\end{array}$ & 0.05 & 0.5 & $50(4)$ & $0.0098(5)$ \\
\hline $\mathrm{Zn}$ & $\begin{array}{c}\text { Gamma } \\
\text { spectroscopy }\end{array}$ & 0.01 & 0.5 & $19.69(17)$ & $0.0063(12)$ \\
\hline $\mathrm{Zn}$ & $\begin{array}{c}\text { Gamma } \\
\text { spectroscopy }\end{array}$ & 0.002 & 0.5 & $0.267(20)$ & $0.030(7)$ \\
\hline $\mathrm{Zn}$ & $\begin{array}{c}\text { Gamma } \\
\text { spectroscopy }\end{array}$ & 0.2 & 5 & $>300$ & $1.7920(18)$ \\
\hline $\mathrm{Zn}$ & $\begin{array}{c}\text { Gamma } \\
\text { spectroscopy }\end{array}$ & 0.05 & 5 & $180(10)$ & $0.021(6)$ \\
\hline $\mathrm{Zn}$ & $\begin{array}{c}\text { Gamma } \\
\text { spectroscopy }\end{array}$ & 0.01 & 5 & $74(8)$ & $<6 \cdot 10^{-3}$ \\
\hline $\mathrm{Zn}$ & $\begin{array}{c}\text { Gamma } \\
\text { spectroscopy }\end{array}$ & 0.002 & 5 & $0.206(7)$ & $<6 \cdot 10^{-3}$ \\
\hline $\mathrm{Co}$ & $\begin{array}{c}\text { Gamma } \\
\text { spectroscopy }\end{array}$ & 0.2 & 0.5 & $<6 \cdot 10^{-3}$ & - \\
\hline $\mathrm{Co}$ & $\begin{array}{c}\text { Gamma } \\
\text { spectroscopy }\end{array}$ & 0.05 & 0.5 & $<6 \cdot 10^{-3}$ & - \\
\hline Co & $\begin{array}{c}\text { Gamma } \\
\text { spectroscopy }\end{array}$ & 0.01 & 0.5 & $<6 \cdot 10^{-3}$ & - \\
\hline Co & $\begin{array}{c}\text { Gamma } \\
\text { spectroscopy }\end{array}$ & 0.002 & 0.5 & $<6 \cdot 10^{-3}$ & - \\
\hline $\mathrm{Co}$ & $\begin{array}{c}\text { Gamma } \\
\text { spectroscopy }\end{array}$ & 0.2 & 5 & $0.49(4)$ & $0.020(24)$ \\
\hline $\mathrm{Co}$ & $\begin{array}{c}\text { Gamma } \\
\text { spectroscopy }\end{array}$ & 0.05 & 5 & $0.136(13)$ & $<6 \cdot 10^{-3}$ \\
\hline $\mathrm{Co}$ & $\begin{array}{c}\text { Gamma } \\
\text { spectroscopy }\end{array}$ & 0.01 & 5 & $0.091(14)$ & - \\
\hline $\mathrm{Co}$ & $\begin{array}{c}\text { Gamma } \\
\text { spectroscopy }\end{array}$ & 0.002 & 5 & $0.0031(9)$ & - \\
\hline
\end{tabular}


Journal of Radioanalytical and Nuclear Chemistry

492 Table A2 Summary of which elements and determinable D-ratios

\begin{tabular}{ll}
\hline $\begin{array}{l}\text { Measurable D-ratio at all concentration for } \\
\text { ICP-MS }\end{array}$ & \\
Measurable D-ratio with $5 \mathrm{~mol} / \mathrm{kg} \mathrm{HCl}$ & $\mathrm{Cu}, \mathrm{Co}$ (only at the highest A336 \\
& concentration) \\
No determinable D-ratio & $\mathrm{Al}, \mathrm{Cr}, \mathrm{Mn}, \mathrm{Pb}, \mathrm{Sb}, \mathrm{Sr}, \mathrm{Te}, \mathrm{W}$ \\
\hline
\end{tabular}

493

494 